Florida International University FIU Digital Commons

FIU Electronic Theses and Dissertations

University Graduate School

3-11-2009

\title{
Synthetic Studies of Azulenyl and Pseudoazulenyl Nitrones
}

Amolkumar Kolhe

Florida International University, akolh002@fiu.edu

DOI: $10.25148 /$ etd.FI10022526

Follow this and additional works at: https://digitalcommons.fiu.edu/etd

\section{Recommended Citation}

Kolhe, Amolkumar, "Synthetic Studies of Azulenyl and Pseudoazulenyl Nitrones" (2009). FIU Electronic Theses and Dissertations. 197. https://digitalcommons.fiu.edu/etd/197

This work is brought to you for free and open access by the University Graduate School at FIU Digital Commons. It has been accepted for inclusion in FIU Electronic Theses and Dissertations by an authorized administrator of FIU Digital Commons. For more information, please contact dcc@fiu.edu. 


\section{FLORIDA INTERNATIONAL UNIVERSITY \\ Miami, Florida}

SYNTHETIC STUDIES OF AZULENYL AND PSEUDOAZULENYL NITRONES

A dissertation submitted in partial fulfillment of the

requirements for the degree of

DOCTOR OF PHILOSOPHY

in

CHEMISTRY

by

Amolkumar Kolhe

2009 
To: Dean Kenneth Furton

College of Arts and Sciences

This dissertation, written by Amolkumar Kolhe, and entitled Synthetic Studies of Azulenyl and Pseudoazulenyl Nitrones, having been approved in respect to style and intellectual content, is referred to you for judgment.

We have read this dissertation and recommend that it be approved.

$\begin{array}{r}\hline \text { Stanislaw Wnuk } \\ \hline \text { John Landrum } \\ \hline \text { Watson Lees } \\ \hline \text { Ophelia Weeks } \\ \hline \text { David Becker, Major Professor }\end{array}$

Date of Defense: March 11, 2009

The dissertation of Amolkumar Kolhe is approved.

Dean Kenneth Furton
College of Arts and Sciences

Florida International University, 2009 
(C) Copyright 2009 by Amolkumar Kolhe All rights reserved. 


\section{DEDICATION}

I dedicate this thesis to my mother who motivated me to pursue higher education. Without her love, support and blessing this work would not have been completed. 


\section{ACKNOWLEDGMENTS}

I would like to thank members of dissertation committee, Dr. Watson Lees, Dr. Stanislaw Wunk, Dr. John Landrum and Dr. Ophelia Weeks for their support, guidance and patience. I would also like to thank other faculty members from the Department of Chemistry and Biochemistry at Florida International University for their valuable guidance. But most of all, I thank my major professor Dr. David Becker for letting me be a part of his research. He taught me organic chemistry with dedication and patience. I'm also thankful to the Department of Chemistry and Biochemistry for teaching me valuable lessons that I would not have learned anywhere else in the world. And finally, I thank Yadira Reynaldo for her constant support and love that I received from her and from entire Reynaldo family. 


\section{ABSTRACT OF THE DISSERTATION \\ SYNTHETIC STUDIES OF AZULENYL AND PSEUDOAZULENYL NITRONES \\ by}

Amolkumar Kolhe

Florida International University, 2009

Miami, Florida

Professor David Becker, Major Professor

Free radicals have been implicated in various pathological conditions such as, stroke, aging and ischemic heart disease (IHD), as well as neurodegenerative diseases like Alzheimer's, Parkinson's, and Huntington's disease. The role of antioxidants in protection from the harmful effects of free radicals has long been recognized. Trapping extremely reactive free radicals and eliminating them from circulation has been shown to be effective in animal models. Nitrone-based free radical traps have been extensively explored in biological systems. Examples include nitrones such as PBN, NXY-059, MDL-101,002, DMPO and EMPO. However, these nitrones have extremely high oxidation potentials as compared to natural antioxidants such as Vitamin E ( $\alpha$ tocopherol), and glutathione. Becker et al. (1995) synthesized novel azulenyl nitrones, which were shown to have oxidation potentials much lower than that of any of the previously reported nitrone based spin traps. Another azulenyl nitrone derivative, stilbazulenyl nitrone (STAZN), was shown to have an even lower oxidation potential within the range of natural antioxidants. STAZN, a second generation free radical trap, was found to be markedly superior than the two most studied nitrones, PBN and NXY059, in animal models of cerebral ischemia and in an in vitro assay of lipid peroxidation. 
In this study, a third generation azulenyl nitrone was synthesized with an electron donating group on the previously synthesized STAZN derivative with the aim to lower the oxidation potential even more. Pseudoazulenes, because of the presence of an annular heteroatom, have been reported to possess even lower oxidation potential than that of the azulenyl counterpart. Therefore, pseudoazulenyl nitrones were synthesized for the first time by extracting and elaborating valtrate from the roots of Centranthus ruber (Red valerian or Jupiter's beard). Several pseudoazulenyl nitrones were synthesized by using a facile experimental protocol. The physical and biological properties of these pseudoazulenyl nitrones can be easily modified by simply changing the substituent on the heteroatom.

Cyclic voltammetry experiments have shown that these pseudoazulenyl nitrones do indeed have low oxidation potentials. The oxidation potential of these nitrones was lowered even more by preparing derivatives bearing an electron donating group at the 3position of the five membered ring of the pseudoazulenyl nitrone. 


\section{TABLE OF CONTENTS}

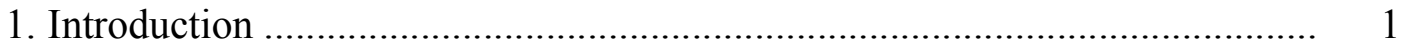

1.1 History ..........................................................................................

1.2 Free Radicals ..............................................................................

1.3 Free Radicals in Pathophysiology ........................................................ 5

1.3.1 Free Radicals in Stroke ............................................................. 5

1.3.2 Free Radicals in Neurodegenerative diseases ............................... 6

1.3.2.1 Alzheimer's Disease ........................................................... 7

1.3.2.2 Parkinson's Disease ............................................................ 8

1.3.2.3 Amyotropic Lateral Scelrosis ............................................ 12

1.3.3 Free Radicals in Aging ………….............................................. 13

1.4 Spin Traps .............................................................................. 14

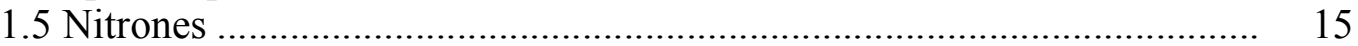

1.5.1 Synthesis of Nitrones ............................................................ 19

1.5.1.1 Condensation of $N$-substituted hydroxylamine with Aldehyde or Ketone .......................................................... 19

1.5.1.2 Oxidation of $N$-substituted hydroxyl amines ...................... 20

1.5.1.3 Oxidation of imines or amines .......................................... 20

1.5.1.4 Reductive cyclization of $\gamma$-nitro-carbony compounds ......... 21

1.5.2 Reactions of Nitrones ................................................................. 21

1.5.2.1 1,3-dipolar cyloaddition reactions ..................................... 21

1.5.2.2 Electrophilic addition reactions ……………………........ 22

1.5.2.3 Michael and Aldol type reactions …………………......... 23

1.6 Edaravone ............................................................................. 24

1.7 Azulenes ................................................................................. 24

1.7.1 Previous work on Azulenyl Nitrones ............................................ 25

2. Research Objective ............................................................................. 36

2.1 Azulenyl nitrones ……………………………………………..... 36

2.2 Pseudoazulenyl nitrones ………………………………..................... 37

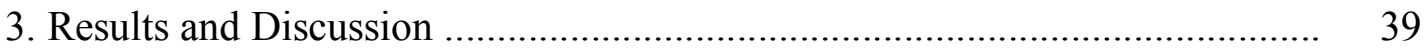

3.1 Synthesis of Third Generation Azulenyl Nitrones .................................. 39

3.1.1 Synthesis of 1-substituted bisazulenyl mononitrone ..................... $\quad 40$

3.2 Synthesis of novel pseudoazulenyl dinitrones........................................ 43

3.2.1 Synthesis of 2-butyl-cyclopenta[c]pyridine-4,7-dinitrone (63) ..... 44

3.2.2 Synthesis of 2-(propyl imidazole)-cyclopenta[c]pyridine4,7-dinitrone (72).....

3.2.3 Synthesis of 2-(3-(dimentylamino)propyl)-cyclopenta[c]pyridine4,7-dinitrone (75)

3.2.4 Synthesis of Spermine analogue (86) ......................................... 51 
3.2.5 Synthesis of 2-octadecylamine-cyclopenta $[c]$ pyridine-

4,7-dinitrone (88)

3.2.6 Synthesis of 2-(6-hexanol)-cyclopenta[c]pyridine4,7-dinitrone (91)

3.2.7 Synthesis of 2-butyl-5-ethylthio-cyclopenta[c]pyridine4,7-dinitrone (94)

3.3 Cyclic Voltammetry

4. Conclusion

5. Experimental section

5.0.1 Synthesis of bis-guiazulenyl monoaldehyde (49)

5.0.2 Synthesis of bis-azulenyl thio-benzothiazolemonoaldehyde derivative (51)

5.0.3 Synthesis of thio-benzothiazole-mononitrone derivative (52) ............. 69

5.0.4 Synthesis of sulfenyl chloride (93) ................................................ $\quad 72$

5.0.5 Synthesis of 1-ethylthio bis-guiazulenyl monoaldehyde (54) ............ $\quad 72$

5.0.6 Synthesis of 1-ethylthio bis-guiazulenyl mononitrone (55) ................. 76

5.0.7 Synthesis of 3-(ethylthio)-guiazulene (57) ……………………......... 79

5.0.8 Synthesis of 3-(ethylthio)-1-carbaldehyde guiazulene (58) ................. 82

5.0.9 Synthesis of 3-(ethylthio)-1-nitrone-guiazulene (56) .......................... 85

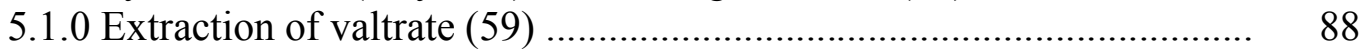

5.1.1 Synthesis of baldrinal (60) ............................................................ 91

5.1.2 Synthesis of 2-butyl-cyclopenta[c]pyridine-4,7-dicarbaldehyde (61) .. 94

5.1.3 Synthesis of 2-butyl-cyclopenta[c]pyridine-4,7-dinitrone (63) ........... 97

5.1.4 Synthesis of 5-bromo-2-butyl-cylopenta[c]pyridine-

4,7-dicarbaldehyde (65)

100

5.1.5 Synthesis of 2-butyl-5-ethylthio-cyclopenta[c]pyridine-

4,7-dicarbaldehyde (92)

5.1.6 Synthesis of 2-butyl-5-ethylthio-cyclopenta[c]pyridine-

4,7-dinitrone (94)

105

5.1.7 Synthesis of 2-(propyl imidazole)-cyclopenta[c]pyridine-

4,7-dicarbaldehyde (71)

108

5.1.8 Synthesis of 2-(propyl imidazole)-cyclopenta[ $[c]$ pyridine-

4,7-dinitrone (72)

110

5.1.9 Synthesis of 2-(3-(dimethylamino)propyl)-cyclopenta[c]pyridine-

4,7-dicarbaldehyde (74)

5.2.0 Synthesis of 2-(3-(dimethylamino)propyl)-cyclopenta[c]pyridine-

4,7-dinitrone (75)

5.2.1 Syntheisis of 2-octadecylamine-cyclopenta[c]pyridine-

4,7-dicarbaldehyde (87)

5.2.2 Synthesis of 2-octadecylamine-cyclopenta[c]pyridine-

4,7-dinitrone (88)

5.2.3 Synthesis of 2-(6-hexanol)-cyclopenta[c]pyridine-

4,7-dicarbaldehyde (90) 
5.2.4 Synthesis of 2-(6-hexanol)-cyclopenta[c]pyridine-4,7-dinitrone (91) .. 125

5.2.5 Synthesis of Spermine analogue of pseudoazulenyl dinitrone (86) ..... 128

5.2.6 Cyclic voltammetry ................................................................... 131

LIST OF REFERENCES .................................................................. 132

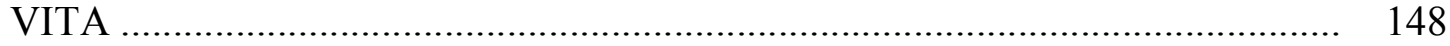




\section{LIST OF FIGURES}

FIGURE

PAGE

1. Glutathione recycling ................................................................ 11

2. Biological fate of L-DOPA .............................................................. 11

3. Reactions of Nitrone and Nitroso compounds with Free Radicals ............ $\quad 14$

4. Resonance structure of Nitroso Spin Adduct ..................................... 15

5. cis-trans isomerization of PBN ...................................................... 16

6. Resonance structure of Nitrone ...................................................... 17

7. Structures of PBN, S-PBN and NXY-059 ........................................ 17

8. Structures of 3-PyBN, 4-PyOBN and 4-MePyBN ................................. 18

9. Structures of MDL-101,002, DMPO, DEPMPO and EMPO ................... 19

10. Reaction of Edaravone with free radicals .......................................... 24

11. Naturally occurring azulenyl compounds ........................................ 25

12. Synthetic scheme of AZN (22) ................................................... 26

13. Double spin adduct of AZN ............................................................ 27

14. Reaction of AZN (22) with peroxyl radical ....................................... 27

15. One electron oxidation of Azulenyl Nitrone ...................................... 29

16. Synthetic scheme of STAZN (32) ................................................... 32

17. Commonly used natural and synthetic antioxidants ........................... 33

18. Attempted synthesis of 1-substituted thio-benzothiazolebis-azulenyl mononitrone (53) .

19. Synthetic scheme of 1-ethylthio-bis-azulenyl mononitrone (55) ............. 42

20. Synthetic scheme of 3-(ethylthio)-guiazulene-1-nitrone (56) ................. 43 
21.Synthetic scheme of Baldrinal (60)

22. Synthetic scheme of 2-butyl-cyclopenta[c]pyridine-4,7-dinitrone (63) ...

23. Attempted synthesis of Bis-pseudoazulenyl Tetraaldehyde (67)

24.Attemtpted synthesis of Pseudoazulenyl Dialdehyde (69)

25. Synthetic scheme of 2-(propyl imidazole)cyclopenta $[c]$ pyridine-4,7-dinitrone (72)

26. Synthetic scheme of 2-(3-(dimethylamino)propyl4,7-cyclopenta $[c]$ pyridine-dinitrone (75)

27. Trypanothione

28. Attempted synthesis of Spermine derivative of pseudoazulenyl dialdehyde (80)

29. Attempted synthesis of piperazine derivative of pseudoazulenyl dinitrone (81)

30. Synthetic scheme of dicationic spermine analogue of pseudoazulenyl dinitrone (86)

31. Synthetic scheme of 2-octadecyl-cyclopenta[ $[c]$ pyridine4,7-dinitrone (88)

32. Synthetic scheme of 2-(6-hexanol)-cyclopenta[c]pyridine4,7-dinitrone (91)

33. Synthetic scheme of 2-butyl-5-(ethylthio)-cyclopenta[c]pyridine4,7-dinitrone (94)

34. Cyclic voltammogram of 2-butyl-5-ethylthio-cyclopenta[ $c]$ pyridine4,7-dinitrone (94)

35. Cyclic voltammogram of STAZN (32) 


\section{[1] INTRODUCTION}

\section{[1.1] History:}

Commoner et al. first discovered free radicals in biological systems in $1954 .^{1}$ Soon after this discovery, Harman proposed his "Free Radical Theory of Aging" in which free radical damage was putatively attributed to mutagenesis, cancer and degenerative diseases of aging. ${ }^{2}$ Harman's theory attracted criticism since most of the scientists at that time believed that free radicals were too reactive to exist in biological system. McCord and Fridovich (1969) isolated superoxide dismutase (SOD) and showed that this enzyme was capable of preventing the oxidation of substances against the superoxide radical $\left(\mathrm{O}_{2}{ }^{-}\right)$, suggesting SOD plays a vital role in protecting organisms against the damaging superoxide radical by accelerating dismutation of superoxide radical $\left(\mathrm{O}_{2}{ }^{--}\right)$to oxygen and hydrogen peroxide $\left(\mathrm{H}_{2} \mathrm{O}_{2}\right) .^{3}$

$2 \mathrm{O}_{2}^{\cdot-}+2 \mathrm{H}^{+} \stackrel{\mathrm{SOD}}{\longrightarrow} \mathrm{H}_{2} \mathrm{O}_{2}+\mathrm{O}_{2}$

The discovery of SOD, whose sole function in physiology is to eliminate harmful reactive oxygen species (ROS), proved pivotal to the understanding of the role of free radicals in physiology. Researchers have shown that transgenic mice lacking this enzyme die soon after birth signifying the biological importance of SOD. ${ }^{4,5}$ Biological macromolecules such as lipids, nucleic acids and proteins are the targets of endogenous free radicals. For example, hydroxyl radicals can rapidly cause oxidation of DNA bases, particularly guanines. It can also attack lipids and proteins to give lipid peroxidation products and carbonyls, respectively. ${ }^{6}$

However, the toxicity of the superoxide radical is not limited to its reaction with biomolecules alone. Superoxide $\left(\mathrm{O}_{2}{ }^{-}\right)$is shown to react with other ROS and free radicals 
to produce even more harmful species. One such reaction is the Haber-Weiss reaction, where in the presence of a catalytic amount of ferric ion, superoxide reacts with hydrogen peroxide to give a hydroxyl radical. ${ }^{7}$

$$
\begin{aligned}
& \mathrm{Fe}^{3+}+\mathrm{O}_{2}^{--} \longrightarrow \mathrm{Fe}^{2+}+\mathrm{O}_{2} \\
& \left.\mathrm{Fe}^{2+}+\mathrm{H}_{2} \mathrm{O}_{2} \longrightarrow \mathrm{Fe}^{3+}+\cdot \mathrm{OH}+{ }^{-} \mathrm{OH}\right] \\
& \mathrm{O}_{2}^{\cdot-}+\mathrm{H}_{2} \mathrm{O}_{2} \longrightarrow \cdot \mathrm{OH}+{ }^{-} \mathrm{OH}+\mathrm{O}_{2} \quad\left[\begin{array}{c}
\text { Net } \\
\text { Reaction } \\
{[4]}
\end{array}\right]
\end{aligned}
$$

Mittal and Murard (1977) published on the biological significance of free radicals. $^{8}$ They suggested that the superoxide ion and hydrogen peroxide can lead to formation of hydroxyl radicals that activate guanylate cyclase which catalyzed the formation of the "second messenger" 3',5'-cyclic guanosine monophosphate (cGMP) from guanosine triphosphate (GTP). Free radicals were shown to be generated by phagocytes in defense against microorganisms. ${ }^{9,10}$ Individuals with chronic granulomatous disease were shown to have abnormal susceptibility to infectious organisms because of a lack of NADPH oxidase, which reduces oxygen to the superoxide radical anion. ${ }^{11}$ Furthermore, free radicals are also important in apoptosis. ${ }^{12}$ The paradoxical role of free radicals triggered extensive research in this field, with ongoing debate on the advantageous and deleterious effects of free radicals.

Even though free radicals play a vital role in signal transduction and defense mechanisms, collateral damage is inevitable. Excessive production of free radicals can lead to various pathological conditions with differing severity. Free radicals have been 
implicated in various disease conditions like hypertension and atherosclerosis, ${ }^{13-15}$ rheumatoid arthritis, ${ }^{16,17}$ cancer, ${ }^{18-21}$ diabetes, ${ }^{22,23}$ and aging, ${ }^{2,24-26}$ as well as degenerative diseases like amyotrophic lateral sclerosis (ALS), ${ }^{27}$ Alzheimer's disease, ${ }^{28-30}$ Down's syndrome, ${ }^{31,32}$ and bovine spongiform encephalopathy. ${ }^{33}$

\section{[1.2] Free Radicals:}

The most oxidizing species in physiology is the hydroxyl $(\cdot \mathrm{OH})$ radical having an extremely short half-life of $10^{-9} \mathrm{~s} .{ }^{34}$ However, the most ubiquitous free radical in physiology is the NO radical. It is a lot less reactive than the $\cdot \mathrm{OH}$ radical. Even though NO is less reactive with other biomolecules, it is still extremely reactive with other free radicals. For example, NO can react with $\mathrm{O}_{2}{ }^{--}$to give peroxynitrite, $\mathrm{ONOO}^{-35,36}$

$$
\mathrm{NO} \cdot \quad+\mathrm{O}_{2}^{\cdot-} \longrightarrow \text { ONOO- }
$$

Decomposition of $\mathrm{ONOO}^{-}$leads to the formation of highly reactive hydroxyl $(\cdot \mathrm{OH})$ radical, via the intermediacy of $\mathrm{ONOOH}$ which itself is highly reactive. ${ }^{37}$

$$
\mathrm{ONOO}^{-}+\mathrm{H}^{+} \longrightarrow \mathrm{ONOOH}
$$

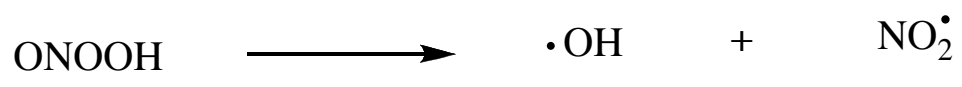

NO- also reacts with hydroxyl and peroxyl radicals to give nitrous acid and peroxynitrites, respectively.

$$
\begin{aligned}
& \mathrm{NO} \cdot+\cdot \mathrm{OH} \longrightarrow \mathrm{HNO}_{2} \\
& \mathrm{NO} \cdot+\mathrm{RO}_{2}^{{ }^{\circ}} \longrightarrow \text { ROONO }
\end{aligned}
$$


Superoxide dismutase (SOD) prevents the excessive formation of ONOO- by removing harmful $\mathrm{O}_{2}{ }^{--}$radicals, thereby limiting the formation of $\cdot \mathrm{OH}^{38}$ Another common way of ROS generation in physiology is by Fenton reaction. In 1894, H.J.H. Fenton observed that $\mathrm{H}_{2} \mathrm{O}_{2}$ and ferrous or ferric ions react together to form hydroxyl and hydroperoxyl radicals, respectively.

$$
\begin{aligned}
& \mathrm{Fe}^{2+}+\mathrm{H}_{2} \mathrm{O}_{2} \longrightarrow \mathrm{Fe}^{3+}+\cdot \mathrm{OH}+-\mathrm{OH} \\
& \mathrm{Fe}^{3+}+\mathrm{H}_{2} \mathrm{O}_{2} \longrightarrow \mathrm{Fe}^{2+}+\cdot \mathrm{OOH}+\mathrm{H}^{+}
\end{aligned}
$$

The presence of iron in this reaction is truly catalytic. Note that, the Fenton reaction is also the second step in the Haber-Weiss reaction. Similarly, other metal ions like copper (I) react with hydrogen peroxide in much the same way as iron but with a greater rate constant.

$\mathrm{Cu}^{+}+\mathrm{H}_{2} \mathrm{O}_{2} \longrightarrow \mathrm{Cu}^{2+}+\cdot \mathrm{OH}+-\mathrm{OH}$

Iron is abundantly available in the body. Fortunately, very little is available as free iron. An average adult body contains approximately 4 grams of iron, most of which is present in hemoglobin $(\sim 60 \%)$. The other major sources of iron are myoglobin, transferrin, ferritin and haemosiderin. ${ }^{39}$ Whereas for copper, approximately $95 \%$ of this metal ion is found in the protein caeruloplasmin with a small amount in albumin and plasma amino acids. 


\section{[1.3] Free Radicals in Pathophysiology:}

\section{[1.3.1] Free Radicals in Stroke:}

According to the National Stroke Association, stroke is the third leading cause of death in America and a leading cause of adult disability. An ischemic stroke results due to acute interruption or reduction of blood flow to the brain caused by thrombosis or embolism of one of the main cerebral arteries, causing hypoxia that can result in either transitory or permanent damage to the brain. Agents that lyse these clots are called thrombolytics such as tissue plasminogen activator $(t \mathrm{PA})$, which reperfuse the brain. Currently, $t \mathrm{PA}$ is the only agent approved by the U.S. Food and Drug Administration (FDA) for stroke resulting due to thrombosis. Another less common cause of stroke is cardiac arrest.

During the early 1970s, research increasingly suggested that free radicals might be responsible for neuronal damage and cell death in the brain. ${ }^{40}$ Studies showed that free radical-mediated oxidative stress may damage the mitochondrial membrane because of the presence of a high level of oxidatively sensitive polyunsaturated fatty acids. ${ }^{40,41}$ Later, increased production of free radicals in the ischemic brain was demonstrated, and there is ample evidence to show that reperfusion of ischemic brain worsens the oxidative stress by producing highly reactive superoxide and hydroxyl radicals. ${ }^{42-44}$ Generation of ROS in reperfused ischemic brain was postulated to be due to the release of metal ions from injured cells. ${ }^{45}$ This increased production of ROS is especially harmful to the nervous system since levels of endogenous antioxidants are low during such pathological conditions. Examples of endogenous antioxidants are- (a) antioxidant enzymes such as superoxide dismutase (SOD), catalase, glutathione reductase (GR) and glutathione 
peroxidase (GPO); (b) antioxidant vitamins such as vitamin E ( $\alpha$-tocopherol), and ascorbic acid. ${ }^{46}$ Deficiency of endogenous antioxidant enzymes results in increased neuronal damage in focal cerebral ischemia, ${ }^{47}$ whereas over expression of these enzymes has been shown to increase resistance to focal cerebral ischemic injury. ${ }^{48,49}$

In a stroke, many of the compounds investigated until now act early during the ischemic cascade (glutamate antagonists, ion channel antagonists, GABA mimetics, thrombolytics, etc.), thereby limiting the duration of the therapeutic window when these drugs could be administered. ${ }^{50}$ Therefore, to be effective, these compounds should be administered very soon after the stroke. Tissue plasminogen activator $(t \mathrm{PA})$, which is currently recommended for acute ischemic stroke therapy, has a very short therapeutic window $(3 \mathrm{~h})$, thereby limiting its utility. Another approach suggested by Green et al. is to develop drugs that are effective during the late ischemic cascade in hopes that they will have a longer therapeutic window with nitrones suggested as effective candidates. ${ }^{50}$

\section{[1.3.2] Free Radicals in Neurodegenerative diseases:}

Neurodegenerative diseases are a heterogeneous group of diseases of various parts of the Central Nervous System (CNS), which include the brain, the spinal cord and the peripheral nervous system. All human tissues, directly or indirectly, are affected by oxidative damage. However, the brain and the nervous system are especially susceptible because of the presence of high amounts of unsaturated fatty acids and iron. ${ }^{51}$ Even though the brain comprises a small percentage of all tissue mass, it is still the most oxygenated mass in the body. The brain consumes about $20 \%$ of basal oxygen in the body because of the high oxygen demand by the cerebral mitochondria to keep up with 
ATP requirements for normal neuronal functioning. Mitochondria are both generators and targets of free radicals. Increased oxidative stress damages mitochondria, which in turn affects the normal neuronal functions since neurons need a constant supply of ATP to function properly. Damaged mitochondria produce more reactive species, which in turn damages more mitochondria, resulting in a vicious cycle eventually causing cell degeneration and apoptosis. The common neurodegenerative diseases are discussed here.

\section{[1.3.2.1] Alzheimer's Disease:}

Alzheimer's disease (AD) is a common form of dementia with impairment of cognitive function and personality. Alzheimer's disease is characterized by neuronal degeneration of pyramidal neurons in the hippocampus, entorhinal cortex and neocortical areas, and by loss of cholinergic neurons in the median forebrain. ${ }^{52,53}$ Alzheimer's disease is thought to occur due to accumulation of neurofibrillary tangles, which consists of hyperphosphorylated tau protein and amyloid plaques of amyloid $\beta(\mathrm{A} \beta)$ protein, resulting in extensive neuronal loss in the brains of Alzheimer's patients. The major component of plaques in $\mathrm{AD}$ is the $40-42$ amino acid, amyloid $\beta$ protein, which is a segment from the larger Amyloid $\beta$ protein precursor ( $\beta$ APP) and result due to alterations in the metabolism of $\beta$ APP. ${ }^{54,55}$ The finding that the amyloid $\beta$ protein is toxic to neurons in vitro led to the hypothesis that amyloid $\beta$ protein plays a role in neuronal degeneration in $\mathrm{AD} .^{56}$ The toxicity of $\mathrm{A} \beta$ protein is thought by some to be due to its ability to form insoluble aggregates which lead to increased production of reactive oxygen species (ROS),${ }^{57}$ loss of calcium homeostasis, ${ }^{58}$ and eventual cell degeneration and apoptosis. However, the reverse has also been implicated in that the toxicity of $\mathrm{A} \beta$ protein has been 
speculated by some to be due to its action as an oxidant. ${ }^{59}$ Such toxic effects of aggregates of Amyloid $\beta$ peptide were later shown by other researchers, supporting earlier data ${ }^{56,60,61}$ Furthermore, $\mathrm{A} \beta$ protein was also shown to induce lipid peroxidation in synaptosomes and cultured cortical cells. ${ }^{62,63}$

Further studies have demonstrated that oxidants promote and antioxidants prevent aggregation of $\mathrm{A} \beta{ }^{64}$ Yan et al. suggested that $\beta$-amyloid peptides cause neurotoxic effects, directly by inducing oxidative stress and indirectly by activating microglia, ${ }^{65}$ which were shown to be the major source of free radicals when activated. ${ }^{65,66}$ However, under normal circumstances, secretion of ROS by microglia is a defense mechanism to protect the brain against invading pathogens. ${ }^{66}$ Further evidence for the production of ROS by glial cells came from the fact that in response to injury, glial cells undergoes gliosis (overgrowth of glial cells/astrocytes). Halks-Miller et al. proposed that when activated, glial cells secrete free radicals and undergo gliosis, which can be prevented by $\alpha$-tocopherol (vitamin E) ${ }^{67}$ Smith et al. correlated Alzheimer's with aging by stating that $\mathrm{AD}$ is an alteration in normal aging processes in the brain areas that are challenged by increased oxidation with increased age. ${ }^{68}$

\section{[1.3.2.2] Parkinson's Disease:}

Parkinson's disease (PD) is the most common neurodegenerative movement disorder and was first described by James Parkinson in 1817. Parkinson's disease involves neurodegeneration of melanin-pigmented dopaminergic neuron of the substantia nigra pars compacta ( $\mathrm{SNpc}$ ) of the midbrain. Parkinson's disease is manifested by declining motor and cognitive functions, and depression. ${ }^{69}$ The exact 
cause of dopaminergic cell loss is still obscure. However, recent research has shown that oxidative stress is one of the main reasons for neuronal death leading to $\mathrm{PD} .^{70,71}$ It has also been established that mitochondrial function in a PD brain is impaired, especially the complex I of the mitochondrial electron transport chain. ${ }^{72,73}$ Most of this evidence comes from studies done on the neurotoxin 1-methyl-4-phenyl-1,2,3,6tetrahydropyridine (MPTP) which gets converted to its active metabolite 1-methyl-4phenylpyridinium $\left(\mathrm{MPP}^{+}\right)$by monoamine oxidase $\mathrm{B} .{ }^{74}$ MPTP causes PD syndrome, which is indistinguishable from idiopathic PD and thus supports the theory of toxic causation. $\mathrm{MPP}^{+}$accumulates rapidly in dopaminergic neurons and inhibits complex I of the mitochondrial electron transport chain. Inhibition of mitochondrial electron transport chain leads to impairment of energy production and eventually leads to the death of dopaminergic neuronal cells. There is substantial evidence that $\mathrm{MPP}^{+}$increases oxidative stress in the brain and antioxidants tend to attenuate the effects of MPTP toxicity. ${ }^{75,76}$ 1-methyl-4-phenyl-1,2,3,6-tetrahydropyridine (MPTP) is often used as an animal model of Parkinson's disease.

It has also been shown that dopamine undergoes oxidation by monoamine oxidase to form $\mathrm{H}_{2} \mathrm{O}_{2}{ }^{77}$ with a subsequent increase in oxidized glutathione (GSSG), incriminating oxidative stress and impairment of major antioxidant systems in PD. ${ }^{78}$ Increased levels of iron in the substantia nigra has also been implicated in $\mathrm{PD}^{79-81}$ which can lead to Fenton reaction between iron and $\mathrm{H}_{2} \mathrm{O}_{2}$ to form highly toxic hydroxyl radicals $(\bullet \mathrm{OH})$ that may then initiate lipid peroxidation and cell death. ${ }^{82-84}$ It was also postulated that the reactions involving $\mathrm{H}_{2} \mathrm{O}_{2}$, iron and dopamine may be responsible for the formation of dopaminergic neurotoxins such as 6-hydroxydopamine. ${ }^{85-87}$ Because of constant 
oxidative bombardment, the brain is also exceptionally well-equipped with antioxidant defense mechanisms with various antioxidants like $\alpha$-tocopherol, glutathione, ascorbic acid, ubiquinol, carotenoids, and flavanoids, as well as antioxidant enzyme systems such as catalase, superoxide dismutase (SOD), glutathione-S-transferase, glutathione reductase, and thioredoxin reductase. ${ }^{88}$ Glutathione plays an important role in protecting the brain against reactive oxidative species. In PD, decreased levels of GSH have been observed. A decreased level of total glutathione $(\mathrm{GSH}+\mathrm{GSSG})$ is one of the first biochemical indicators in PD brain, appearing even before the decreased activity of mitochondrial complex I. It has been established that the magnitude of GSH depletion parallels the severity of PD making it an excellent biomarker. ${ }^{89,90}$

Nitric oxide reacts with the hydrogen peroxide $\left(\mathrm{H}_{2} \mathrm{O}_{2}\right)$ to form peroxynitrite $\left(\mathrm{ONOO}^{-}\right)$, which is not only a strong oxidizing agent but also degrades to an even more powerful hydroxyl radical $(\bullet \mathrm{OH}){ }^{91}$ Nitric oxide is responsible for reversible and irreversible damage to mitochondrial respiratory complex I and IV. ${ }^{92}$ Furthermore, NO may also affect GSH levels by selectively inhibiting GSH reductase which is crucial for the conversion of oxidized glutathione (GSSG) back to its reduced form, $\mathrm{GSH}^{93}$ In normal physiology, GSH and GSSG are in the ratio of 98:2 and are interconvertible by the action of two enzymes, glutathione peroxidase (GSH-Px) and glutathione reductase (GSSG-R). 


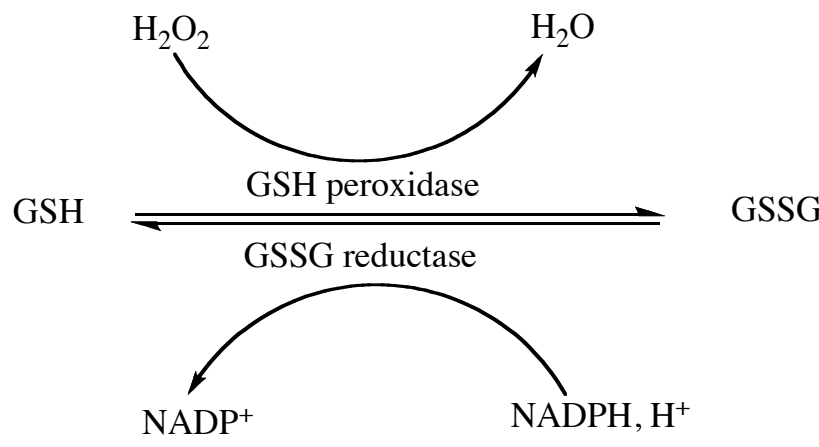

Figure 1. Glutathione recycling

The most frequently prescribed drug for PD is Levodopa (L-DOPA), which acts as a prodrug and gets converted to dopamine by DOPA decarboxylase in the CNS.
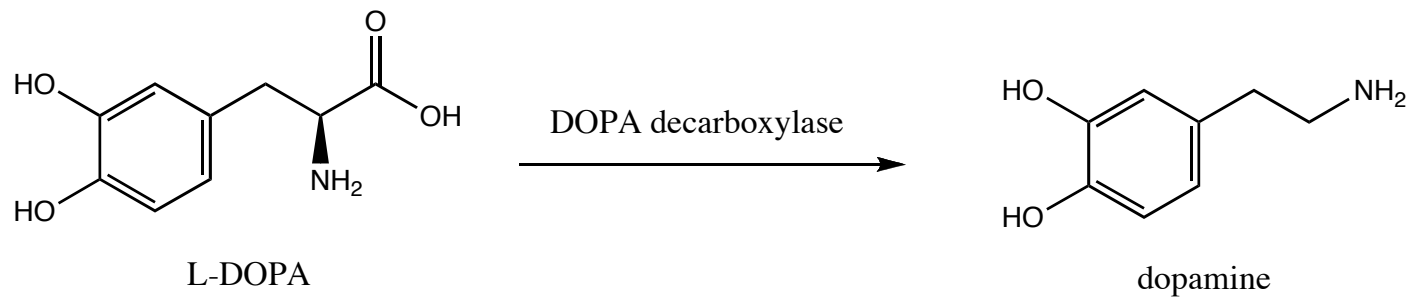

Figure 2. Biological fate of L-DOPA

Levodopa is preferred over dopamine because of its ease in crossing the blood brain barrier (BBB). However, levodopa is easily inactivated peripherally by DOPA decarboxylase. Therefore, levodopa is usually combined with DOPA decarboxylase inhibitors such as carbidopa or benserazid, to prevent peripheral levodopa degradation. However, this treatment suffers from some major drawbacks. Levodopa and dopamine are both found to undergo autoxidation under physiological conditions to give cytotoxic 
reactive oxygen species. ${ }^{94}$ Furthermore, they only provide symptomatic relief and patients develop tolerance over time. Therefore increased doses are needed which in turn increases the severity of side effects. ${ }^{95}$

\section{[1.3.2.3] Amyotrophic Lateral Sclerosis:}

Amyotrophic lateral sclerosis (ALS) or Lou Gehrig's disease is an age dependant motor neuron degenerative disease and occurs in the $5^{\text {th }}$ or $6^{\text {th }}$ decade of life. ${ }^{96}$ Amyotrophic lateral sclerosis is characterized by progressive loss of motor neurons in the motor cortex, the brain stem and the spinal cord, that affect motor functions and is followed by progressive muscle atrophy. ${ }^{97}$ Certain familial Amyotrophic lateral sclerosis cases have been linked to a genetic defect in chromosome 21 , in the gene encoding CuZnSOD protein. ${ }^{98}$ However, the mechanism behind this gene alteration is still uncertain. These mutant CuZnSOD have been linked to the pathogenesis of ALS due to alteration in the functions of SOD. Approximately $20 \%$ of familial ALS cases have been attributed to such mutations. ${ }^{99}$ Lee et al. have shown that the cell cultures overexpressing normal $\mathrm{CuZnSOD}$ are more resistant to oxidative stress, serum deprivation, addition of $\mathrm{H}_{2} \mathrm{O}_{2}$, and 4-hydroxynonenal (cytotoxic unsaturated end product of lipid peroxidation). On the other hand, cell cultures over expressing mutant CuZnSOD were found to be extremely vulnerable to such insults. ${ }^{100}$ Even though the exact mechanism of the toxicity of mutant CuZnSOD is poorly understood, it was found that mutant CuZnSOD is less stable in vitro and may therefore denature more quickly than normal CuZnSOD, thus releasing copper and zinc metal ${ }^{101,102}$ which are known to act as a catalyst to increase oxidative stress in physiology. ${ }^{101,103}$ 


\section{[1.3.3] Free Radicals in Aging:}

It has been almost 60 years since the free radical theory of aging was proposed by Harman. ${ }^{2}$ Since the inception of this theory, an enormous amount of data has accumulated over the years in support of this theory. Mice carrying a targeted mutation of the $\mathrm{p} 66^{\text {Shc }}$ gene have shown prolonged life spans with about $30 \%$ more than control mice ${ }^{104}$ and also exhibited increased resistance to oxidative stress and decreased production of intracellular oxidants. ${ }^{105,106}$ Hazelton et al. showed that glutathione concentration decreases during aging. ${ }^{107}$ In animal models, up to $20-30 \%$ decreases in GSH levels were observed in liver, kidney and heart; however, they suggested that decreases in GSH levels are not restricted to a particular tissue but occur in all aging tissue. Even though GSSG levels were almost unaltered, it was suggested that the GSH/GSSG ratio is critical in aging. Furthermore, a reduced capacity to detoxify free radicals and xenobiotics due to reduced GSH levels was suggested to be the toxicological basis of aging. ${ }^{107}$ In a study done on community-based elderly, good health and fewer illness were associated with higher levels of GSH, whereas subjects associated with illnesses such as arthritis, diabetes, and heart disease were found to possess lower levels of GSH. ${ }^{108,109}$ Furthermore, decreased levels of GSH are also associated with impairment of mitochondrial functions. When cells were exposed to mitochondrial poisons like Antimycin $\mathrm{A}, \mathrm{KCN}$, and/or 1-methyl-4-phenylpyridinium ion (MPP ${ }^{+}$), these compounds were shown to produce a marked decrease in GSH levels. This decrease in GSH levels was proposed to be a result of the loss of ATP production in mitochondrial poisoning. ${ }^{110}$ When GSH in rat brain was depleted by L-buthionine sulfoximine, mitochondrial function was reported to be decreased by $27 \% .{ }^{111}$ 


\section{[1.4] Spin Traps:}

Direct detection of most free radicals is exceedingly difficult due their extremely short half-life. Therefore, the technique of spin trapping is usually employed where these short-lived free radicals are trapped with nitrones or nitroso compounds to give spin adducts (nitroxides) which are considerably more stable than the parent free radical. The structure or identity of free radicals can in some cases be identified using the Electron Spin Resonance (ESR) [also called as Electron Paramagnetic Resonance (EPR)] technique based on the signature spectrum that these molecules produce.

The compounds that trap the free radicals are called spin traps. Janzen coined the term "spin trapping" due to similarities between the processes of spin labeling and spin trapping. ${ }^{112}$ The addition product of a free radical and a spin trap is called a "spin adduct". 113

$$
\mathrm{R} \cdot \quad+\quad \text { Spin Trap } \longrightarrow \quad \text { Spin Adduct }
$$

As stated above, the two most commonly used free radical traps are nitrones and nitroso compounds. Their reactions with free radicals to yield nitroxides are shown in the figure below.

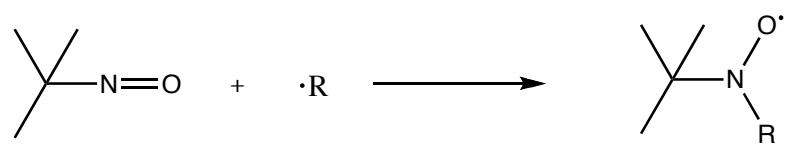

$t$-Nitrosobutane

Nitroso spin adduct

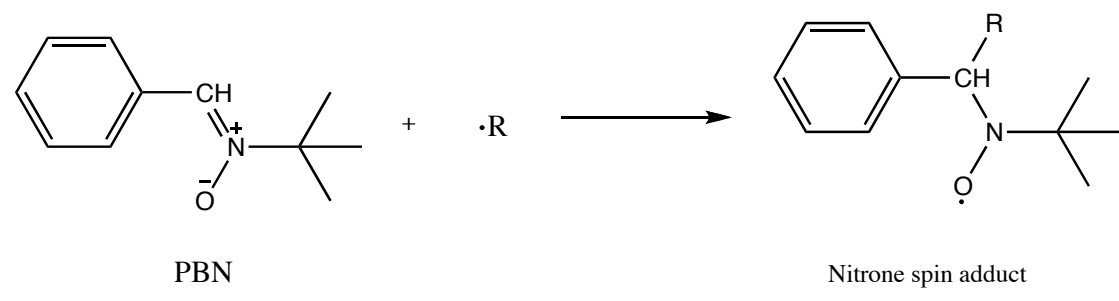

Figure 3. Reactions of Nitrone and Nitroso compounds with Free Radicals 
The stability of these spin adducts are due to resonance delocalization of the unpaired electron.
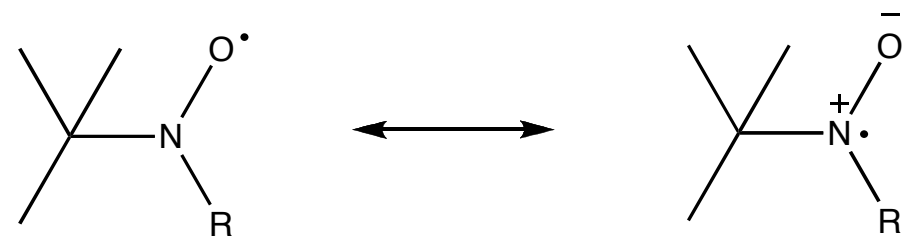

Nitroso spin adduct

Figure 4. Resonance structure of Nitroso Spin Adduct

In spin adducts resulting from nitroso compounds, the free radicals became attached directly to the nitrogen therefore giving additional hyperfine coupling that could in principle make the identification of free radicals easier than that resulting from nitrone spin traps. However, despite this obvious advantage, the use of nitroso compounds as spin traps suffers from various drawbacks. Thus, nitroso compounds are toxic, thermally and photochemically unstable, and the lifetime of their oxygen-centered radical adducts are exceedingly short. ${ }^{114}$ For these reasons, researchers prefer nitrones over nitroso compounds, especially in biological systems, despite the fact that the EPR spectra of their nitroxide spin adducts provide less structural information.

\section{[1.5] Nitrones:}

Nitrones are the N-oxide of an imine represented by the general formula as shown in (1). Pfeiffer in 1916 coined the term "nitrone" considering the similarity of the $\mathrm{N} \rightarrow \mathrm{O}$ group in nitrones to the $\mathrm{C}=\mathrm{O}$ group in ketones. ${ }^{115}$ 


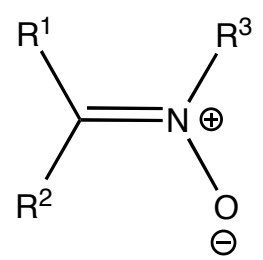

(1)

An early review on nitrones and structural analogues states that it is not the nitrogenoxygen bond that behaves as a carbonyl, but the entire nitrone moiety as shown in (1). ${ }^{116}$ It has been proved by nuclear magnetic resonance (NMR) and infrared (IR) studies that aldonitrones possess a stable trans geometry. ${ }^{117}$ Cis-PBN was shown to isomerize completely to trans-PBN in benzene solution within $24 \mathrm{~h}$.

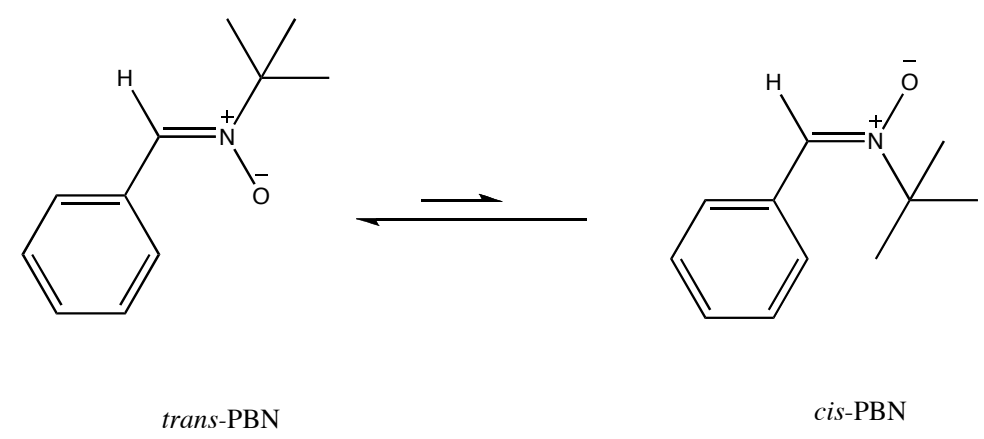

Figure 5. cis-trans isomerization of PBN

Nitrones can be written in two resonance forms, with major contribution from form I. ${ }^{118}$ Because of these resonance structures, nitrones behave as 1,3-dipolar compounds and undergo reactions typical for this group of compounds, i.e., 1,3-dipolar cycloaddition reactions. 


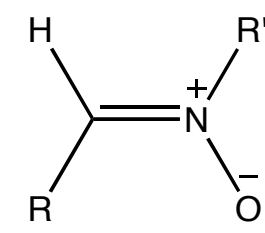

I

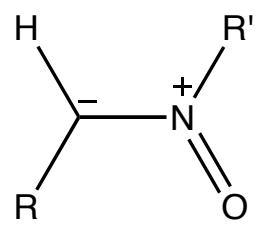

II

Figure 6. Resonance structure of Nitrone

An archetypal representative from the nitrone class of compounds is $\alpha$-phenyl-Ntert-butyl nitrone ( $\alpha$-PBN) (2). $\alpha$-phenyl-N-tert-butyl nitrone is the most extensively studied nitrone. It reacts, albeit not always efficiently, with short-lived free radicals such as superoxide, alkoxyl and hydroxyl radicals and forms a stable nitroxide (Figure 3), thereby, in some cases, neutralizing these harmful free radicals and removing them from circulation. $\alpha$-phenyl-N-tert-butyl nitrone (PBN), at relatively high concentration, also has the ability to prevent oxidation of lipids like low-density lipoprotein. ${ }^{119}$ Although, various derivatives of $\mathrm{PBN}$ have been synthesized, the most extensively studied derivatives in vivo are S-PBN (3) and NXY-059 (4).<smiles></smiles>

PBN (2)

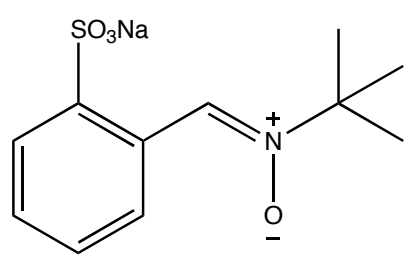

S-PBN (3)<smiles>CC(C)(C)[N+]([O-])=Cc1ccc(S(=O)(=O)O)cc1S(=O)(=O)[O-]</smiles>

NXY-059 (4)

Figure 7. Structures of PBN, S-PBN and NXY-059 
Comparison of the activity of PBN, S-PBN and NXY-059 with free radicals showed that the nitroxides resulting from NXY-059 are the most stable. ${ }^{120}$ Recently, AstraZeneca stopped development of NXY-059 drug for acute stroke after failure of phase IIIb clinical trials. However, NXY-059 was reported to show promising results in Phase II and Phase IIIa clinical trials. Various reasons have been hypothesized for the failure of NXY-059 such as variable concentration of tert-butylhydroxylamine as an active hydrolysis product in older batches and NXY-059's low blood brain barrier permeability. ${ }^{121,122}$

Various other derivatives of PBN have been synthesized in order to improve spintrapping physicochemical properties, like 3PyBN ( $N$-tert-butyl- $\alpha$-(3-pyridyl)nitrone) (5), ${ }^{123}$ 4-PyOBN ( $\alpha$-pyridyl-1-oxide N-tert-butyl nitrones) (6), ${ }^{124}$ and 4-MePyBN (4-(Nmethylpyridinium)-t-butyl nitrone) (7). ${ }^{125}$

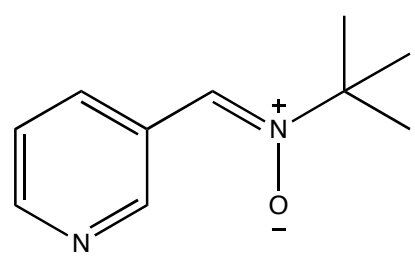

3-PyBN (5)

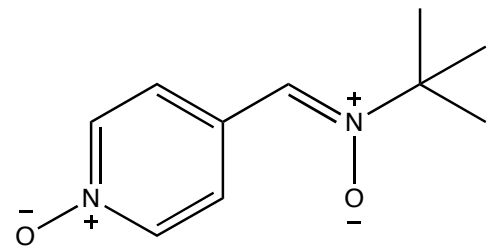

4-PyOBN (6)

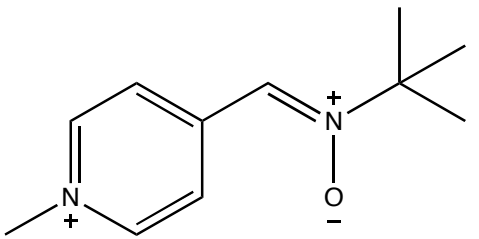

4-MePyBN (7)

Figure 8. Structures of 3-PyBN, 4-PyOBN and 4-MePyBN

MDL-101,002 (8) is a cyclic variant of PBN, synthesized with the purpose to increase the potency of PBN. Fixing the $t$-butyl group to the back exposes the nitrone functionality making it a more potent spin trap than PBN. Other cyclic variants of nitrones like DMPO (5,5-dimethyl-1-pyrroline-N-oxide) (9), ${ }^{126}$ DEPMPO (2-diethoxyphosphoryl-2-methyl- 
3,4-dihydro-2H-pyrrole-1-oxide) (10), ${ }^{127}$ and EMPO (5-ethoxycarbonyl-5-methylpyrroline $N$-oxide) $(11)^{128}$ were also synthesized.

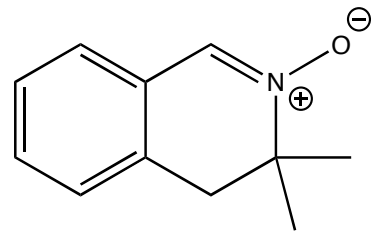

MDL-101,002 (8)

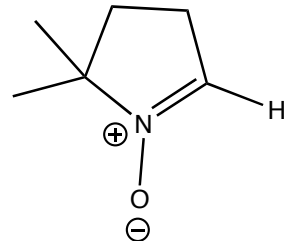

DMPO (9)

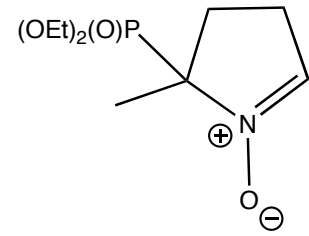

DEPMPO (10)

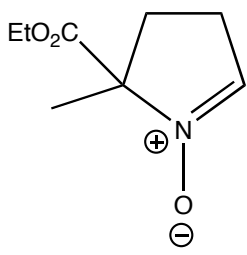

EMPO (11)

Figure 9. Structures of MDL-101,002, DMPO, DEPMPO, and EMPO

\section{[1.5.1] Synthesis of Nitrones:}

Some important and common routes to synthesize nitrones are discussed in this section.

\section{[1.5.1.1] Condensation of $\mathrm{N}$-substituted hydroxylamine with Aldehyde or Ketone:}

The most common method to synthesize a nitrone is by condensation of $\mathrm{N}$ substituted hydroxylamines with an aldehyde or a ketone as shown in the scheme below. $^{129,130}$ This reaction usually gives a very good yield, especially with unhindered aldehydes and ketones.<smiles>[R]C(=O)[18OH]</smiles>

Aldehyde/Ketone<smiles>CNO</smiles>

Hydroxylamine<smiles>[R]C([R])=[N+]([R])[O-]</smiles>

Nitrone 


\section{[1.5.1.2] Oxidation of $N$-substituted hydroxyl amines:}

Nitrones can be readily prepared by oxidation of corresponding N,N-disubstituted hydroxylamines. Oxidation can be achieved by a variety of oxidizing agents such as yellow mercuric oxide, ${ }^{131}$ potassium permanganate, lead oxide, ${ }^{132}$ air oxidation ${ }^{133}$ and hydrogen peroxide. ${ }^{134}$ These methods are particularly useful for the synthesis of cyclic nitrones.
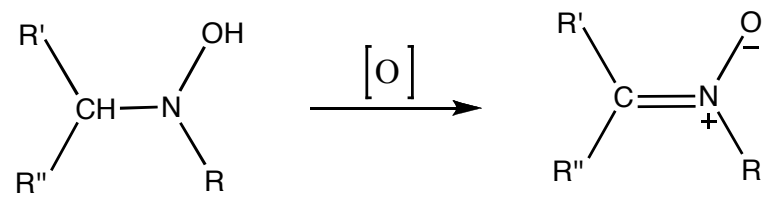

\section{[1.5.1.3] Oxidation of imines or amines:}

MDL 101,002 was synthesized by oxidation of an imine. ${ }^{135}$ This reaction suffers from the drawback of long reaction times (7 days) and multiple additions of oxidants. By reducing imines to amines and then oxidizing the amines to nitrones, one can eliminate both of these drawbacks and obtain a cleaner reaction. ${ }^{136,137}$

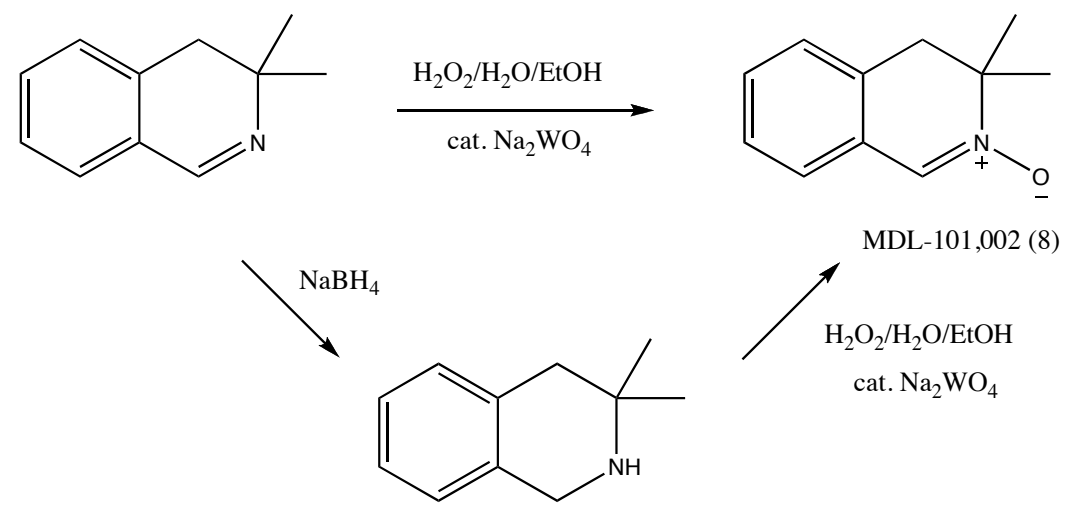




\section{[1.5.1.4] Reductive cyclization of $\gamma$-nitro-carbonyl compounds:}

The reduction of $\gamma$-nitro-carbonyl compounds with zinc dust and ammonium chloride gives cyclic nitrones. ${ }^{138}$ Various derivates of DMPO were synthesized via this route.
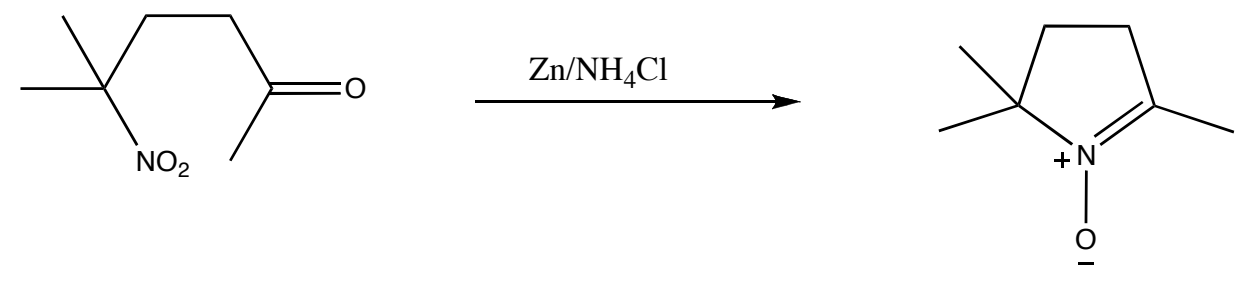

DMPO

\section{[1.5.2] Reactions of Nitrones:}

\section{[1.5.2.1] 1,3-dipolar cycloaddition reactions:}

Nitrones undergo 1,3-dipolar cycloaddition reactions with alkenes $(3+2)$ to give isoxazolidines in much the same way as the classical (4+2) Diels-Alder reaction. ${ }^{118,139,140}$ Isoxazolidines are used as precursor in the synthesis of many natural products such as alkaloids. ${ }^{139}$<smiles>[R]C([R])=[N+]([2H])[O-]</smiles>

Nitrone<smiles>PC=C(P)P</smiles>

Alkene

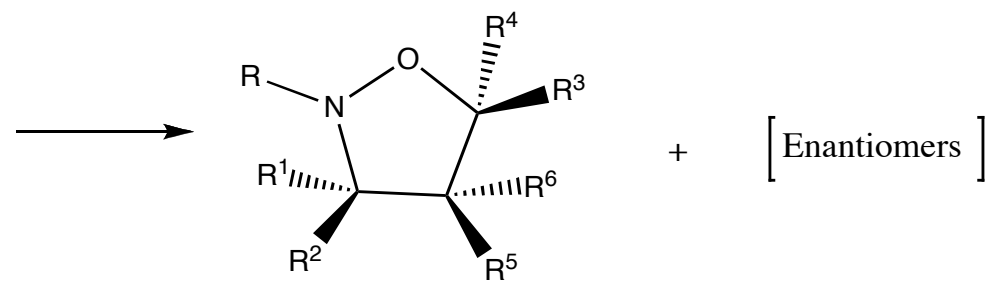

isoxazolidine

Analogously, nitrones were also shown to undergo cycloaddition reactions with various substituted alkynes. ${ }^{141}$ 


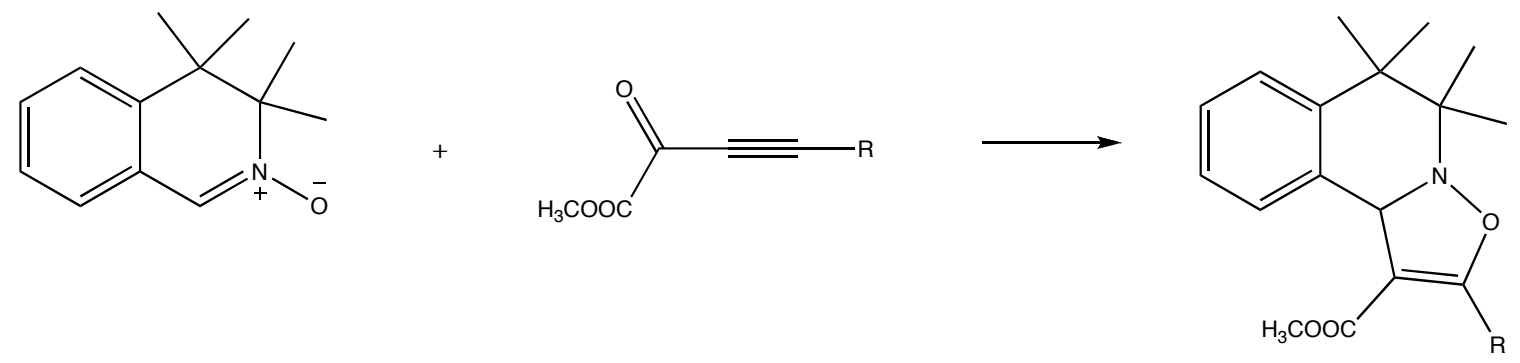

\section{[1.5.2.2] Electrophilic addition reactions:}

Nitrones possess one of the most polarized $\mathrm{C}=\mathrm{N}$ bonds, giving them the ability to undergo metal catalyzed electrophilic addition reactions. Nitrones were shown to undergo addition reactions with organomagnesium or organolithium compounds to give $\mathrm{N}, \mathrm{N}-$ disubstituted hydroxylamines which can be easily reduced to secondary amines. This reaction is often used as an alternative to the addition of organometallic reagents to $\mathrm{C}=\mathrm{N}$ bonds of imines or imine derivatives such as hydrazones and oximes.
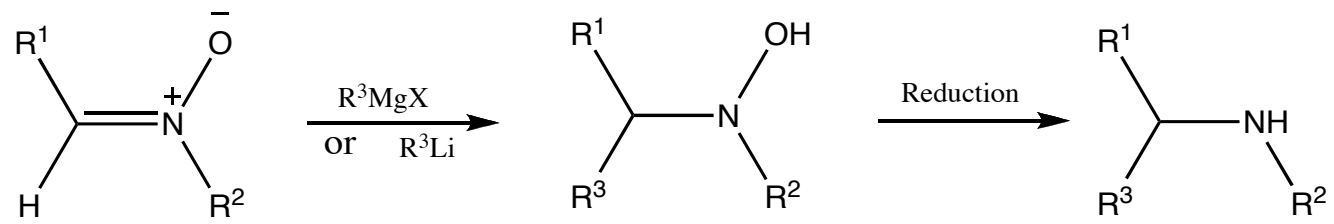

Furthermore, nitrones contain a highly reactive electronegative oxygen, which can chelate strongly with metal ions and chiral auxiliaries to provide control over the setreoselectivity of addition. ${ }^{142}$<smiles>COC[C@H](c1ccccc1)N(O)[C@@H](COC)[C@H](C)c1ccccc1</smiles> 
The proposed chelated transition state involved in these reactions is shown below. ${ }^{142}$

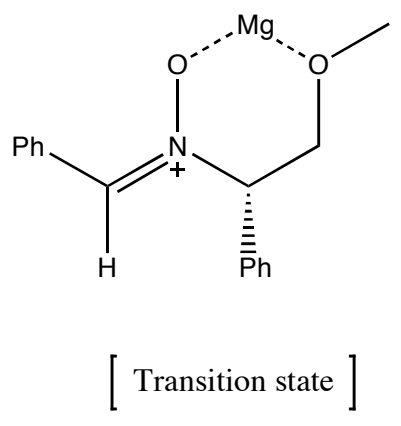

\section{[1.5.2.3] Michael and Aldol type reactions:}

Cyclic as well as acyclic nitrones readily undergo deprotonation to furnish the corresponding resonance-stabilized carbanions, which undergo Michael type and aldol type reactions. $^{143}$
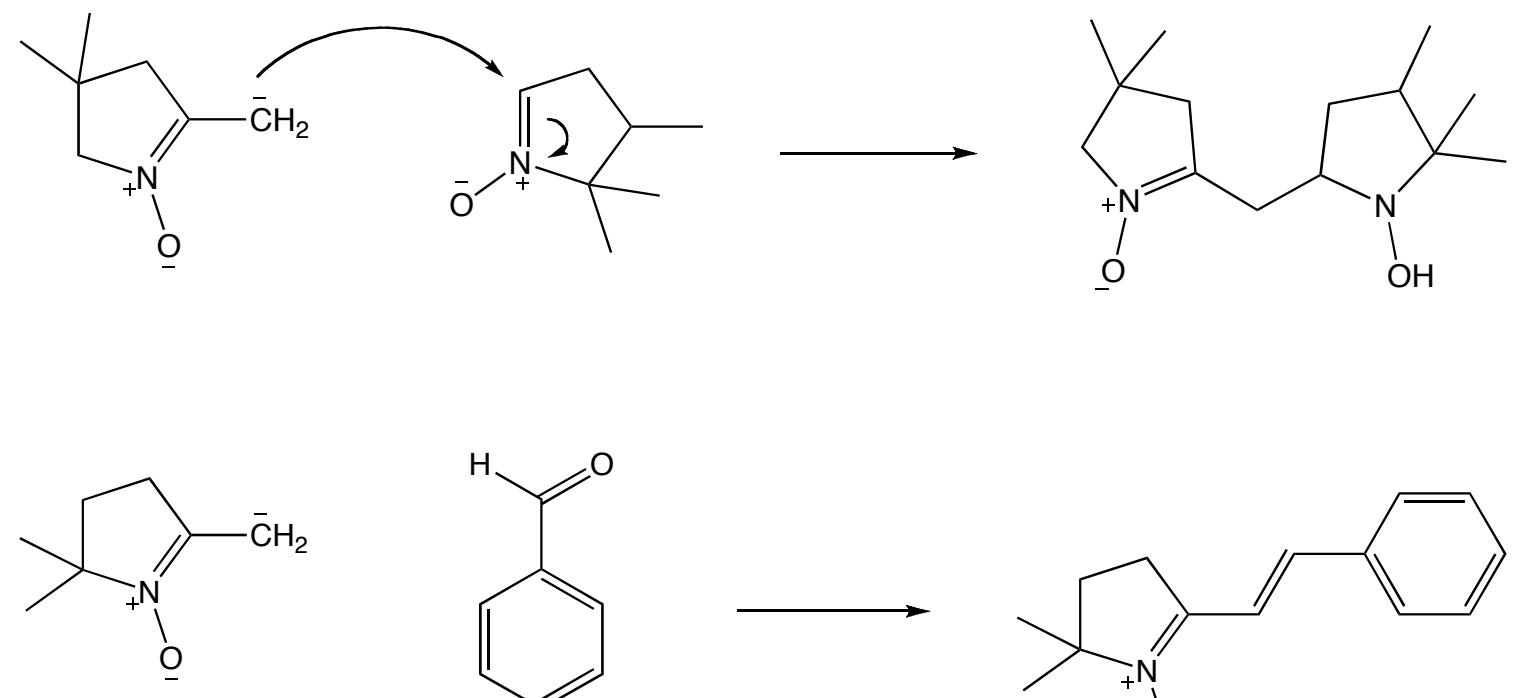<smiles>O=Cc1ccccc1</smiles>

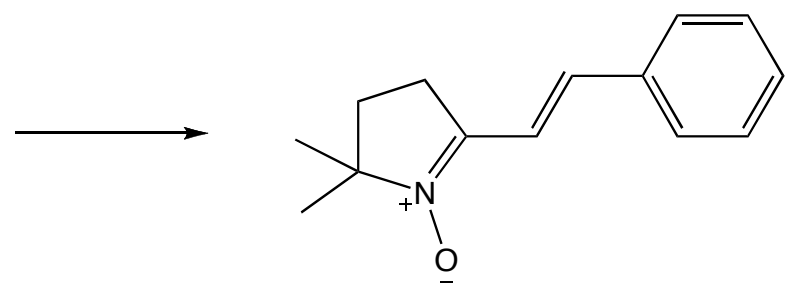

Because of the flexibilities offered by the nitrone functionality, many total syntheses employ nitrone intermdediates. 


\section{[1.6] Edaravone:}

Edaravone (MCI-186) (12), although not a nitrone, is an efficient antioxidative radical scavenging agent. It is the only agent from this category in clinical practice in Japan for acute ischemic stroke. ${ }^{144}$ Edaravone enolate (13) is reported to be the active form in scavenging free radicals by one electron transfer. It is also effective in acute myocardial infarction. ${ }^{145}$ Edaravone was shown to be effective in quenching the hydroxyl radical $(\cdot \mathrm{OH})$ and inhibiting both $\cdot \mathrm{OH}$-dependent and $\cdot \mathrm{OH}$-independent lipid peroxidation. The biological fate of edaravone is shown in figure 10 .

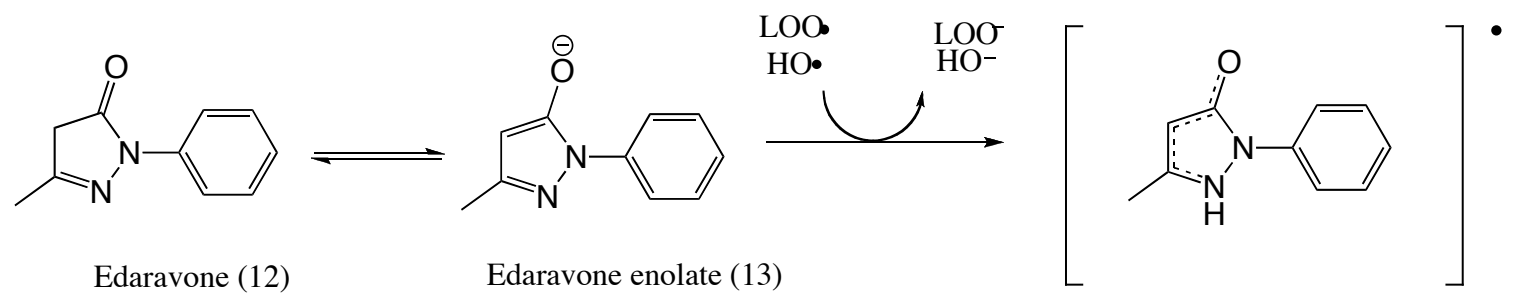

(14)

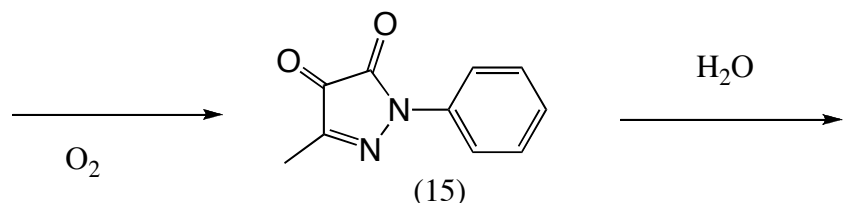

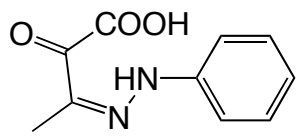

OPB (16)

[2-oxo-3-(phenylhydrazono)-butanoic acid]

Figure 10. Reaction of Edaravone with free radicals

\section{[1.7] Azulenes:}

Azulenes are non-benzenoid bicyclic aromatic compounds. The parent compound from this class is azulene (17), which is a deep blue-colored solid. Azulene hydrocarbons 
are obtained from natural sources. For example, guiazulene (18) is obtained from the wood of Guaiacum officinale, from patchoule oil of Pogostemon pathouli, and from eucalyptus oil of Eucalyptus globulus; chamazulene (19) is obtained from camomile oil of Matricaria camimilla, from oil of yarrow Achillea millefoum, and from oil of wormwood Artemisia absinthium; lactaroviolin (20) is obtained from edible fungi ${ }^{146}$ and vetivazulene (21) from vetiver oil. Azulenes were shown to have therapeutic properties, for example, guiazulene itself was shown to exhibit anti-inflammatory and antioxidant properties. $^{147}$

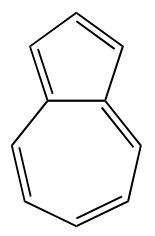

Azulene (17)

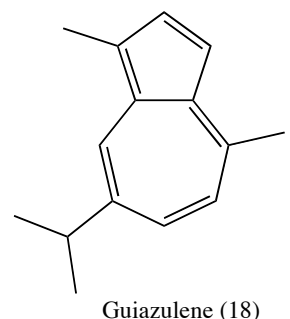

Guiazulene (18)
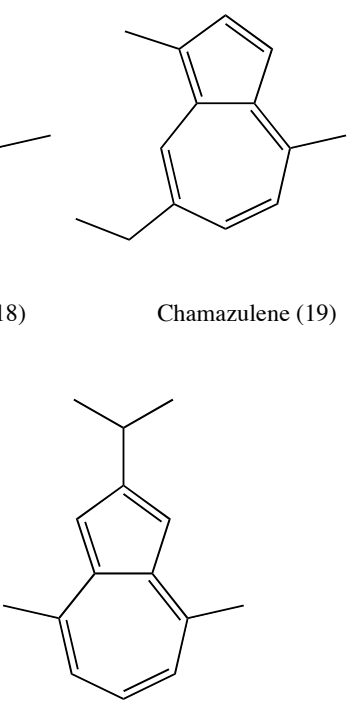

Vetivazulene (21)

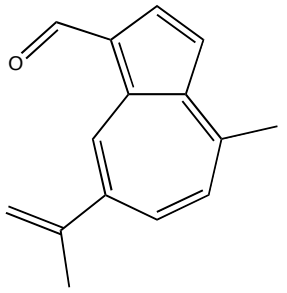

Lactaroviolin (20)

Figure 11. Naturally occuring azulenyl compounds

\section{[1.7.1] Previous work on Azulenyl Nitrones:}

In 1995, Becker reported the synthesis of a novel azulenyl nitrone AZN (22) in three efficient steps from the readily available sesquiterpene, guiazulene (18). ${ }^{148}$ 


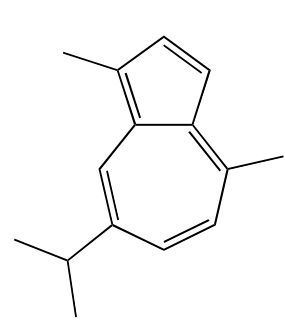

Guiazulene (18)
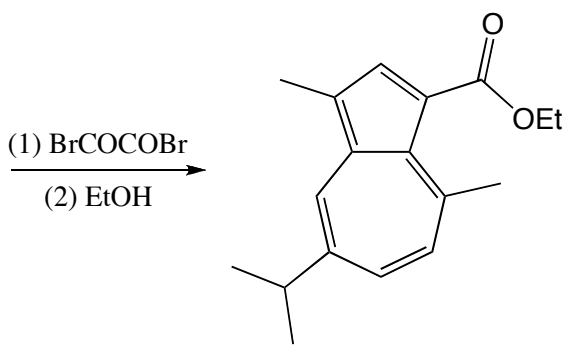

(23)

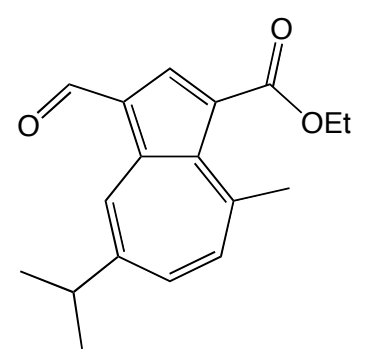

AZA (24)
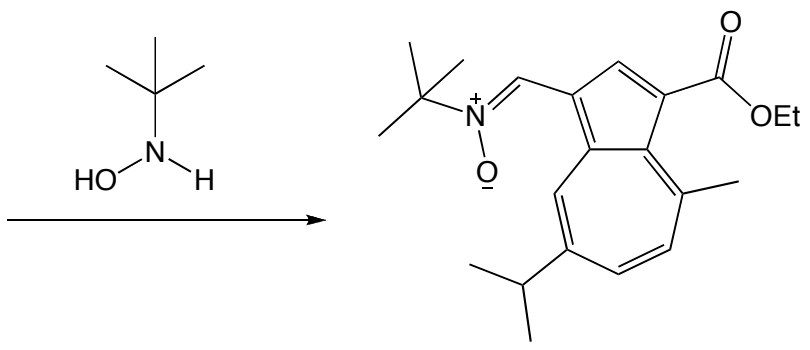

AZN (22)

Figure 12. Synthetic scheme of AZN (22)

This first publication on azulenyl nitrones focused on spin trapping with colorimetric detection, since AZN yields characteristically colored and highly visible diamagnetic (and paramagnetic) spin adducts.

Therefore, when emerald green azulenyl nitrone (22) was treated with an azo-compound (23) in toluene at $95^{\circ} \mathrm{C}$, the violet colored double spin adduct (24) was formed. 


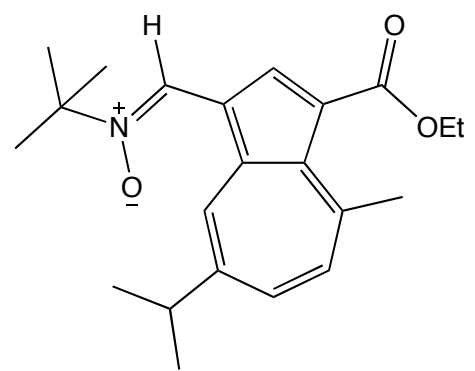

Azulenyl Nitrone (22) Emerald Green
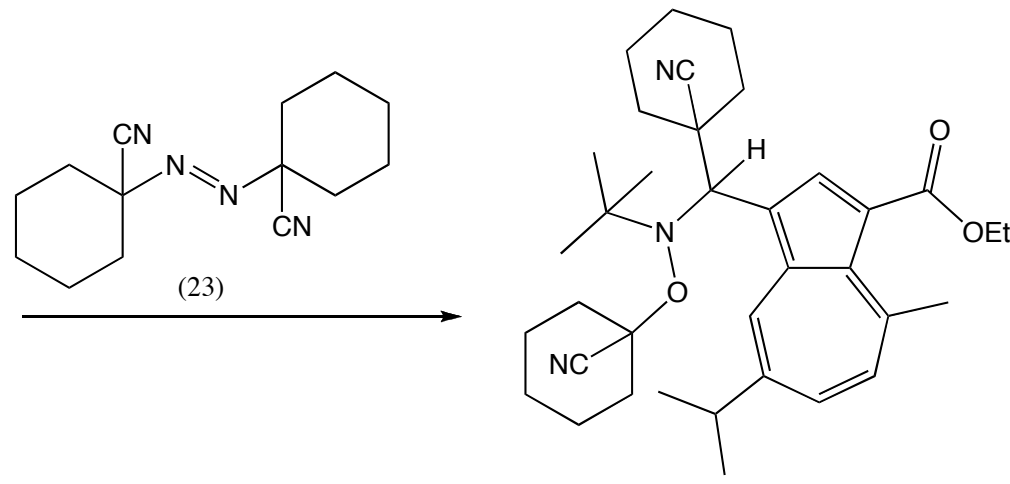

Azulenyl Nitrone (24) Violet

Figure 13. Double spin adduct of AZN

This colorimetric detection of free radicals is highly convenient and was extended to biological systems. It was shown that AZN upon trapping peroxyl radical gives nitroxide (25), which undergoes fragmentations to give azulenyl aldehyde (26).<smiles>CCOC(=O)c1cc(/C=[N+](\[O-])C(C)(C)C)c2cc(C(C)C)ccc(C)c1-2</smiles>

Azulenyl Nitrone (22)

Emerald Green

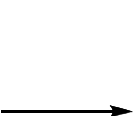

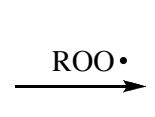<smiles></smiles><smiles>CCOC(=O)c1cc(C=O)c2cc(C(C)C)ccc(C)c1-2</smiles>

Aldehyde (26) Red
Nitroxide (25)

Purpule<smiles>CC(C)(C)N([O])O[Na]</smiles>

Akloxy alkyl nitroxide

Figure 14. Reaction of AZN (22) with peroxyl radical 
Aldehyde (26) can be easily detected by analytical techniques such as UV/VIS colorimetric detection. The formation of this aldehyde was shown to be an excellent indicator of oxidative stress in brain ischemia/reperfusion in gerbil models. ${ }^{149}$ and in a transgenic mouse model of ALS. ${ }^{183}$

The oxidation potential of azulenyl nitrone (22) was found to be $0.84 \mathrm{~V}$ vs SCE, which was considerably lower than previously reported nitrones. Unlike conventional nitrones such as PBN (2) and S-PBN (3), oxidation of azulenyl nitrones are chemically and electrochemically fully reversible. ${ }^{75,150}$ For the first time, the oxidation potential of a nitrone based spin trap was reported to be close to that of the oxidation potentials of important biological antioxidants such as glutathione $(\mathrm{Ep}=0.69 \mathrm{~V})$ and $\beta$-carotene $(\mathrm{Ep}=0.76 \mathrm{~V})$. Previous studies to correlate oxidation potential with free radical scavenging ability have shown that antioxidants possessing efficient free radical scavenging ability have significantly low oxidation potentials. ${ }^{151}$ Oxidation potentials of some nitrones are given in Table 1.

Table 1. Oxidation Potential of various nitrones

\begin{tabular}{|l|l|}
\hline Nitrones & $\begin{array}{l}\text { Oxidation Potential } \\
\text { in } \boldsymbol{V}\end{array}$ \\
\hline PBN (2) & 1.47 \\
\hline 2-S-PBN (3) & 1.34 \\
\hline 4-PyBN (5) & 1.93 \\
\hline 3-PyBN & 1.67 \\
\hline 3-PyOBN (6) & 1.84 \\
\hline 4-PyOBN & 1.37 \\
\hline DMPO (9) & 1.63 \\
\hline 4-MePyBN (7) & 2.32 \\
\hline 3-MePyBN & 2.10 \\
\hline
\end{tabular}


Furthermore, direct correlation of oxidation potential from this list can be drawn such that, electron-withdrawing groups are seen to increase the oxidation potential, thus making it difficult for nitrones to lose an electron to an oxidizing species. ${ }^{152}$

The unusually low oxidation potential of an azulenyl nitrone was attributed to the formation of the resonance stabilized radical cation as an $\alpha, \beta$-unsaturated aminoxyl (27) in addition to the presence of the aromatic tropylium cation (28).<smiles>[R]C(=C1C=CC2=CC=CC=CC21)[N+]([R])[2H]</smiles>

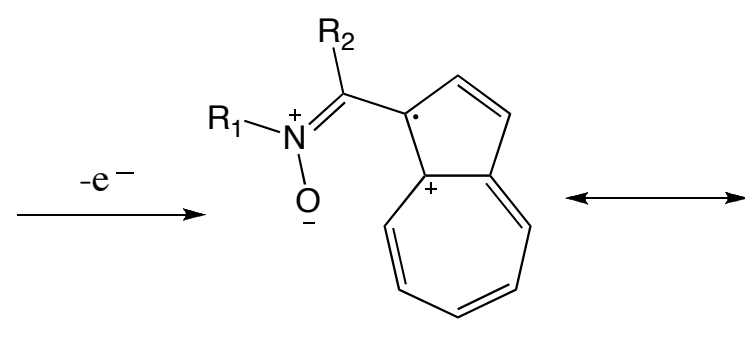

(27)

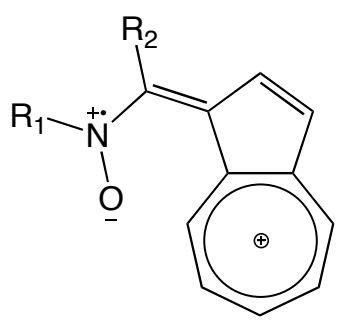

(28)

Figure 15. One electron oxidation of Azulenyl Nitrone

Another water soluble azulenyl derivative, azulenyl bis-nitrones (w-AZN)(29) was shown to have even lower oxidation potential of $0.63 \mathrm{~V}$ vs. SCE. ${ }^{153}$

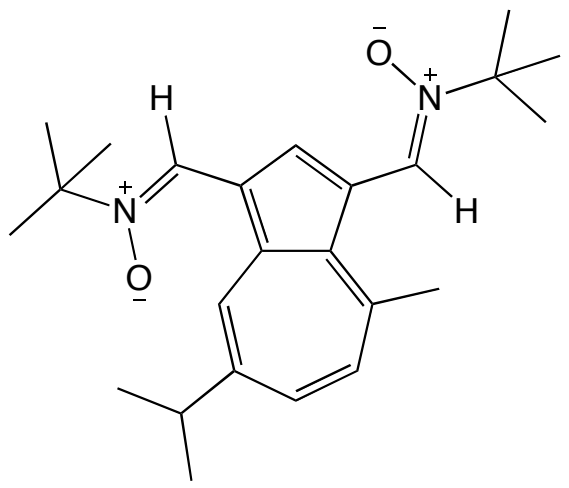

W-AZN (29) 
Evaluation of the pharmacological activity of AZN (22) and W-AZN (29) against oxidative stress has shown that azulenyl nitrones are excellent therapeutic candidates in free radical-mediated pathological conditions. ${ }^{75}$ Pharmacological evaluation of these first generation azulenyl nitrones has shown that they protect the brain against MPTP-induced neurotoxicity in Parkinsonism. ${ }^{75}$ Both lipid soluble AZN and water-soluble W-AZN provided dose dependent protection against dopamine depletion and homovanillic acid depletion. It was also shown that the number of dying axotomized ganglion cells in the developing chick retina can be reduced by administration of AZN alone or in combination with $N$-acetyl cysteine (NAC) ${ }^{154}$ The combination of azulenyl nitrone and NAC has a synergistic effect, which is in contrast to the antagonistic effect shown by the combination of PBN and NAC. In a competition experiment performed to determine the efficacy of AZN in spin trapping as compared to PBN (3), AZN turned out to be $50 \%$ more effective as PBN in trapping free radicals. ${ }^{150}$ This increased potential of azulenyl nitrone to trap free radicals has been attributed to its low oxidation potential.

In 1964, Hünig et al. correctly assigned the structure of the remarkably stable hydrocarbon radical cation (31). ${ }^{155} \mathrm{In}$ methylene chloride, a $10^{-5} \mathrm{M}$ solution of compound (31) showed remarkable stability and a $2.5 \times 10^{-2} \mathrm{M}$ solution of (31) in ethylene chloride/methylene chloride (1:9) was shown to be stable for 1 day. ${ }^{155}$ Such stability of a hydrocarbon radical cation was unprecedented. 


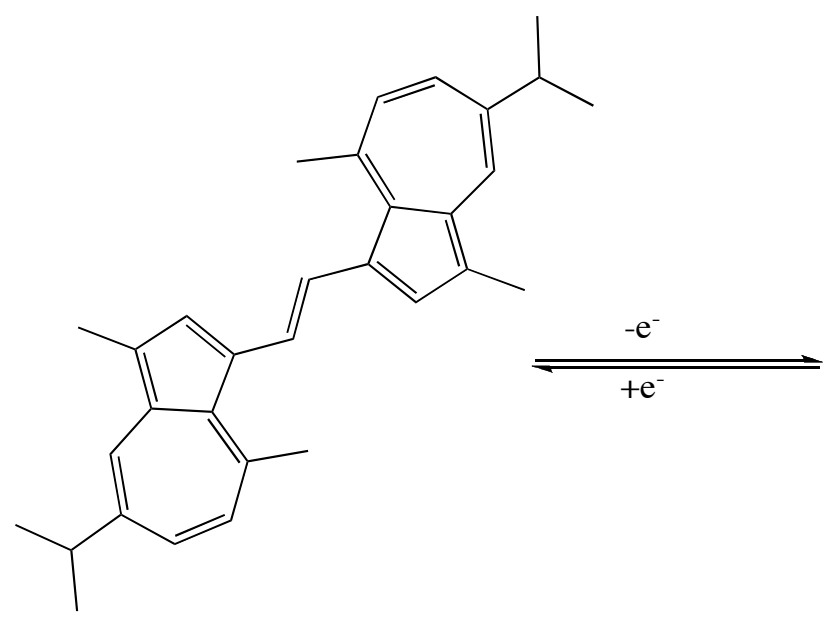

(30)

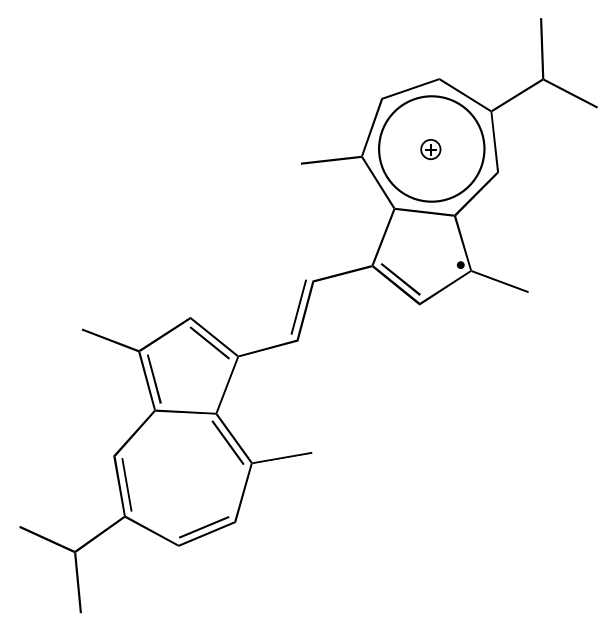

$(31)$

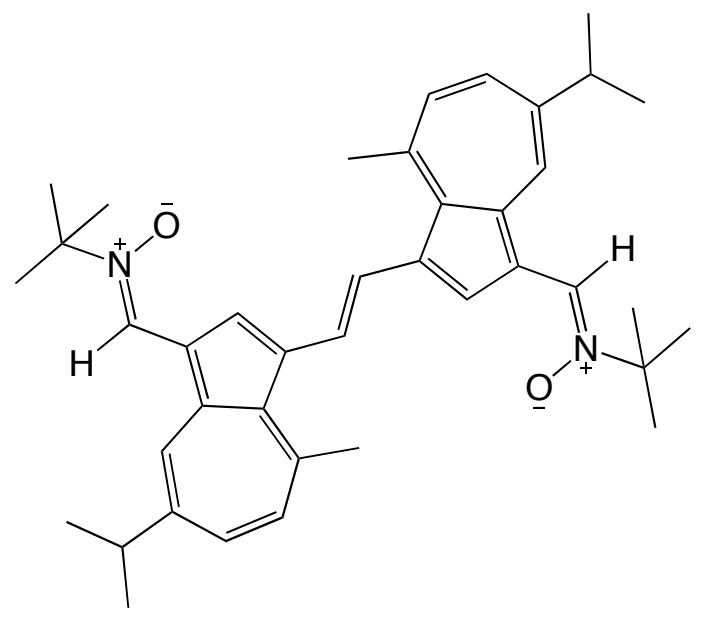

(32)

In an attempt to synthesize an azulenyl nitrone with even lower oxidation potential than $\mathrm{AZN}$ or $\mathrm{W}-\mathrm{AZN}$, Becker et al. synthesized the novel second generation azulenyl nitrone, stilbazulenyl nitrone (STAZN) (32) in five efficient steps starting from guiazulene (18) as shown in figure $16 .{ }^{156}$ Cyclic voltammetry experiments to determine the oxidation potential of STAZN (32) have shown that STAZN does have an exceptionally low oxidation potential that is fully reversible. 


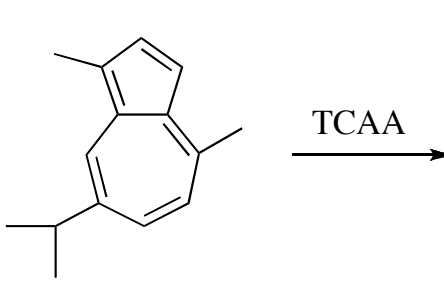

Guaiazulene

(18)

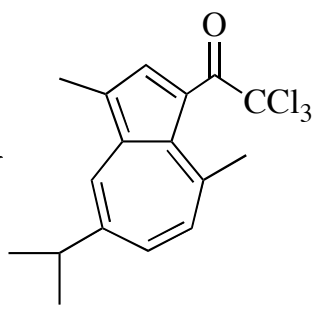

(33)

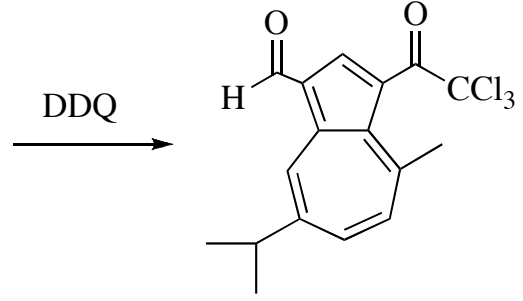

(34)

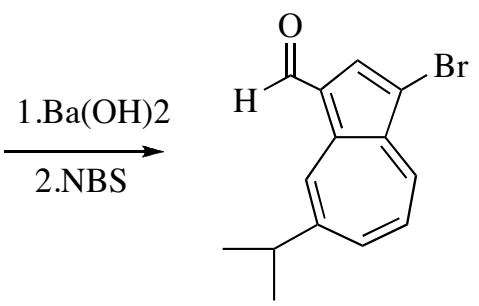

(35)<smiles>CCC[Sb]C=C[SbH2]C(C)(C)C</smiles>

$\mathrm{SnBu}_{3}$<smiles></smiles>

(36)

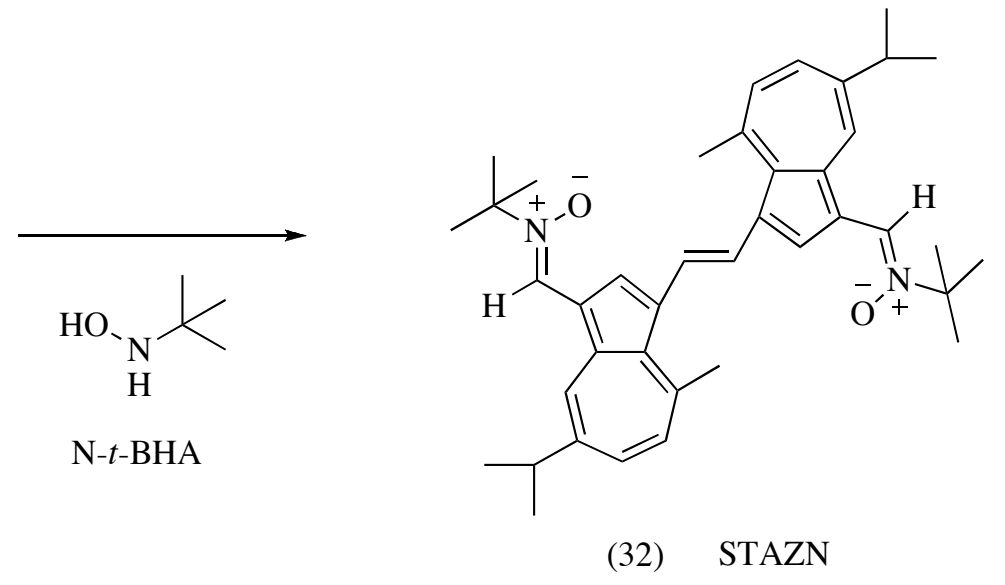

Figure 16. Synthetic scheme of STAZN (32)

For the first oxidation, the $\mathrm{E}^{1} / 2$ value was found out be $0.33 \mathrm{~V}$ vs $\mathrm{SCE}$ and for the second oxidation, $\mathrm{E}^{1 / 2}$ value was $0.54 \mathrm{~V}$ vs. SCE. Owing to its low oxidation potential, STAZN was expected to be an improved free radical trap/antioxidant than any of the previously 
reported nitrone based spin traps. ${ }^{157}$ Lipid peroxidation assays were done to compare the efficacy of STAZN with other widely studied nitrone based spin traps such as PBN (2), S-PBN (3), NXY-059 (4), and AZN (22) and other conventional antioxidants such as butylated hydroxytoluene (BHT) (37), probucol (38), $\beta$-carotene (39) and vitamin E $(40) \cdot{ }^{157}$

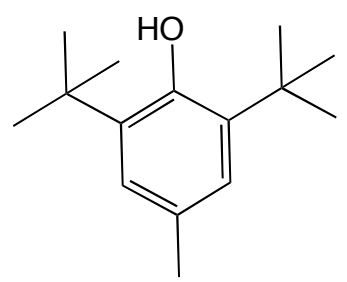

Butylated hydroxytoluene (37)

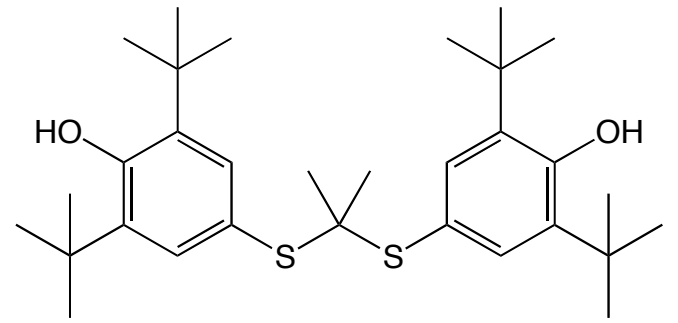

Probucol (38)<smiles>CC1=C(/C=C/C(C)=C/C=C/C(C)=C/C=C/C=C(C)/C=C/C=C(C)/C=C/C2=C(C)CCCC2(C)C)C(C)(C)CCC1</smiles>

Beta-carotene (39)<smiles>Cc1c(C)c2c(c(C)c1O)CC[C@](C)(CCC[C@H](C)CCC[C@H](C)CCCC(C)C)O2</smiles>

Vitamin E (40)

Figure 17. Commonly used natural and synthetic antioxidants

These assays were done at half the concentration of STAZN (32) as compared to other nitrones to compensate for the presence of an extra nitrone group in STAZN. The antioxidant activity of STAZN was shown to be far superior to all the other nitrones in this study. In fact, STAZN was shown to be more effective in inhibiting peroxidation of 
cumene than NXY-059 (4) even at $1 / 100^{\text {th }}$ the concentration. These assays showed that STAZN is in fact ca. 300 times more potent than NXY-059 in suppressing free radical driven peroxidation of cumene. ${ }^{157}$ It was also shown to be 2-3 orders of magnitude more potent that PBN (2) in this assay. Other results with this assay showed that STAZN markedly outperformed $\beta$-carotene, and was found to be almost as potent as BHT (37); however, STAZN was substantially out performed by vitamin E (40) and probucol (39) in a non-polar solvent medium. When the same experiment was repeated in a polar medium, i.e. in methanol instead of benzene, a dramatic solvent effect was seen. In methanol, STAZN significantly outperformed conventional antioxidants namely $\beta$-carotene, BHT, and probucol and rivaled the activity of vitamin E. These findings were significant because, for the first time, a nitrone based spin trap was demonstrating antioxidant potency at a level ascribed to $\alpha$-tocopherol.

In order to assess the pharmacological potency of STAZN in traumatic brain injury, it was shown that STAZN markedly improves neurological and histological outcomes. ${ }^{156}$ Rats treated with STAZN showed improved neurological scores $(6.1 \pm 0.8)$ as compared to vehicle treated rats $(7.6 \pm 0.3)$ and total contusion area was reduced by $63 \%$ with STAZN. ${ }^{156}$ A more elaborate animal study done on 52 rats showed that STAZN provides an excellent neuroprotection in a focal ischemic stroke model with detectable neurobehavioral improvement as early as 1 to 1.5 hours after administration of the first STAZN dose. ${ }^{158}$ Furthermore, in one half of STAZN treated animals, cortical infract was virtually abolished. Interestingly, such neuroprotection was reported only at total dose of $1.2-2.4 \mathrm{mg} / \mathrm{kg}$ of STAZN as compared to $700-800 \mathrm{mg} / \mathrm{kg}$ of total dose required of NXY-059 for equivalent neuroprotection. ${ }^{159-161}$ 
Stilbazulenyl nitrone (STAZN) was also shown to provide neuroprotection in an animal model of Parkinson's disease caused by MPTP (1-methyl-4-phenyl-1,2,3,6tetrahydropyridine) toxicity and in a murine model of Huntington's disease caused by the neurotoxin 3-nitropropionic acid. ${ }^{162}$ 1-methyl-4-phenyl-1,2,3,6-tetrahydropyridine (MPTP) is known to cause depletion of dopamine in this Parkinson's disease model and STAZN protected about $40 \%$ of endogenous dopamine from depletion by MPTP in this model. Furthermore, STAZN inhibited lipid peroxidation produced by systemic administration of 3-nitropropionic acid in the striatum, the cerebral cortex, and the cerebellum.

In a study done to determine the efficacy of STAZN in protecting the brain in an animal model of focal ischemic stroke, it was found that STAZN has respectable blood brain barrier permeability ( $2.5 \%$ of plasma level at 3 hour after i.v. infusion) along with $56 \%$ in heart and $41 \%$ in kidney. ${ }^{163}$ The circulatory half-life of STAZN was found out to be $\sim 14$ hours as compared to that of $\sim 2$ hours of PBN which ensures infrequent dosing. Even though the metabolic fate of STAZN is currently unknown, it has been hypothesized to undergo hepatic metabolism as a clearance pathway. ${ }^{163}$ In addition to the neuroprotective activity of STAZN, the compound was also shown to be cardioprotective in a study done to determine the effectiveness of STAZN in myocardial ischemia/reperfusion injury. ${ }^{164}$

This work describes the synthetic and cyclic voltammetric studies to determine the accessibility and oxidation potentials of novel third generation azulenyl nitrones and fourth generation pseudoazulenyl nitrones. 


\section{[2] RESEARCH OBJECTIVE}

The objective of this research is to design and synthesize third generation azulenyl nitrones and various novel pseudoazulenyl nitrones with lower oxidation potentials than that of previously synthesized nitrones. Towards this goal, the following nitrones were pursued as potential targets.

\section{[2.1] Azulenyl nitrones:}

It was theorized that by placing electron donating groups on the five-membered ring of the previously synthesized azulenyl nitrones, electron density could be increased which could result in azulenyl nitrones with yet lower oxidation potentials. Towards this goal, compound (45), a derivative of AZN (22) as well as compound (46), a derivative of STAZN (32), were pursued as potential targets.

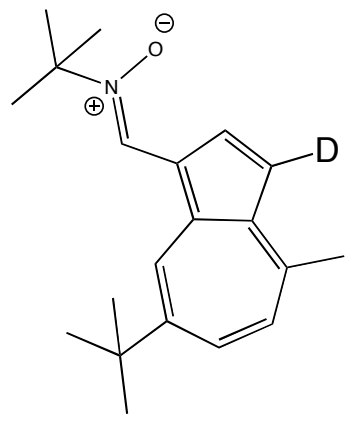

Compound (45)

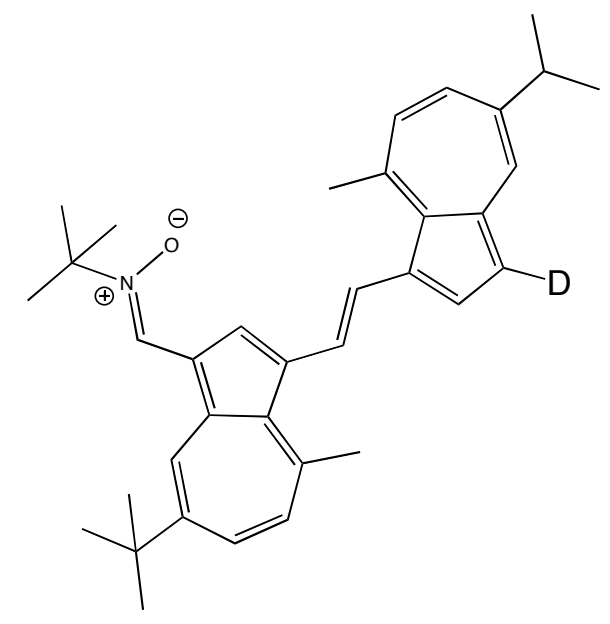

Compound (46)

Where,
$\mathrm{D}=$ electron donating group 


\section{[2.2] Pseudoazulenyl nitrones:}

Pseudoazulenes are iso- $\pi$-electronic analogues of azulenes containing heteroatom (S, O, or NR), which provide two mobile electrons. ${ }^{165}$ They are chemically named based on the type and position of heteroatom. ${ }^{166}$ For example,

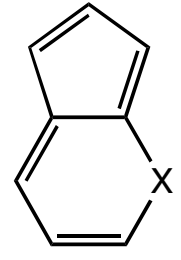

41a: $\mathrm{X}=\mathrm{N}-\mathrm{R}$ (cyclopenta[b]pyridine) 41b: $\mathrm{X}=\mathrm{O}$ (cyclopenta[b]pyran) 41c: $\mathrm{X}=\mathrm{S}$ (cyclopenta[b]thiopyran)

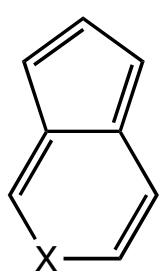

42a: $\mathrm{X}=\mathrm{N}-\mathrm{R}$ (cyclopenta $[c]$ pyridine) 42b: $\mathrm{X}=\mathrm{O}$ (cyclopenta[c]pyran) 42c: $X=S$ (cyclopenta $[c]$ thiapyran

Pseudoazulenes containing two heteroatoms are also known. ${ }^{167}$

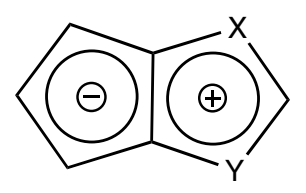

(43)

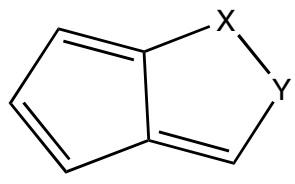

(44)

Studies done on theses pseudoazulenes have shown that stability and aromatic character decreases in the order given below. 


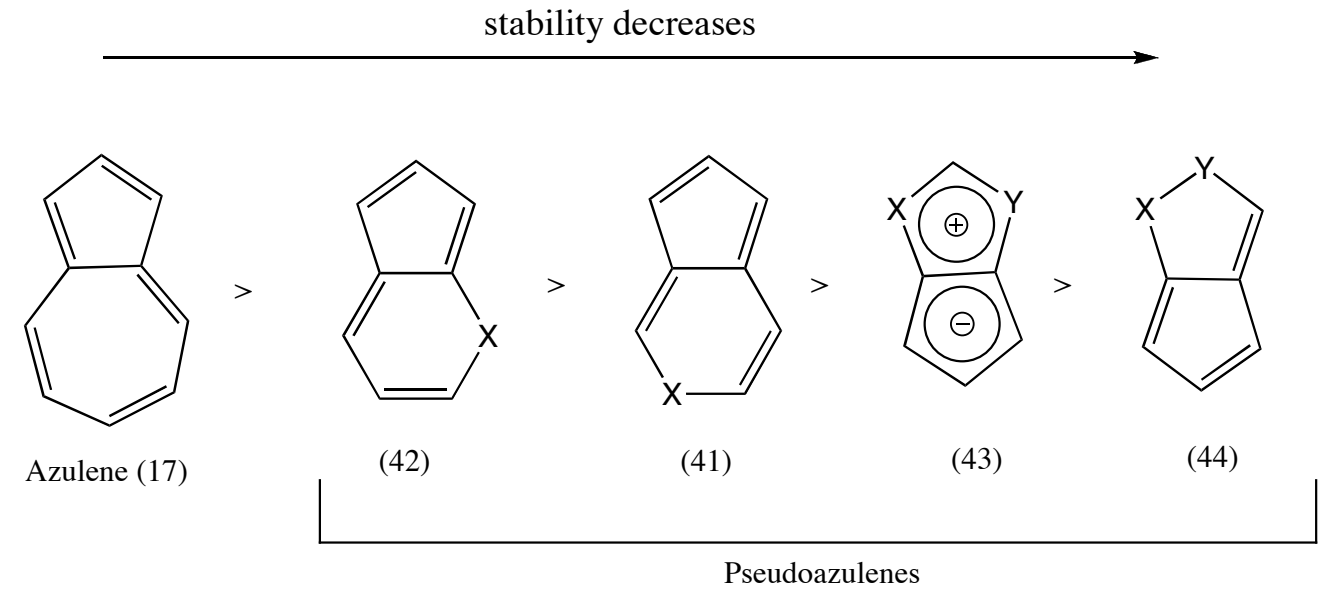

Certain pseudoazulenes have been shown to possess antifungal properties. ${ }^{168}$

Pseudoazulenes, because of the presence of an electronegative heteroatom in the ring structure, possess lower oxidation potentials than that of corresponding benzenoid and counterpart. Nitrones in conjugation with pseudoazulenes, therefore, were expected to result in spin traps having even lower oxidation potential than those resulting from benzenoids and azulenes. The general structure of these targets are as shown below:<smiles>[R]n1cc(/C=[N+](/[O-])C(C)(C)C)c2ccc(/C=[N+](/[O-])C(C)(C)C)c-2c1</smiles>

Compound (47)<smiles>[R]n1cc2c(/C=[N+](/[O-])C(C)(C)C)cc([2H])c-2c(/[N+]([O-])=N/[O-])c1</smiles>

Compound (48)

$$
\begin{aligned}
& \text { Where, } \\
& \mathrm{D}=\text { electron donating group and, } \\
& \mathrm{R}=\text { alkyl group }
\end{aligned}
$$


The presence of the nitrogen heteroatom in the pseudoazulenyl system permits various possibilities of improving or modifying the physicochemical properties of the pseudoazulenyl nitrone. For example, simply by changing the substituent $\mathrm{R}$ above, we were able synthesize lipophilic, hydrophilic, or amphiphilic compounds, or compounds that are putatively equipped to target specific organ or cell structures such as mitochondria. Such diversity and flexibility is warranted when designing drug candidates.

\section{[3] RESULTS AND DISCUSSION}

\section{[3.1] Synthesis of Third Generation Azulenyl Nitrones:}

It has been established that nitrones having low oxidation potential are efficient as antioxidants in trapping free radicals in vitro and likely in vivo. ${ }^{34,157}$ Therefore, it was decided to further lower the oxidation potentials of azulenyl nitrones by increasing the electron density in the five membered ring of the azulenyl system, which can be done by attaching electron donating groups such as hydroxyl (-OH), alkoxyl (-OR), mercapto ($\mathrm{SH})$, or alkylthio (-SR). The vacant 1-position on bis-azulenyl monoaldehyde (49) is ideal for such a purpose since it is the most electronegative position in the azulene system.

Most electronegative Position

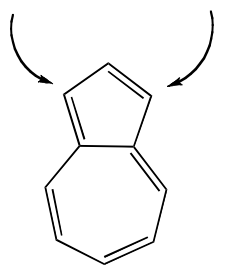

Azulene (17)

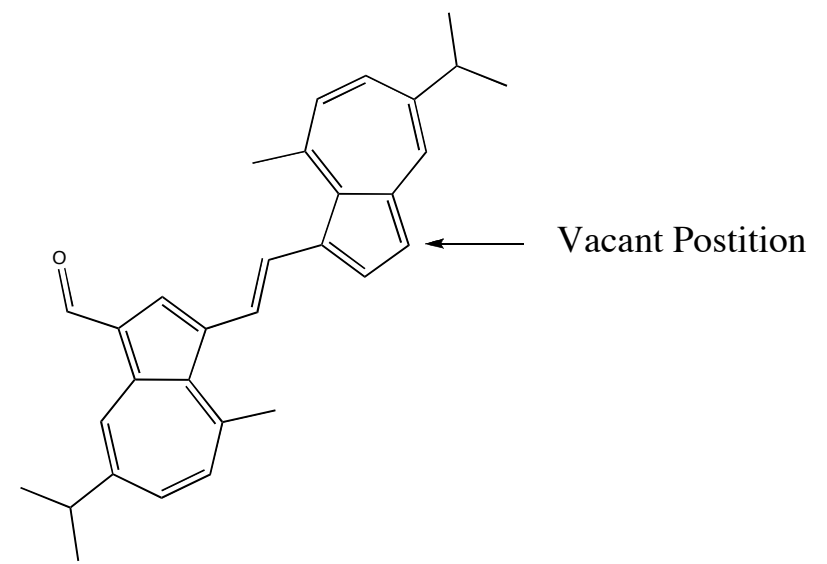

Bis-azulenyl monoaldehyde (49) 


\section{[3.1.1] Synthesis of 1-substituted bisazulenyl-mononitrone:}

Bis-azulenyl dialdehyde (36) had already been synthesized by Becker et al. ${ }^{157}$ Following the same protocol, bis-azulenyl dialdehyde (36) was synthesized and then decarbonylated by using a half equivalent of Wilkinson's catalyst at $110^{\circ} \mathrm{C}$ under argon to give bis-azulenyl monoaldehyde (49). The bis-azulenyl monoaldehyde (49) was reacted with 2,2'-dithiobis-benzothiazole (Altax) (50) at $200^{\circ} \mathrm{C}$ in ethylene glycol to give bisazulenyl thiobenzothiozole monoaldehyde derivative (51) in excellent yield according to the procedure of Porshnev et al. ${ }^{169}$ The resulting bisazulenyl thiobenzothiozole monoaldehyde was then successfully converted to the mononitrone (52) by condensation with $\mathrm{N}$-t-butyl hydroxylamine at $100^{\circ} \mathrm{C}$. Various attempts to cleave the sulfur-carbon bond to yield 1-substituted bis-azulenyl mononitrone (53) in basic condition or with ethyl iodide failed.

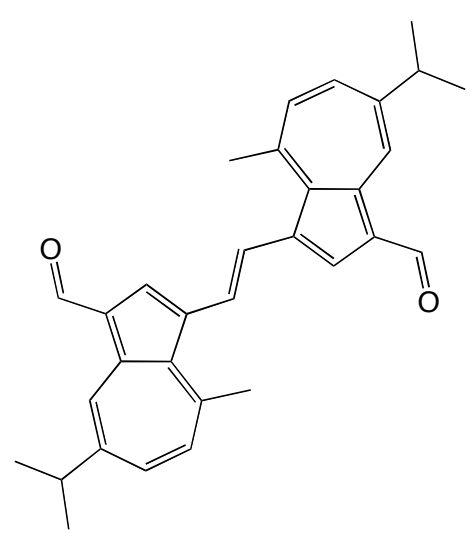

Bis-azulenyl dialdehyde (36)
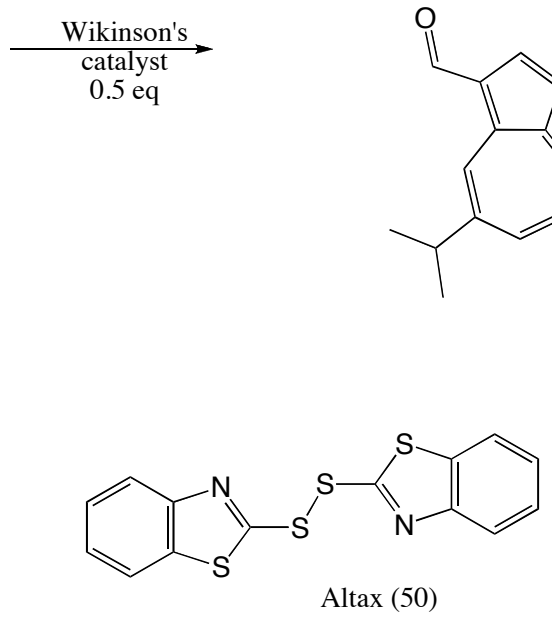

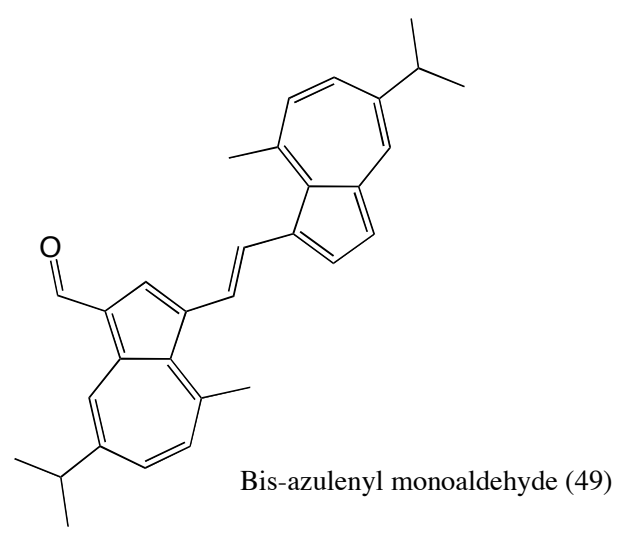

Ethylene glycol $200^{\circ} \mathrm{C}$ 

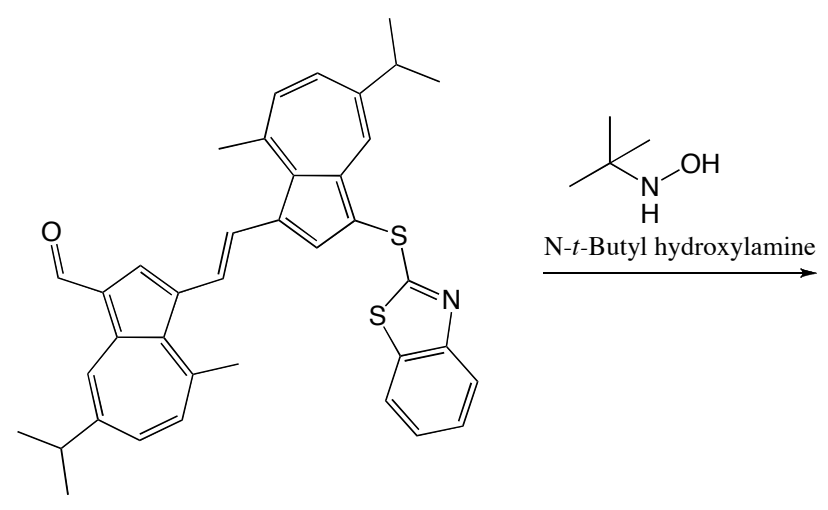

Thio benzothiazole Monoaldehyde derivative (51)

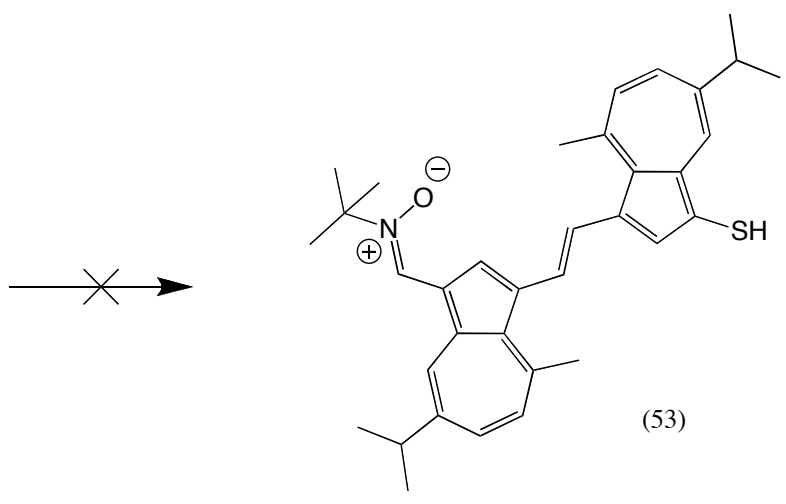

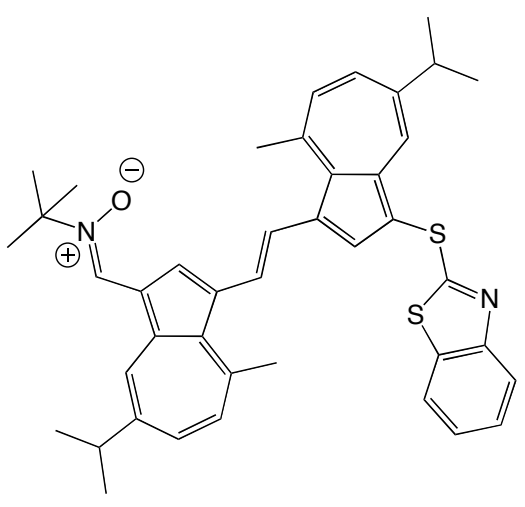

Thio benzothiazole Mononitrone derivative (52)

Figure 18. Attempted synthesis of 1-substituted thio-benzothiozole bis-azulenyl mononitrone (53)

Palei et al. showed that alkylthio groups can be introduced on the azulenyl derivatives at $-78^{\circ} \mathrm{C}$ by reacting azulenes with ethylsulfenyl chloride. ${ }^{170}$ Following the same protocol, 1-ethylthio-bis-azulenyl-monoaldehyde (54) was synthesized with an ethylthio group at the 1-position. 1-substituted monoaldehyde (54) was then easily converted to 1-ethylthio-bis-azulenyl-mononitrone (55) by condensing the 1-ethylthiobis-azulenyl-monoaldehyde (54) with $N$-(tert-butyl)hydroxylamine. 


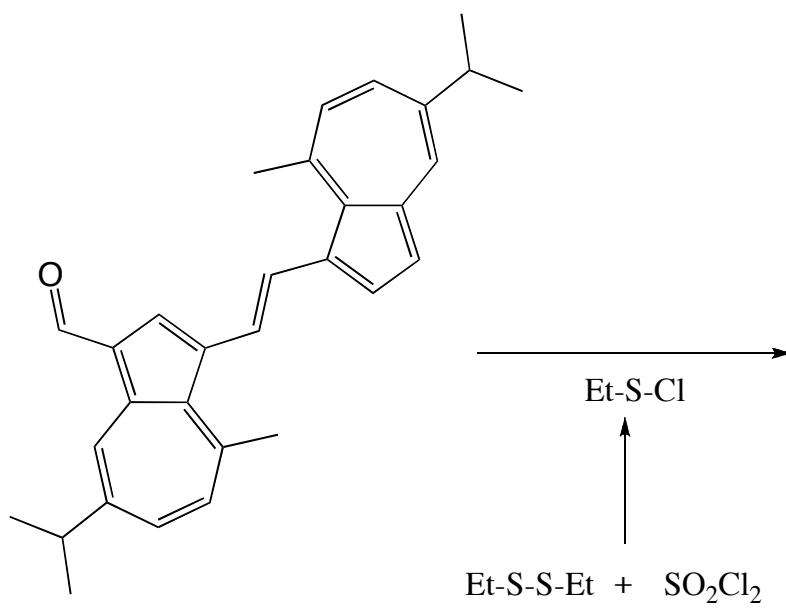

Bis-azulenyl monoaldehyde (49)

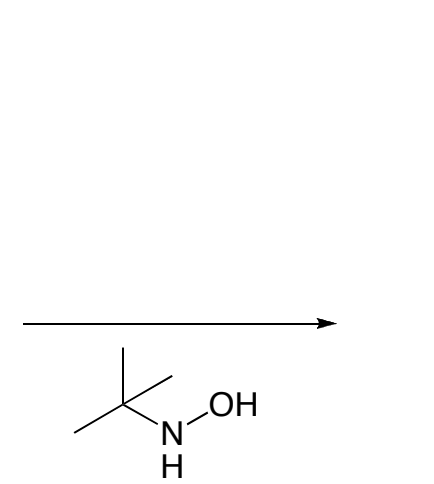

N-t-Butyl hydroxylamine

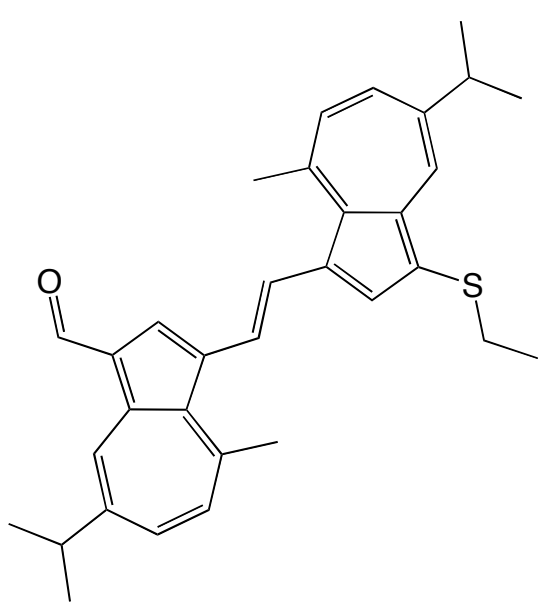

1-Ethylthio bis-azulenyl monoaldehyde (54)

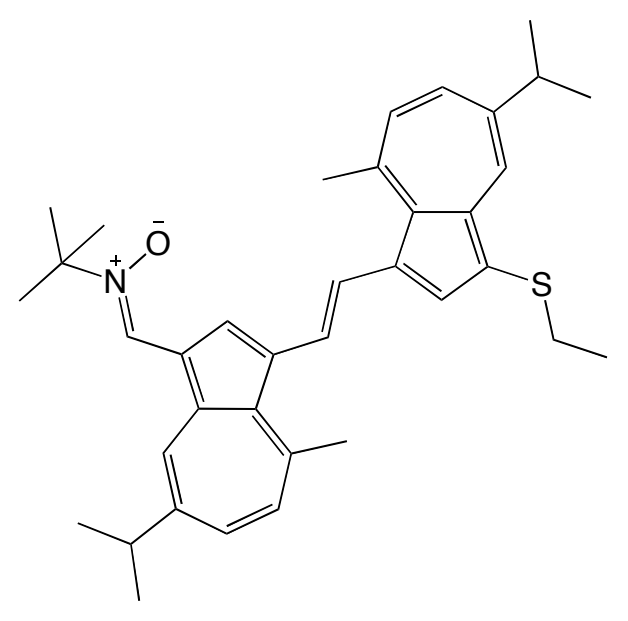

1-Ethylthio Bis-azulenyl mononitrone (55)

Figure 19. Synthetic scheme of 1-ethylthio-bis-azulenyl mononitrone (55)

Using the same protocol, a guiazulenyl nitrone with ethylthio group at 3-position (56) was also synthesized in three efficient steps from guiazulene.

First, guiazulene (18) was converted to 1-ethylthio-guiazulene (57) using the protocol of Palei. ${ }^{170}$ The 1-methyl group on compound (57) was oxidized by 2,3dichloro-5,6-dicyanobenzoquinone (DDQ) to give 3-(ethylthio)-guiazulene-1- 
carbaldehyde (58) which was then condensed with N-t-butylhydroxyl amine to give 3(ethylthio)-guiazulene-1-nitrone (56).

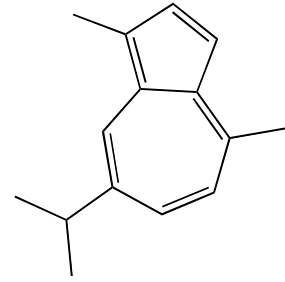

Guiazulene (18)

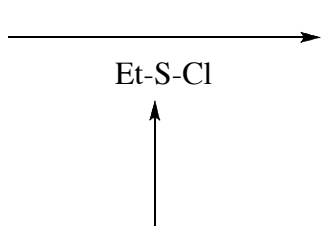

Et-S-S-Et $+\mathrm{SO}_{2} \mathrm{Cl}_{2}$

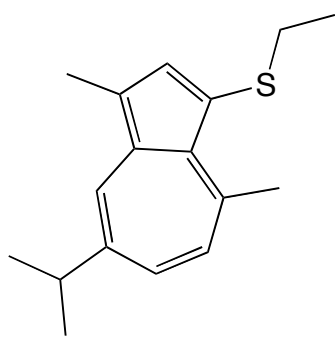

1-ethylthio-guiazulene (57)

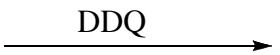

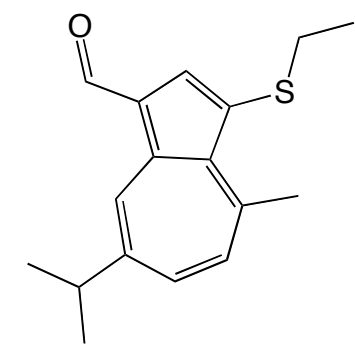

3-(ethylthio)-guiazulene-1-carbaldehyde (58)

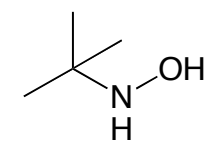

$\mathrm{N}-t$-Butyl hydroxylamine

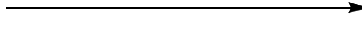

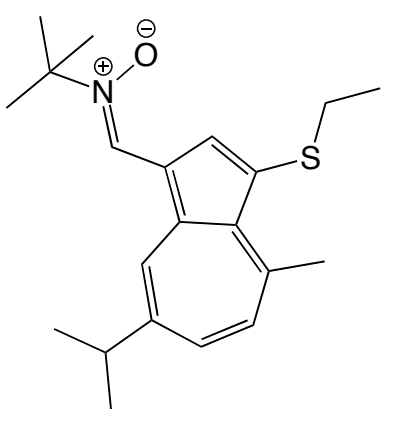

3-(ethylthio)-1-nitrone-guiazulene (56)

Figure 20. Synthetic scheme of 3-(ethylthio)-guiazulene-1-nitrone (56)

\section{[3.2] Synthesis of novel pseudoazulenvl dinitrones:}

The synthesis of novel pseudoazulenyl dinitrones starts with the extraction of valtrate (59) from the finely ground root of Centranthus ruber (Red Valerian or Jupiter's Beard) with ethanol. ${ }^{171}$ After filtration and another extraction with chloroform, crude valtrate was collected. For further purification, silica gel column chromatography with hexane/ethyl acetate $(8: 2)$ was necessary. According to the protocol by Theis, valtrate 
was treated with an acid such as trifluroacetic acid or trichloroacetic acid, to yield yellow baldrinal (60). ${ }^{172}$ Recently it was discovered that baldrinal (60) could also be synthesized from valtrate extracted from finely ground and dried root of Valeriana officinalis using ethanol as solvent. Even though the yield of baldrinal obtained root of Valeriana officinalis is approximately $50 \%$ less than that obtained from the root of Centhranthus ruber, nevertheless, the dried root Valeriana officinalis is less expensive and conveniently available in finely ground form in bulk quantity from Pacific Botanicals. Baldrinal (60) was used to synthesize various pseudoazulenyl dinitrone derivatives.

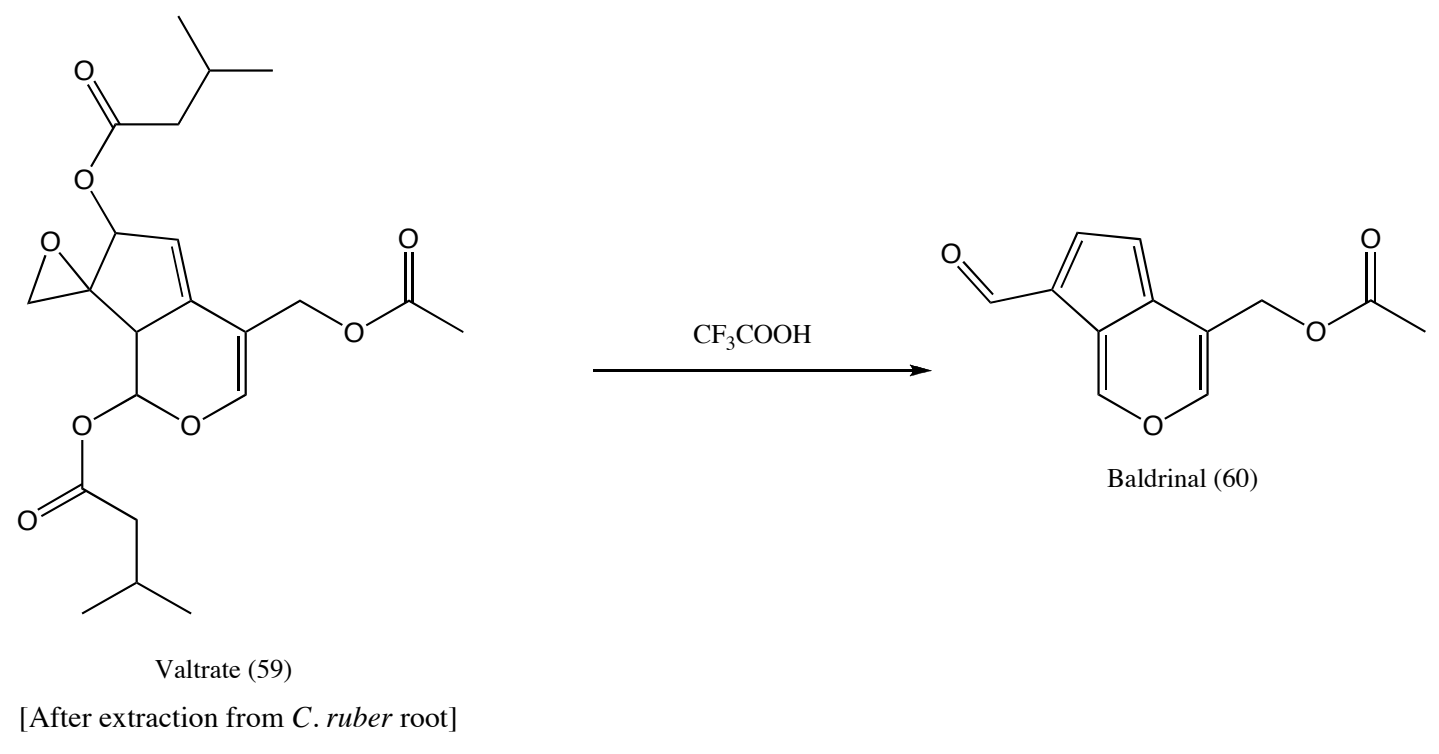

Figure 21. Synthetic scheme of Baldrinal (60)

\section{[3.2.1] Synthesis of 2-butyl-cyclopenta[c]pyridine-4,7-dinitrone (63):}

Baldrinal (60) was converted to a 2-butyl-cyclopenta[c]pyridine4,7-dialdehyde (61) by treating it with $n$-butyl amine according to the procedure by Seitz et al. ${ }^{173}$ Even though this reaction could be done without any solvent, for practical purposes, use of a 
small amount of chloroform as a solvent was found out to be convenient for completion of the reaction. Compound (61) was then condensed with $\mathrm{N}-t$-butyl hydroxylamine to yield 2-butyl-cyclopenta[c]pyridine-4,7-dinitrone (63).
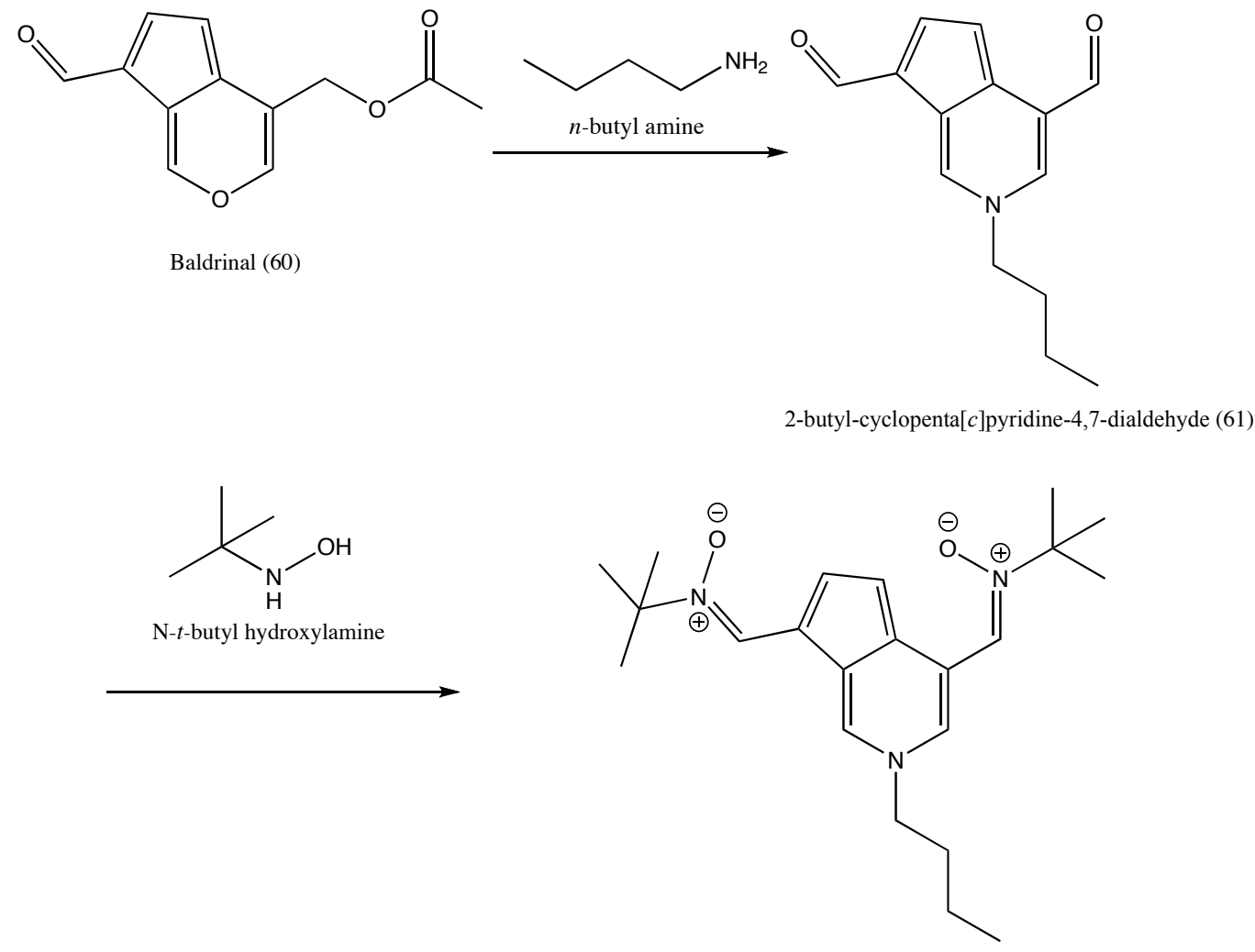

2-butyl-cyclopenta[c]pyridine-4,7-dinitrone (63)

Figure 22. Synthetic scheme of 2-butyl-cyclopenta[c]pyridine-4,7-dinitrone (63)

Because STAZN possess an extremely low oxidation potential, it was decided to synthesize a STAZN analogue, a dimer of pseudoazulenyl dinitrone (63) containing four nitrone groups. Therefore, in an attempt to synthesize dimer (64), dialdehyde (61) was converted to the 1-bromo-dialdehyde derivative (65) via bromination with $\mathrm{N}$ bromosuccinimide (NBS). Stille coupling of compound (65) with 1,2bis(tributylstannyl)ethane (66) in the presence of catalytic Pd-catalyst failed to give the required tetra aldehyde dimer (67). 


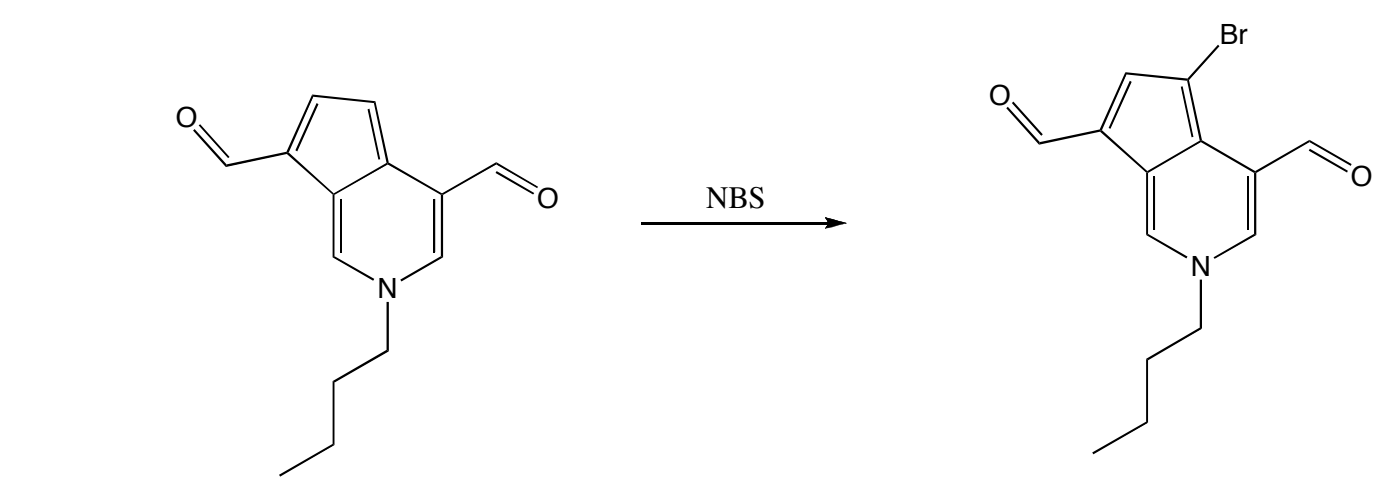

2-butyl-cyclopenta[c]pyridine-4,7-dialdehyde (61)

5-bromo-2-butyl-cyclopenat [c]pyridine4,7-dicarbaldehyde (65)
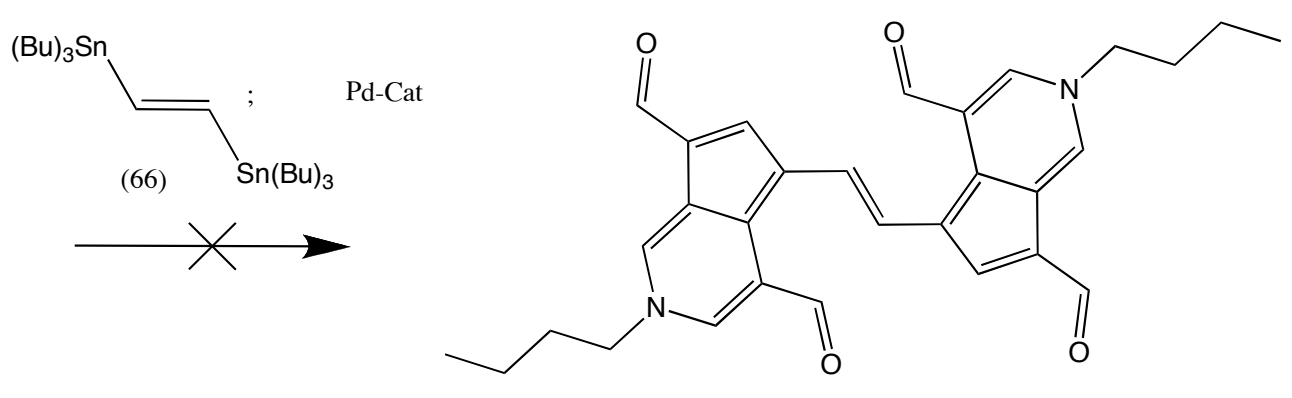

Pseudoazulenyl Dimer (67) Expected product
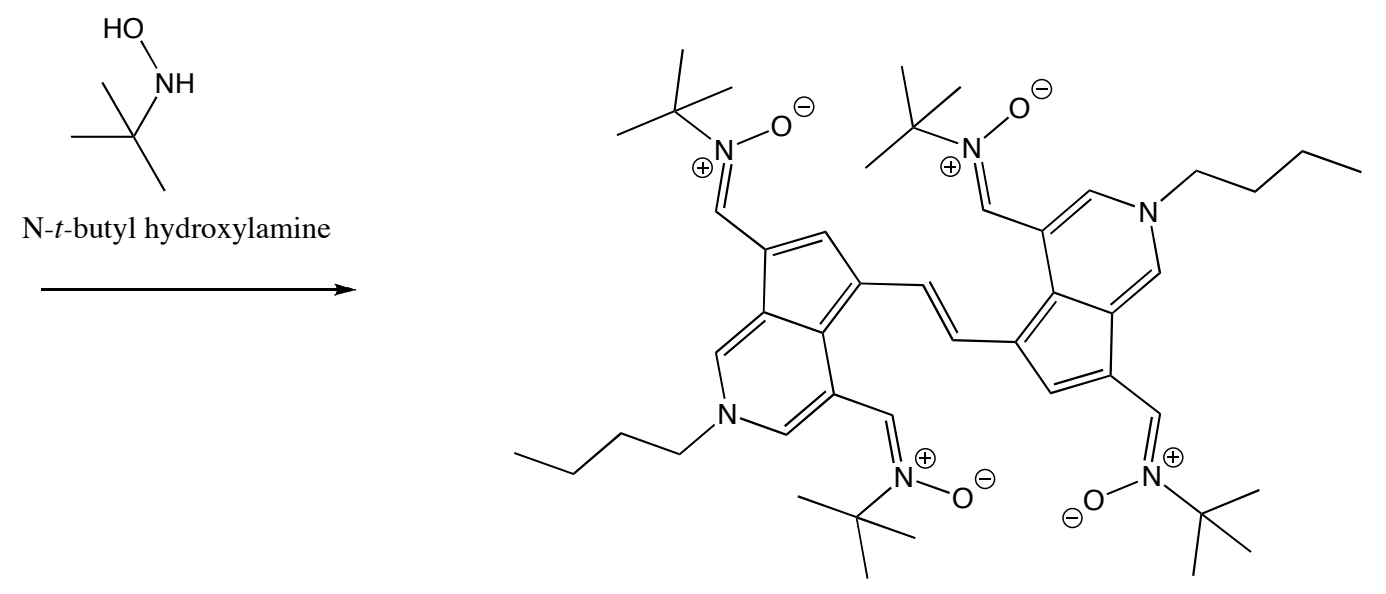

Pseudoazulenyl Tetranitrone (64)

Figure 23. Attempted synthesis of Bis-pseudoazulenyl Tetraaldehyde (67) 
Failure to form this Stille product (67) could be the result of the fact that the pseudoazulenyl compounds are electron rich and may not constitute a good electrophile. Furthermore, bromo derivative (65) was found out to be unstable at the reaction temperature of $110^{\circ} \mathrm{C}$, which is standard for such coupling reactions. Such instability for these high temperatures could be expected from compounds having such low oxidation potentials.

\section{[3.2.2] Synthesis of 2-(propyl imidazole)-cyclopenta[c]pyridine-4,7-dinitrone (72):}

After successfully synthesizing the first pseudoazulenyl dinitrone, 2-butylcyclopenta[c]pyridine-4,7-dinitrone (63), it was decided to examine the prospect of incorporating greater functionality. Histamine is a biogenic amine and is involved in various physiological functions such as in immune responses, as a neurotransmitter and as a chemotactic agent. ${ }^{174}$ Reactive oxygen species are generated at inflammatory sites and aggravate tissue damage, which can be minimized or abrogated by scavenging these free radicals.

Furthermore, the mitochondrion produces $90 \%$ of the total free radicals. These free radicals are formed due to the constant leakage of electrons during oxidative phosphorylation. As result of proton pumping, mitochondria have an overall negative potential. Cationic species could be targeted towards the mitochondria to scavenge free radicals at the site of their formation. ${ }^{186}$ Therefore, pseudoazulenyl dinitrone containing histamine functionality was decided as a potential synthetic target, since at physiological $\mathrm{pH}$ the nitrogen on the imidazole ring is expected to be protonated. However, product (69) could not be obtained. This reaction of baldrinal (60) with histamine (70) leads to a 
mixture of products that could not be identified by nuclear magnetic resonance (NMR) or mass spectrometry.

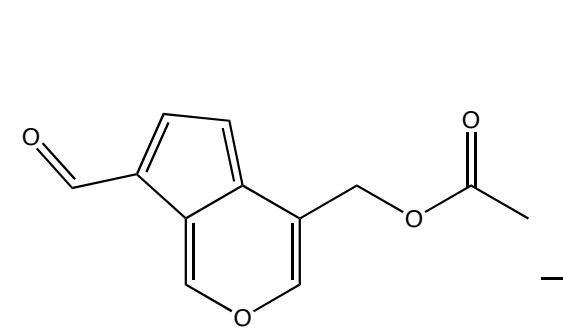

Baldrinal (60)
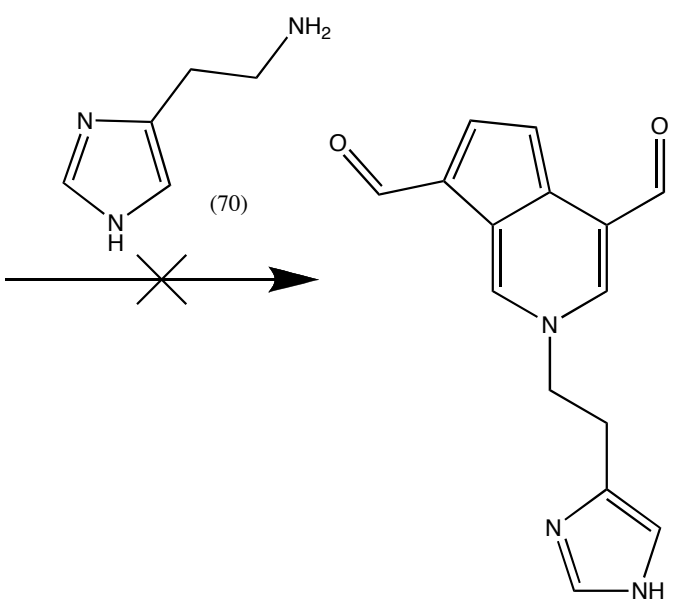

Pseudoazulenyl dialdehyde derivative of

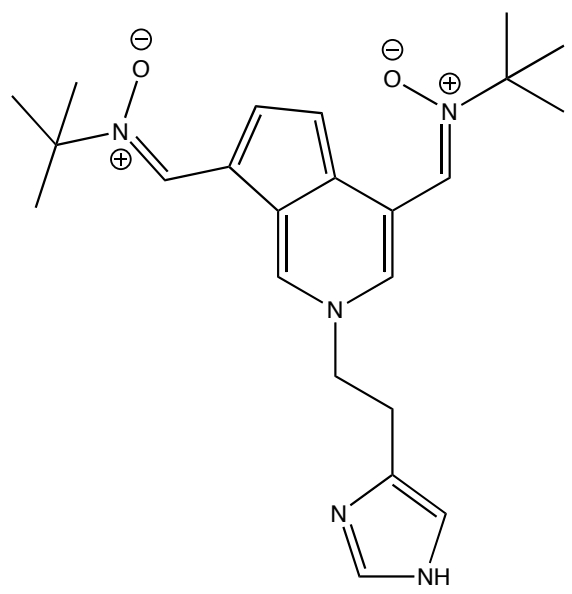

Pseudoazulenyl Dinitrone (68) histamine (69)

Figure 24. Attempted synthesis of Pseudoazulenyl Dialdehyde (69)

Since histamine did not yield the required product, another derivative containing imidazole ring was successfully synthesized. Similar to histamine, this dinitrone, 2(propyl imidazole)-cyclopenta[c]pyridine-4,7-dinitrone (72), is expected to be partially protonated at physiological $\mathrm{pH}$. 

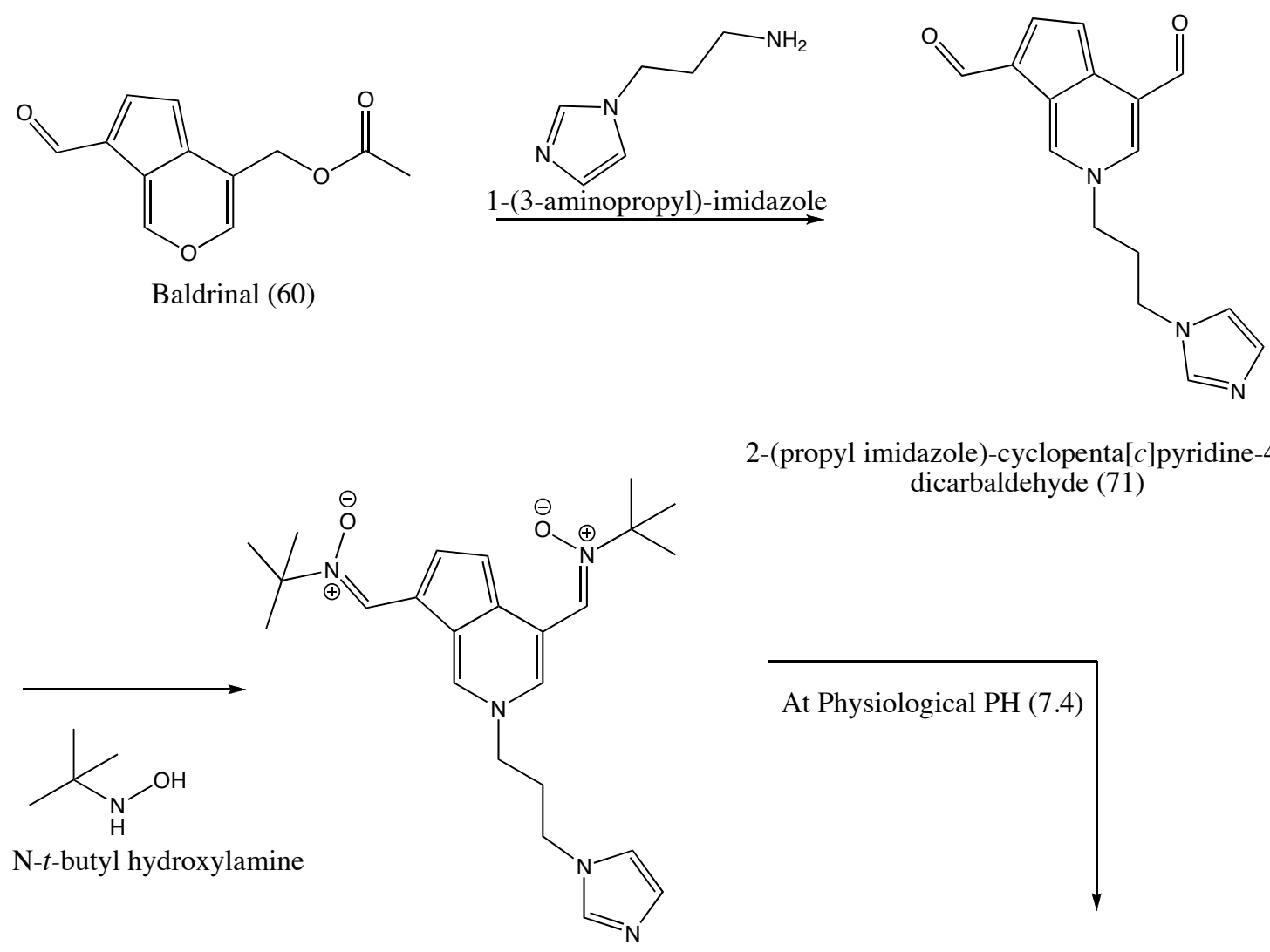

2-(propyl imidazole)-cyclopenta[c]pyridine-4,7dicarbaldehyde (71)

2-(propyl imidazole)-cyclopenta[c]pyridine-4,7-dinitrone

(72)

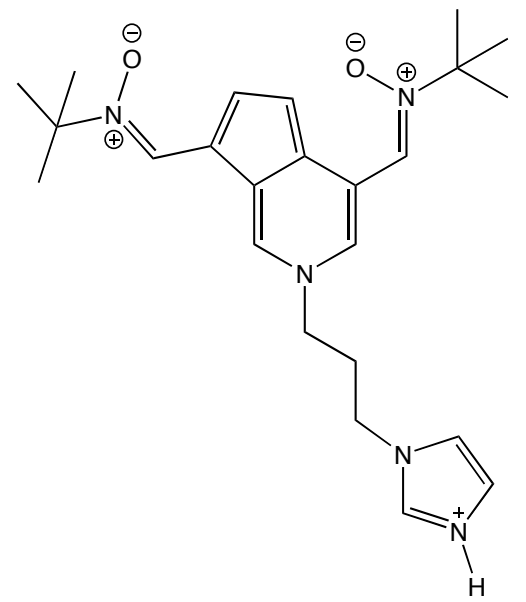

Protonated form of (72)

Figure 25. Synthetic scheme of 2-(propyl imidazole)-cyclopenta[c]pyridine-4,7-dinitrone (72) 


\section{[3.2.3] Synthesis of 2-(3-(dimethylamino)propyl)-cyclopenta[c]pyridine-4,7-dinitrone}

(75):

Another nitrogen containing pseudoazulenyl dinitrone derivative, 2-(3(dimethylamino)propyl)-cyclopenta[c]pyridine-4,7-dinitrone (75) was synthesized by treating $N, N$-dimethylpropane-1-3-diamine with baldrinal (60) to get dialdehyde (74), which was then condensed with N-tert-butyl hydroxylamine to give dinitrone (75).

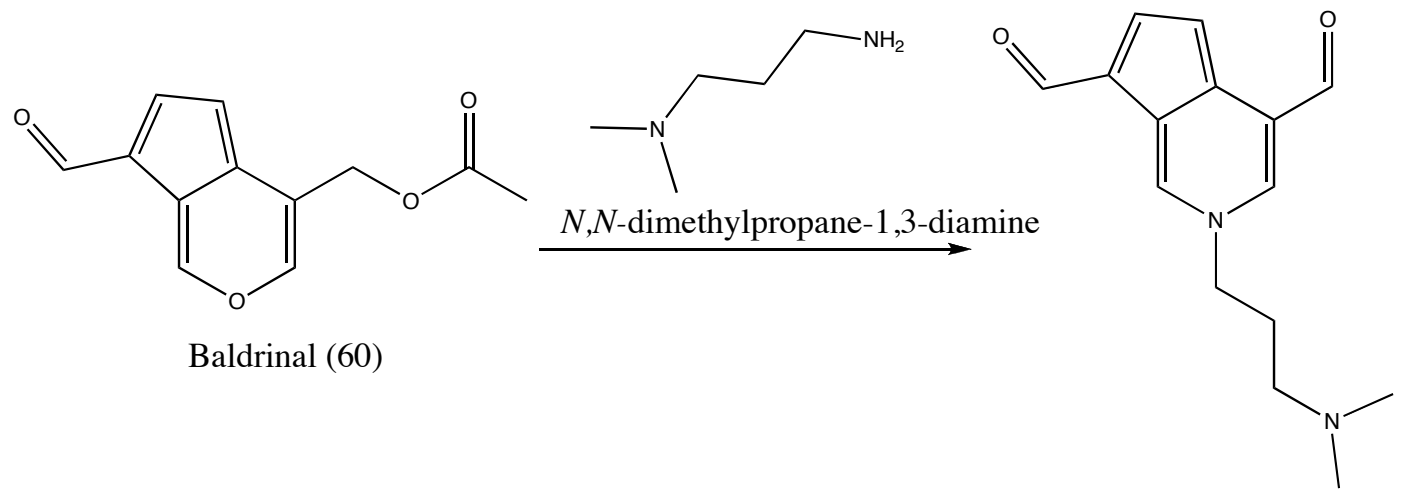

2-(3-(dimethylamino)propyl)-

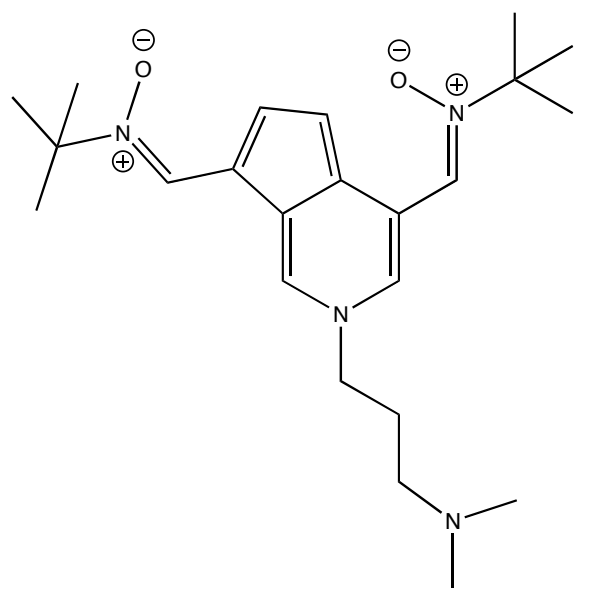
cyclopenta[c]pyridine-4,7-dicarbaldehyde (74)

2-(3-(dimethylamino)propyl)-cyclopenta[c]pyridine-4,7-dinitrone (75)

Figure 26. Synthetic scheme of 2-(3-(dimethylamino)propyl)-cyclopenta[c]pyridine-4,7-dinitrone (75) 


\section{[3.2.4] Synthesis of spermine analogue (86):}

Spermine (76) and spermidine (77) are biogenic polyamines required by both prokaryotes and eukaryotes for cell growth and differentiation. ${ }^{175}$ At physiologic $\mathrm{pH}$, these polyamines exist as poly-cations.

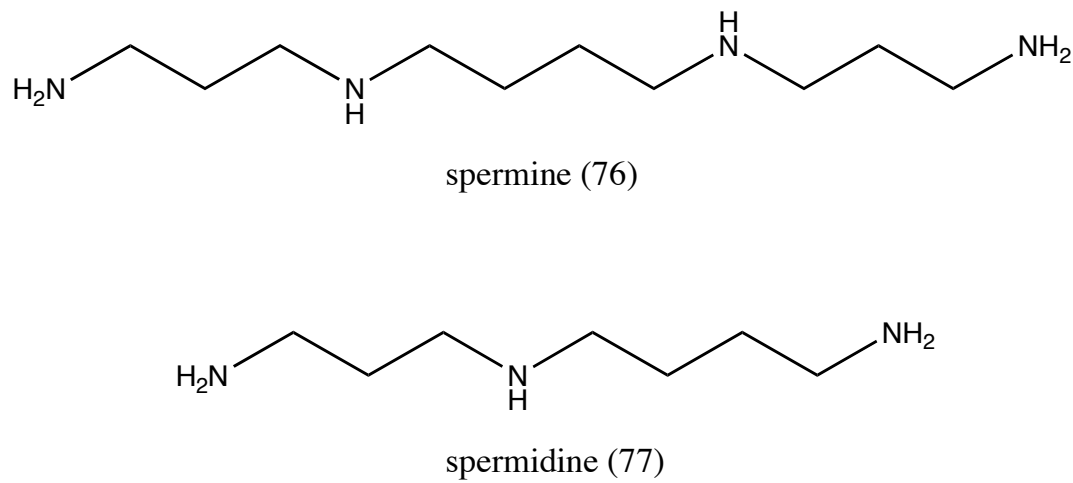

Interestingly, despite the fact that mitochondria lack biosynthetic pathways for these polyamines, substantial amounts of spermine and spermidine were detected in the mitochondrial matrix. ${ }^{176}$ These polyamines are known to bind to DNA. ${ }^{177}$ Furthermore, spermine was shown to exert antioxidative free radical scavenging activity even at submillimolar concentration, thereby protecting DNA against oxidative stress. ${ }^{178,179}$ Since DNA is constantly under oxidative attack, it was proposed that incorporating sperminelike structures into pseudoazulenyl nitrones might bolster the antioxidative effect of spermine and better attenuate oxidative damage to DNA strands. Furthermore, since spermine is cationic at physiological $\mathrm{pH}$, it might help direct pseudoazulenyl nitronepolyamine conjugates to mitochondria. 
One such naturally occurring polyamine-antioxidant conjugate that is active in mitochondria is trypanothione (79), a unique spermidine/glutathione derivative from trypanosomes and leishmania. Trypanosomes and leishmania are parasitic protozoa responsible for African sleeping sickness, Chagas' disease and leishmaniasis. These parasites were found to be surprisingly tolerant to oxidative stress. Even though they contain glutathione, the lack of glutathione reductase in these parasites generated interest in knowing their mechanism for oxidative detoxification. Fairlamb et al. (1985) reported isolation of the unique glutathione derivative from trypanosomes (also present in leishmania), which they called trypanothione $\left[N^{1}, N^{8}\right.$-bis(glutathionyl) spermidine $]$ (79). ${ }^{180}$ Trypanothione, which is the two electron reduced form of trypanothione disulfide $\left(\mathrm{T}[\mathrm{S}]_{2}\right)(78)$, has a unique structure containing two glutathione moieties coupled to a spermidine unit by peptide bonds. The reduction of $\mathrm{T}[\mathrm{S}]_{2}$ to trypanothione is carried out by trypanothione reductase which is similar to glutathione reductase. ${ }^{181}$ At physiologic $\mathrm{pH}$, the -SH groups of trypanothione are more reactive than those of glutathione. ${ }^{182}$

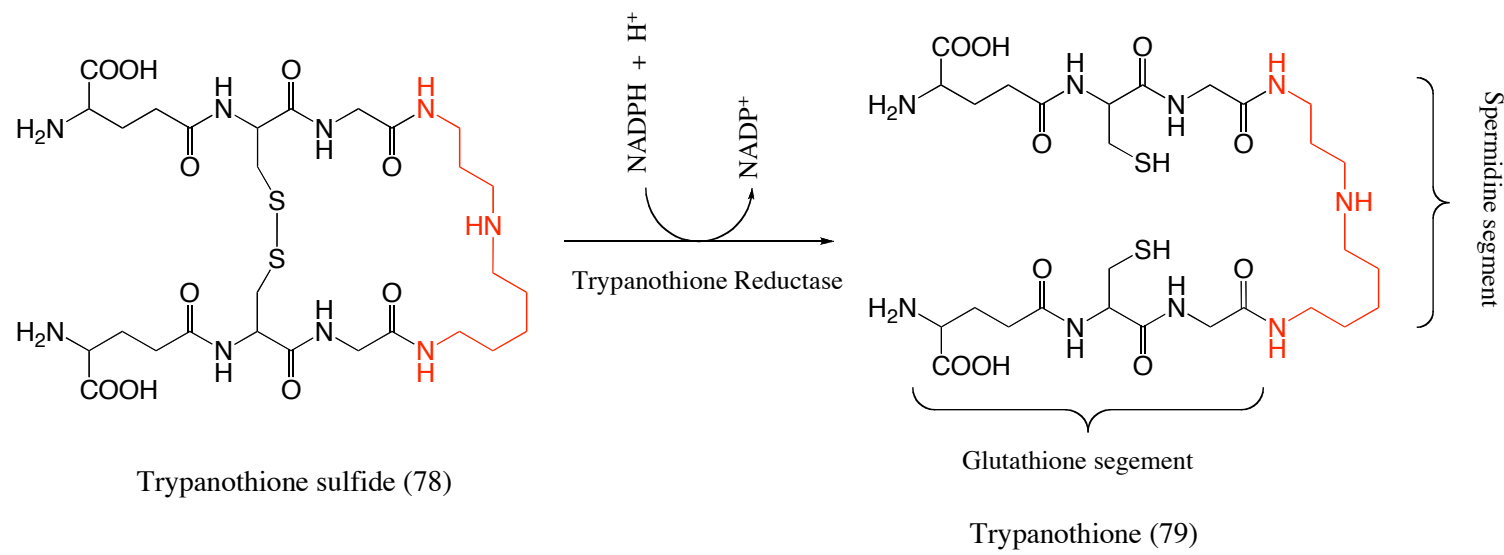

Figure 27. Trypanothione 
Towards the goal of synthesizing a conjugated spermine pseudoazulenyl dinitrone, spermine (76) was treated with baldrinal (60), but unfortunately, the sperminepseudoazulenyl dialdehyde derivative (80) could not be obtained.
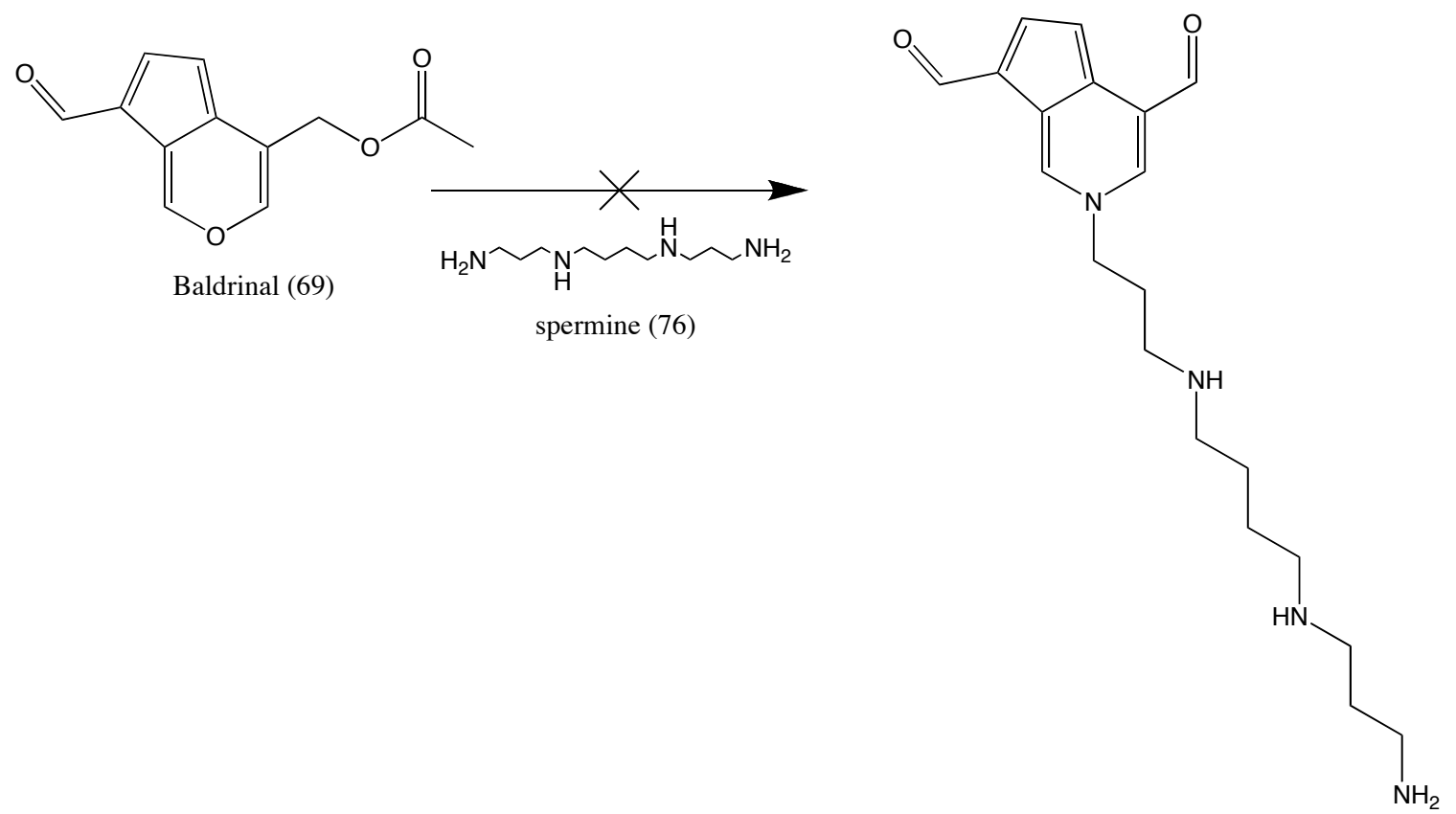

Spermine-Pseudoazulenyl dialdehyde (80)

Figure 28. Attempted synthesis of Spermine derivative of pseudoazulenyl dialdehyde (80)

From the failed reactions of baldrinal with spermine and histamine, it was thought that the secondary amine group might be reacting with the aldehyde group to form iminium salts. Therefore, it was decided to attempt to synthesize a 1,4-Bis(3aminopropyl)-piperazine derivative (81) that lacks the secondary amino groups. But even this product (81) was elusive. 

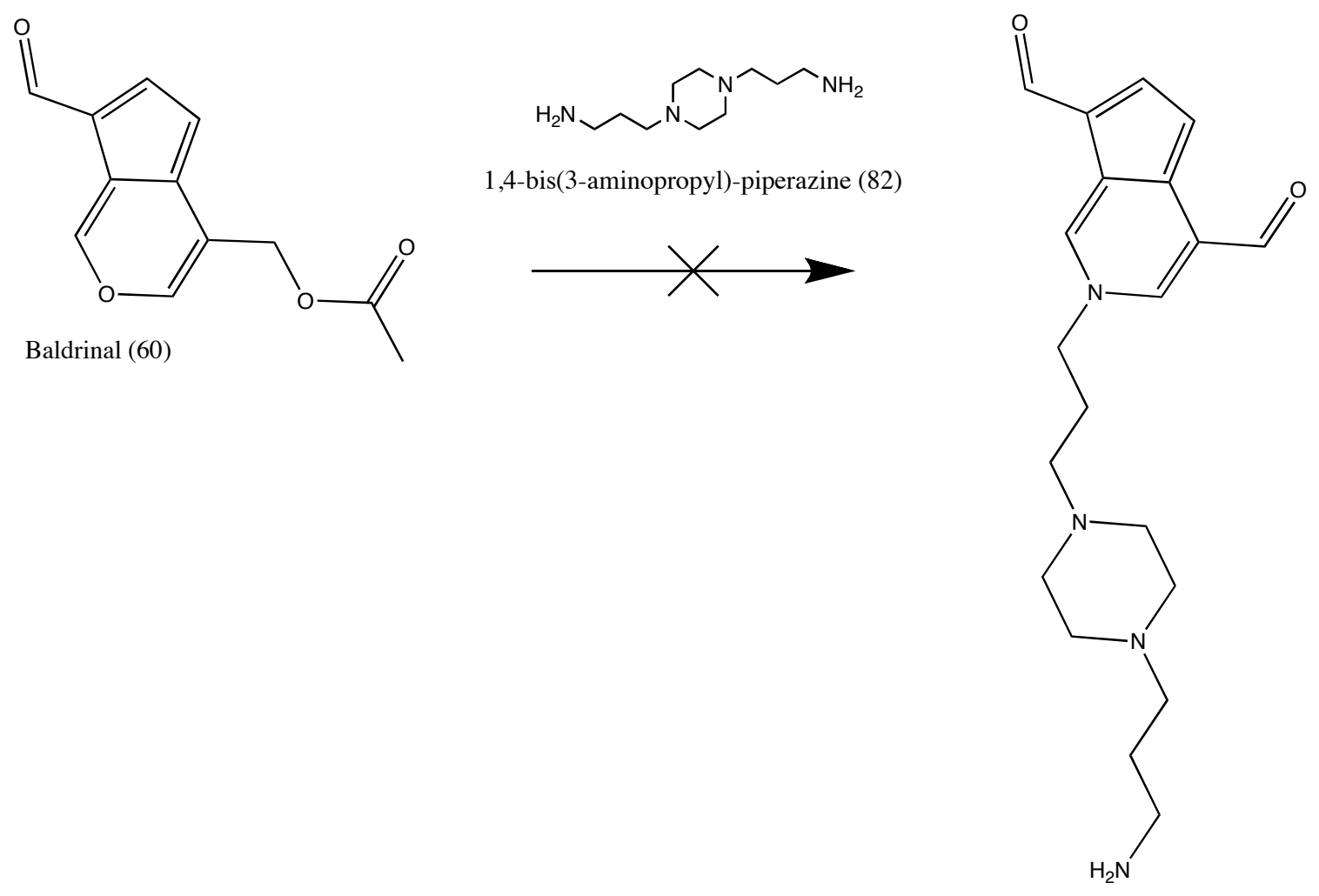

Piperazine analogue (81)

Figure 29. Attempted synthesis of piperazine derivative of pseudoazulenyl dinitrone (81)

After failing to get the required spermine analogue, it was decided to pursue the synthesis of a spermine analog from the 2-(3-(dimethylamino)propyl)-cyclopenta[c]pyridine-4,7dinitrone (75). Therefore, compound (75) was treated with 1,4-diiodobutane (83) to get compound (84) which was successively treated with $N^{1}, N^{1}, N^{3}, N^{3}$-tetramethylpropane-1,3diamine (85) to get dicationic species (86). This highly polar compound was difficult to purify. Nevertheless, support for the assigned structure was obtained by mass spectroscopy with detection of a strong peak at $\mathrm{m} / \mathrm{z}=293.2$. 


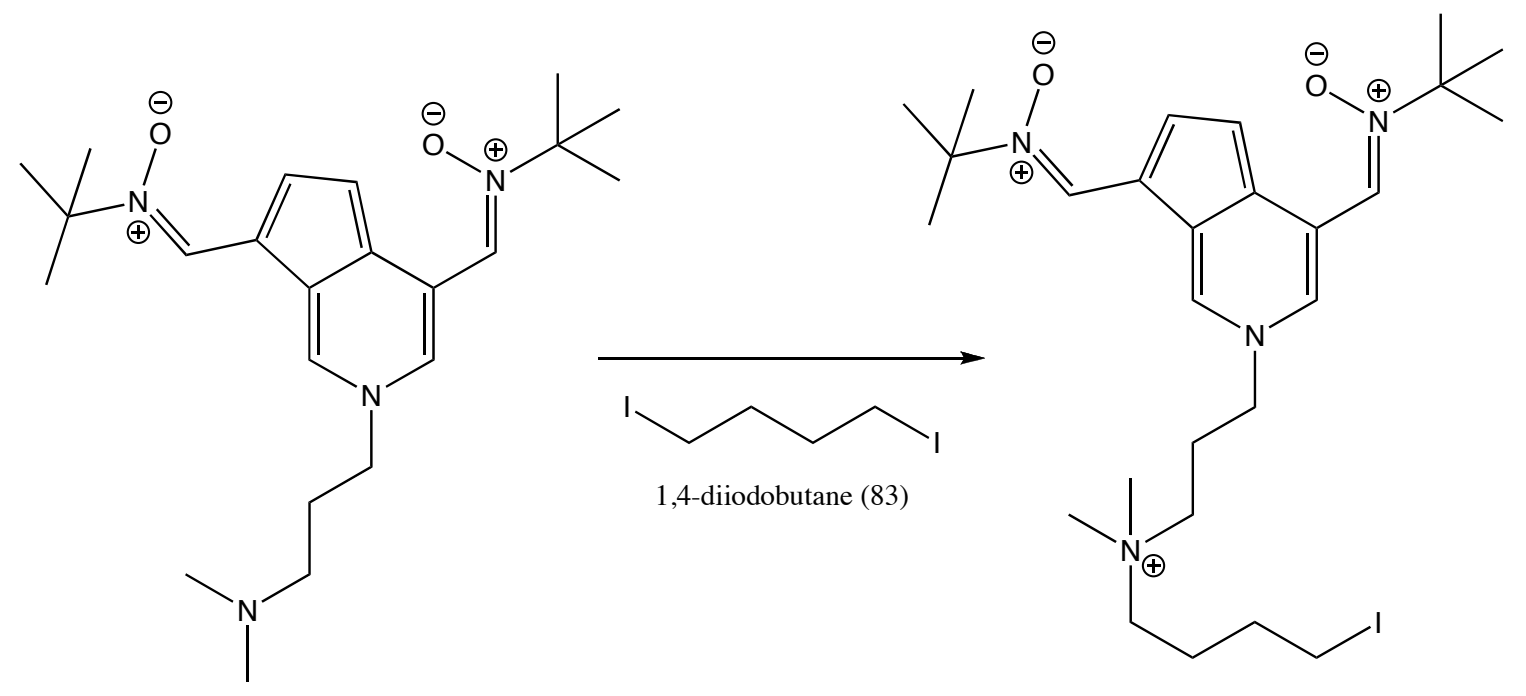

(84)

Dimethylamino propyl dinitrone (75)

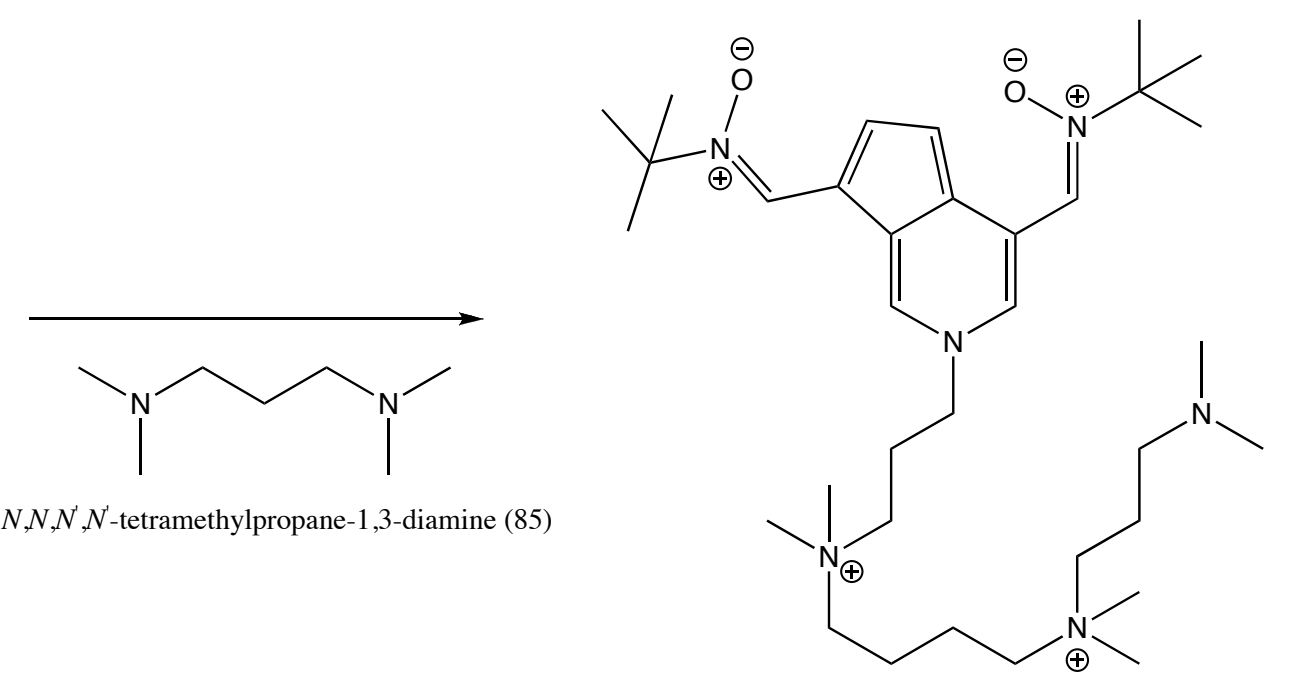

Spermine analogue (86)

Figure 30. Synthetic scheme of dicationic spermine analogue of pseudoazulenyl dinitrone (86)

\section{[3.2.5] Synthesis of 2-octadecyl-cyclopenta[c]pyridine-4,7-dinitrone (88):}

Targeted drug delivery to the brain has received considerable attention in recent times. ${ }^{185}$ Because the brain cell membranes are rich in polyunsaturated fatty acids 
(PUFAs), as a rule, lipophilic molecules more easily pass through the BBB. Therefore, increasing the lipophilicity of organic molecules is an often applied strategy to direct drug molecules into the brain. ${ }^{184}$ Towards this goal, to impart lipophilicity to pseudoazulenyl nitrones, 2-octadecylamine-cyclopenta[c]pyridine-4,7-dinitrone (88), a pseudoazulenyl dinitrone containing a long hydrophobic alkyl chain was synthesized.<smiles>CC(=O)OCc1cocc2c(C=O)ccc1-2</smiles>

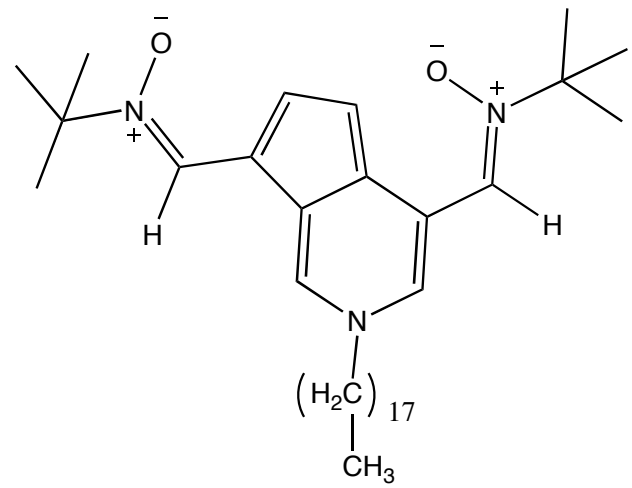

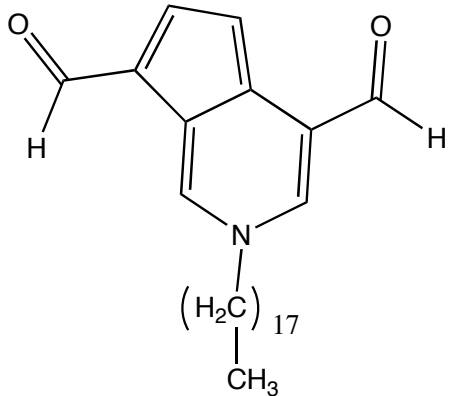

2-octadecyl-cyclopenta[c]pyridine-4,7dicarbaldehyde $(87)$

2-octadecyl-cyclopenta[c]pyridine-4,7-dinitrone (88)

Figure 31. Synthetic scheme of 2-octadecyl-cyclopenta[c]pyridine-4,7-dinitrone (88)

\section{[3.2.6] Synthesis of 2-(6-hexanol)-cyclopenta[c]pyridine-4,7-dinitrone (91):}

6-hydroxyhexyl containing pseudoazulenyl dinitrone derivative was synthesized by treating 6-aminohexan-1-ol (89) with baldrinal (60) to get dialdehyde (90), which was then condensed with N-tert-butyl hydroxylamine to give 2-(6-hexanol)- 
cyclopenta[c]pyridine-4,7-dinitrone (91). The advantage of having hydroxyl functionality is that it can be easily modified or functionalized.

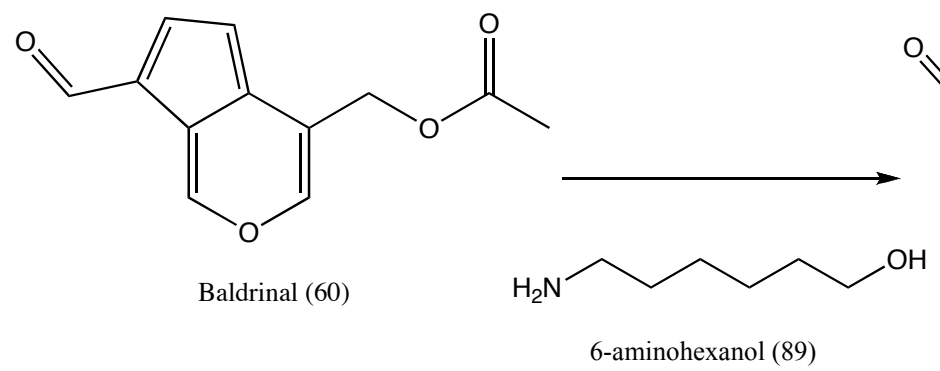

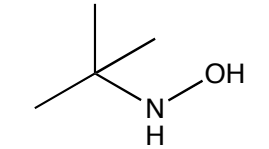

$\mathrm{N}-t$-butyl hydroxylamine
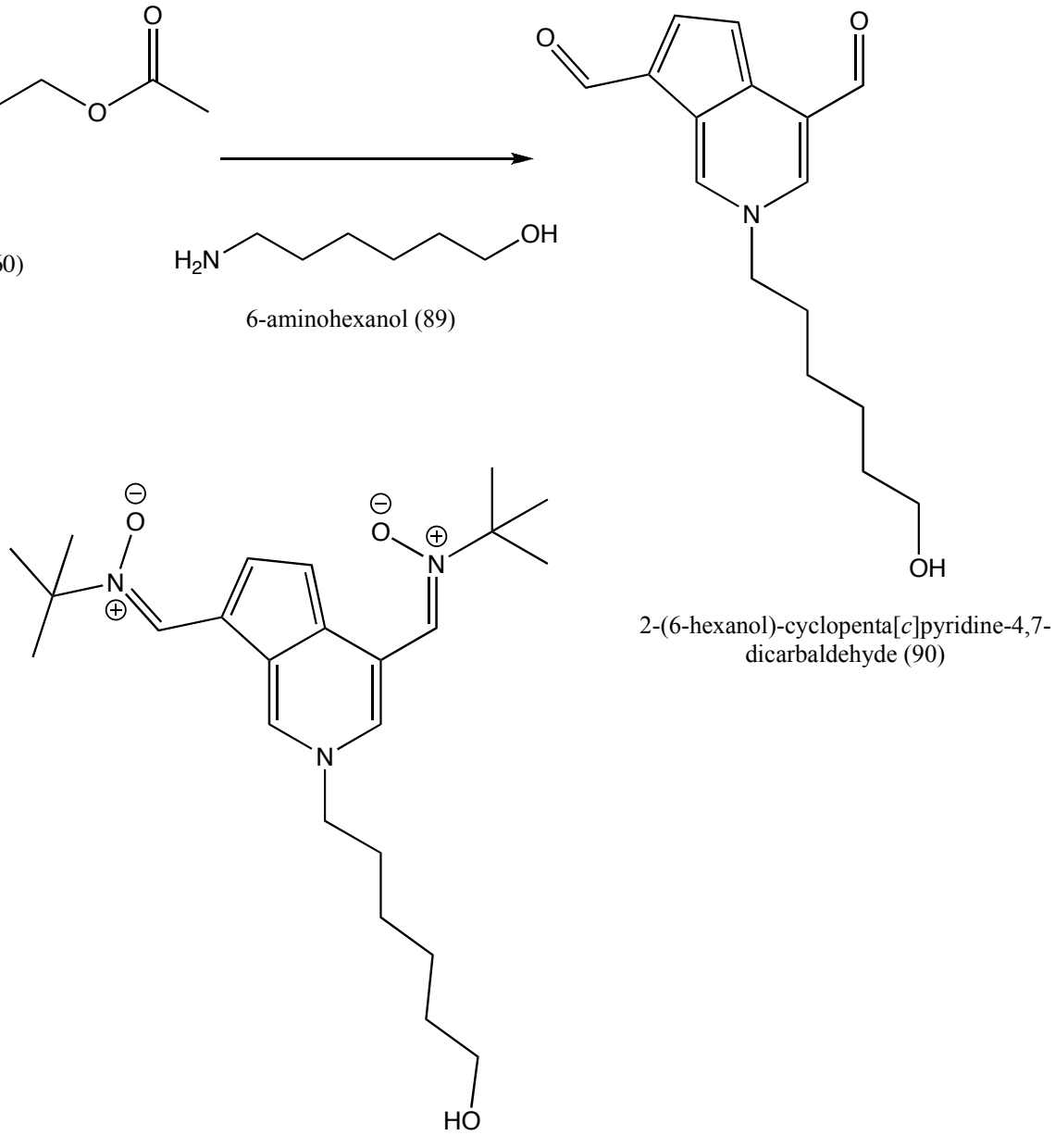

2-(6-hexanol)-cyclopenta[c]pyridine-4,7-dinitrone (91)

Figure 32. Synthetic scheme of 2-(6-hexanol)-cyclopenta[c]pyridine-4,7-dinitrone (91)

\section{[3.2.7] Synthesis of 2-butyl-5-ethylthio-cyclopenta[c]pyridine-4,7-dinitrone (94):}

After cyclic voltammetric studies revealed that the oxidation potential of the pseudoazulenyl bis-nitrones were slightly higher than that of STAZN, it was decided to 
pursue the preparation of pseudoazulenyl dinitrones that were equipped with electrondonating alkylthio groups.

Experiments to introduce an electron donating group at the 1-position of pseudoazulenyl dinitrones were performed. Using the protocol of Palei, ${ }^{170} 1$-ethylthio substituted pseudoazulenyl dialdehyde (92) was synthesized by reacting dialdehyde (61) with ethyl sulfenyl chloride (93). 1-ethylthio substituted dialdehyde (92) was converted to 1-ethylthio substituted dinitrone (94) by condensation with N-tert-butyl hydroxyl amine.

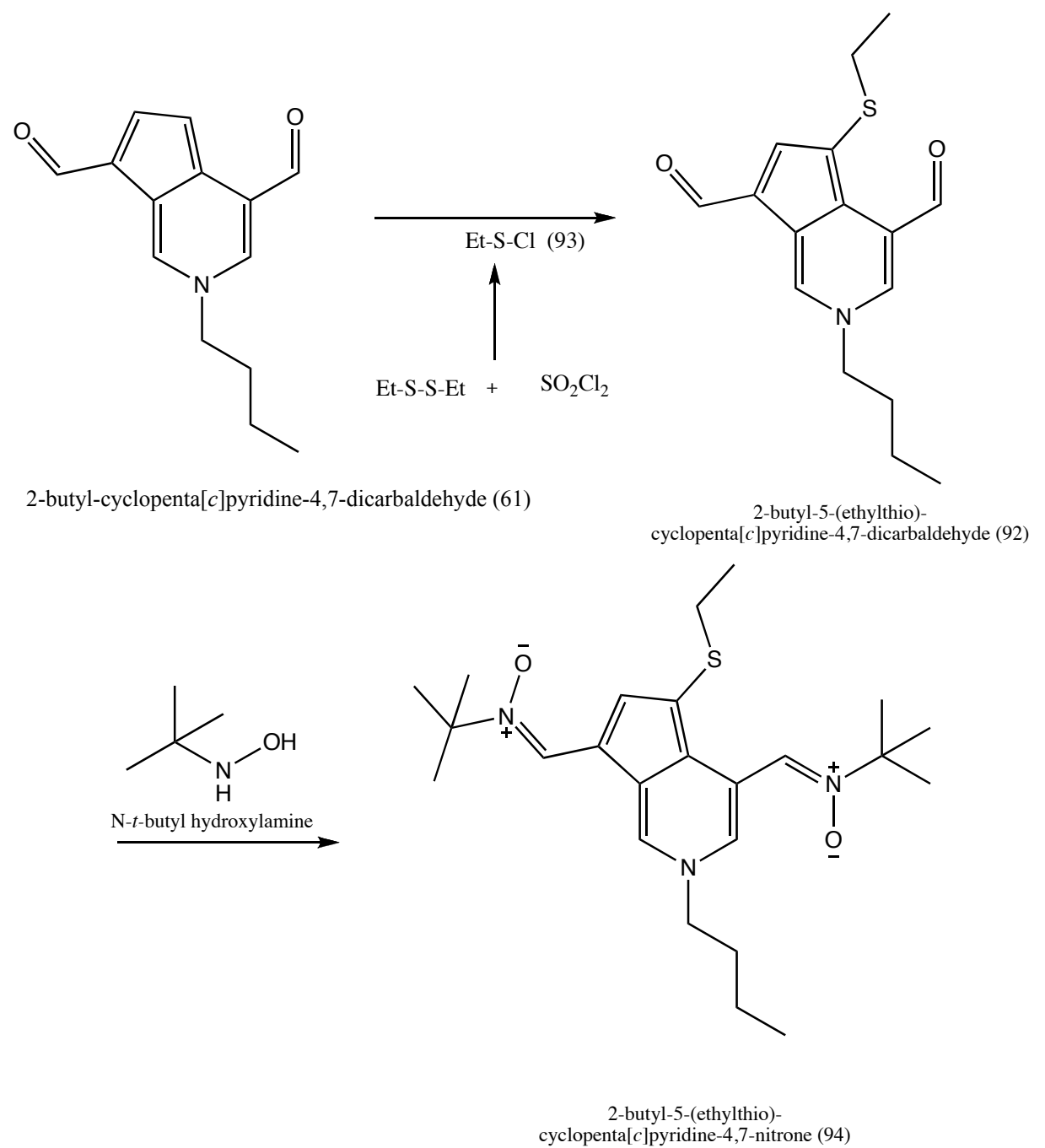

Figure 33. Synthetic scheme of 2-butyl-5-(ethylthio)-cyclopenta[c]pyridine-4,7-dinitrone (94) 


\section{[3.3] Cyclic Voltammetry:}

Cyclic voltammetry experiments were performed to determine the oxidation potential of 2-butyl-5-ethylthio-cyclopenta[c]pyridine-4,7-dinitrone (94). The results were compared to STAZN (32) under the same conditions, since STAZN was in possession of the lowest recorded oxidation potential for the nitrone-based spin traps.

The cyclic voltammogram of 2-butyl-5-ethylthio-cyclopenta[c]pyridine-4,7dinitrone (94) clearly shows that the oxidation potential of this compound is lower than that of STAZN. As can be seen from figure 34, the oxidation of compound (94) is fully reversible with first oxidation occurring at $0.31 \mathrm{~V}$ vs SCE. As compared to STAZN (first oxidation at $0.45 \mathrm{~V}$ vs SCE) (figure 35), the first oxidation potential for pseudoazulenyl nitrone (94) is more than $100 \mathrm{mV}$ lower.

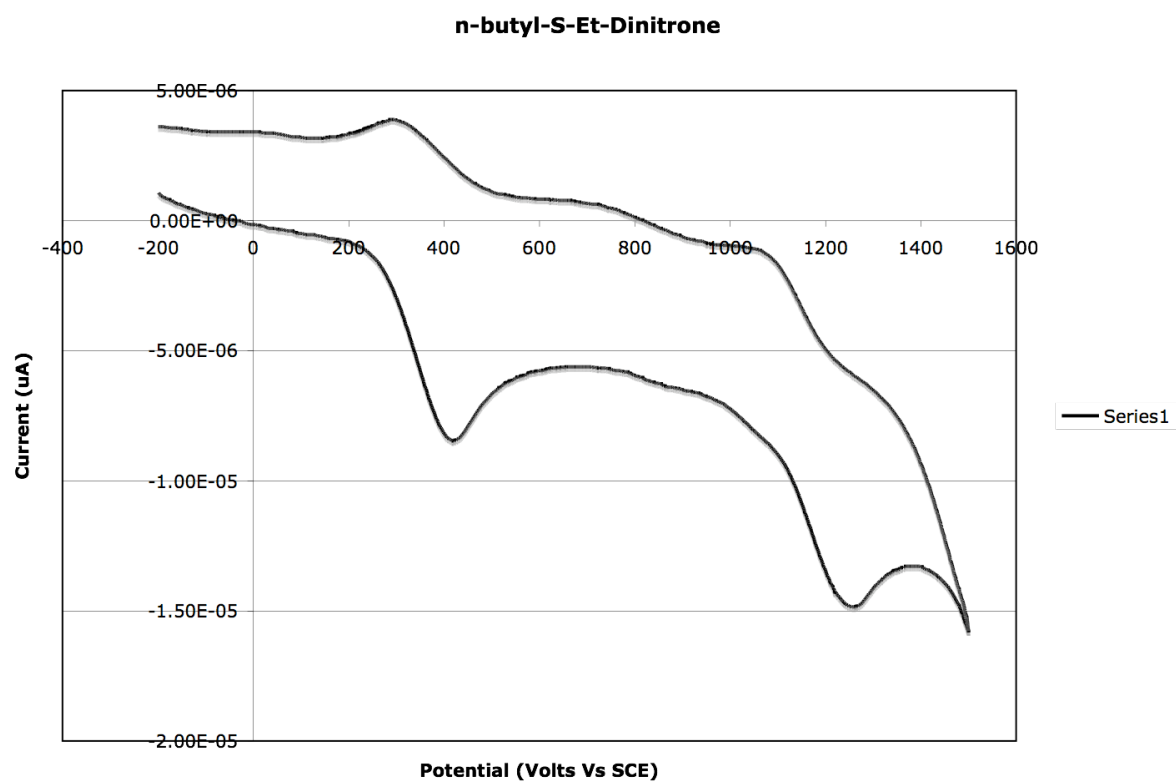

Figure 34. Cyclic voltammogram of 2-butyl-5-ethylthio-cyclopenta[c]pyridine-4,7-dinitrone (94)

A solution of compound (94) in $\mathrm{CH}_{2} \mathrm{Cl}_{2}$ at a $100 \mathrm{mM}$ with scan rate of $100 \mathrm{mV} \mathrm{s}^{-1}$ and glassy carbon working electrode. The electrolyte is tetrabutylammonium hexaflurophosphate (TBAPF 6 ) at a concentration of $100 \mathrm{mM}$. 


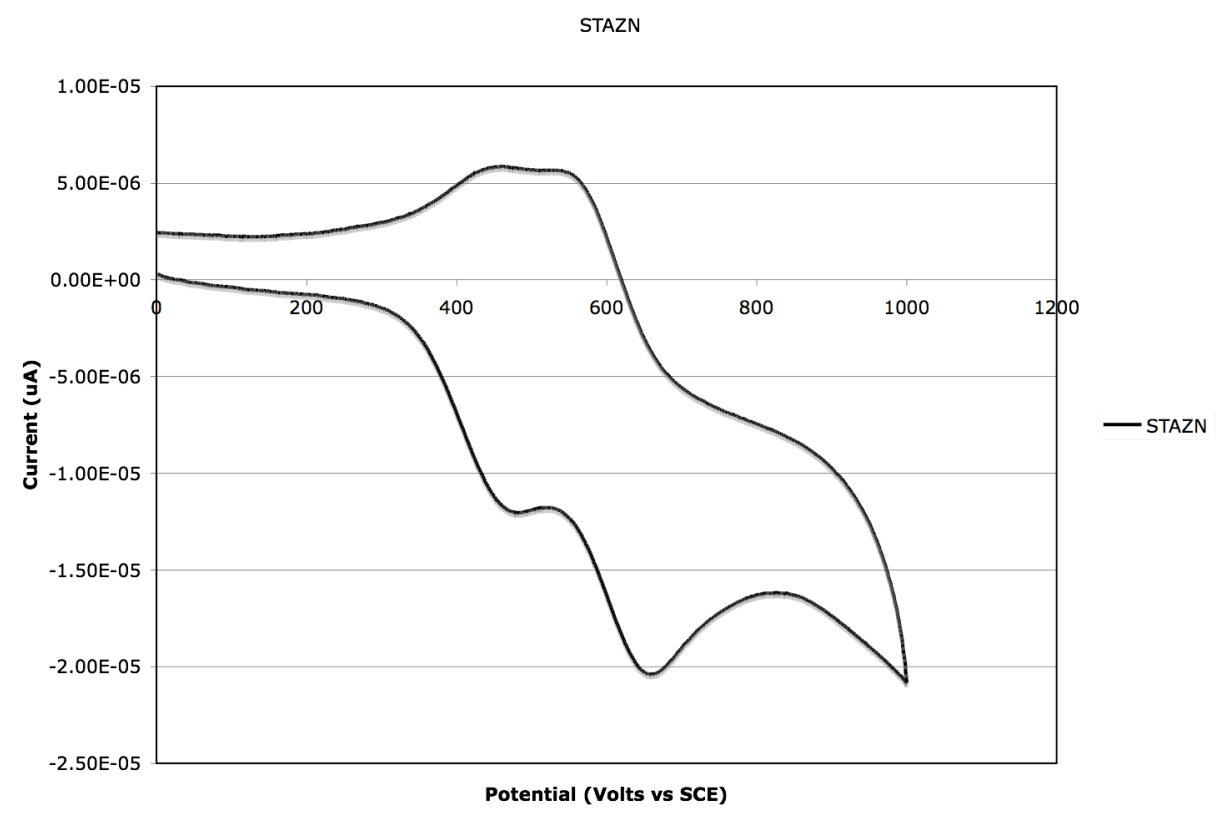

Figure 35. Cyclic voltammogram of STAZN (32)

A solution of STAZN (32) in $\mathrm{CH}_{2} \mathrm{Cl}_{2}$ at a $100 \mathrm{mM}$ with scan rate of $100 \mathrm{mV} \mathrm{s}^{-1}$ and glassy carbon working electrode. The electrolyte is tetrabutylammonium hexaflurophosphate $\left(\mathrm{TBAPF}_{6}\right)$ at a concentration of $100 \mathrm{mM}$.

\section{[4] CONCLUSION}

It has been more than 60 years since Commoner et al. first brought attention to the harmful effects of free radicals on biological systems. ${ }^{1}$ Since then, reactions of free radicals have been widely studied in vivo and in vitro to fully understand their chemical and biological fate. Over the years, nitrones have shown enormous potential as free radical traps. The ability of nitrones to trap free radicals and form stable nitroxide has led to hypotheses that nitrones could act as chain-breaking antioxidants and prevent damages caused by free radicals in biological systems. Surely, nitrones are emerging as potential drug candidates in diseases like stroke, ischemic heart disease (IHD) and aging, as well as neurodegenerative diseases like Alzheimer's, Parkinson's and Huntington's disease. 
However, many of the nitrones studied by others possess unusually high oxidation potential.

Earlier, Becker et al. have successfully synthesized azulenyl nitrones with oxidation potentials much lower than any of the previously synthesized nitrones and close to those of endogenous biological antioxidants. ${ }^{157}$ In this study, synthesis of a nitrone with an oxidation potential significantly lower than that of the much heralded STAZN was accomplished.

Towards this goal to synthesize nitrone with oxidation potential lower than that of STAZN, range of structurally diverse nitrones and a particular novel pseudoazulenyl dinitrone was synthesized. The presence of the nitrogen heteroatom in the pseudoazulenyl structure was strategically exploited to synthesize various dinitrone congeners, which theoretically could render pseudoazulenyl dinitrones mitochondriotropic. These pseudoazulenyl dinitrones are anticipated to have increased bioavailability than any of the previously synthesized nitrones. However, the oxidation potentials of these pseudoazulenyl dinitrones were found out to be slightly higher than that of STAZN.

In order to synthesize nitrones with oxidation potentials even lower than that of STAZN, pseudoazulenyl dinitrone (94) with an electron donating group at 1-position was synthesized. Cyclic voltammetry studies have shown that 1-ethylthio substituted pseudoazulenyl dinitrone (94) does indeed possess an oxidation potential more than 100 $\mathrm{mV}$ lower than STAZN. Based on these results, 1-substituted pseudoazulenyl dinitrone (94) is expected to be an even more efficient free radical trap than STAZN.

The importance of this research resides in the expedient synthetic protocol described to prepare a diverse array of highly electron-rich pseudoazulenyl dinitrones. 
Starting with the dried ground root of Centranthus ruber or Valeriana officinalis, various pseudoazulenyl dinitrones were synthesized in four efficient steps. Moreover, further one-step modification of this pathway has resulted in the preparation of a pseudoazulenyl dinitrone in possession of the lowest oxidation potential recorded for any of the nitrone based spin trap yet examined. Further studies to evaluate the efficacy of these novel pseudoazulenyl dinitrones in animal models of stroke and neurodegenerative diseases, like Alzheimer's, Parkinson's and Huntington's disease are underway.

\section{[5] EXPERIMENTAL SECTION}

\section{General procedure}

All proton $\left({ }^{1} \mathrm{H}\right)$ NMR and carbon $\left({ }^{13} \mathrm{C}\right)$ NMR measurements were recorded on Bruker AVANCE-400 spectrometer. All low resolution mass spectra were recorded on Finnigan Navigator LC/MS instrument by using direct injection into the mass spectrometer and detecting molecular ion mass with Atmospheric Pressure Chemical Ionization (APCI). Thin layer chromatography (TLC) was performed by using silica gel $60 \mathrm{~F}_{254}$. Column chromatography was performed using $60 \AA$ (230-400 mesh). 


\section{[5.0.1] Synthesis of bis-guiazulenyl monoaldehyde (49):}

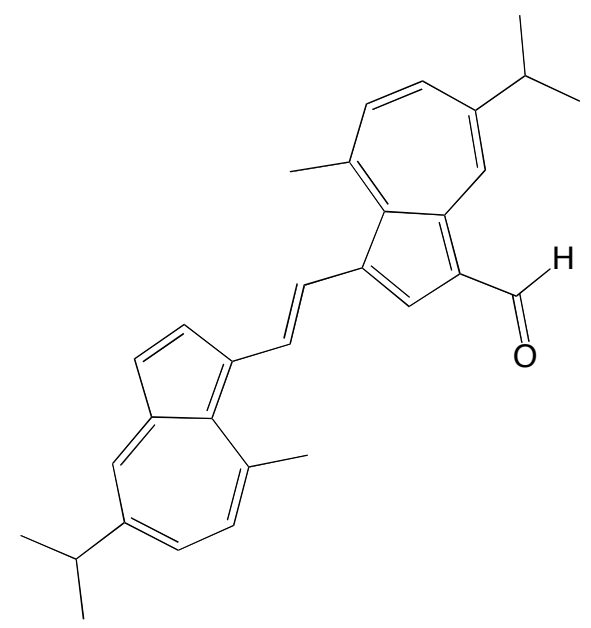

Bis-guiazulenyl dialdehyde (49) (342 mg, $0.74 \mathrm{mmol}$ ) and Wilkinson's catalyst, chlorotris(triphenylphosphine) rhodium(I), $(680 \mathrm{mg}, 73 \mathrm{mmol})$ were mixed in $8 \mathrm{ml}$ of toluene. The reaction mixture was heated at $110^{\circ} \mathrm{C}$ for 12 $\mathrm{h}$ under argon. Silica gel thin layer chromatography showed non-polar green di-decarboxylated compound followed by greenish brown product. Product was purified via silica gel column chromatography using hexane as the solvent until all green di-decarboxylated product was collected and then the solvent polarity was increased by the use of a 20:1 hexane/ethyl acetate solvent system until $104 \mathrm{mg}$ (34\%) of monoaldehyde (49) was collected. $R_{f}=0.23$ (Hexane/ethyl acetate 9:1)

${ }^{1}$ H NMR (400 MHz, CDCl $): \delta 10.36(\mathrm{~s}, 1 \mathrm{H}), 9.60(\mathrm{~d}, J=1.8 \mathrm{~Hz}, 1 \mathrm{H}), 8.39(\mathrm{~s}, 1 \mathrm{H}), 8.12$ (d, $J=1.8 \mathrm{~Hz}, 1 \mathrm{H}), 8.06$ (d, $J=4.2 \mathrm{~Hz}, 1 \mathrm{H}), 7.85$ (d, $J=15.4 \mathrm{~Hz}, 1 \mathrm{H}), 7.64$ (d, $J=15.4 \mathrm{~Hz}$, 1H), $7.54(\mathrm{dd}, J=10.7,1.9 \mathrm{~Hz}, 1 \mathrm{H}), 7.32-7.26(\mathrm{~m}, 2 \mathrm{H}), 7.25(\mathrm{~m}, 1 \mathrm{H}), 6.96(\mathrm{~d}, J=10.5 \mathrm{~Hz}$, 1H), 3.19-3.10 (m, 7H), 3.10-2.93 (m, 1H), 1.39 (d, $J=6.9 \mathrm{~Hz}, 6 \mathrm{H}), 1.34$ (d, $J=6.9 \mathrm{~Hz}$, 6H). ${ }^{13}$ C NMR: $\left(400 \mathrm{MHz}, \mathrm{CDCl}_{3}\right): \delta$ 186.66, 149.84, 149.14, 147.08, 143.80, 142.34, $141.83,141.73,139.72,137.60,137.33,135.50,134.98,132.68,132.60,130.93,129.25$, $129.05,128.08,127.32,125.03,124.33,119.61,38.18,37.64,28.71,24.53,24.41$. LRMS: (LC/MS-APCI, MeOH) m/e $435.2\left(\mathrm{MH}^{+}\right)$. 


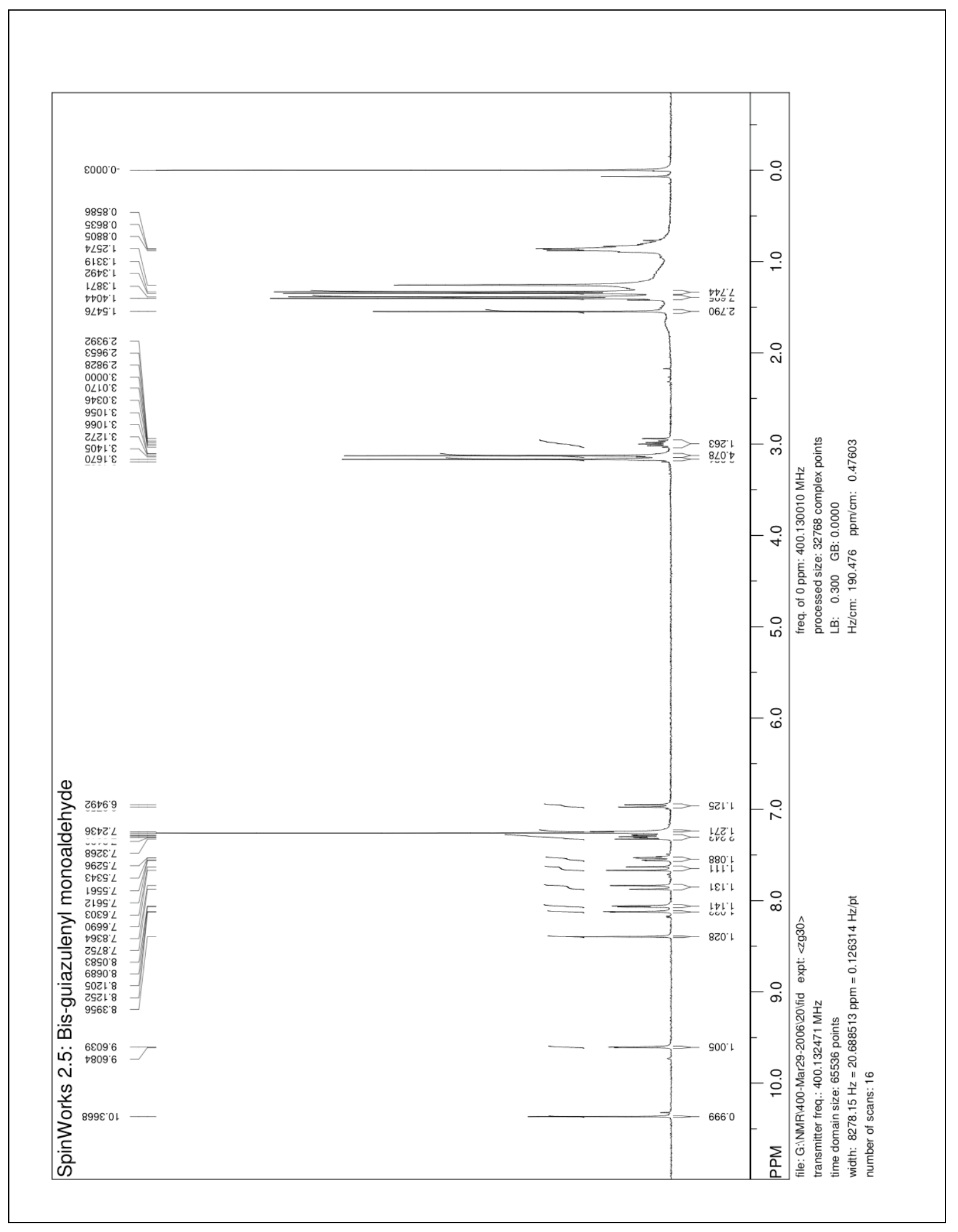




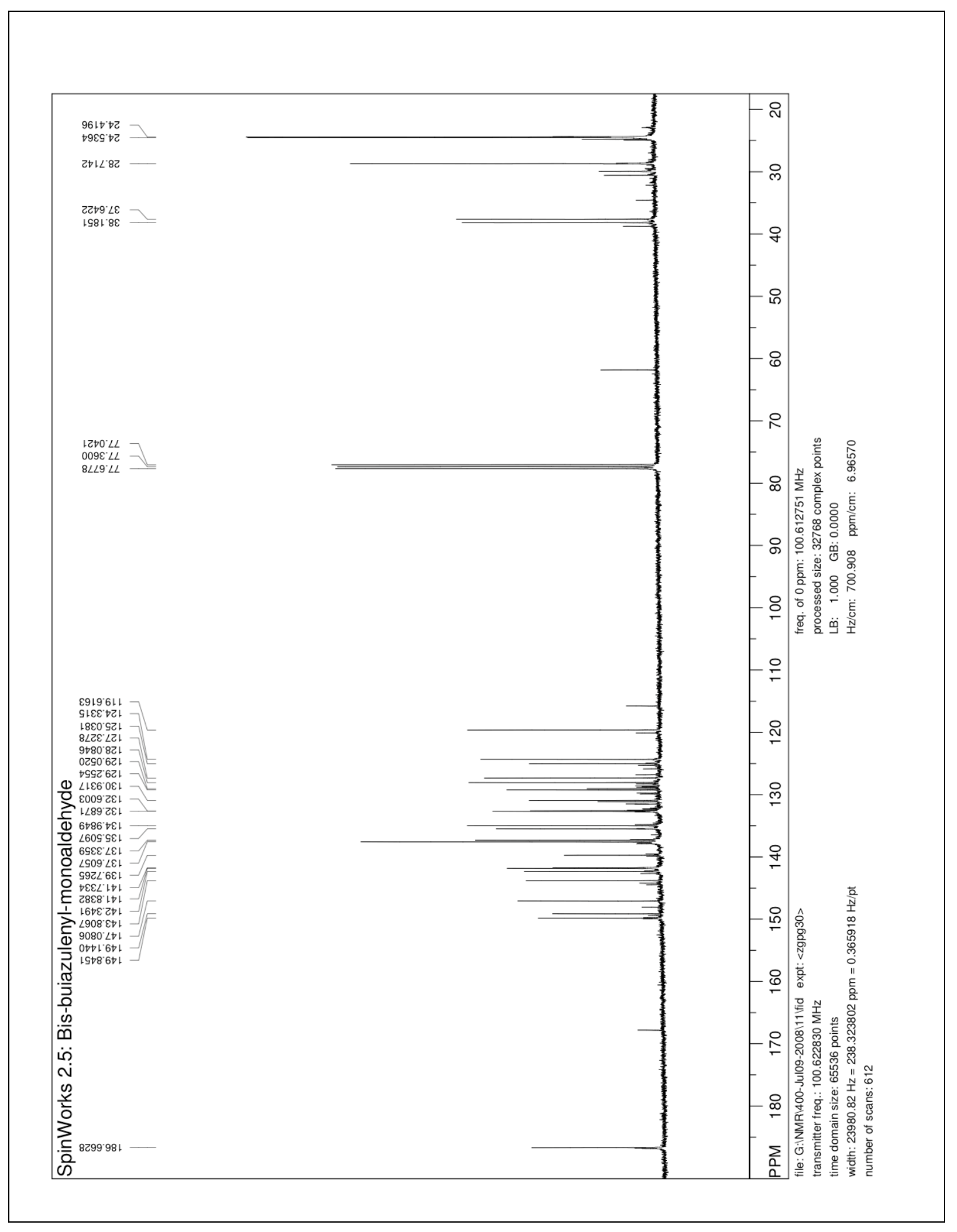




\section{[5.0.2] Synthesis of bis-azulenyl thio-benzothiazole monoaldehyde derivative (51):}

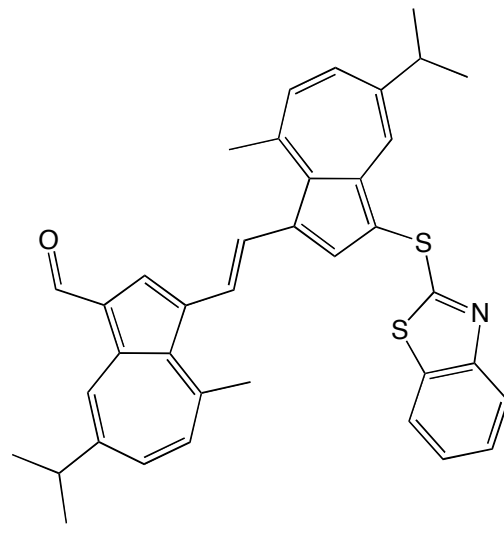

$(51)$

Bis-guiazulene monoaldehyde (49) (242 mg, $0.57 \mathrm{mmol})$ was mixed with 2,2'-dithiobisbenzothiazole (altax) (50) (211 $\mathrm{mg}, 0.63 \mathrm{mmol})$ and $5 \mathrm{ml}$ of ethylene glycol was added. The reaction mixture was heated at $220{ }^{\circ} \mathrm{C}$ for 2.5 $\mathrm{h}$ under argon. Silica gel thin layer chromatography showed greenish-brown product running slower than starting material. When the starting material had

disappear, as determined by silica gel thin layer chromatography, the reaction was stopped and partitioned between water and chloroform to remove the ethylene glycol. The chloroform layer was collected and the volume was reduced by rotary evaporator to provide a dense black oil. The product was purified via silica gel column chromatography with 8:2 hexane:ethyl acetate. After purification, $211 \mathrm{mg}(58 \%)$ of product was collected. $\mathrm{R}_{\mathrm{f}}=0.38$ (hexane/ethyl acetate $7: 3$ ).

${ }^{1}$ H NMR: (400 MHz, $\left.\mathrm{CDCl}_{3}\right): \delta 10.39$ (s, 1H), 9.61 (d, J=1.6 Hz, 1H), 8.68 (d, J=1.8 Hz, 1H), $8.41(\mathrm{~s}, 1 \mathrm{H}), 8.34(\mathrm{~s}, 1 \mathrm{H}), 7.87(\mathrm{~d}, J=8.1 \mathrm{~Hz}, 1 \mathrm{H}), 7.77$ (d, J=15.6 Hz, 1H), 7.65 (d, $J=15.5 \mathrm{~Hz}, 1 \mathrm{H}), 7.58-7.52(\mathrm{~m}, 2 \mathrm{H}), 7.49(\mathrm{dd}, J=11.0,2.0 \mathrm{~Hz}, 1 \mathrm{H}), 7.39-7.36(\mathrm{~m}, 2 \mathrm{H})$, 7.27 (d, $J=1.9 \mathrm{~Hz}, 1 \mathrm{H}), 7.24$ (d, $J=2.0 \mathrm{~Hz}, 1 \mathrm{H}), 3.19$ (s, 3H), 3.17-3.12 (m, 4H), 3.08$3.03(\mathrm{~m}, 1 \mathrm{H}), 1.39(\mathrm{~d}, J=6.9 \mathrm{~Hz}, 6 \mathrm{H}), 1.29$ (d, J=6.9 Hz, 6H). ${ }^{13} \mathrm{C}$ NMR: $(400 \mathrm{MHz}$, $\left.\mathrm{CDCl}_{3}\right): \delta 186.84,154.75,150.08,149.72,149.06,145.48,143.21,142.57,142.12$ $141.84,140.15,137.99,137.93,137.61,136.63,136.27,135.89,133.16,131.08,130.37$, $129.23,126.50,126.30,126.05,125.65,124.20,123.04,121.97,121.09,112.13,38.40$, 38.04, 29.10, 29.05, 24.67, 24.60. LRMS: (LC/MS-APCI, MeOH) m/e $586.3\left(\mathrm{MH}^{+}\right)$. 


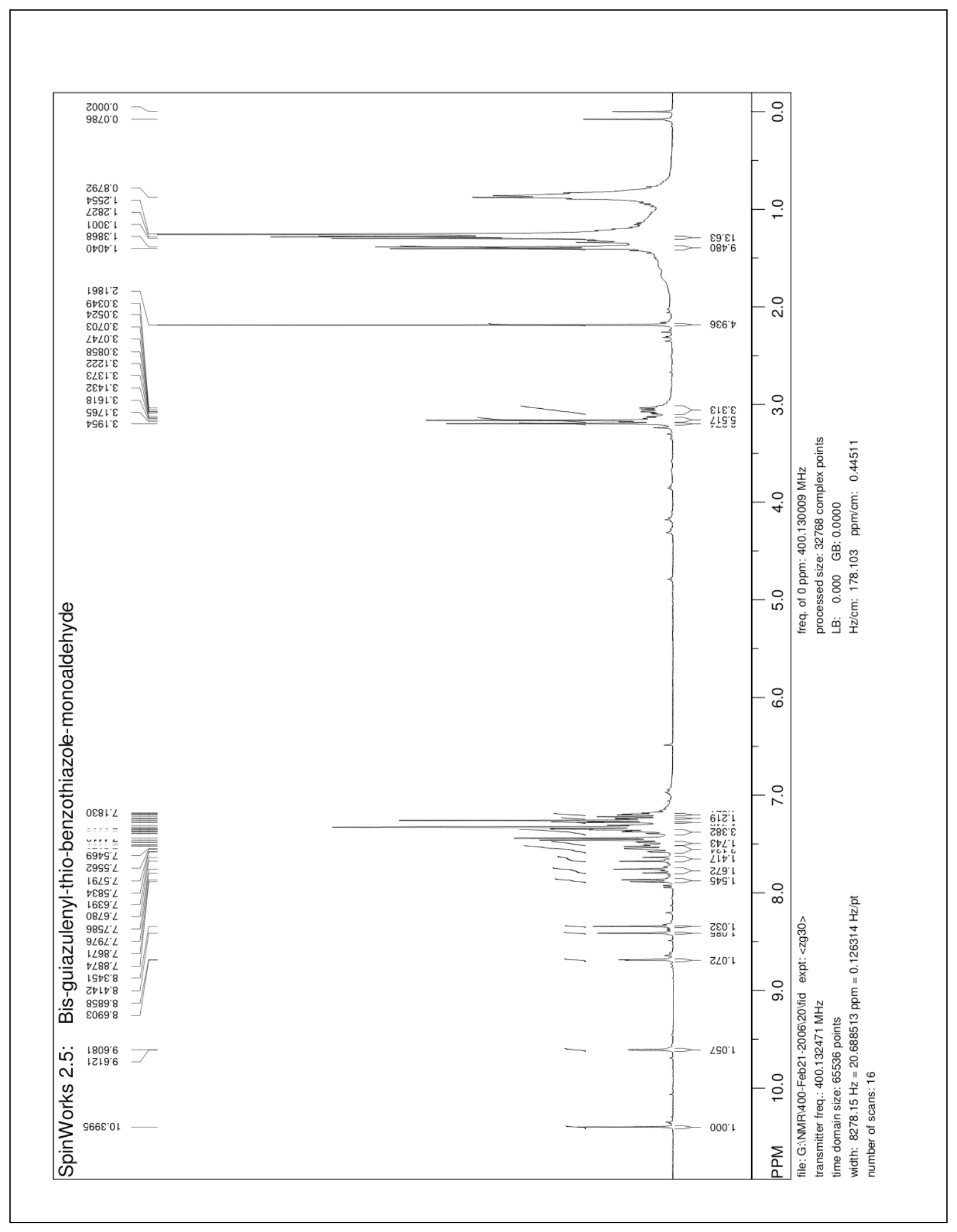




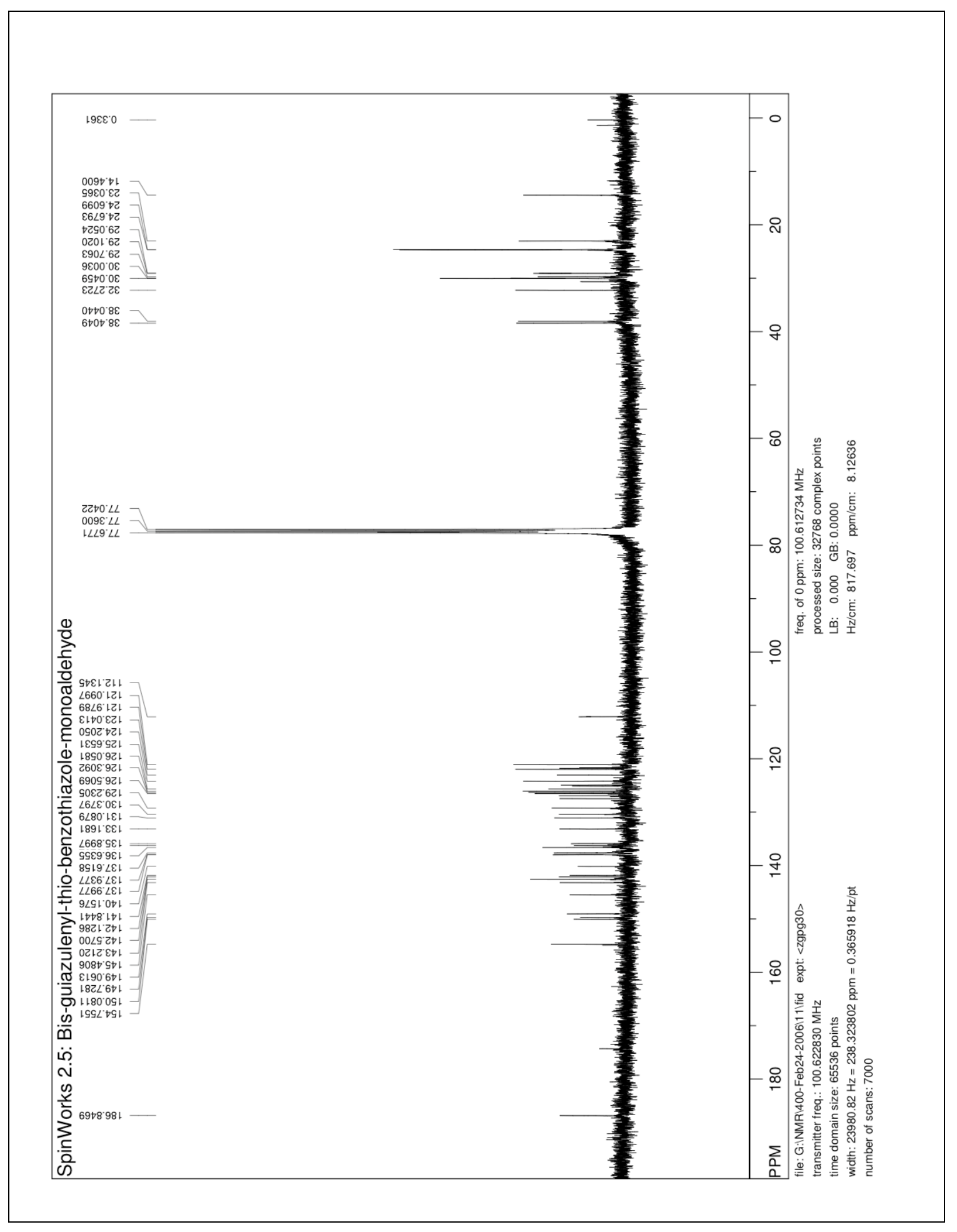




\section{[5.0.3] Synthesis of thio-benzothiazole-mononitrone derivative (52):}

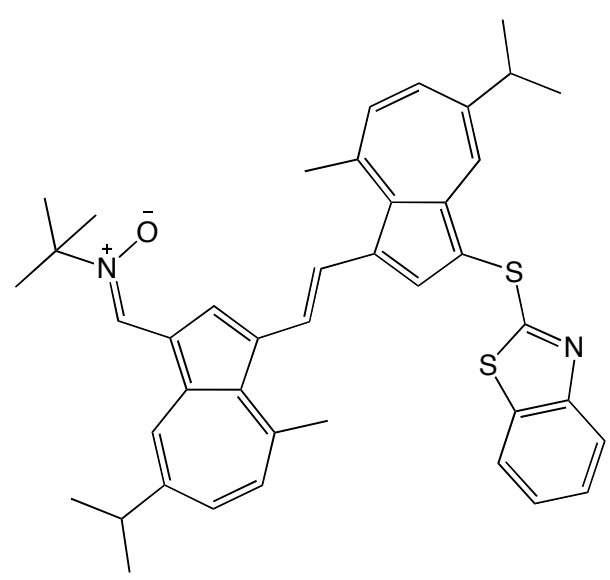

$(52)$

Bis-azulenyl thio-benzothiazole monoaldehyde derivative (51) (141 $\mathrm{mg}, 0.24 \mathrm{mmol}), t$-butyl hydroxyl amine (60 $\mathrm{mg}, 0.48 \mathrm{mmol}$, $)$ and magnesium sulfate $(58 \mathrm{mg}, 0.48 \mathrm{mmol})$ were mixed with $1 \mathrm{ml}$ of pyridine. Reaction mixture was heated at $90{ }^{\circ} \mathrm{C}$ for $14 \mathrm{~h}$. After $14 \mathrm{~h}$, silica gel thin layer chromatography indicated that all the starting material had reacted. The reaction was stopped and

product was purified via silica gel column chromatography using hexane/ethyl acetate (7:3) as eluent. $96 \mathrm{mg}(61 \%)$ of product was collected. $\mathrm{R}_{\mathrm{f}}=0.27$ (hexane/ethyl acetate $1: 1)$

${ }^{1}$ H NMR: $\left(400 \mathrm{MHz}, \mathrm{CDCl}_{3}\right): \delta 9.73(\mathrm{~s}, 1 \mathrm{H}), 8.66(\mathrm{~d}, J=2.0 \mathrm{~Hz}, 1 \mathrm{H}), 8.30(\mathrm{~s}, 1 \mathrm{H}), 8.18$ (s, 1H), 8.12 (d, J=1.7 Hz, 1H), 7.91-7.86 (m, 2H), 7.73 (d, $J=15.5 \mathrm{~Hz}, 1 \mathrm{H}), 7.54$ (dd, $J=7.9,0.46 \mathrm{~Hz}, 1 \mathrm{H}), 7.47(\mathrm{dd}, J=10.7,1.9 \mathrm{~Hz}, 1 \mathrm{H}), 7.39-7.34(\mathrm{~m}, 2 \mathrm{H}), 7.21-7.17$ (m, 2H), $7.06(\mathrm{~d}, J=10.6 \mathrm{~Hz}, 1 \mathrm{H}), 3.21(\mathrm{~s}, 3 \mathrm{H}), 3.12(\mathrm{~s}, 3 \mathrm{H}), 3.05(\mathrm{~m}, 2 \mathrm{H}), 1.73(\mathrm{~s}, 9 \mathrm{H}), 1.36$ $(\mathrm{d}, J=6.8 \mathrm{~Hz}, 6 \mathrm{H}), 1.28(\mathrm{~d}, J=6.9 \mathrm{~Hz}, 6 \mathrm{H}) .{ }^{13} \mathbf{C}$ NMR: $\left(400 \mathrm{MHz}, \mathrm{CDCl}_{3}\right): \delta 154.81$, $149.56,148.07,145.05,143.49,143.09,142.74,141.61,137.61,137.48,136.34,136.24$, $136.22,135.98,135.88,132.05,130.87,130.60,130.39,129.99,126.58,126.20,126.16$, $124.08,123.31,121.89,121.15,118.96,111.82,69.88,38.37,38.02,30.04,29.24,28.91$, 24.68, 24.62. LRMS: (LC/MS-APCI, MeOH) m/e $657.2\left(\mathrm{MH}^{+}\right)$. 


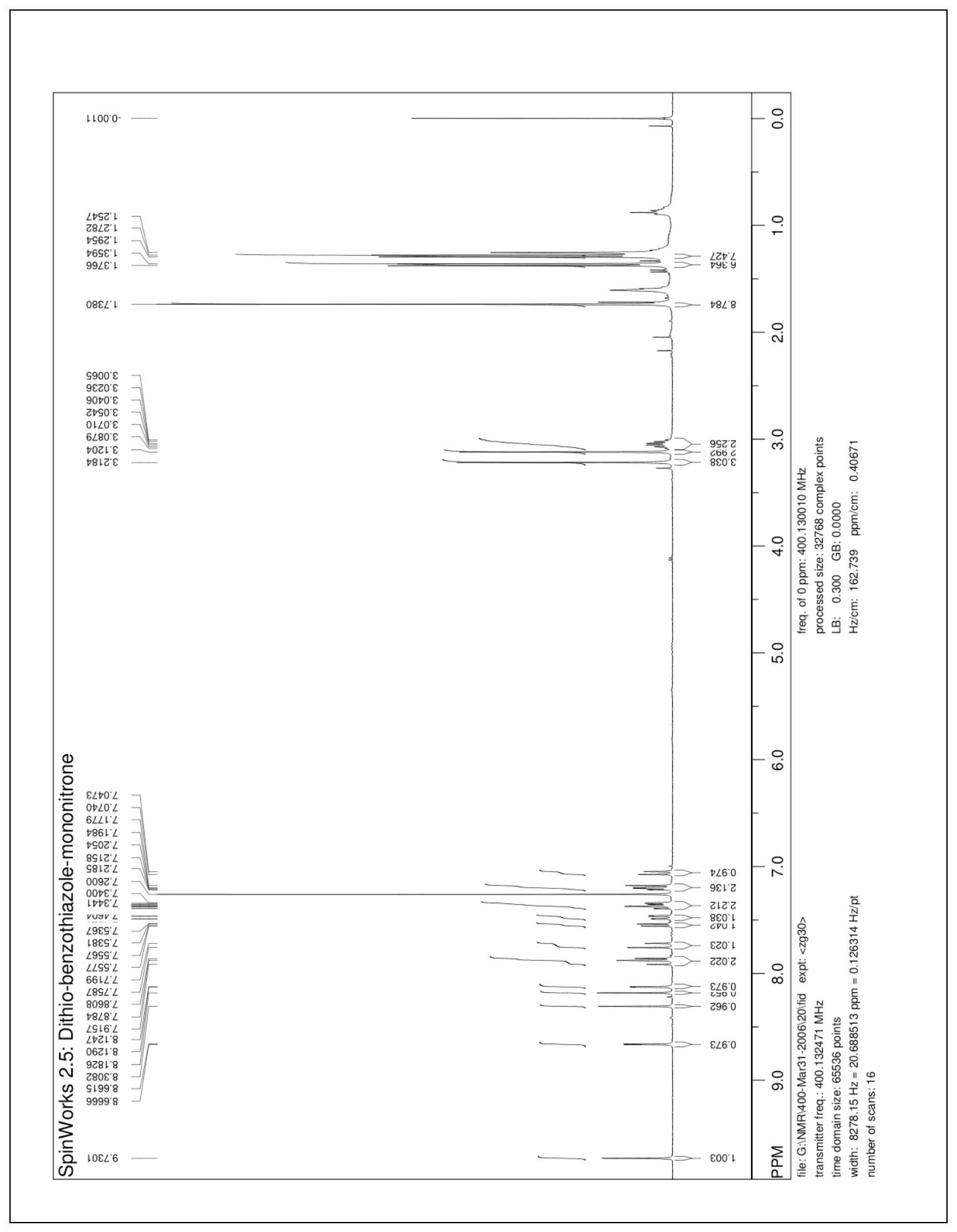




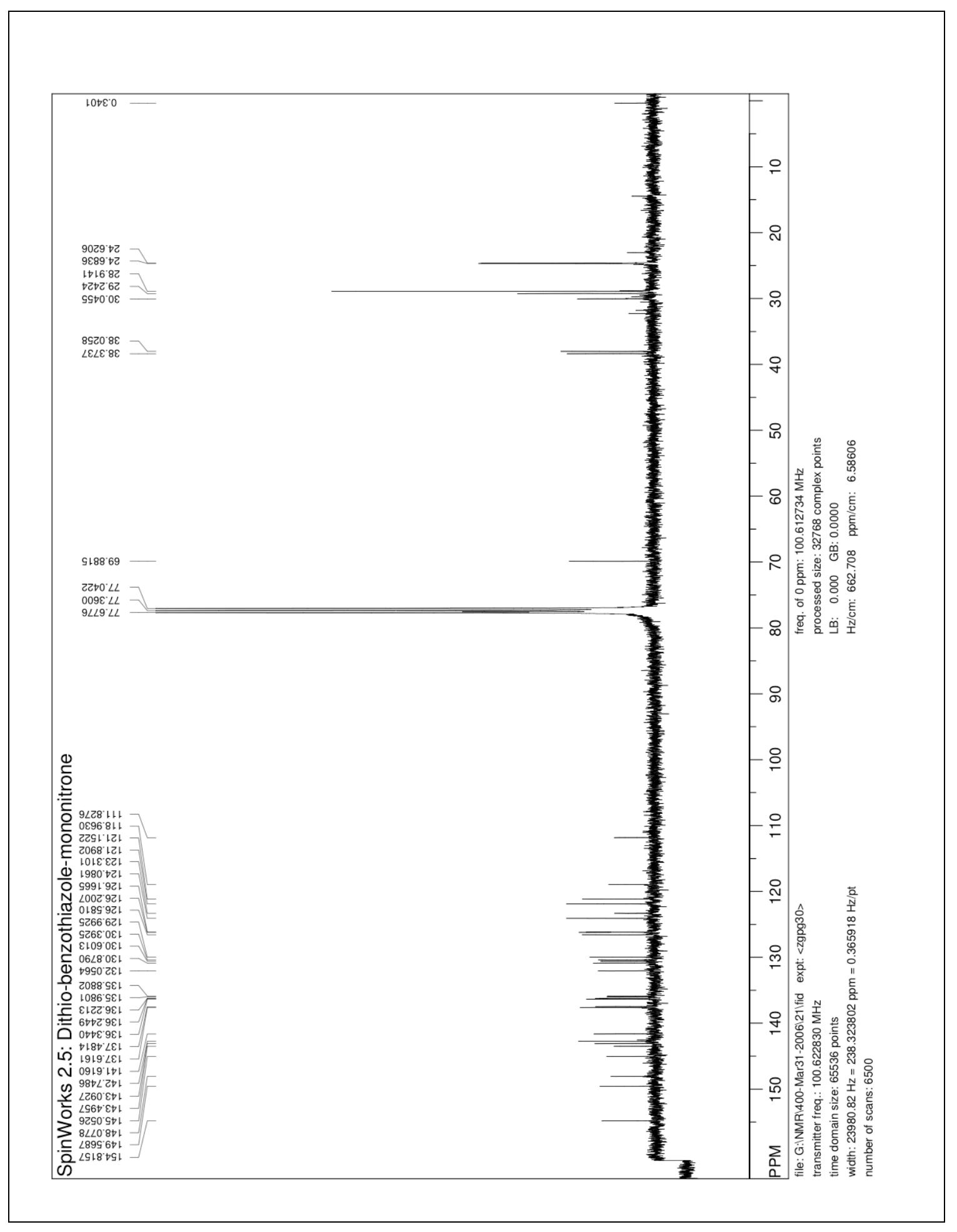




\section{[5.0.4] Synthesis of sulfenyl chloride (93):}

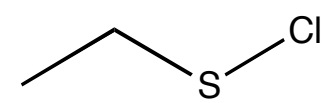

A solution of 1,2-diethyldisulfide (100 $\mathrm{mg}, 0.82 \mathrm{mmol})$ was prepared by dissolving it in 3 $\mathrm{ml}$ of dry methylene chloride. This solution was kept under argon and cooled to $0^{\circ} \mathrm{C}$ on an ice bath. Another solution of sulfuryl chloride $(110.4 \mathrm{mg}, 0.82 \mathrm{mmol})$ in $5 \mathrm{ml}$ of dry methylene chloride was prepared and was added slowly to diethyldisulfide solution over a period of $10 \mathrm{~min}$ with vigorous stirring under argon. After stirring for $10 \mathrm{~min}$, this solution was kept at $-70{ }^{\circ} \mathrm{C}$ in a dry-ice/acetone bath. This freshly prepared solution containing sulfenyl chloride (Et-S-Cl) was used for further synthesis.

\section{[5.0.5] Synthesis of 1-ethylthio bis-guiazulenyl monoaldehyde (54):}

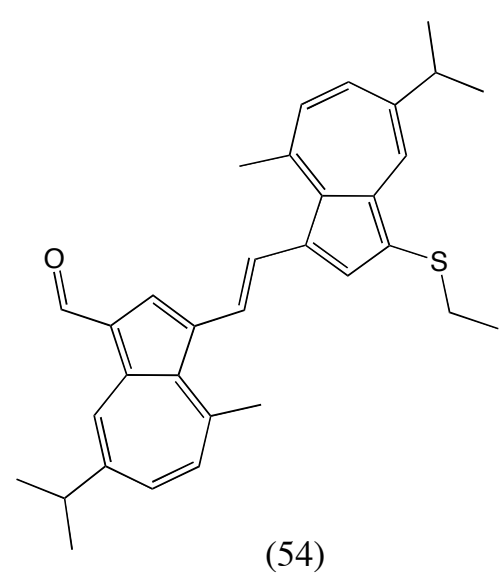

$(54)$
Bis-guiazulenyl monoaldehyde (49) (71 mg, $0.16 \mathrm{mmol})$ was dissolved in $15 \mathrm{ml}$ of dry hexane and $1 \mathrm{ml}$ of dry methylene chloride and cooled to $-70{ }^{\circ} \mathrm{C}$ in a dryice/acetone bath while under argon. Ethyl sulfenyl chloride (93) $(1.7 \mathrm{ml}, 0.17 \mathrm{mmol})$ solution was added slowly over a period of 30 min with vigorous stirring and evacuation. After all the ethyl sulfenyl chloride solution

was added, the reaction mixture was stirred for additional $30 \mathrm{~min}$ and then slowly brought back to room temperature over a period of 60-90 min. A layer of chloform was added and the reaction mixture was extracted with saturated sodium bicarbonate to neutralize acid. The chlorform layer was evaporated to a thick black oil that was purified 
via silica gel column chromatography with 9:1 hexane/ethyl acetate as eluent. After purification, $31 \mathrm{mg}$ (38\%) of pure product (54) was collected. $\mathrm{R}_{\mathrm{f}}=0.21$ (hexane/ethyl acetate 9:1).

${ }^{1}$ H NMR: $\left(400 \mathrm{MHz}, \mathrm{CDCl}_{3}\right): \delta 10.36(\mathrm{~s}, 1 \mathrm{H}), 9.61(\mathrm{~d}, J=1.8 \mathrm{~Hz}, 1 \mathrm{H}), 8.65(\mathrm{~d}, J=2.0$ Hz, 1H), 8.38 (s, 1H), 8.15 (s, 1H), $7.78(\mathrm{~d}, J=15.5 \mathrm{~Hz}, 1 \mathrm{H}), 7.63$ (d, J=15.5 Hz, 1H), $7.56(\mathrm{dd}, J=10.6,1.9 \mathrm{~Hz}, 1 \mathrm{H}), 7.37-7.31(\mathrm{~m}, 2 \mathrm{H}), 7.00$ (d, $J=10.6 \mathrm{~Hz}, 1 \mathrm{H}), 3.17$ (s, 3H), $3.11(\mathrm{~s}, 3 \mathrm{H}), 3.22-3.04(\mathrm{~m}, 2 \mathrm{H}), 2.82$ (q, $J=7.3 \mathrm{~Hz}, 2 \mathrm{H}), 1.39$ (d, $J=6.9 \mathrm{~Hz}, 6 \mathrm{H}), 1.37$ (d, $J=7.0 \mathrm{~Hz}, 6 \mathrm{H}), 1.24$ (t, $J=7.0 \mathrm{~Hz}, 3 \mathrm{H}) .{ }^{13} \mathbf{C}$ NMR: $\left(400 \mathrm{MHz}, \mathrm{CDCl}_{3}\right): \delta 186.85,150.07$, $149.52,147.57,143.32,143.29,142.05,141.92,140.78,140.01,137.92,137.87,136.68$ $136.57,134.66,132.94,130.90,129.21,128.11,127.01,125.17,125.08,119.99,38.39$, 38.05, 32.18, 30.05, 28.99, 28.96, 24.68, 15.68. LRMS: (LC/MS-APCI, MeOH) m/e $481.0\left(\mathrm{MH}^{+}\right)$. 


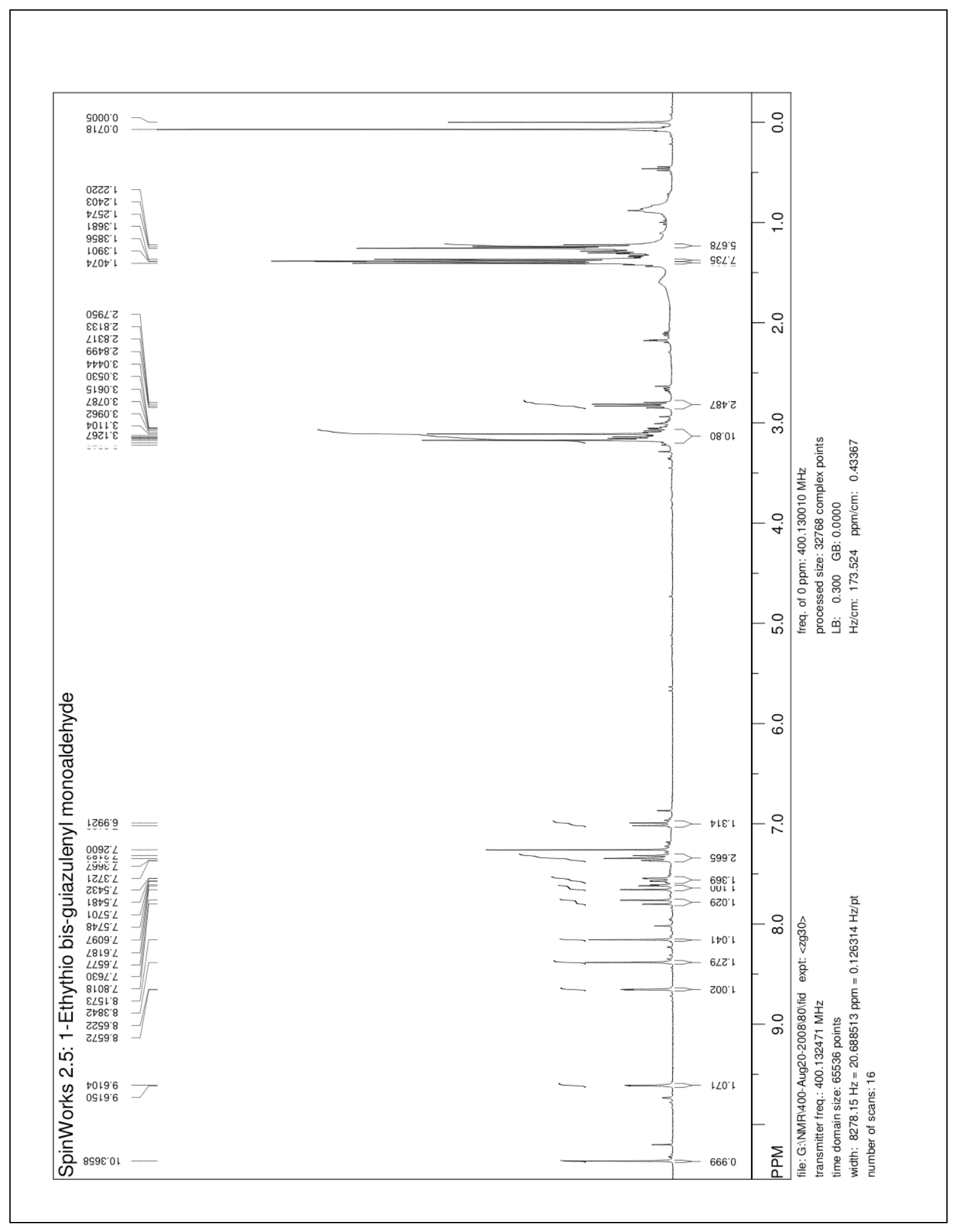




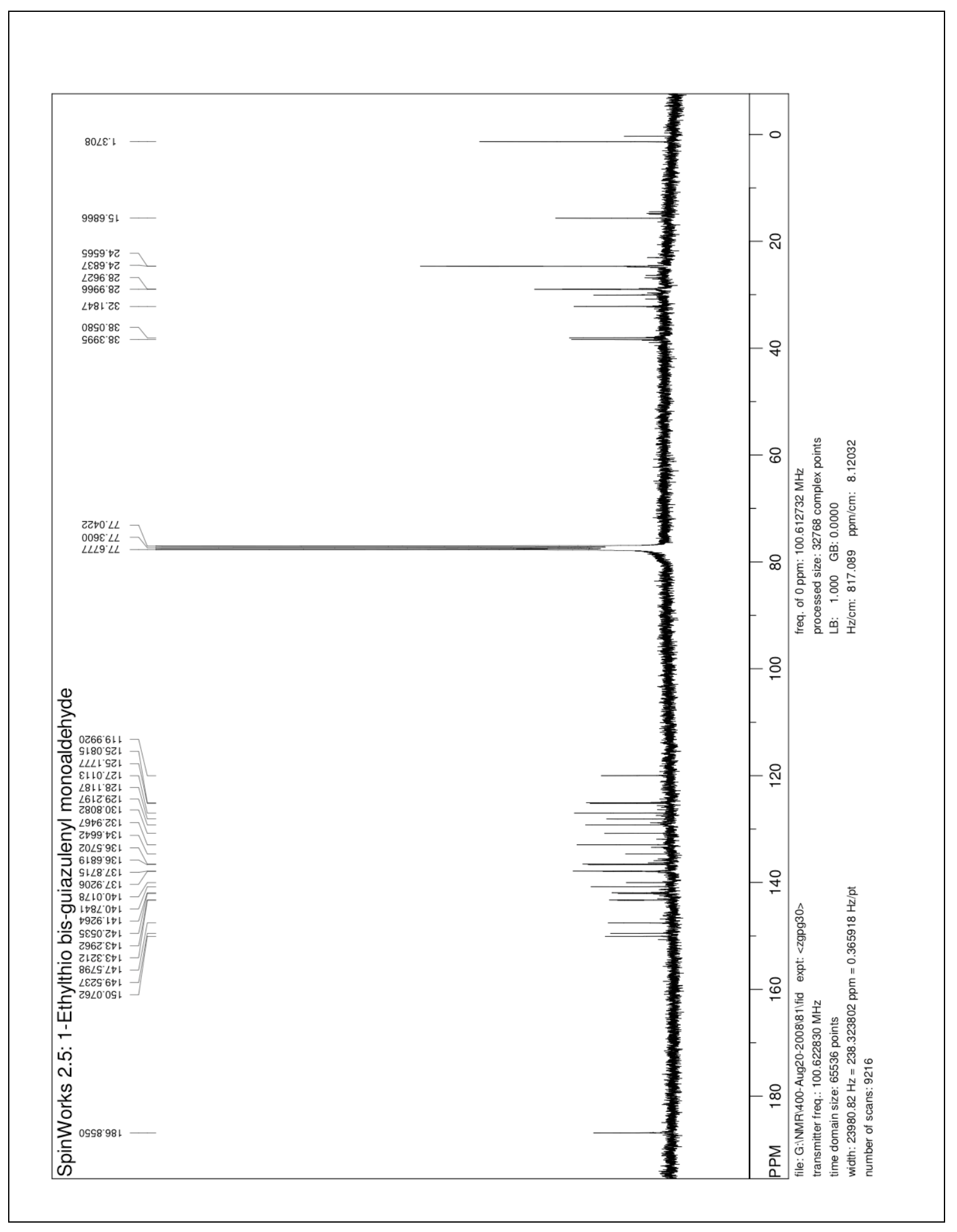




\section{[5.0.6] Synthesis of 1-ethylthio bis-guiazulenyl mononitrone (55):}

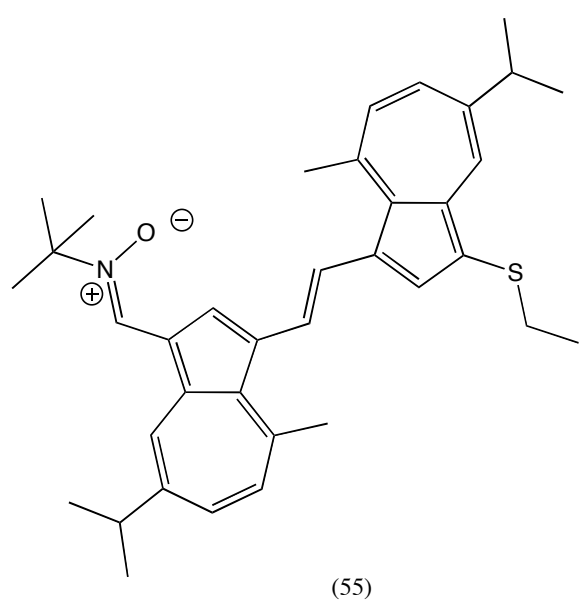

1-Ethylthio bis-guiazulenyl monoaldehyde (54) (21 mg, $0.04 \mathrm{mmol})$ was mixed with $\mathrm{N}-t$ butylhydroxylamine $(11 \mathrm{mg}, \quad 0.08 \mathrm{mmol})$ and magnesium sulfate $(10.5 \mathrm{mg}, 0.08 \mathrm{mmol})$ in $3 \mathrm{ml}$ of anhydrous pyridine. The reaction mixture was stirred at $50{ }^{\circ} \mathrm{C}$ under argon for $48 \mathrm{~h}$. The crude product was partitioned between water and chloroform. The

chloroform layer was evaporated and the residue was purified via silica gel column chromatography using 8:2 hexane/ethyl acetate as eluent. After purification, $18 \mathrm{mg}(74 \%)$ of product was collected. $\mathrm{R}_{\mathrm{f}}=0.10$ (Hexane/ethyl acetate $7: 3$ ).

${ }^{1}$ H NMR (400 MHz, $\left.\mathrm{CDCl}_{3}\right): \delta 9.70(\mathrm{~s}, 1 \mathrm{H}), 8.61(\mathrm{~d}, J=2.1 \mathrm{~Hz}, 1 \mathrm{H}), 8.17(\mathrm{~s}, 1 \mathrm{H}), 8.11$ (s, 1H), $8.10(\mathrm{~d}, J=1.8 \mathrm{~Hz}, 1 \mathrm{H}), 7.88(\mathrm{~d}, J=15.5 \mathrm{~Hz}, 1 \mathrm{H}), 7.70(\mathrm{~d}, J=15.5 \mathrm{~Hz}, 1 \mathrm{H}), 7.35$ $7.30(\mathrm{~m}, 2 \mathrm{H}), 7.04$ (d, J=10.4 Hz, 1H), $6.86(\mathrm{~d}, J=10.7 \mathrm{~Hz}, 1 \mathrm{H}), 3.09$ (s, 3H), 3.09 (s, 3H), 3.07-3.02 (m, 2H), 2.80 (q, J=7.3 Hz, 2H), $1.73(\mathrm{~s}, 9 \mathrm{H}), 1.36(\mathrm{~d}, J=6.9 \mathrm{~Hz}, 12 \mathrm{H})$, $1.23(\mathrm{t}, J=7.3 \mathrm{~Hz}, 3 \mathrm{H}) .{ }^{13} \mathrm{C}$ NMR $\left(400 \mathrm{MHz}, \mathrm{CDCl}_{3}\right): \delta 148.07,143.25,143.12,142.85$, $141.62,141.01,137.59,136.54,136.29,136.12,135.70,135.61,134.60,131.92,131.06$, $130.14,128.88,128.88,126.72,125.77,123.24,119.64,119.01,69.89,38.36,38.04$, 32.14, 29.17, 29.09, 28.94, 24.66, 14.55, 15.68. LRMS: (LC/MS-APCI, MeOH) m/e $552.1\left(\mathrm{MH}^{+}\right)$. 


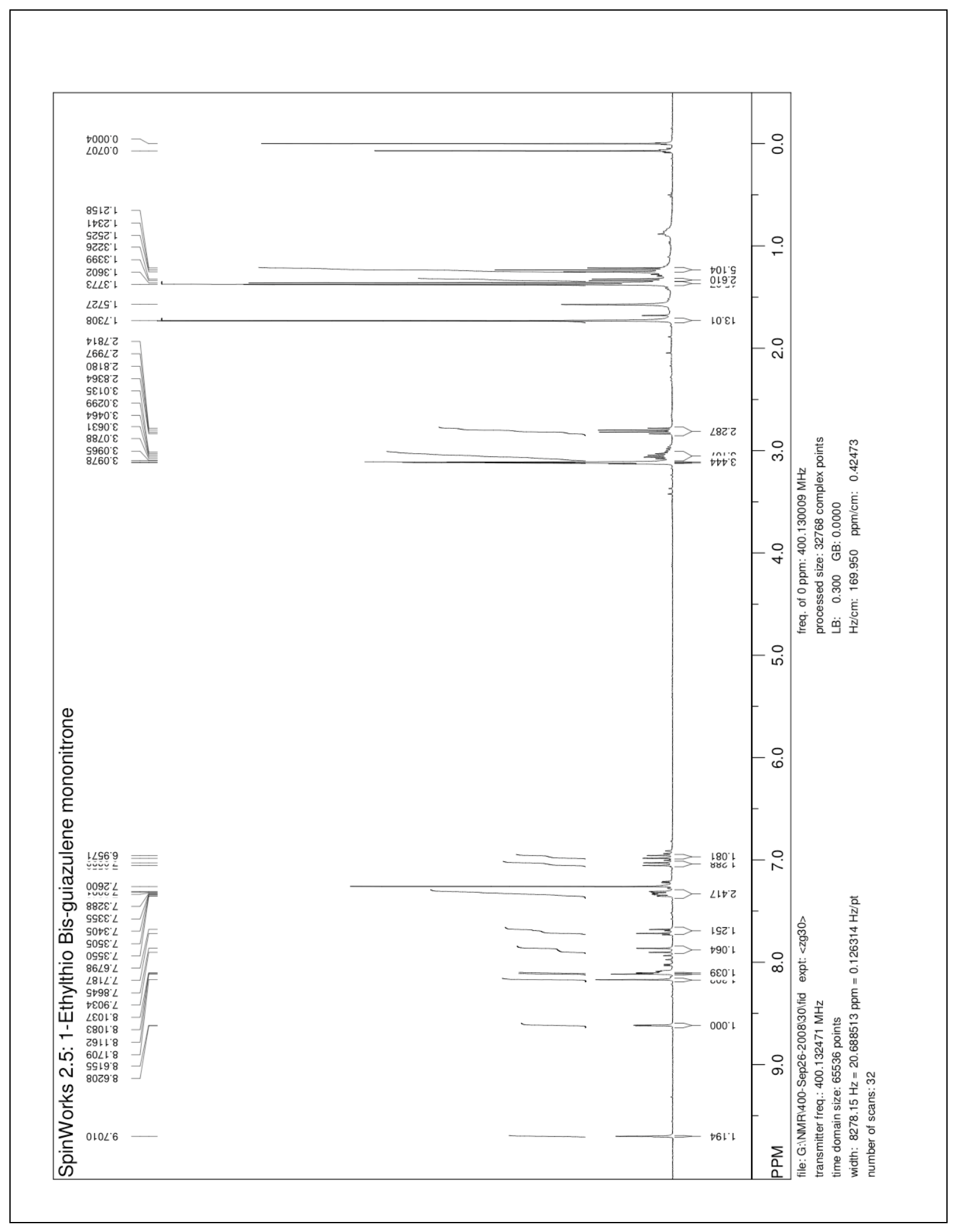




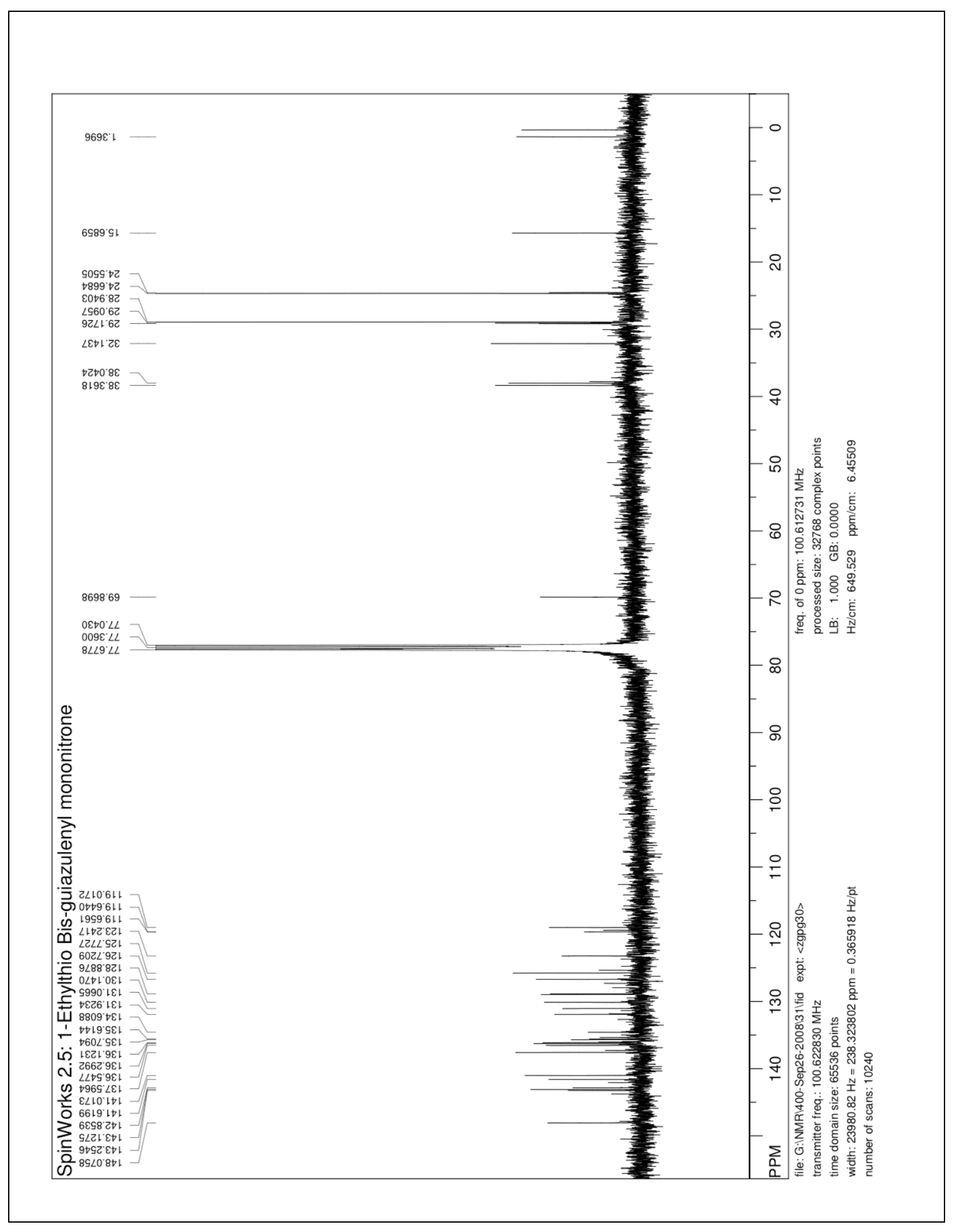




\section{[5.0.7] Synthesis of 3-(ethylthio)-guiazulene (57):}

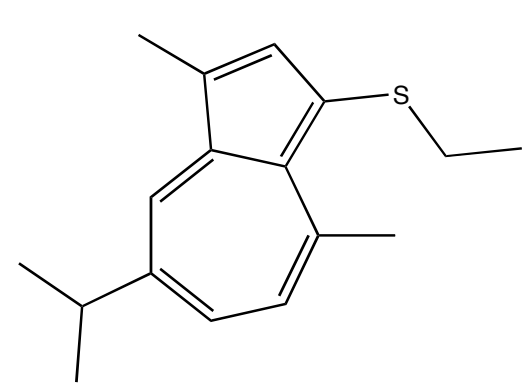

(57)

Guiazulene (57) (162 mg, $0.81 \mathrm{mmol})$ was dissolved in $40 \mathrm{ml}$ of dry hexane and the resulting solution was cooled to $-70{ }^{\circ} \mathrm{C}$ in a dry-ice/acetone bath while under argon. Ethyl sulfenyl chloride (93) (8ml, $0.81 \mathrm{mmol})$ solution was added slowly over a period of 30 min with vigorous stirring and evacuation. After all the ethyl sulfenyl chloride solution was added, the reaction mixture was stirred for additional $30 \mathrm{~min}$ and then slowly brought back to room temperature over a period of $60-90 \mathrm{~min}$. A layer of chloform was added and the reaction mixture was partitioned between chloroform and aqueous saturated sodium bicarbonate. The chloroform layer was evaporated to get a dark green oil, which was purified via silica gel column chromatography with hexane/ethyl acetate (20:1) as eluent. After purification, $140 \mathrm{mg}(66 \%)$ of pure product (57) was collected. $\mathrm{R}_{\mathrm{f}}=0.26$ (Hexane).

${ }^{1}$ H NMR (400 MHz, $\left.\mathrm{CDCl}_{3}\right): \delta 8.03(\mathrm{~d}, J=2.1 \mathrm{~Hz}, 1 \mathrm{H}), 7.61(\mathrm{~s}, 1 \mathrm{H}), 7.28(\mathrm{dd}, J=10.7$, $2.0 \mathrm{~Hz}, 1 \mathrm{H}), 6.86(\mathrm{~d}, J=10.7 \mathrm{~Hz}, 1 \mathrm{H}), 3.24(\mathrm{~s}, 3 \mathrm{H}), 3.06-2.96(\mathrm{~m}, 1 \mathrm{H}), 2.91(\mathrm{q}, J=7.3$, 2H), $2.61(\mathrm{~s}, 3 \mathrm{H}), 1.34(\mathrm{~d}, J=6.9 \mathrm{~Hz}, 6 \mathrm{H}), 1.29(\mathrm{t}, J=7.3 \mathrm{~Hz}, 3 \mathrm{H}) .{ }^{13} \mathbf{C}$ NMR $(400 \mathrm{MHz}$, $\left.\mathrm{CDCl}_{3}\right): \delta 147.46,141.54,140.07,138.96,135.66,135.25,133.71,127.76,125.04$ 117.65, 37.92, 32.08, 27.35, 24.77, 14.74, 13.13. LRMS: (LC/MS-APCI, MeOH) m/e $259.0\left(\mathrm{MH}^{+}\right)$. 


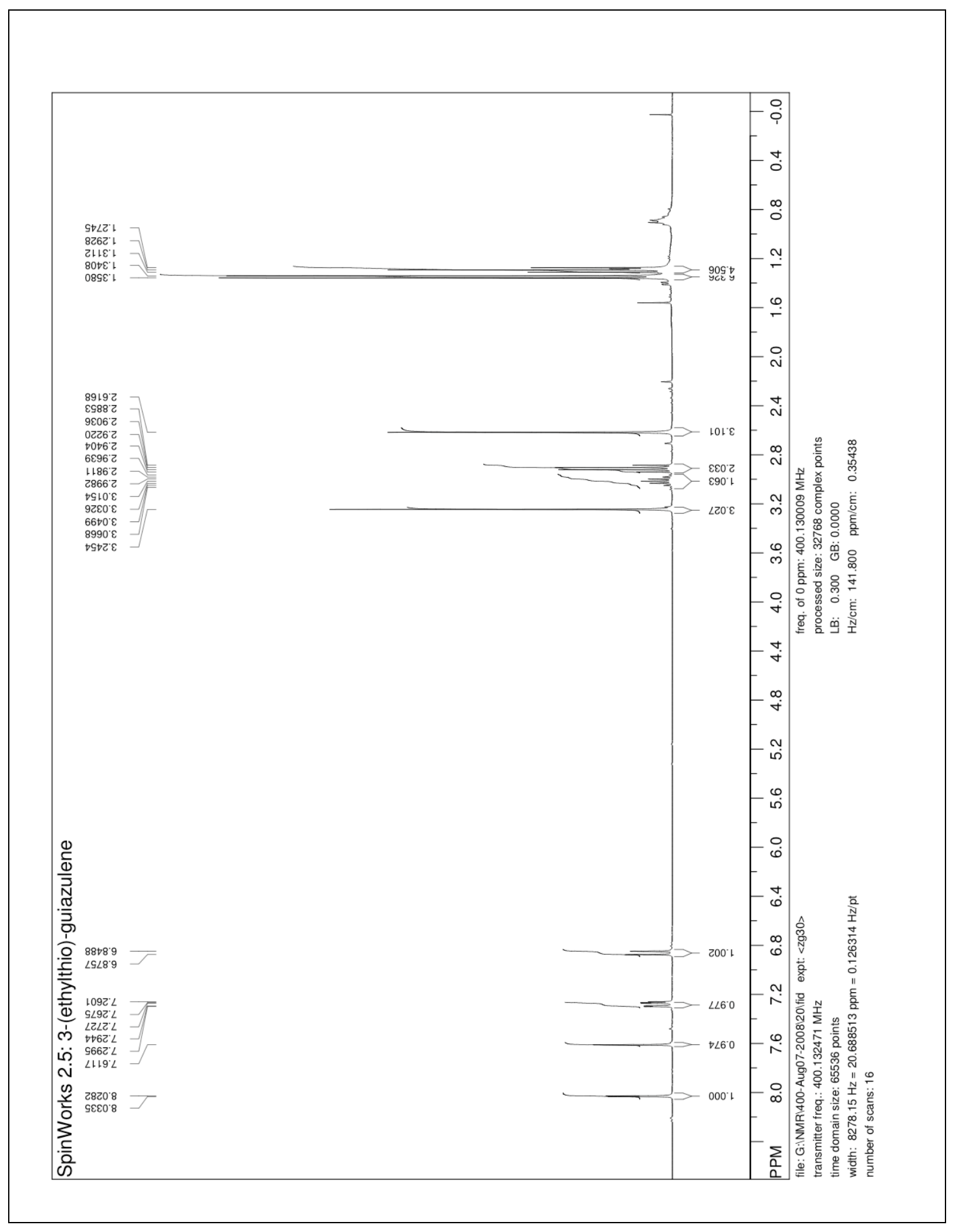




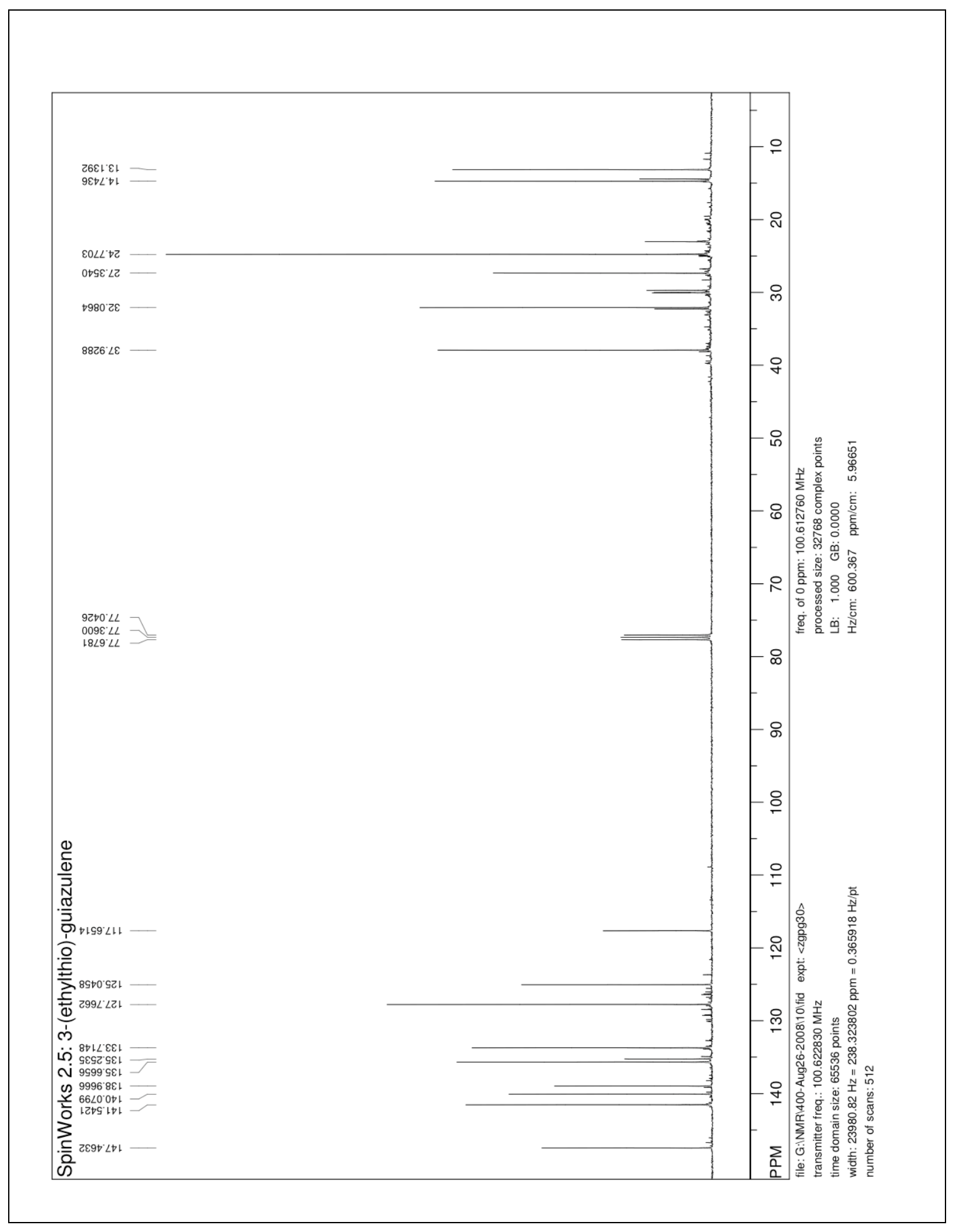




\section{[5.0.8] Synthesis of 3-(ethylthio)-1-carbaldehyde guiazulene (58):}

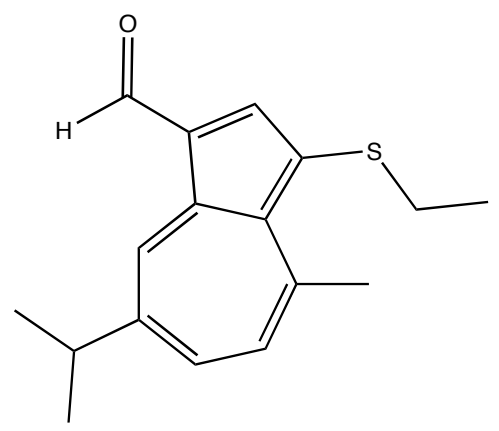

(58)

3-(Ethylthio)-guiazulene (57) (316 mg, $1.22 \mathrm{mmol})$ was dissolved in $100 \mathrm{ml}$ of acetone/water (9:1) mixture. 2,3dichloro-5,6-dicyanobenzoquinone (DDQ) (555 mg, 2.44 mmol) was added and reaction mixture was stirred at room temperature. After $10 \mathrm{~min}$, silica gel thin layer chromatography showed no starting material. $20 \mathrm{ml}$ of saturated sodium bicarbonate and $20 \mathrm{ml}$ saturated sodium bisulfite solution was added to neutralize and reduce unreacted DDQ. The crude product was isolated by extraction with chloroform. A layer of water was added to facilitate the extraction. The chloroform layer was collected and evaporated using a rotary evaporator. After purifying the product via silica gel column chromatography using hexane/ethyl acetate (9:1) as eluent, $164 \mathrm{mg}$ $(49 \%)$ of product (58) was collected. $R_{\mathrm{f}}=0.47$ (Hexane/Ethyl acetate $\left.9: 1\right)$

${ }^{1}$ H NMR $\left(400 \mathrm{MHz}, \mathrm{CDCl}_{3}\right): \delta 10.27(\mathrm{~s}, 1 \mathrm{H}), 9.61(\mathrm{~d}, J=2.0 \mathrm{~Hz}, 1 \mathrm{H}), 8.10(\mathrm{~s}, 1 \mathrm{H}), 7.58$ (dd, $J=10.8,2.1 \mathrm{~Hz}, 1 \mathrm{H}), 7.33$ (d, $J=10.8 \mathrm{~Hz}, 1 \mathrm{H}), 3.32$ (s, 3H), 3.2-3.0 (m, 1H), 2.95 (q, $J=7.3 \mathrm{~Hz}, 2 \mathrm{H}), 1.38$ (d, $J=6.9 \mathrm{~Hz}, 6 \mathrm{H}), 1.32$ (t, $J=7.3 \mathrm{~Hz}, 3 \mathrm{H})$.

${ }^{13}$ C NMR: (400 MHz, $\left.\mathrm{CDCl}_{3}\right): \delta$ 186.17, 151.41, 149.54, 145.29, 142.04, 141.65, $138.54,137.776,133.60,124.91,122.11,38.34,31.50,27.96,24.68,14.48$. LRMS: (LC/MS-APCI, MeOH) m/e $273.0\left(\mathrm{MH}^{+}\right)$. 


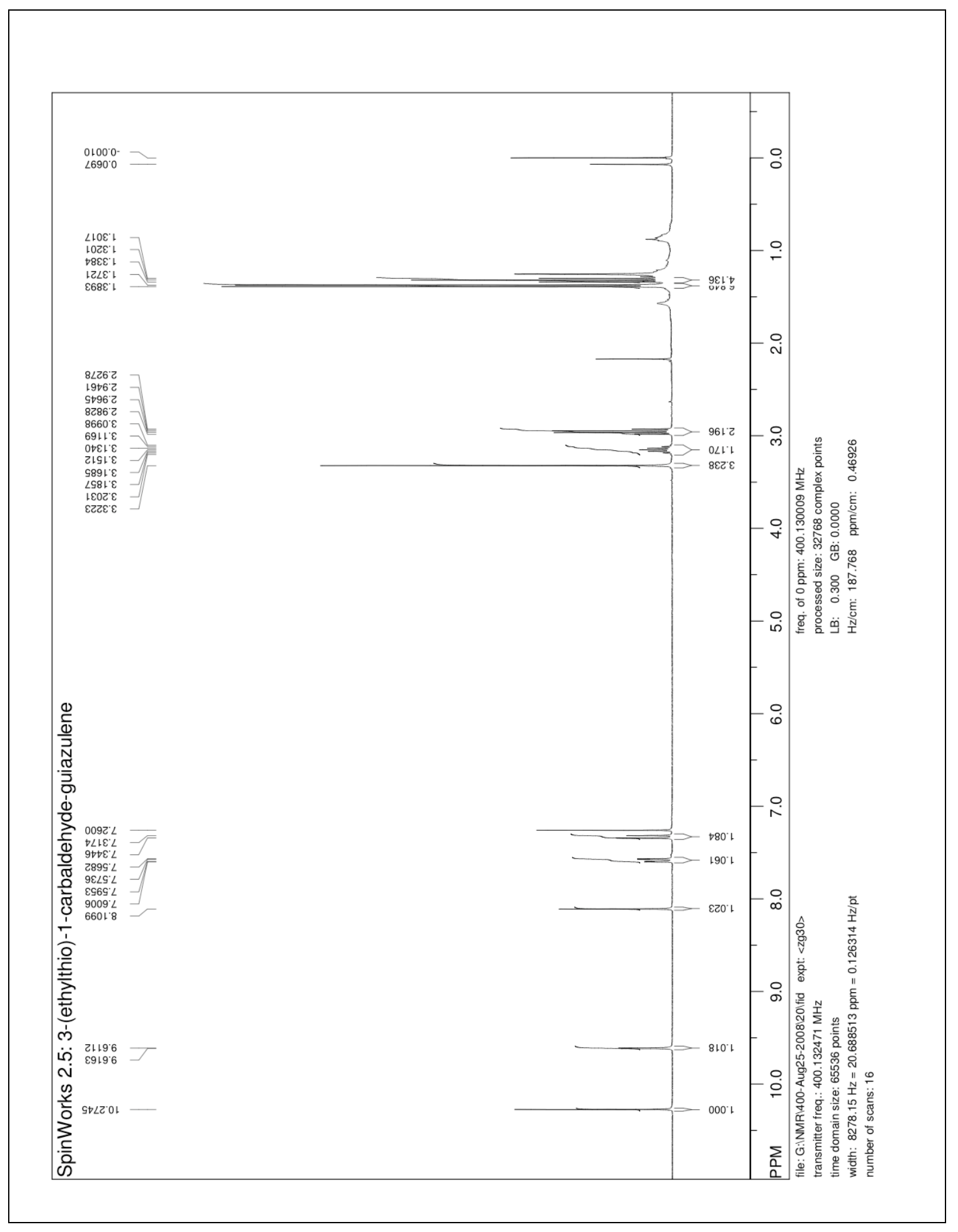




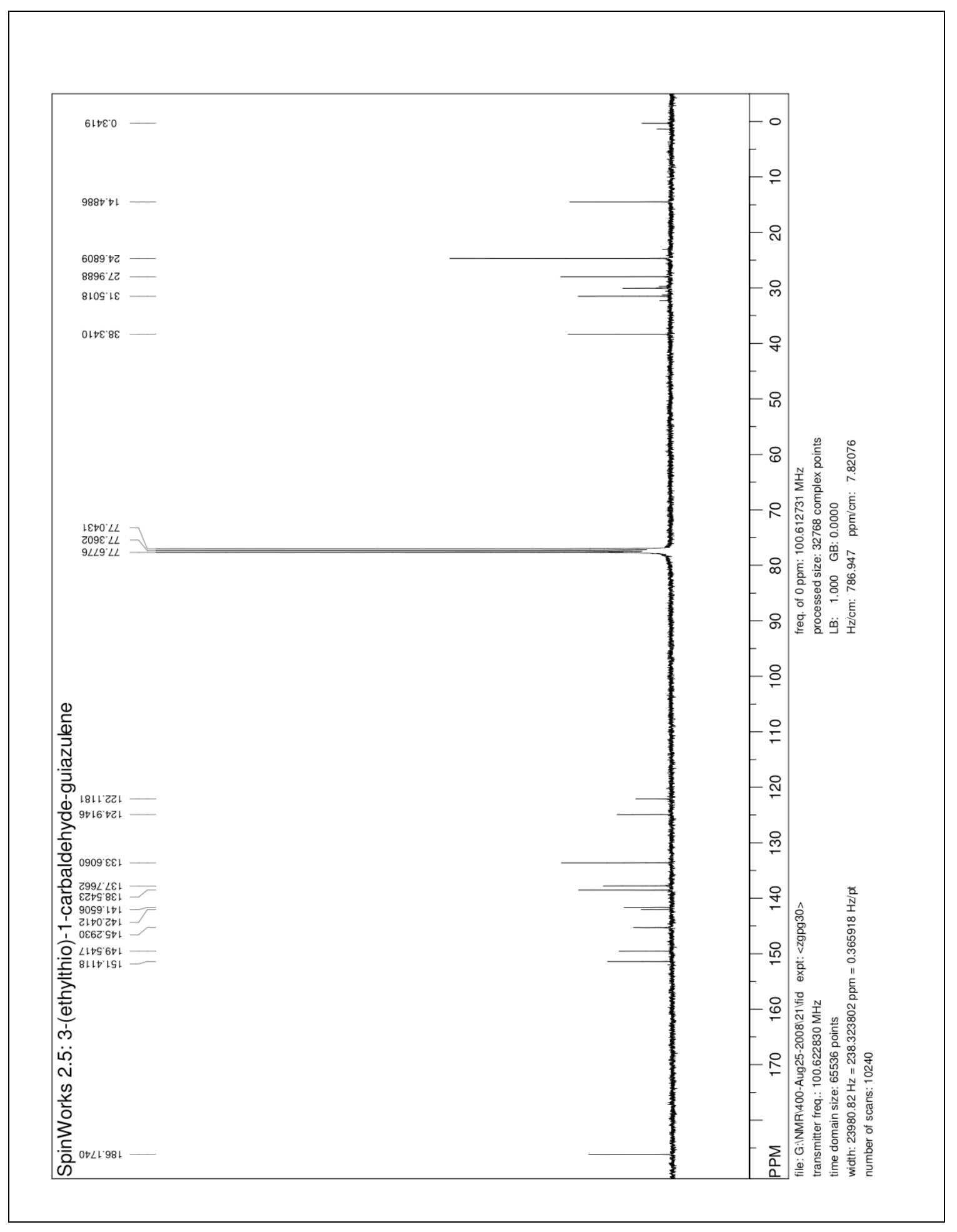




\section{[5.0.9] Synthesis of 3-(ethylthio)-1-nitrone-guiazulene (56):}

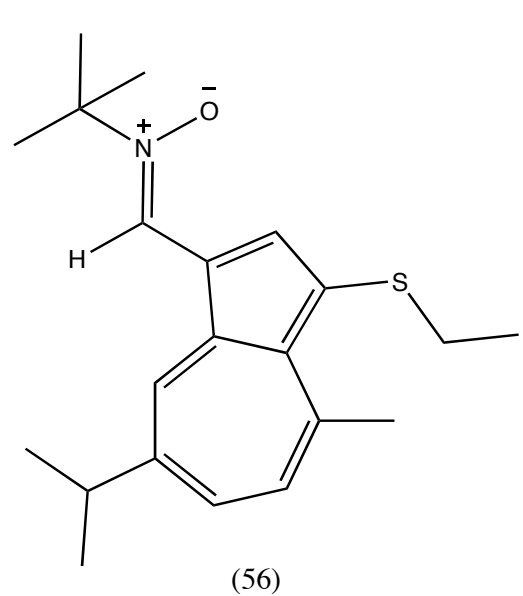

(56)

3-(Ethylthio)-1-carbaldehyde guiazulene (58) (24 mg, $0.08 \mathrm{mmol}$ ) was dissolved in $3 \mathrm{ml}$ pyridine. N-t-butyl hydroxyl amine $\mathrm{HCl}(21 \mathrm{mg}, \quad 0.16 \mathrm{mmol})$ and magnesium sulfate $(20 \mathrm{mg}, 0.16 \mathrm{mmol})$ were added. The reaction mixture was stirred under argon at $95{ }^{\circ} \mathrm{C}$ for 14 $h$ at the end of which silica gel thin layer chromatography showed no starting material. After

purification via silica gel column chromatography using hexane/ethyl acetate (7:3) as eluting solvent, $17 \mathrm{mg}(58 \%)$ of greenish product (56) was collected. $\mathrm{R}_{\mathrm{f}}=0.21$ (hexane/ethyl acetate 7:3).

${ }^{1}$ H NMR (400 MHz, CDCl $): \delta 9.39$ (s, 1H), 8.10 (s, 1H), 8.06 (d, J=1.9 Hz, 1H), 7.32 (dd, $J=10.7,1.8 \mathrm{~Hz}, 1 \mathrm{H}), 6.97$ (d, $J=10.7 \mathrm{~Hz}, 1 \mathrm{H}), 3.22$ (s, 3H), 3.10 (q, $J=7.3 \mathrm{~Hz}, 2 \mathrm{H}$ ), 3.0-2.9 (m, 1H), $1.70(\mathrm{~s}, 9 \mathrm{H}), 1.36-1.32(\mathrm{~m}, 9 \mathrm{H}) .{ }^{13} \mathbf{C}$ NMR (400 MHz, $\left.\mathrm{CDCl}_{3}\right): \delta$ 149.23, $142.56,140.22,138.96,136.91,136.89,132.02,130.25,123.84,122.82,118.76,69.80$ 38.27, 30.52, 28.88, 27.49, 24.64, 14.51. LRMS: (LC/MS-APCI, MeOH) m/e 344.0 $\left(\mathrm{MH}^{+}\right)$. 


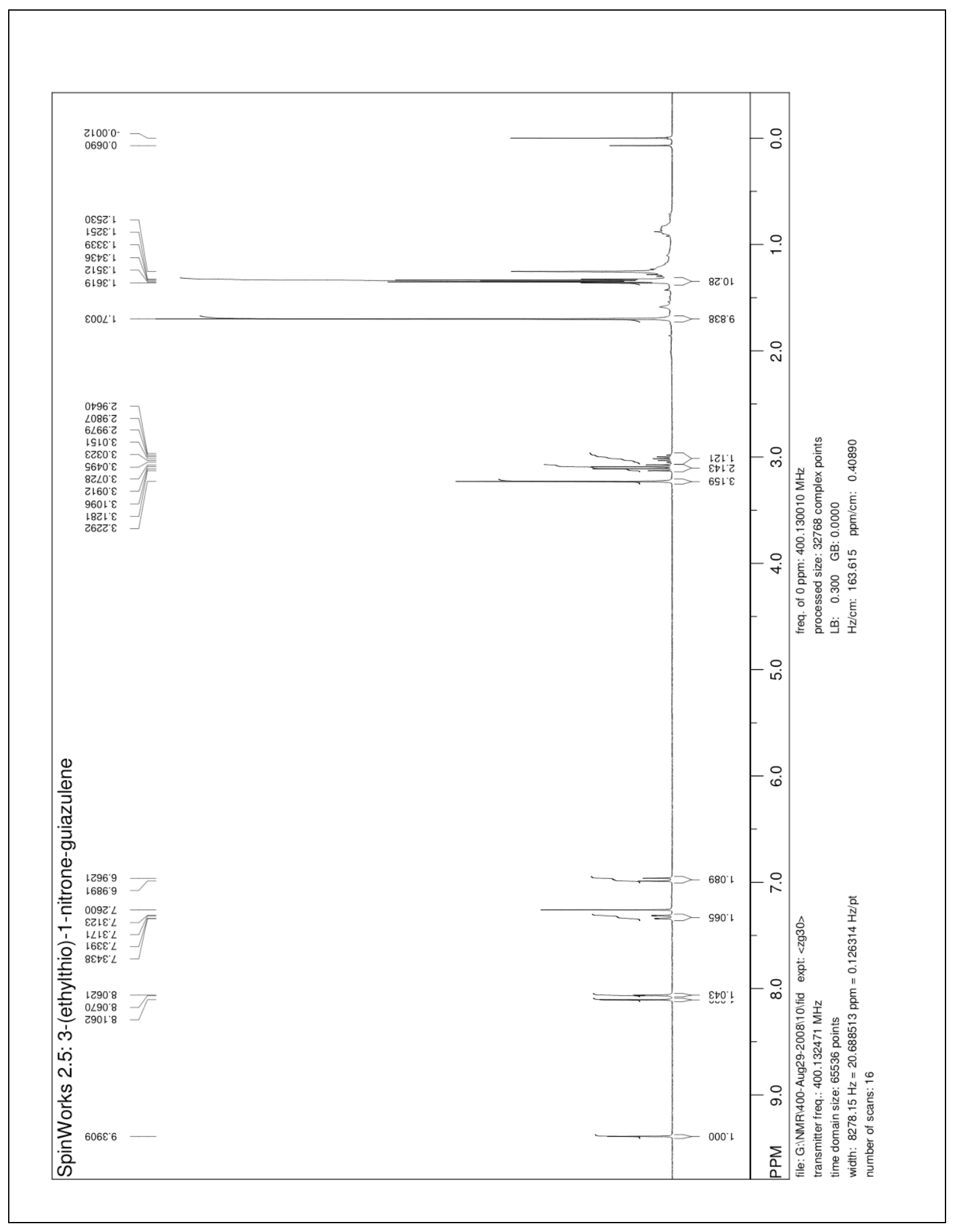




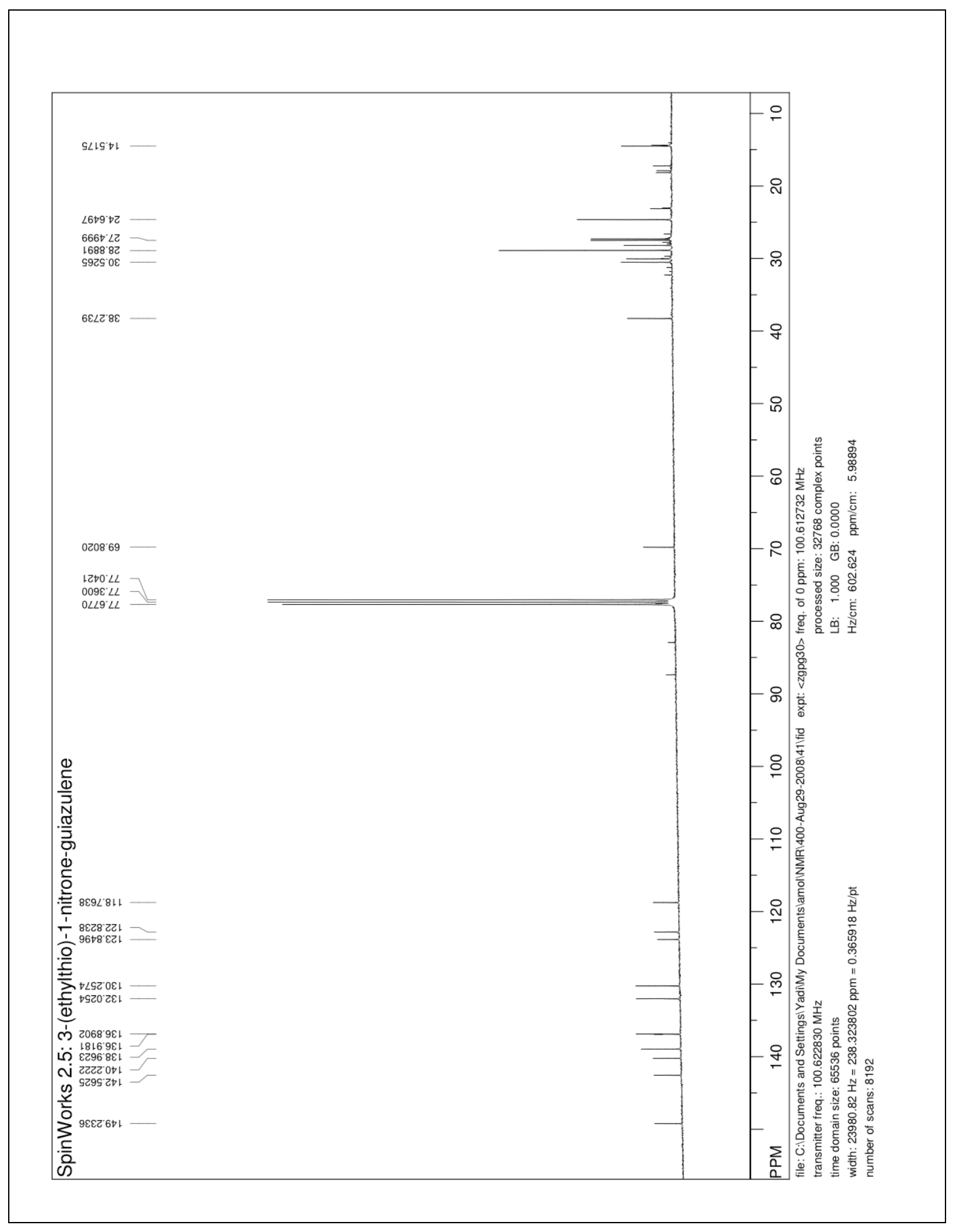




\section{[5.1.0] Extraction of valtrate (59):}

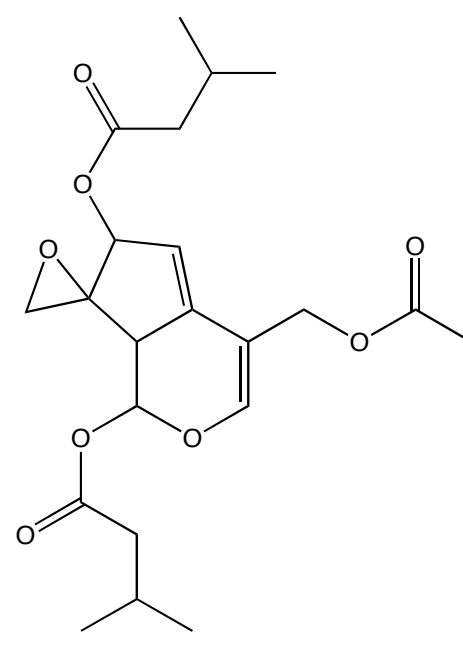

Valtrate (59)

$100 \mathrm{~g}$ of finely grounded root of Centranthus ruber (Red Valerian) was stirred in $800 \mathrm{~mL}$ of ethanol for $15 \mathrm{~min}$. After performing vacuum filtration and evaporating the ethanol using a rotary evaporator, the crude valtrate was obtained in the form of thick paste. A layer of chloroform was added, which was filtered and the filtrate was collected. This filtrate contains fairly pure valtrate (59). After performing silica gel column chromatography with hexane/ethyl acetate (8:2) as eluent, $9.2 \mathrm{~g}(9.2 \%)$ of valtrate (59) was obtained. $\mathrm{R}_{\mathrm{f}}=0.23$ (hexane/ethyl acetate 8:2).

${ }^{1}$ H NMR $\left(400 \mathrm{MHz}, \mathrm{CDCl}_{3}\right): \delta 6.68(\mathrm{~s}, 1 \mathrm{H}), 5.96(\mathrm{~d}, J=10.1 \mathrm{~Hz}, 1 \mathrm{H}), 5.84(\mathrm{t}, J=2.7 \mathrm{~Hz}$ 1H), 5.35 (d, $J=2.7 \mathrm{~Hz}, 1 \mathrm{H}), 4.68$ (dd, $J=28.9,12.3 \mathrm{~Hz}, 2 \mathrm{H}), 3.41$ (dd, $J=10.1,2.4 \mathrm{~Hz}$, $1 \mathrm{H}), 3.94(\mathrm{dd}, J=47.7,4.8 \mathrm{~Hz}, 2 \mathrm{H}), 2.22-2.21(\mathrm{~m}, 2 \mathrm{H}), 2.20(\mathrm{~m}, 2 \mathrm{H}), 2.18-2.06(\mathrm{~m}, 2 \mathrm{H})$, $2.03(\mathrm{~s}, 3 \mathrm{H}), 0.96(\mathrm{~d}, J=6.6 \mathrm{~Hz}, 6 \mathrm{H}), 0.92(\mathrm{~d}, J=6.5 \mathrm{~Hz}, 6 \mathrm{H}) .{ }^{13} \mathbf{C}$ NMR $(400 \mathrm{MHz}$, $\left.\mathrm{CDCl}_{3}\right): \delta 172.43,170.85,170.28,148.48,140.91,116.63,108.34,92.57,83.04,64.15$ $60.81,47.85,43.36,43.02,43.00,25.79,25.57,22.31,22.30,22.19,20.90$. LRMS: (LC/MS-APCI, MeOH) m/e $423.2\left(\mathrm{MH}^{+}\right)$. 


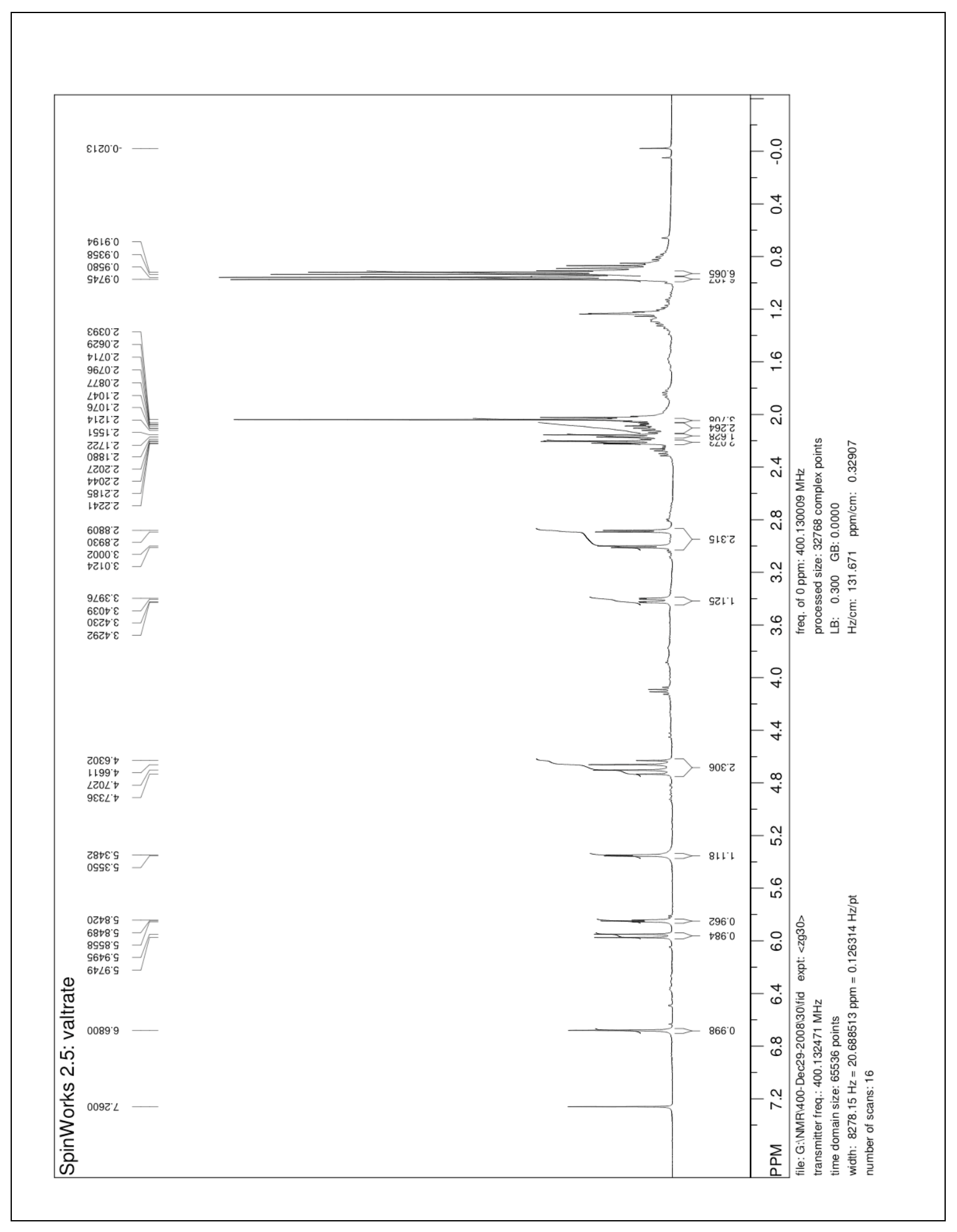




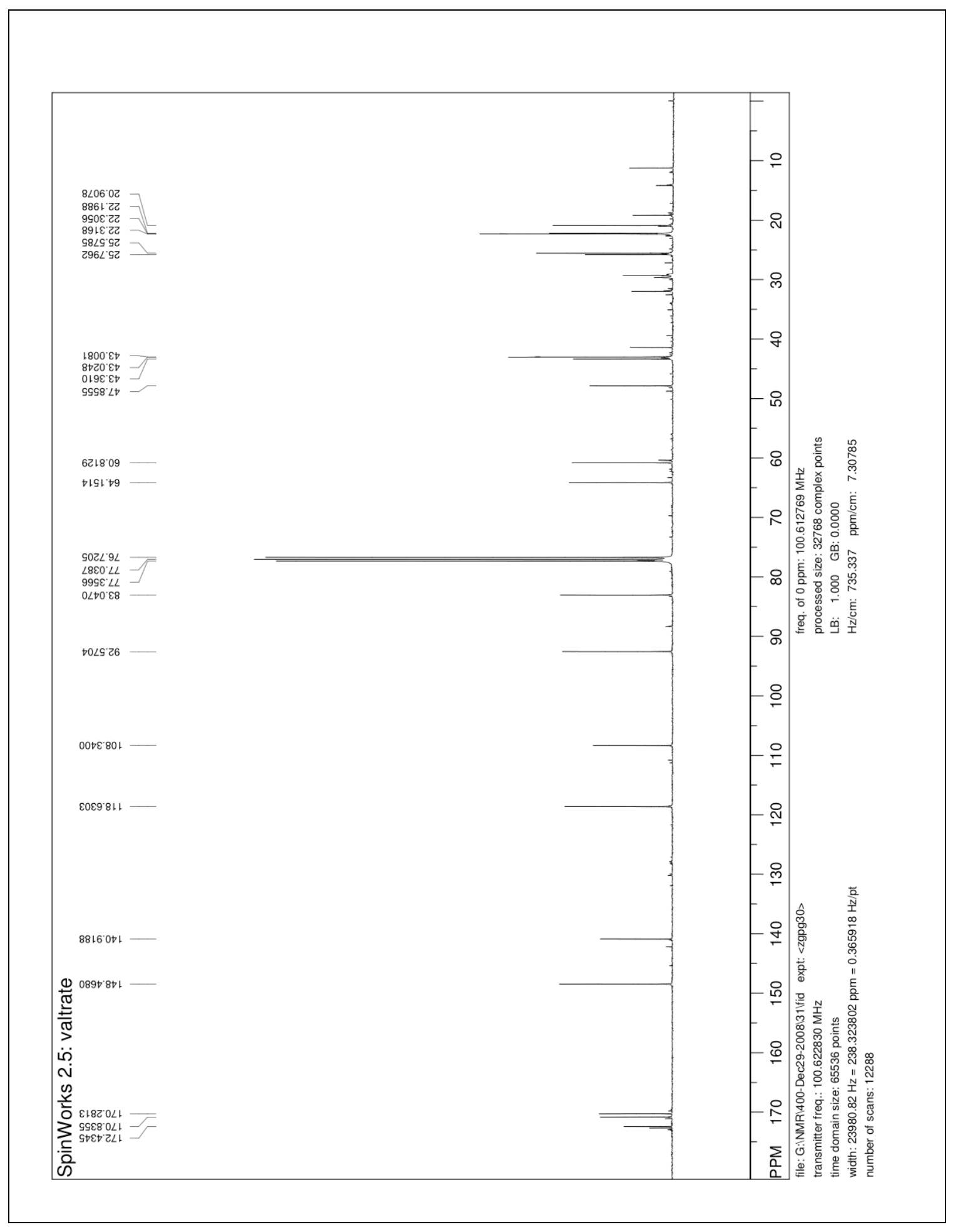




\section{[5.1.1] Synthesis of baldrinal (60):}

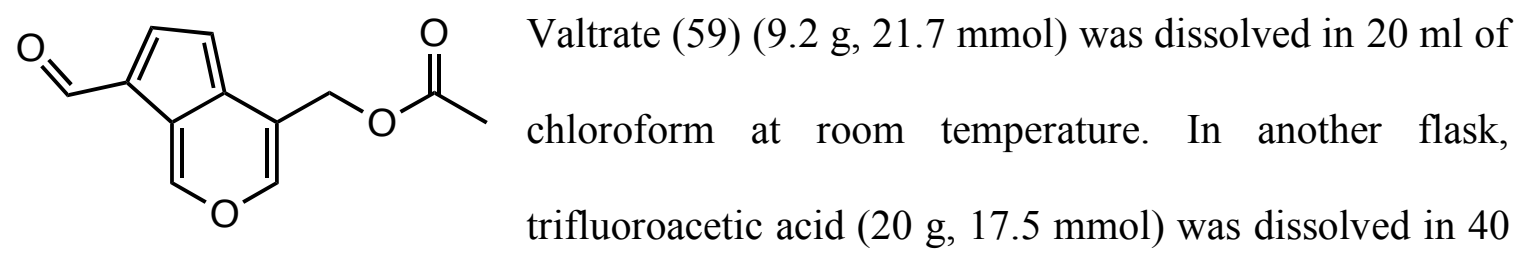

Baldrinal (60) $\mathrm{ml}$ of chloroform. This trifluroacetic acid solution was added to the solution containing valtrate. The clear valtrate solution became dark green/blue after stirring for $5 \mathrm{~min}$. When silica gel thin layer chromatography showed no valtrate, $160 \mathrm{ml}$ of chloroform was added and washed with water until $\mathrm{pH}-4$ was reached. A mixture of saturated aqueous $\mathrm{NaCl}$ solution and saturated aqueous $\mathrm{NaHCO}_{3}$ solution (1:1) was added until the $\mathrm{pH}-7$ was reached. At this point, the solution turned yellowbrown. This solution was carefully extracted successively with chloroform, where the yellow chloroform layer was collected. After evaporating the chloroform using a rotary evaporator, the product was further purified by performing silica gel column chromatography with hexane/ethyl acetate (8:2) as eluting solvent. $1.1 \mathrm{~g}$ of baldrinal (60) $(23 \%)$ was collected as a yellow solid. $R_{\mathrm{f}}=0.21$ (Hexane/Ethyl acetate 8:2).

Baldrinal (60) can also be obtained from valtrate extracted from finely ground and dried root of Valeriana officinalis using the same protocol. Starting with 100 gm of finely ground and dried root of Valeriana officinalis, $500 \mathrm{mg}$ of baldrinal (60) was obtained which is approximately $55 \%$ less yield of baldrinal as compared to the baldrinal obtained from the root of Centhranthus ruber.

${ }^{1} \mathbf{H}$ NMR (400 MHz, CDCl $)$ ): $\delta 9.93(\mathrm{~s}, 1 \mathrm{H}), 9.09$ (s, 1H), 7.89 (s, 1H), 7.87 (d, J=3.28

$\mathrm{Hz}, 1 \mathrm{H}), 6.61(\mathrm{dd}, J=3.26,0.58 \mathrm{~Hz}, 1 \mathrm{H}), 5.26(\mathrm{~d}, J=0.42 \mathrm{~Hz}, 2 \mathrm{H}), 2.12(\mathrm{~s}, 3 \mathrm{H}) .{ }^{13} \mathbf{C}$ 
NMR: $\left(400 \mathrm{MHz}, \mathrm{CDCl}_{3}\right): \delta 185.04,170.73,150.78,146.33,142.24,133.91,124.99$, 123.13, 119.45, 109.61, 60.57, 20.88. LRMS: (LC/MS-APCI, MeOH) m/e $219.0\left(\mathrm{MH}^{+}\right)$.

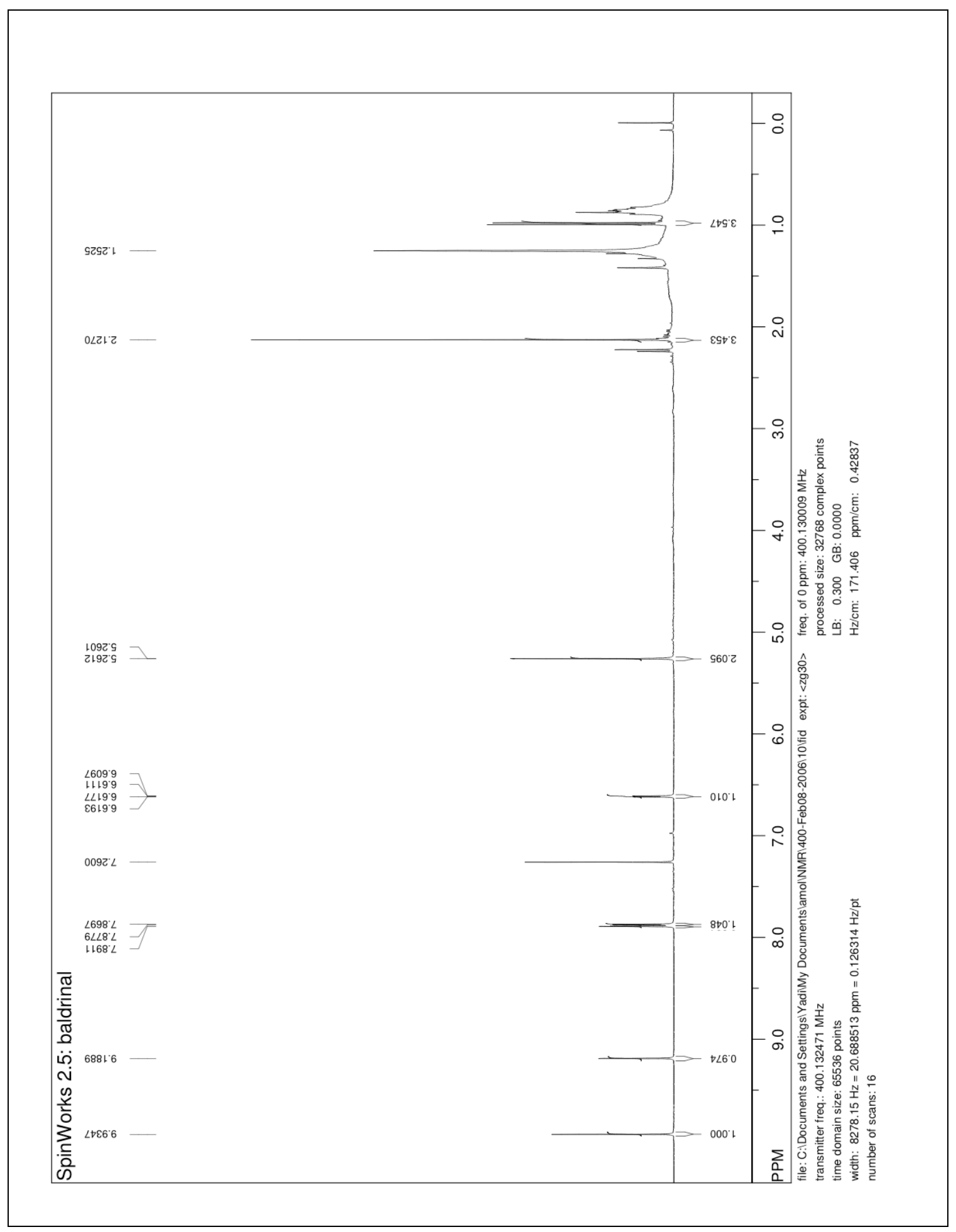




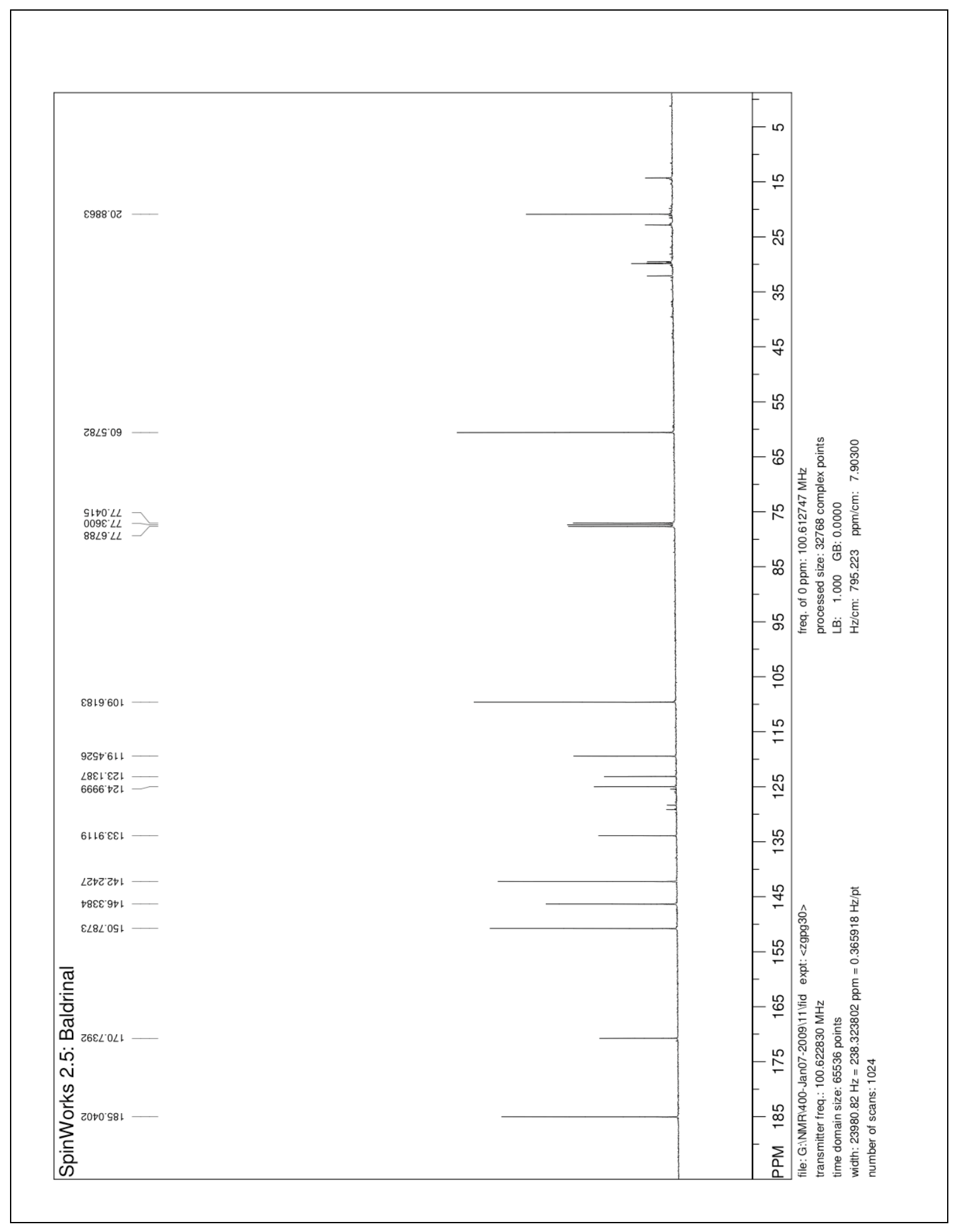




\section{[5.1.2] Synthesis of 2-butyl-cyclopenta[c]pyridine-4,7-dicarbaldehyde (61):}

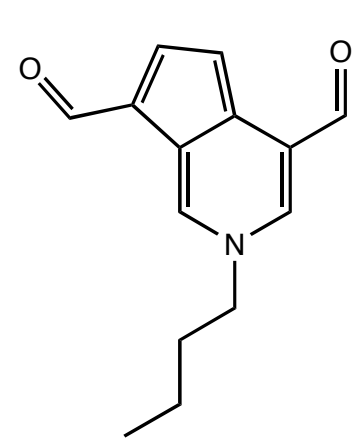

$(61)$

Baldrinal (60) $(2.5 \mathrm{~g}, 11 \mathrm{mmol})$ was dissolved in $4 \mathrm{ml}$ of chloroform. n-butyl amine (4.38 g, $60 \mathrm{mmol})$ was added. After stirring for $10 \mathrm{~min}$ at room temperature, color changed from yellow to orange/red. When silica gel thin layer chromatography showed no baldrinal, the excess of amine was removed under vacuum. After performing silica gel column chromatography with hexane/ethyl acetate (8:2) as eluent, $272 \mathrm{mg}$ (11\%) of wine colored product (61) was collected. $\mathrm{R}_{\mathrm{f}}=0.90$ (chloroform/methanol 99:1).

${ }^{1}$ H NMR (400 MHz, $\left.\mathrm{CDCl}_{3}\right): \delta 10.25$ (s, 1H), 9.92 (s, 1H), 9.03 (s, 1H), 7.97 (d, J=3.6 $\mathrm{Hz}, 1 \mathrm{H}), 7.84(\mathrm{~d}, J=1.5 \mathrm{~Hz}, 1 \mathrm{H}), 7.23$ (dd, $J=3.6,0.46 \mathrm{~Hz}, 1 \mathrm{H}), 4.29$ (t, $J=7.3 \mathrm{~Hz}, 2 \mathrm{H})$, 2.01-1.94 (m, 2H), 1.46-1.37 (m, 2H), $0.99(\mathrm{t}, J=7.3 \mathrm{~Hz}, 3 \mathrm{H}) .{ }^{13} \mathbf{C}$ NMR (400 MHz, $\left.\mathrm{CDCl}_{3}\right): \delta 189.73,185.23,145.61,134.63,133.14,133.06,127.77,122.12,121.23$, 107.98, 59.63, 33.92, 19.97, 13.83. LRMS: (LC/MS-APCI, MeOH) m/e 230.1 $\left(\mathrm{MH}^{+}\right)$ 


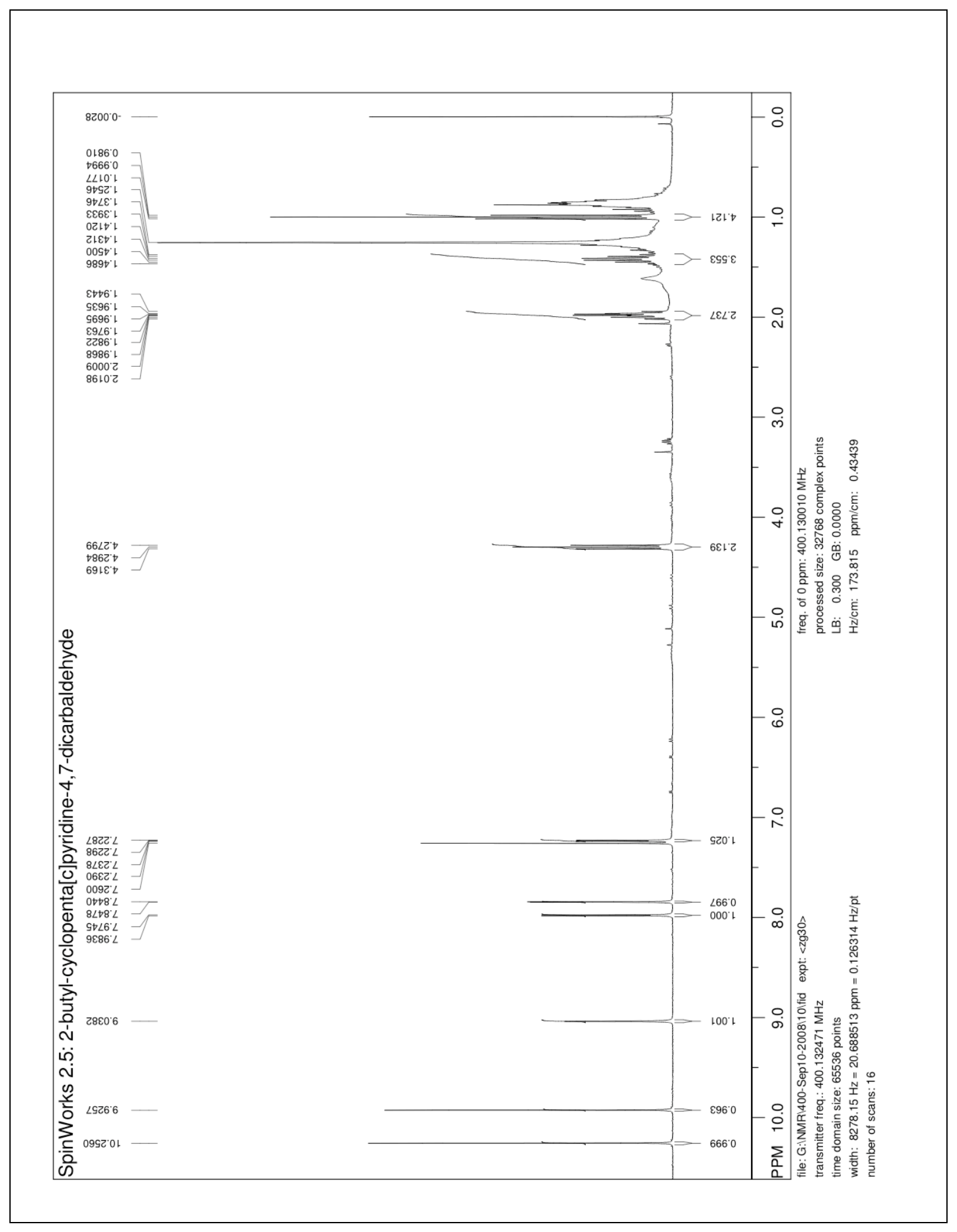




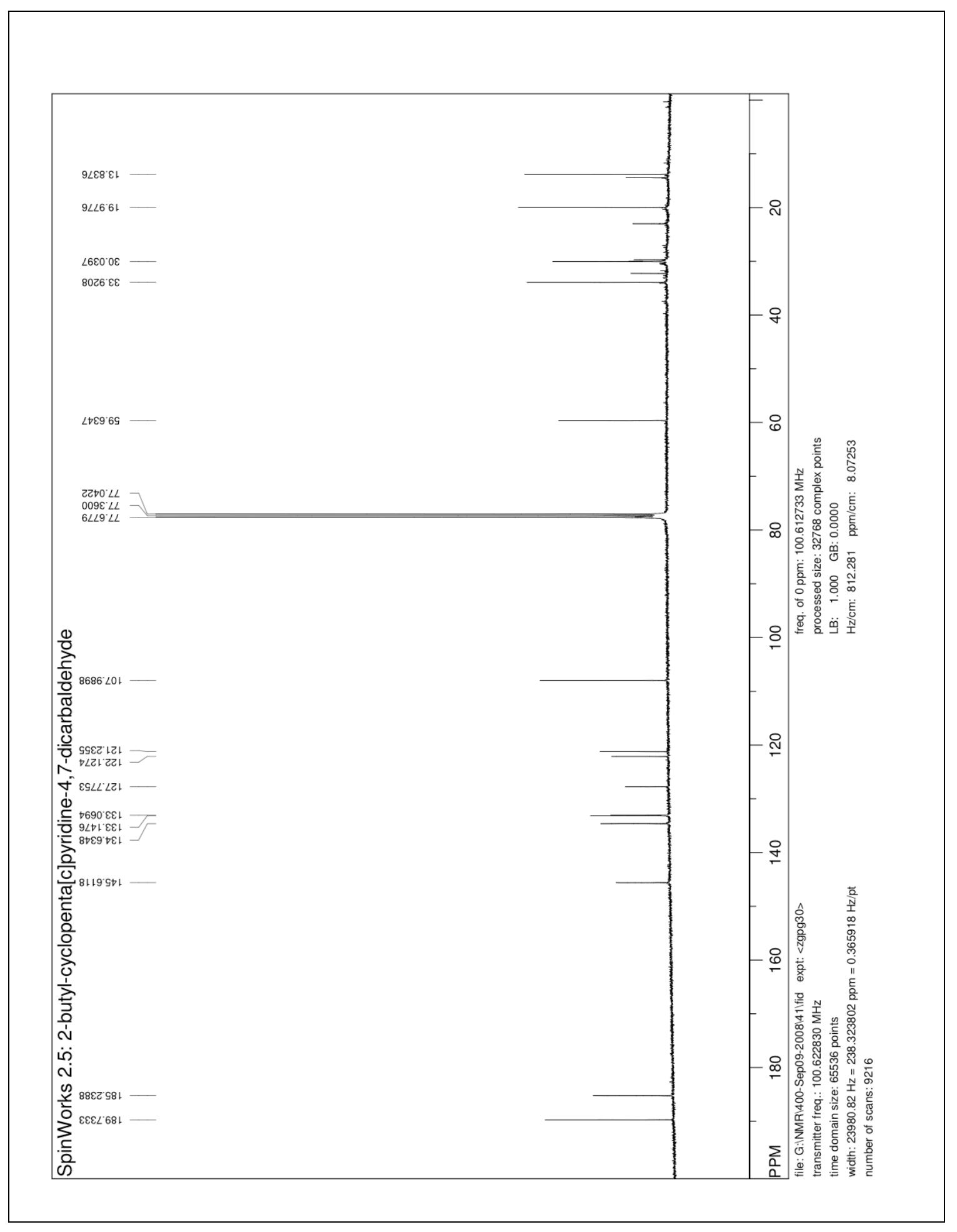




\section{[5.1.3] Synthesis of 2-butyl-cyclopenta[c]pyridine-4,7-dinitrone (63):}

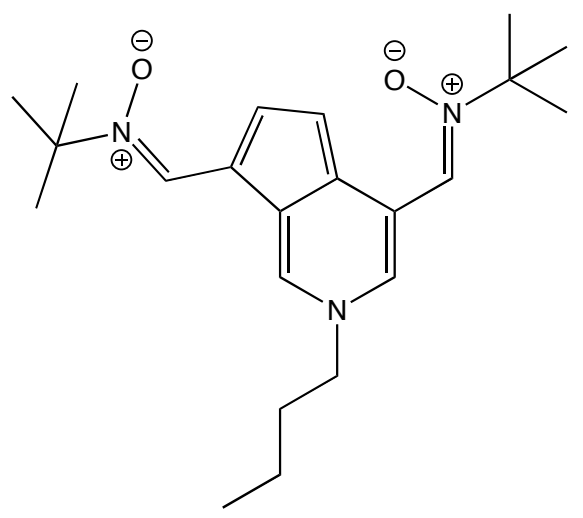

(63)

2-butyl-cyclopenta[c]pyridine-4,7-dicarbaldehyde

(61) (16 mg, $0.04 \mathrm{mmol})$ was mixed with N-tertbutyl hydroxylamine hydrochloride $(21 \mathrm{mg}, 0.16$ mmol ) and magnesium sulfate (20 $\mathrm{mg}, 0.16 \mathrm{mmol})$ followed by $2 \mathrm{ml}$ of pyridine. The flask was flushed with argon and the reaction mixture was heated at 50 ${ }^{\circ} \mathrm{C}$. After $48 \mathrm{~h}$, silica gel thin layer chromatography

showed no starting material. The product was purified by silica gel column chromatography with hexane/ethyl acetate (7:3) as eluent. $12.5 \mathrm{mg}(46 \%)$ of dinitrone (63) was collected along with a small amount of the mononitrone. $R_{f}=0.23$ (chloroform/methanol 20:1).

${ }^{1}$ H NMR: (400 MHz, $\left.\mathrm{CDCl}_{3}\right): \delta 9.75(\mathrm{~s}, 1 \mathrm{H}), 9.54(\mathrm{~d}, J=1.2 \mathrm{~Hz}, 1 \mathrm{H}), 8.08(\mathrm{~s}, 1 \mathrm{H}), 7.80$ $(\mathrm{d}, J=2.9 \mathrm{~Hz}, 1 \mathrm{H}), 7.72(\mathrm{~s}, 1 \mathrm{H}), 6.63(\mathrm{~d}, J=3.6 \mathrm{~Hz}, 1 \mathrm{H}), 4.17$ (t, $J=7.8 \mathrm{~Hz}, 2 \mathrm{H}), 1.99-1.91$ (m, 2H), $1.66(\mathrm{~s}, 9 \mathrm{H}), 1.63(\mathrm{~s}, 9 \mathrm{H}), 1.39$ (sextet, $J=7.5 \mathrm{~Hz}, 2 \mathrm{H}), 0.95$ (t, $J=7.3 \mathrm{~Hz}, 3 \mathrm{H})$. ${ }^{13}$ C NMR: (400 MHz, $\left.\mathrm{CDCl}_{3}\right): \delta$ 137.68, 136.33, 132.92, 128.33, 126.07, 124.52, $124.43,116.61,111.57,102.54,71.49,67.56,59.81,33.92,28.94,28.67,20.17,13.97$. LRMS: (LC/MS-APCI, MeOH) m/e $372.3\left(\mathrm{MH}^{+}\right)$ 


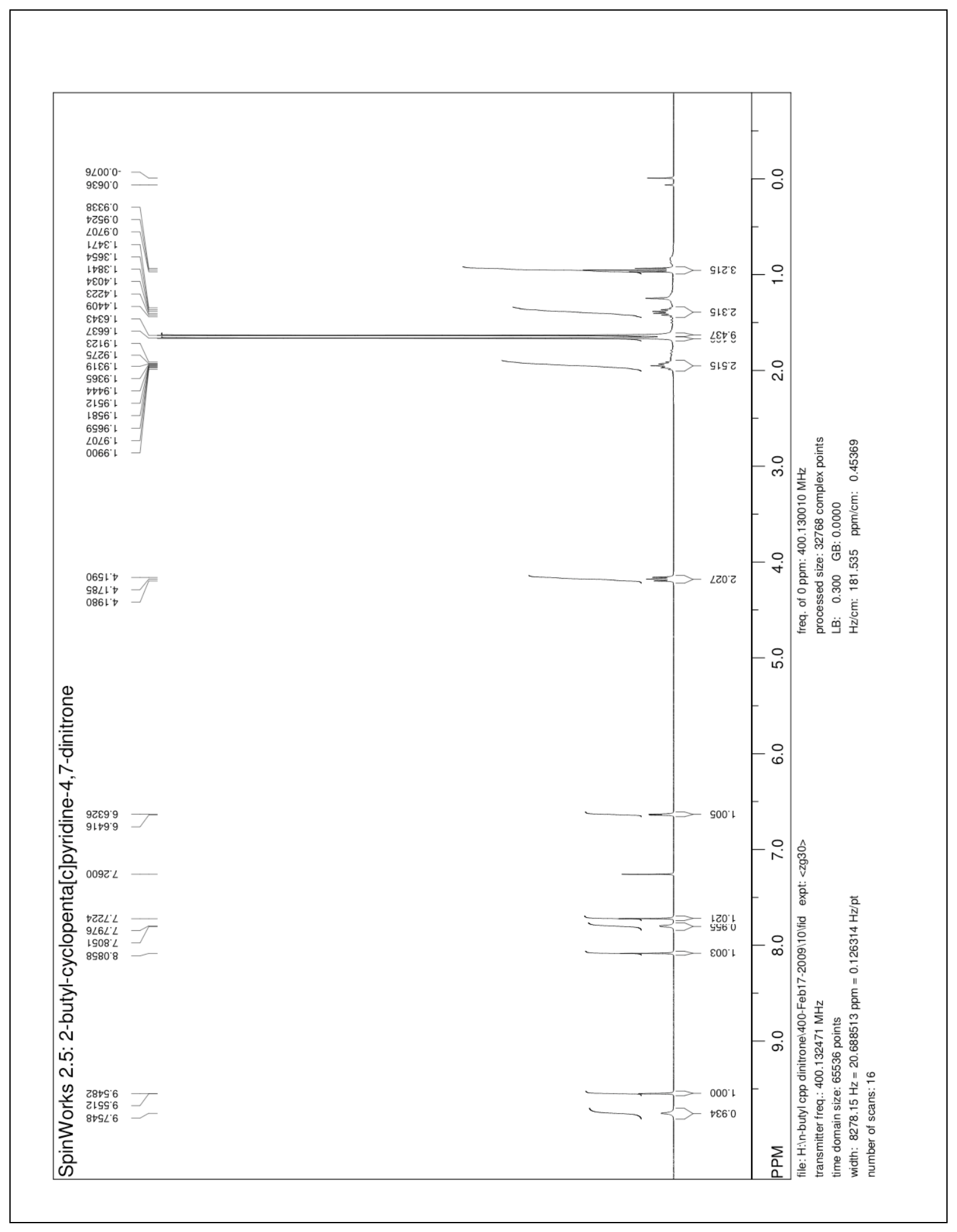




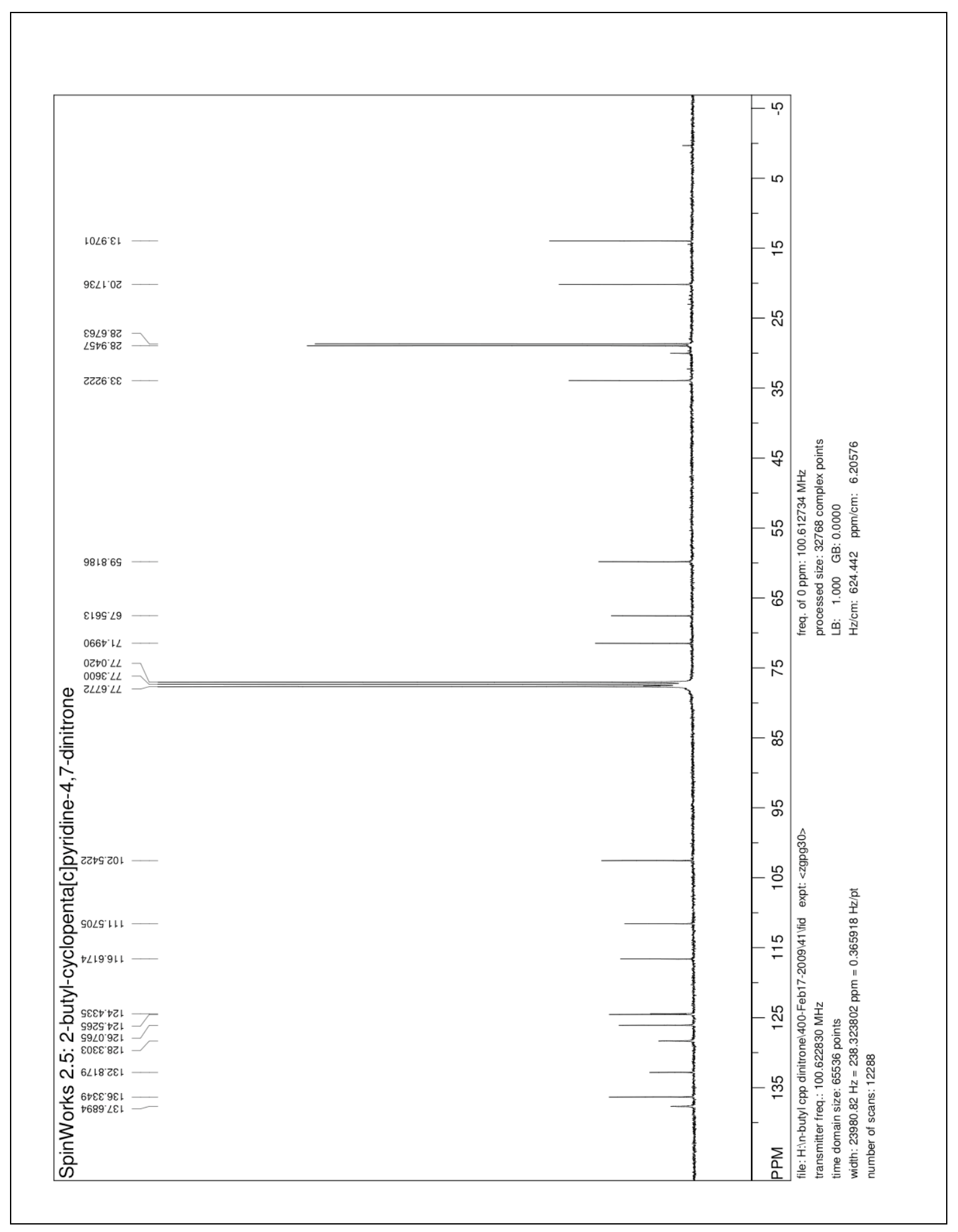




\section{[5.1.4] Synthesis of 5-bromo-2-butyl-cylopenta[c]pyridine-4,7-dicarbaldehyde (65):}

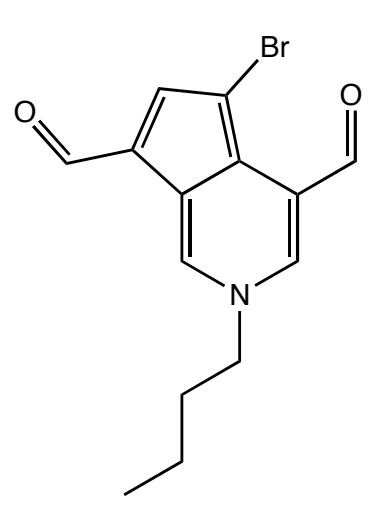

(65)

2-butyl-cyclopenta[c]pyridine-4,7-dicarbaldehyde (61) (40 mg, $0.17 \mathrm{mmol}$ ) and $N$-bromosuccinimide $(31 \mathrm{mg}, 0.17 \mathrm{mmol})$ were dissolved in $1 \mathrm{ml}$ of diethyl ether. Reaction was carried out under argon at room temperature. After $30 \mathrm{~min}$, silica gel thin layer chromatography showed no reactant and product was purified by silica gel column chromatography using hexane/ethyl acetate (7:3) as eluent. $41 \mathrm{mg}(76 \%)$ of product was collected. $\mathrm{R}_{\mathrm{f}}=0.15$ (hexane/ethyl acetate 7:3).

${ }^{1} \mathbf{H}$ NMR (400 MHz, $\left.\mathrm{CDCl}_{3}\right): \delta 11.42(\mathrm{~s}, 1 \mathrm{H}), 9.84(\mathrm{~s}, 1 \mathrm{H}), 9.07(\mathrm{~d}, J=1.6,1 \mathrm{H}), 8.08(\mathrm{~d}$, $J=1.6,1 \mathrm{H}), 7.80(\mathrm{~s}, 1 \mathrm{H}), 4.27(\mathrm{t}, J=7.6 \mathrm{~Hz}, 2 \mathrm{H}), 1.99-1.91(\mathrm{~m}, 2 \mathrm{H}), 1.44-1.34(\mathrm{~m}, 2 \mathrm{H})$, 1.00-0.96 (m, 3H). ${ }^{13} \mathbf{C}$ NMR (400 MHz, $\left.\mathrm{CDCl}_{3}\right): \delta 189.07,184.26,144.86,134.55$, $130.70,128.64,127.58,122.31,120.65,91.09,59.60,33.52,19.81,13.49$. LRMS: (LC/MS-APCI, MeOH) m/e $308.0\left(\mathrm{MH}^{+}\left[{ }^{79} \mathrm{Br}\right]\right), 310.0\left(\mathrm{MH}^{+}\left[{ }^{81} \mathrm{Br}\right]\right)$. 


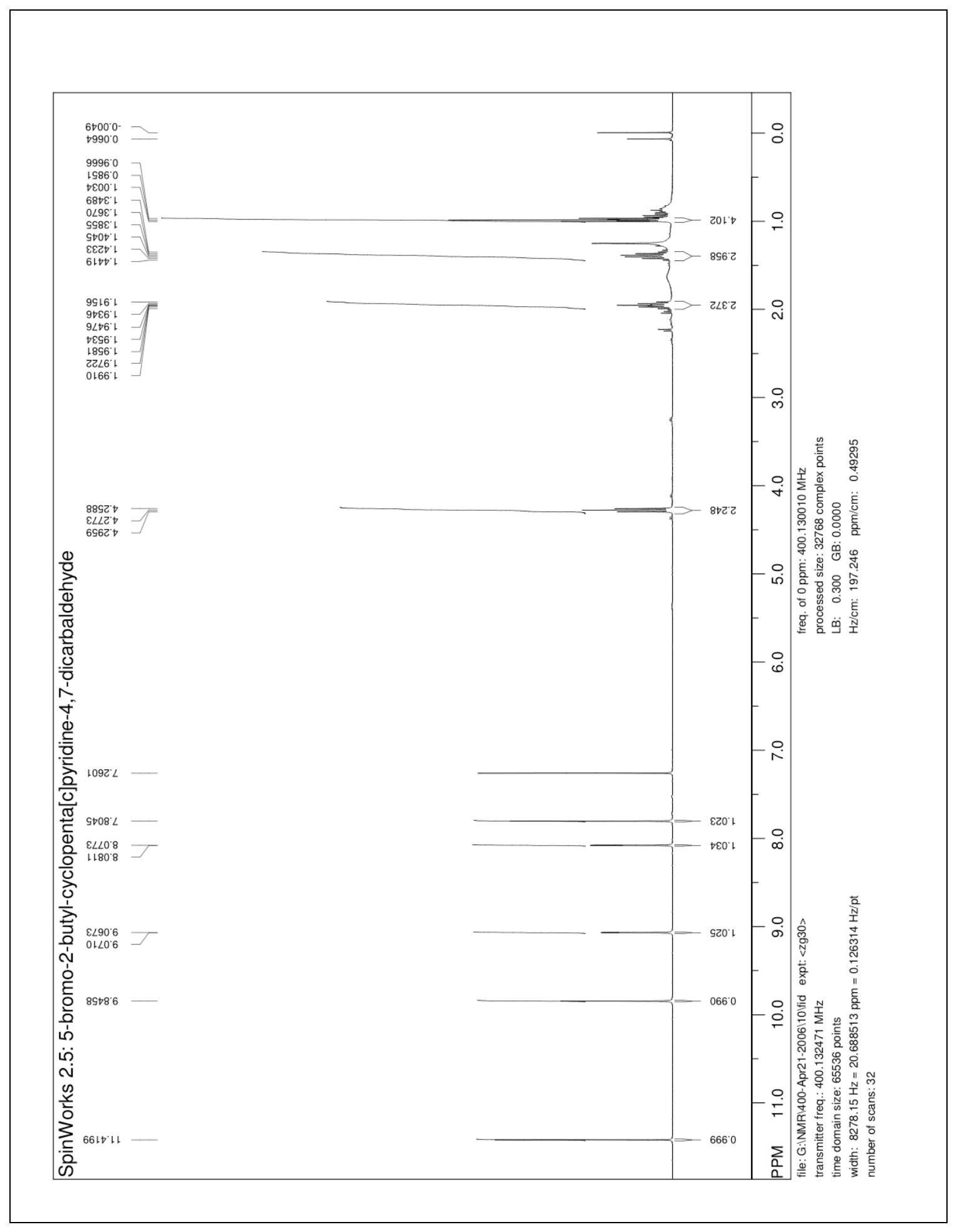




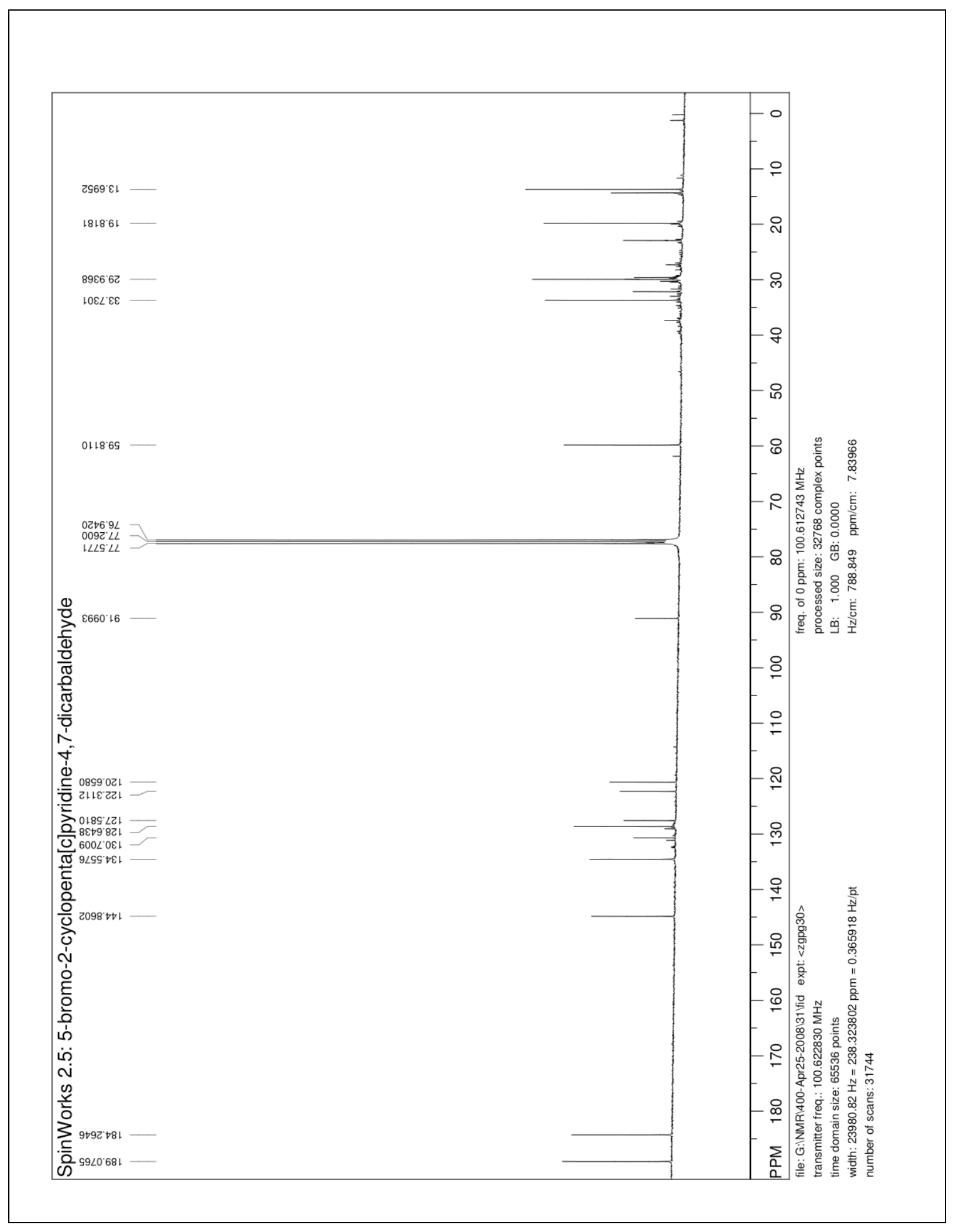




\section{[5.1.5] Synthesis of 2-butyl-5-ethylthio-cyclopenta[c]pyridine-4,7-dicarbaldehyde}

(92):

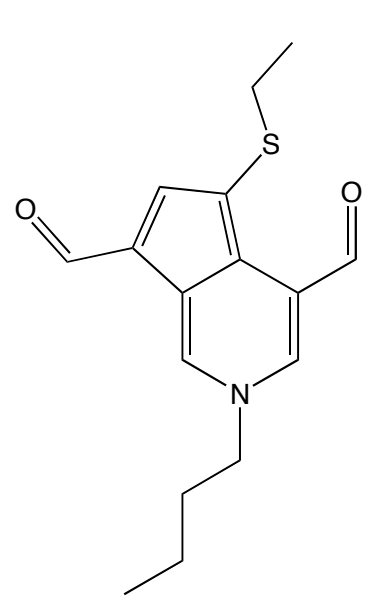

(92) 2-butyl-cyclopenta[c]pyridine-4,7-dicarbaldehyde (61) (48 mg, $0.21 \mathrm{mmol}$ ) was dissolved in $10 \mathrm{ml}$ of dry hexane and $0.5 \mathrm{ml}$ of dry methylene chloride and was cooled to $-70^{\circ} \mathrm{C}$ while under argon. Ethyl sulfenyl chloride (93) (2.2 $\mathrm{ml}, 0.22 \mathrm{mmol})$ solution in methylene chloride was added slowly over a period of $30 \mathrm{~min}$ with vigorous stirring and evacuation. After all the ethyl sulfenyl chloride solution was added, the mixture was stirred for additional 30 min and then slowly brought back to room temperature over a period of $60-90 \mathrm{~min}$. The red solution turned green. A layer of chloform was added and the reaction mixture was extracted with a saturated solution of sodium carbonate. The chloroform layer became red. The chloroform layer was concentrated to thick red/brown oil and purified with silica gel column chromatography with hexane/ethyl acetate (7:3) as eluent. $15 \mathrm{mg}$ (25\%) of product (92) was collected. $\mathrm{R}_{\mathrm{f}}=0.14$ (hexane/ethyl acetate 7:3).

${ }^{1} \mathbf{H}$ NMR (400 MHz, CDCl $): \delta 11.67(\mathrm{~s}, 1 \mathrm{H}), 9.87(\mathrm{~s}, 1 \mathrm{H}), 9.06(\mathrm{~d}, J=1.5 \mathrm{~Hz}, 1 \mathrm{H}), 8.06$ (d, $J=1.6 \mathrm{~Hz}, 1 \mathrm{H}), 7.90(\mathrm{~s}, 1 \mathrm{H}), 4.27$ (t, $J=7.4 \mathrm{~Hz}, 2 \mathrm{H}), 2.77$ (q, $J=7.3 \mathrm{~Hz}, 2 \mathrm{H}), 1.99-1.92$ (m, 2H), 1.45-1.35 (m, 2H), $1.22(\mathrm{t}, J=7.3 \mathrm{~Hz}, 3 \mathrm{H}), 0.98(\mathrm{t}, J=7.3 \mathrm{~Hz}, 3 \mathrm{H})$.

LRMS: (LC/MS-APCI, MeOH) m/e $290.1\left(\mathrm{MH}^{+}\right)$. 


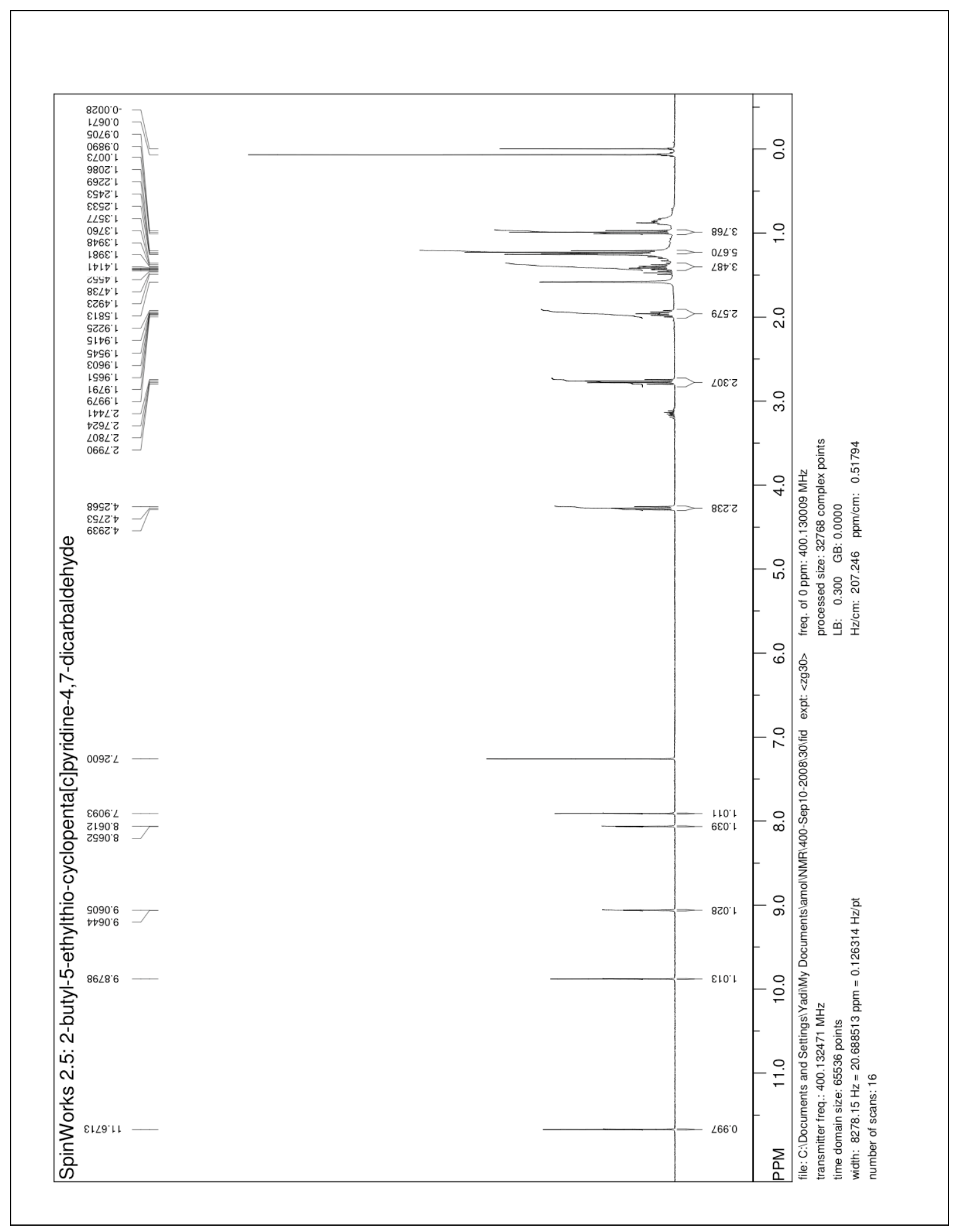




\section{[5.1.6] Synthesis of 2-butyl-5-ethylthio-cyclopenta[c]pyridine-4,7-dinitrone (94):}

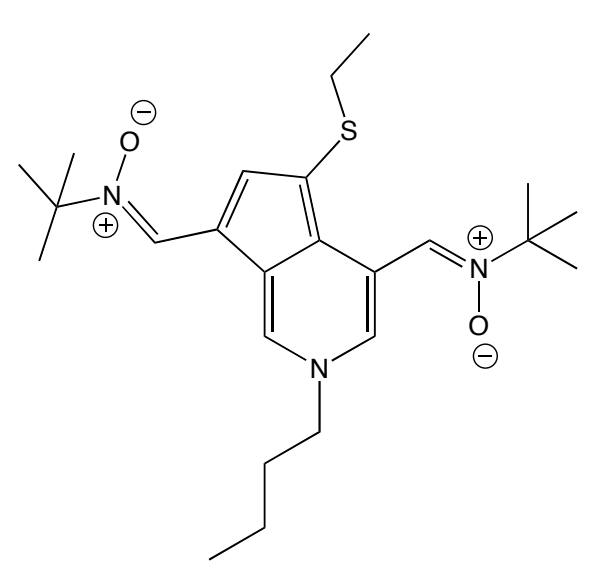

(94)

2-butyl-5-ethylthio-cyclopenta[c]pyridine-4,7dicarbaldehyde (92) (13 mg, $0.04 \mathrm{mmol})$ was mixed with N-t-butylhydroxylamine hydrochloride $(28 \mathrm{mg}$,

$0.22 \mathrm{mmol})$ and magnesium sulfate $(26.8 \mathrm{mg}, 0.22$ mmol) in $1.5 \mathrm{ml}$ of pyridine. This reaction mixture was stirred at $35^{\circ} \mathrm{C}$ under argon for $72 \mathrm{~h}$ after which it was partitioned between a saturated solution of

sodium carbonate and chloroform. The chloroform layer was concentrated and the resulting mixture was purified by silica gel column chromatography. Initial eluent was hexane/ethyl acetate (8:2) and $4 \mathrm{mg}(25 \%)$ of mononitrone was collected, after which the solvent system was changed to hexane/acetone (6:4) to collect $5 \mathrm{mg}(26 \%)$ of dinitrone (94). The product seems to undergo one electron oxidation in the presence of air. Therefore it was extracted with saturated solution of sodium thiosulfate before storage. $\mathrm{R}_{\mathrm{f}}=0.33$ (chloroform/methanol 20:1)

${ }^{1}$ H NMR (400 MHz, $\left.\mathrm{CDCl}_{3}\right): \delta 10.00(\mathrm{~s}, 1 \mathrm{H}), 9.85(\mathrm{~d}, J=1.2 \mathrm{~Hz}, 1 \mathrm{H}), 9.63(\mathrm{~s}, 1 \mathrm{H}), 7.88$ (s, 1H), 7.66 (s, 1H), 4.17 (t, J=7.8 Hz, 2H), 2.68 (q, J=7.3 Hz, 2H), 1.99-1.92 (m, 2H), $1.68(\mathrm{~s}, 9 \mathrm{H}), 1.63(\mathrm{~s}, 9 \mathrm{H}), 1.43-1.37(\mathrm{~m}, 2 \mathrm{H}), 1.14(\mathrm{t}, J=7.3 \mathrm{~Hz}, 3 \mathrm{H}), 0.96(\mathrm{t}, J=7.3 \mathrm{~Hz}$ 3H). ${ }^{13} \mathrm{C}$ NMR (400 MHz, $\left.\mathrm{CDCl}_{3}\right): \delta 144.05,136.56,131.59,127.15,126.69,126.36$, $125.88,118.43,111.42,106.06,71.87,68.05,59.83,33.86,30.55,28.94,28.79,20.18$, 15.08, 13.96. LRMS: (LC/MS-APCI, MeOH) m/e 432.1 $\left(\mathrm{MH}^{+}\right)$. 


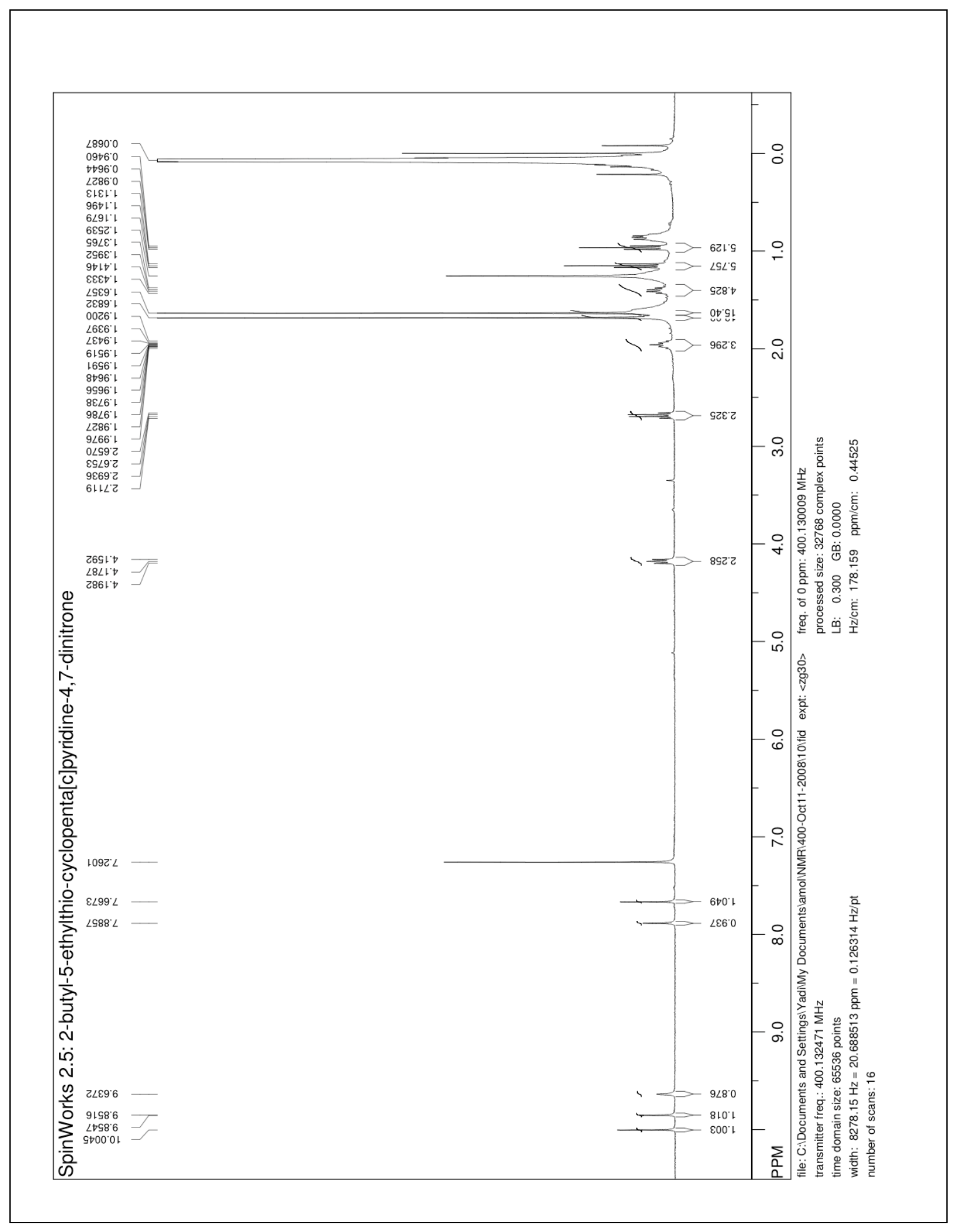




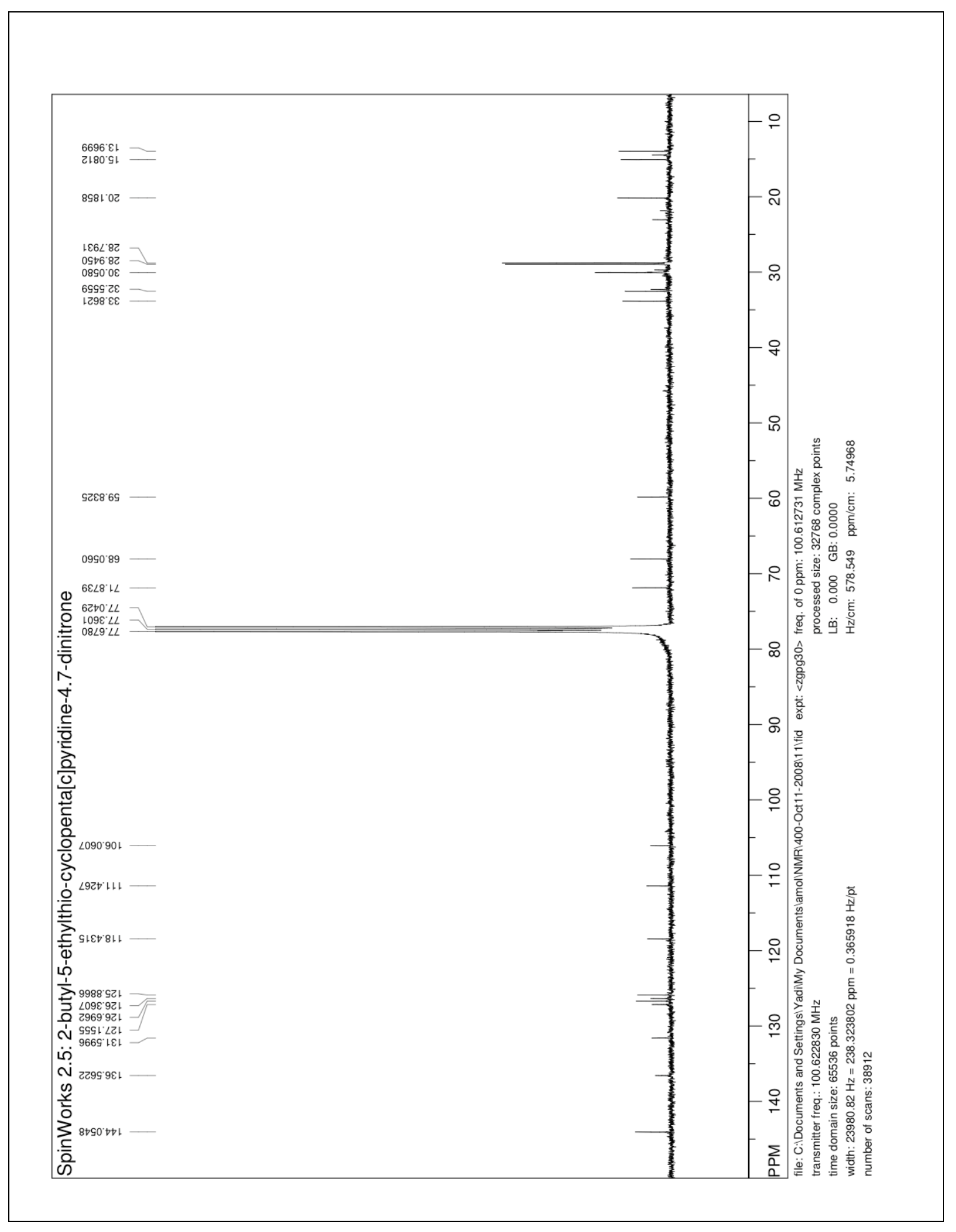




\section{[5.1.7] Synthesis of 2-(propyl imidazole)-cyclopenta[c]pyridine-4,7-dicarbaldehyde}

(71):

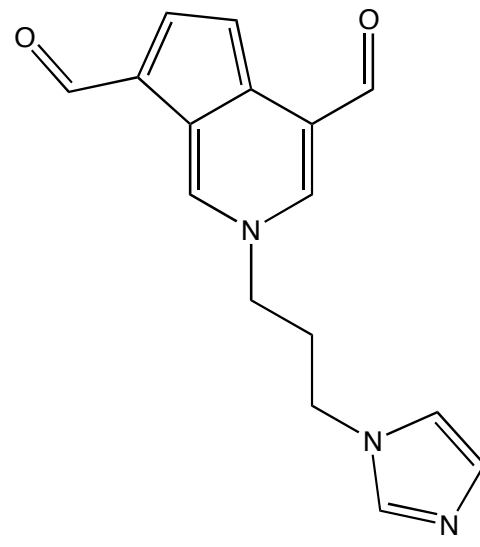

(71)
Baldrinal (60) (2.0 g, $8.61 \mathrm{mmol})$ was dissolved in $4 \mathrm{ml}$ of chloroform. To this solution, 1-(3-aminopropyl)-imidazole (2.15 g, $17 \mathrm{mmol})$ was added. After stirring for $10 \mathrm{~min}$ at room temperature, the color changed from yellow to red and silica gel thin layer chromatography showed no baldrinal. The product was purified by silica gel column chromatography. The eluent for this system was triethylamine/methanol/chloroform (2:1:100). $229 \mathrm{mg}$

(8.8\%) of red product (71) was collected. $\mathrm{R}_{\mathrm{f}}=0.21$ (chloroform/methanol 99:1).

${ }^{1}$ H NMR (400 MHz, CDCl $)$ ): $\delta 10.21$ (s, 1H), $9.91(\mathrm{~s}, 1 \mathrm{H}), 9.00$ (s, 1H), 7.99 (d, J=3.6, 1H), 7.73 (d, $J=1.2 \mathrm{~Hz}, 1 \mathrm{H}), 7.50$ (s, 1H), 7.24 (d, $J=3.6 \mathrm{~Hz}, 1 \mathrm{H}), 7.12$ (s, 1H), 6.95 (s, 1H), 4.27 (t, $J=7.0 \mathrm{~Hz}, 2 \mathrm{H}), 4.07$ (t, $J=7.0 \mathrm{~Hz}, 2 \mathrm{H}$ ), 2.51 (quintet, $J=7.0,2 \mathrm{H}$ ). LRMS: (LC/MS-APCI, MeOH) m/e $282.1\left(\mathrm{MH}^{+}\right)$. 


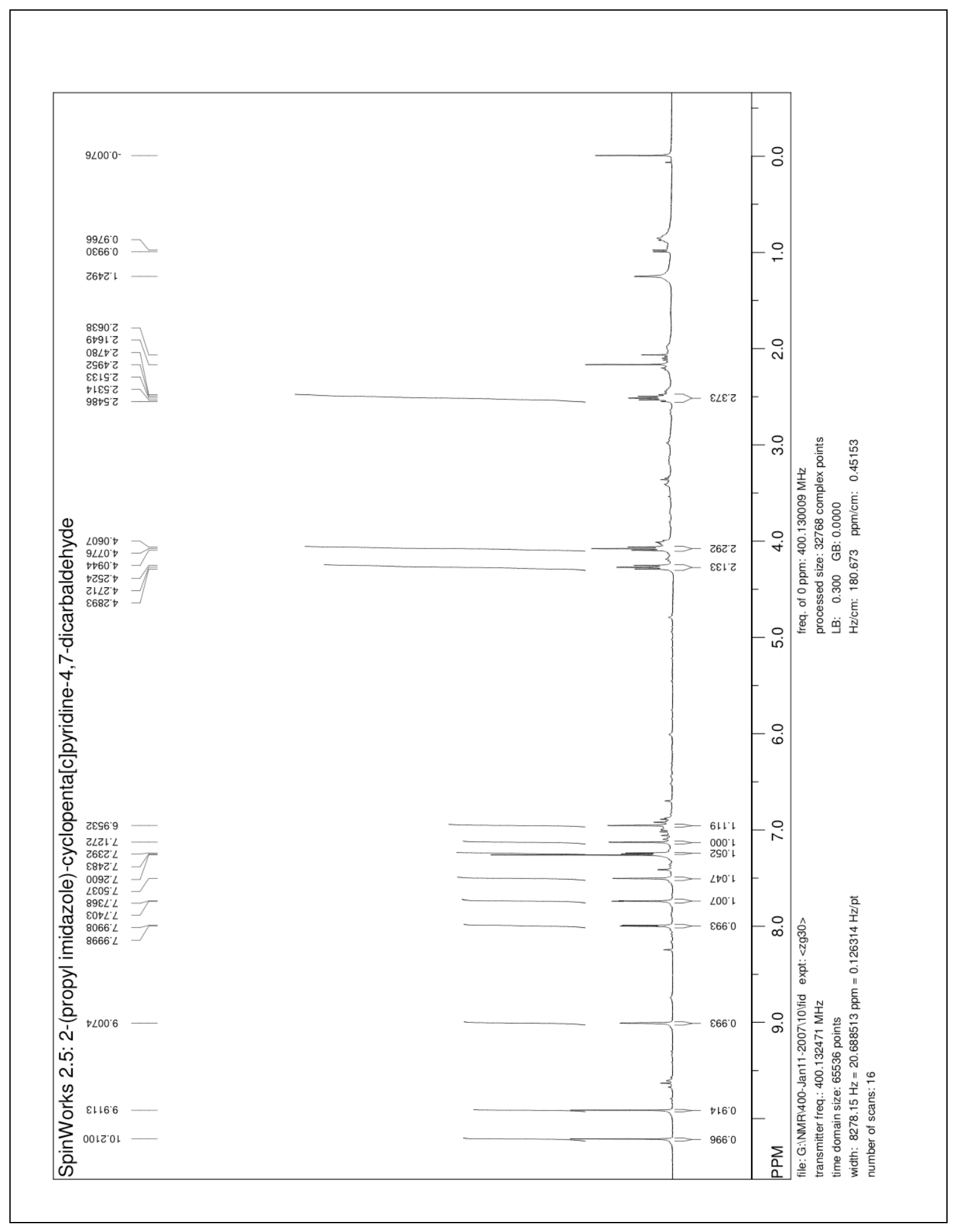




\section{[5.1.8] Synthesis of 2-(propyl imidazole)-cyclopenta[c]pyridine-4,7-dinitrone (72):}

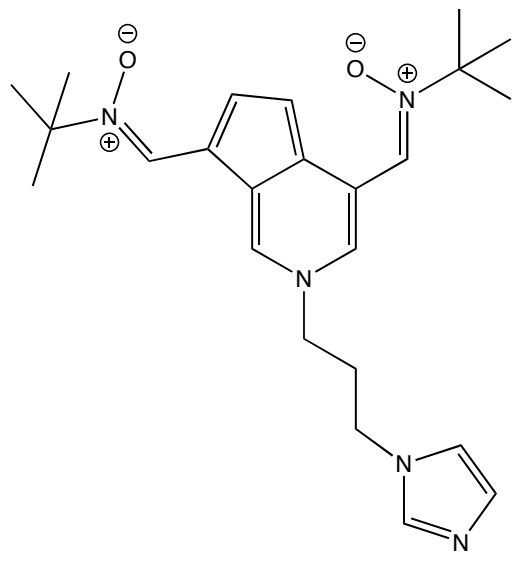

(72)

2-(propyl-imidazole)-cyclopenta[c]pyridine-4,7dicarbaldehyde (71) $(12.6 \mathrm{mg}, \quad 0.04 \mathrm{mmol})$ was mixed with N-tert-butyl hydroxylamine $(22.5 \mathrm{mg}, 0.18 \mathrm{mmol})$ and magnesium sulfate $(22 \mathrm{mg}, 0,18 \mathrm{mmol})$ in $2 \mathrm{ml}$ of anhydrous pyridine. The reaction mixture was heated at $50{ }^{\circ} \mathrm{C}$ for $48 \mathrm{~h}$ under argon. When silica gel thin layer chromatography showed no starting material (71),

product was purified by silica gel column chromatography. The eluent for this system was triethylamine/methanol/chloroform (2:2:100). $9.1 \mathrm{mg}(48 \%)$ of red product (72) was collected. $R_{\mathrm{f}}=0.25$ (chloroform/methanol 9:1).

${ }^{1} \mathbf{H}$ NMR $\left(400 \mathrm{MHz}, \mathrm{CDCl}_{3}\right): \delta 9.87(\mathrm{~s}, 1 \mathrm{H}), 9.53(\mathrm{~d}, J=0.7 \mathrm{~Hz}, 1 \mathrm{H}), 8.06(\mathrm{~s}, 1 \mathrm{H}), 7.74$ (s, 1H), $7.73(\mathrm{~s}, 1 \mathrm{H}), 7.60(\mathrm{~s}, 1 \mathrm{H}), 7.08(\mathrm{~s}, 1 \mathrm{H}), 7.013(\mathrm{~s}, 1 \mathrm{H}), 6.65(\mathrm{~d}, J=3.6,1 \mathrm{H}), 4.19(\mathrm{t}$, $J=7.0,2 \mathrm{H}), 4.01$ (t, $J=7.0,2 \mathrm{H}), 2.45$ (quintet, $J=7.0,2 \mathrm{H}$ ), 1.65 (s, 9H), 1.62 (s, 9H). ${ }^{13} \mathbf{C}$ NMR (400 MHz, $\left.\mathrm{CDCl}_{3}\right): \delta 138.01,136.97,132.79,130.31,129.27,125.70,124.50$, $123.93,119.21,117.00,111.81,103.33,77.56,71.68,67.66,56.33,32.88,28.85,28.62$. LRMS: (LC/MS-APCI, MeOH) m/e 424.2 $\left(\mathrm{MH}^{+}\right)$. 


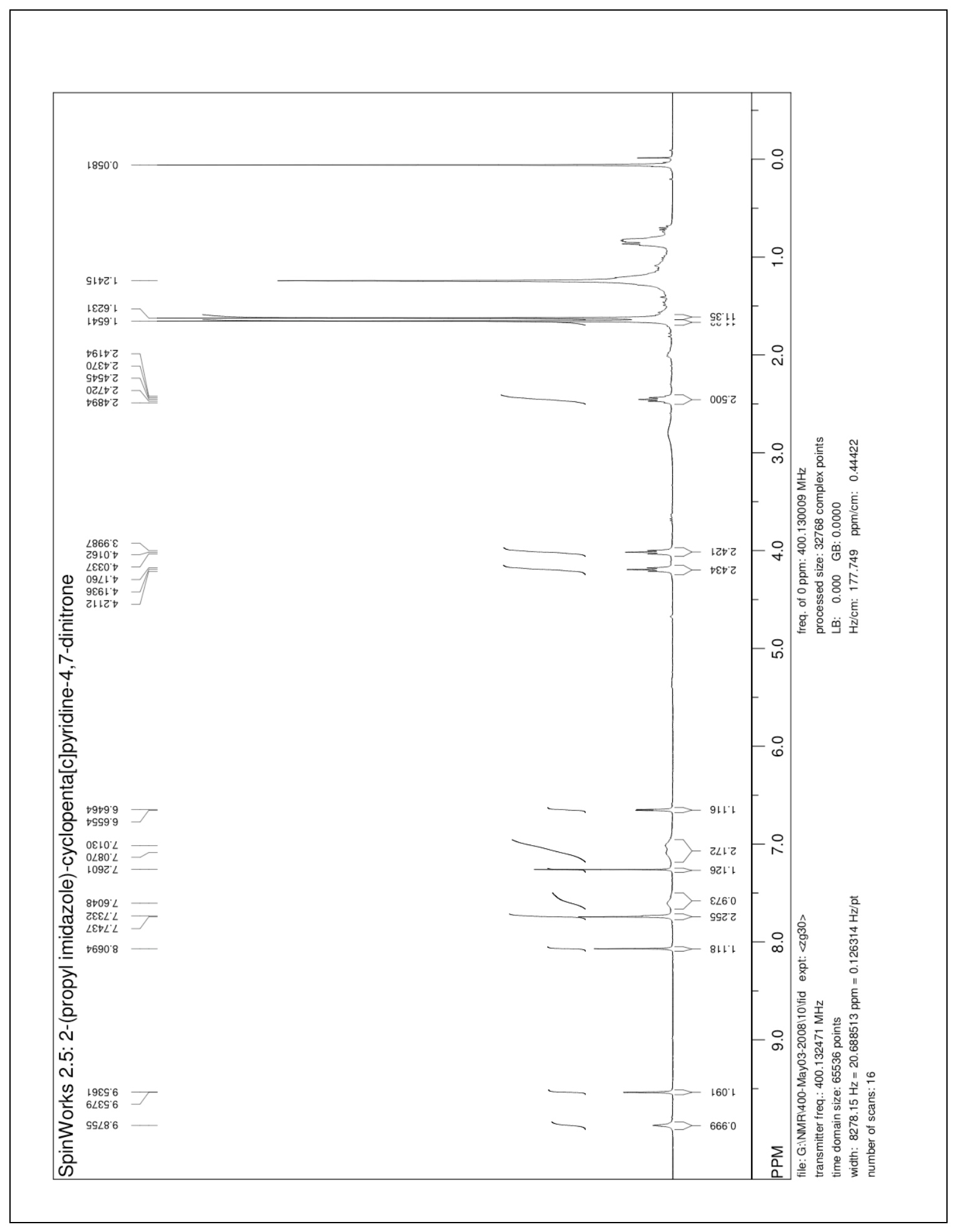




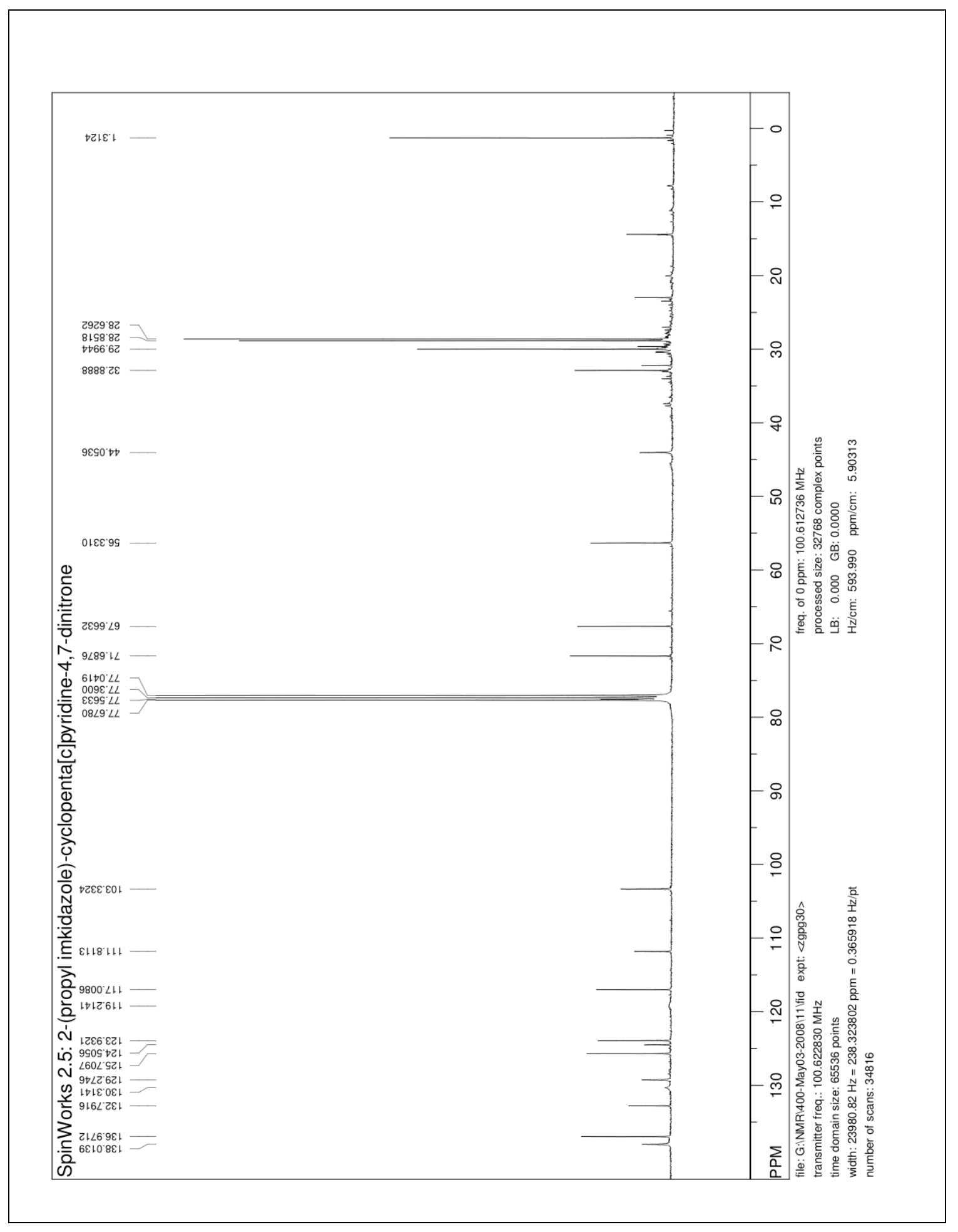




\section{[5.1.9] Synthesis of 2-(3-(dimethylamino)propyl)-cyclopenta[c]pyridine-4,7-}

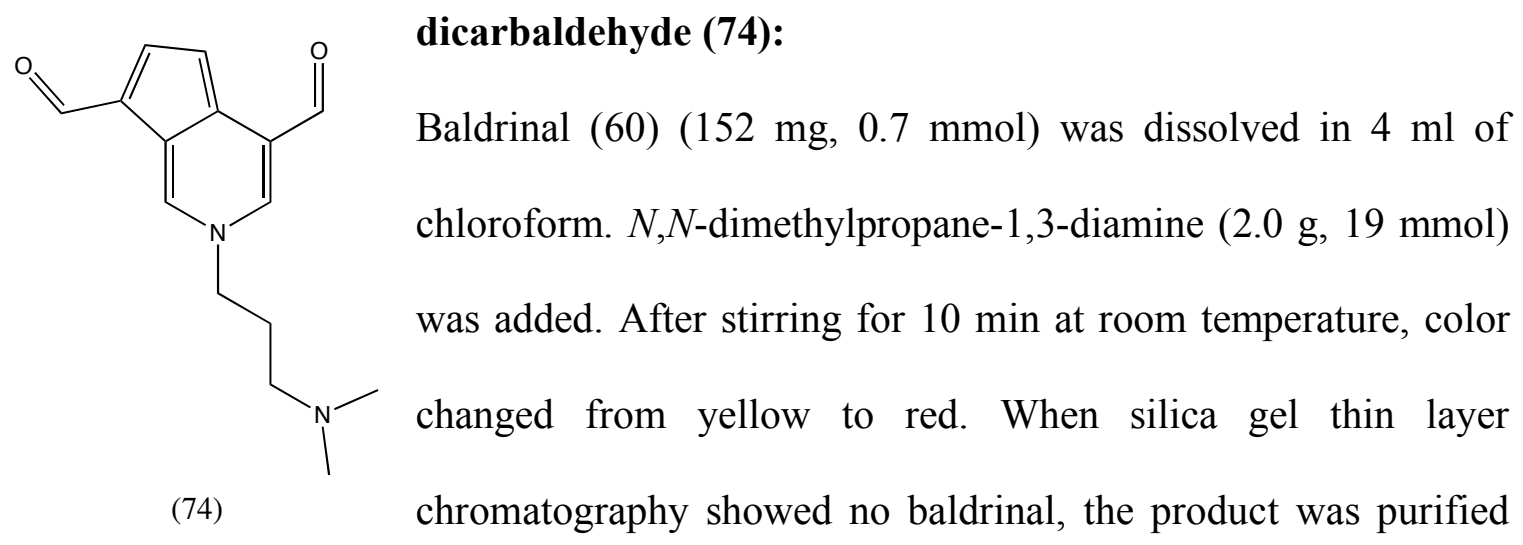

by silica gel column chromatography using chloroform/methanol (50:1) as eluent. After purification, $40 \mathrm{mg}(22 \%)$ of product was collected. $\mathrm{R}_{\mathrm{f}}=0.26$ (chloroform $/$ methanol 99:1).

${ }^{1}$ H NMR: $\left(400 \mathrm{MHz}, \mathrm{CDCl}_{3}\right): \delta 10.23(\mathrm{~s}, 1 \mathrm{H}), 9.92(\mathrm{~s}, 1 \mathrm{H}), 9.08(\mathrm{~s}, 1 \mathrm{H})$, 7.98-7.97 (m, 2H), 7.24 (d, $J=3.6 \mathrm{~Hz}, 1 \mathrm{H}), 4.42(\mathrm{t}, J=6.5 \mathrm{~Hz}, 2 \mathrm{H}), 2.23$ (s, 6H), 2.21 (t, $J=6.2 \mathrm{~Hz}, 2 \mathrm{H})$, 2.08 (quintet, $J=6.3 \mathrm{~Hz}, 2 \mathrm{H})$. LRMS: (LC/MS-APCI, MeOH) m/e $259.1\left(\mathrm{MH}^{+}\right)$. 


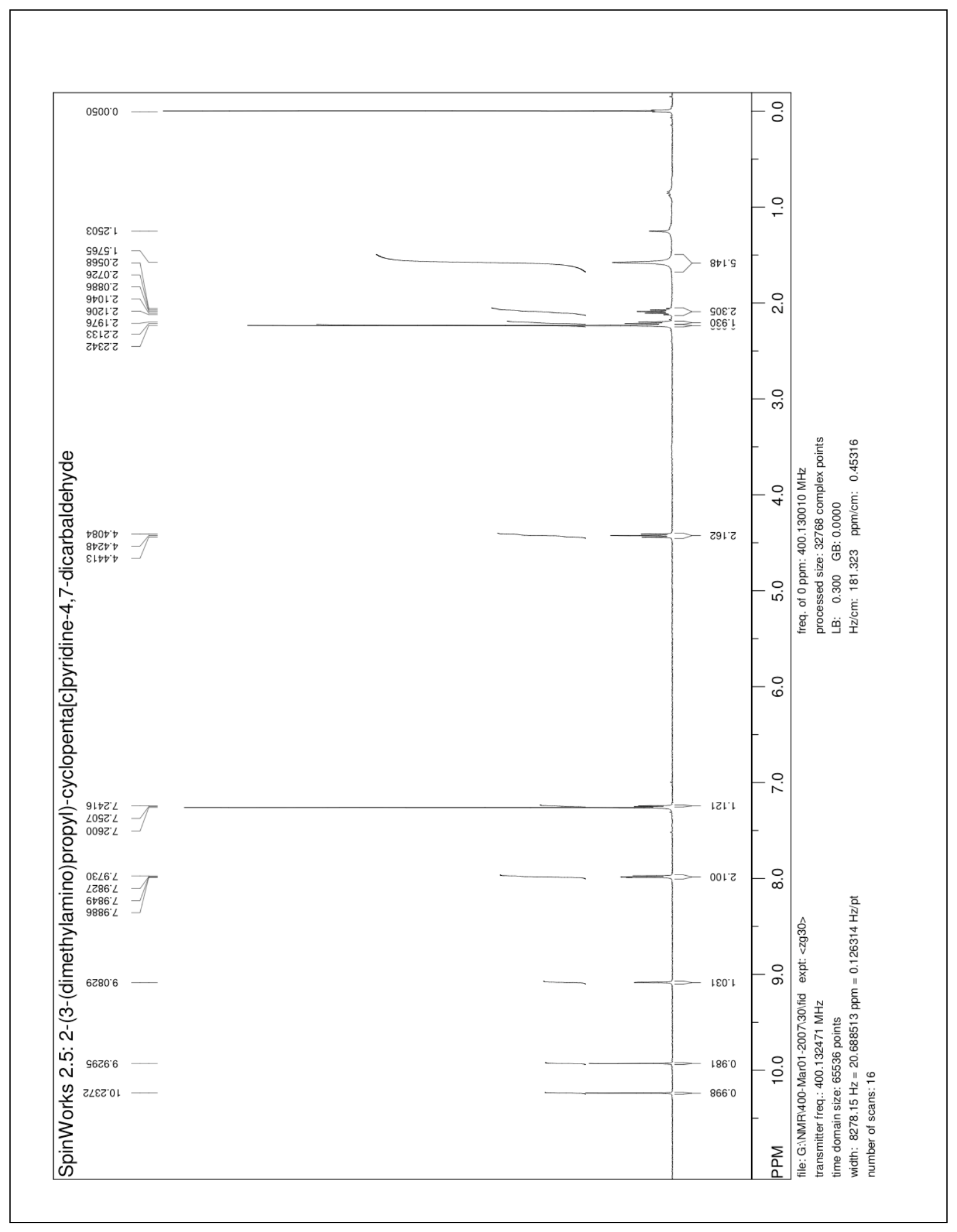




\section{[5.2.0] Synthesis of 2-(3-(dimethylamino)propyl)-cyclopenta[c]pyridine-4,7-dinitrone}

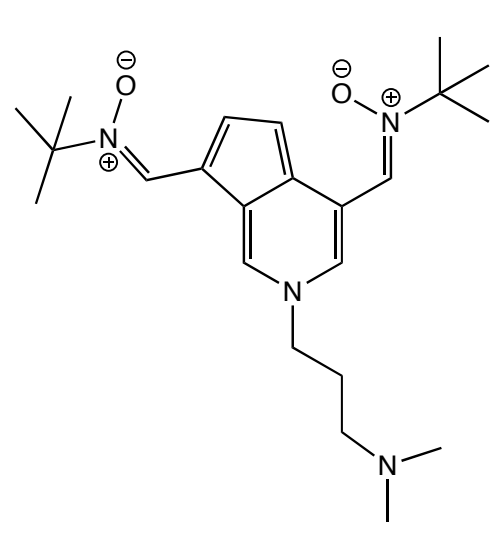

(75)

(75):

2-(3-(dimethylamino)propyl-cyclopenta[c]pyridine-4,7dicarbaldehyde (74) (34 mg, $0.13 \mathrm{mmol})$ was mixed with N-tert-butyl hydroxylamine $(66.1 \mathrm{mg}, 0.52 \mathrm{mmol})$ and magnesium sulfate $(63.3 \mathrm{mg}, 0.52 \mathrm{mmol})$ in $2 \mathrm{ml}$ of pyridine. The reaction mixture was heated at $50{ }^{\circ} \mathrm{C}$ for 48 $\mathrm{h}$ under argon. Silica gel thin layer chromatography showed some mono nitrone. The product was purified by silica gel column chromatography. The eluent for this system was triethylamine/methanol/chloroform (2:2:100) After purification, $30 \mathrm{mg}(57 \%)$ of red product collected. $\mathrm{R}_{\mathrm{f}}=0.26$ (chloroform/methanol 9:1)

${ }^{1}$ H NMR $\left(400 \mathrm{MHz}, \mathrm{CDCl}_{3}\right): \delta 9.55(\mathrm{~s}, 1 \mathrm{H}), 9.54(\mathrm{~s}, 1 \mathrm{H}), 8.08(\mathrm{~s}, 1 \mathrm{H}), 7.99$ (d, J=2.7 Hz, 1H), $7.74(\mathrm{~s}, 1 \mathrm{H}), 6.64(\mathrm{~d}, J=3.5 \mathrm{~Hz}, 2 \mathrm{H}), 4.27(\mathrm{t}, J=7.1 \mathrm{~Hz}, 2 \mathrm{H}), 2.29(\mathrm{t}, J=6.7 \mathrm{~Hz}, 2 \mathrm{H})$, $2.23(\mathrm{~s}, 6 \mathrm{H}), 2.0$ (quintet, $J=6.9 \mathrm{~Hz}, 2 \mathrm{H}), 1.65(\mathrm{~s}, 9 \mathrm{H}), 1.62(\mathrm{~s}, 9 \mathrm{H}) .{ }^{13} \mathbf{C}$ NMR $(400 \mathrm{MHz}$, $\left.\mathrm{CDCl}_{3}\right): \delta 136.62,136.17,132.54,127.71,125.93,124.80,124.61,116.67,111.43$ 102.80, 71.49, 67.60, 57.28, 55.72, 45.53, 30.01, 28.89, 28.65. LRMS: (LC/MS-APCI, $\mathrm{MeOH}) m / e 401.5\left(\mathrm{MH}^{+}\right)$. 


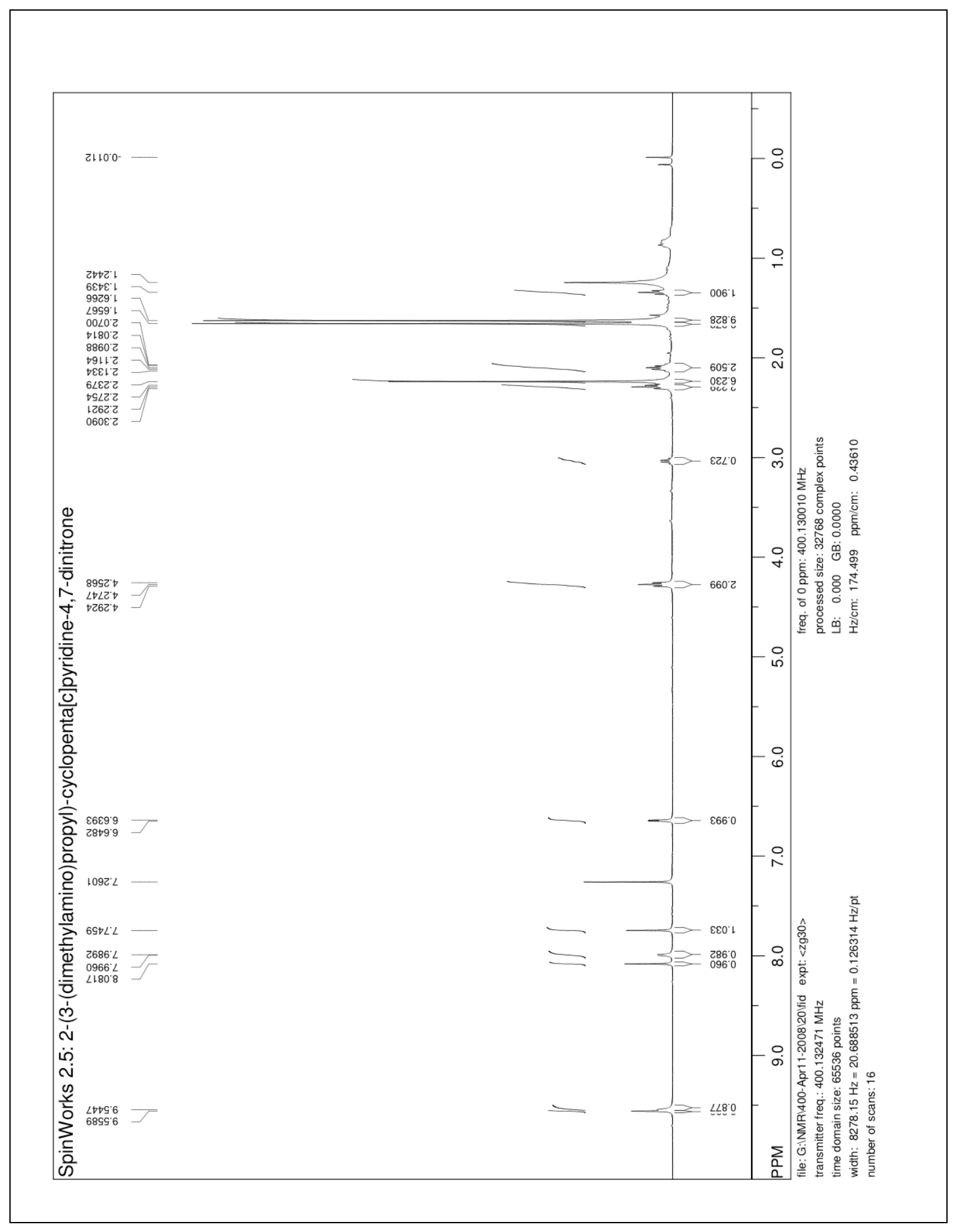




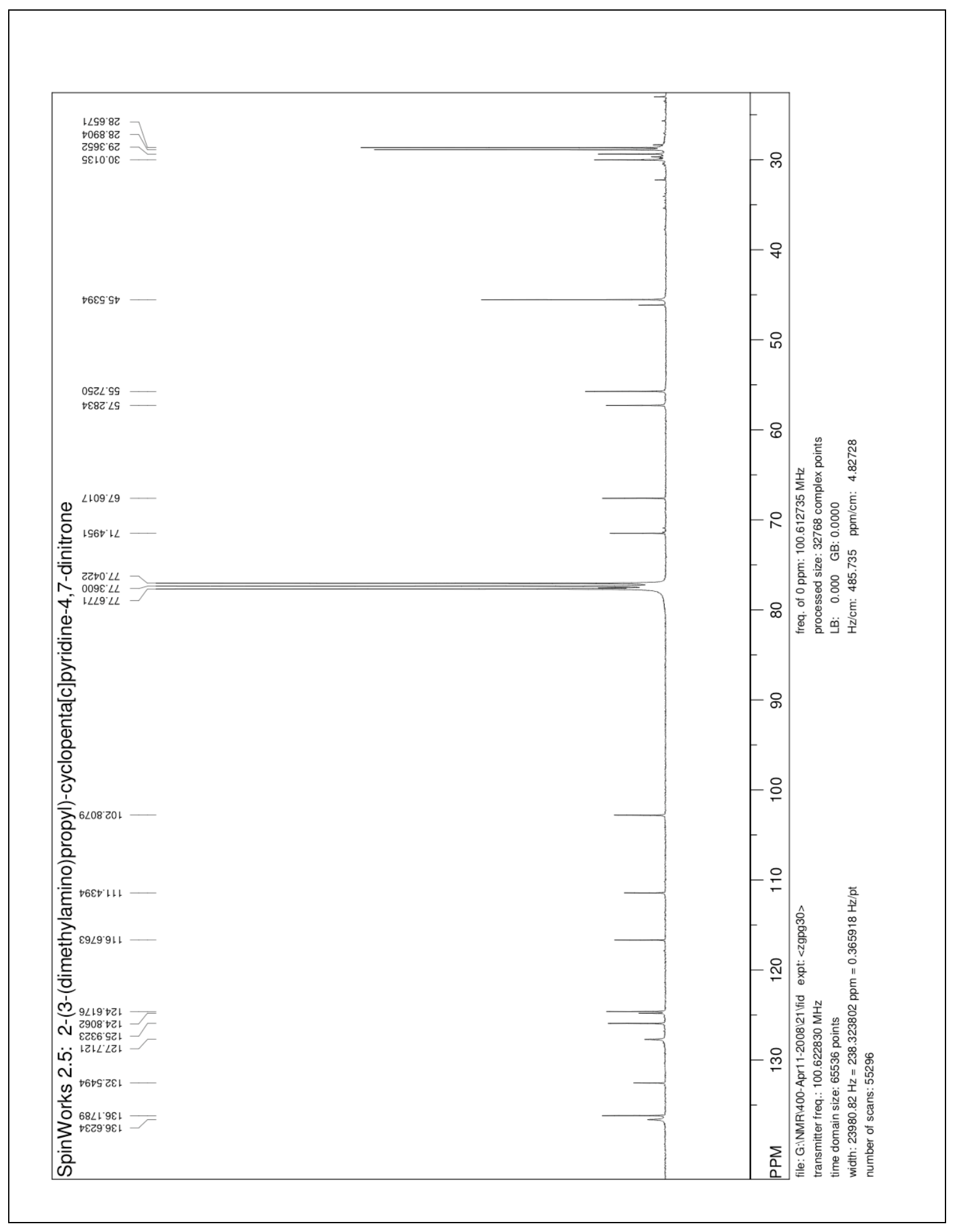




\section{[5.2.1] Synthesis of 2-octadecylamine-cyclopenta[c]pyridine-4,7-dicarbaldehyde}

(87):

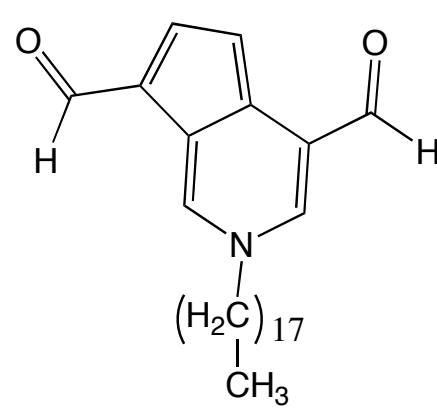

(87)
Baldrinal (60) (620 $\mathrm{mg}, 2.84 \mathrm{mmol})$ was reacted with octadecylamine $(1.45 \mathrm{~g}, 5.38 \mathrm{mmol})$ in $6 \mathrm{ml}$ of chloroform. After stirring for $15 \mathrm{~min}$ at room temperature, the solution turned thick red. When the starting material had disappeared, as determined by thin layer silica gel chromatography, the product was purified by silica gel column chromatography

using hexane/ethyl acetate (7:3) as eluent. $72 \mathrm{mg}(6 \%)$ of orange product (87) was collected. $\mathrm{R}_{\mathrm{f}}=0.17$ (chloroform/methanol 99:1).

${ }^{1} \mathbf{H}$ NMR (400 MHz, CDCl $): \delta 10.25(\mathrm{~s}, 1 \mathrm{H}), 9.92(\mathrm{~s}, 1 \mathrm{H}), 9.03$ (s, 1H), 7.97 (d, J=3.7 Hz, 1H), 7.84 (d, $J=1.4 \mathrm{~Hz}, 1 \mathrm{H}), 7.23$ (d, $J=3.5 \mathrm{~Hz}, 1 \mathrm{H}), 4.28$ (t, $J=7.4 \mathrm{~Hz}, 2 \mathrm{H}), 2.02-$ $1.94(\mathrm{~m}, 2 \mathrm{H}), 1.24(\mathrm{~m}, 32 \mathrm{H}), 0.89-0.85$ (m, 3H). LRMS: (LC/MS-APCI, MeOH) m/e $426.2\left(\mathrm{MH}^{+}\right)$. 


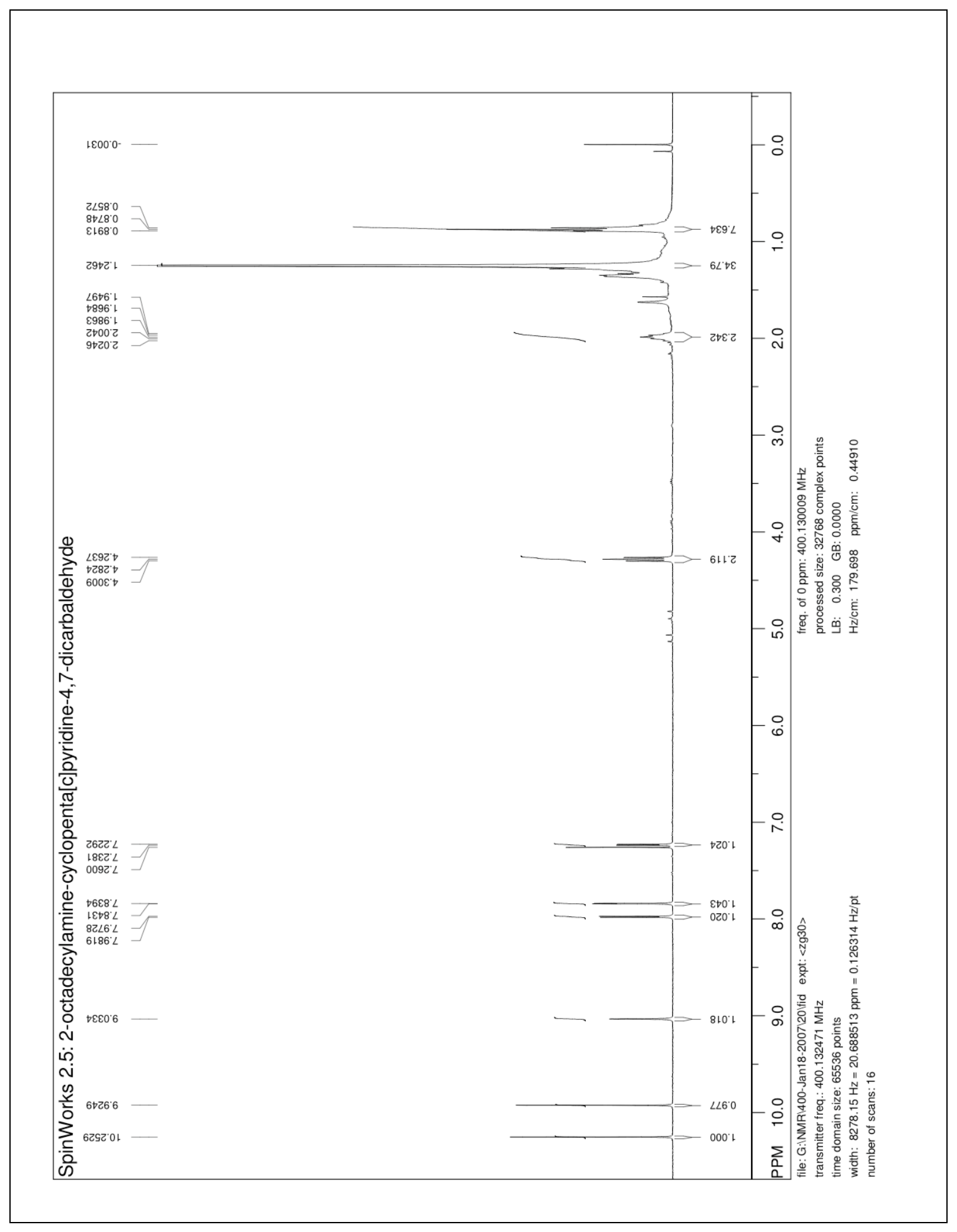




\section{[5.2.2] Synthesis of 2-octadecylamine-cyclopenta[c]pyridine-4,7-dinitrone (88):}

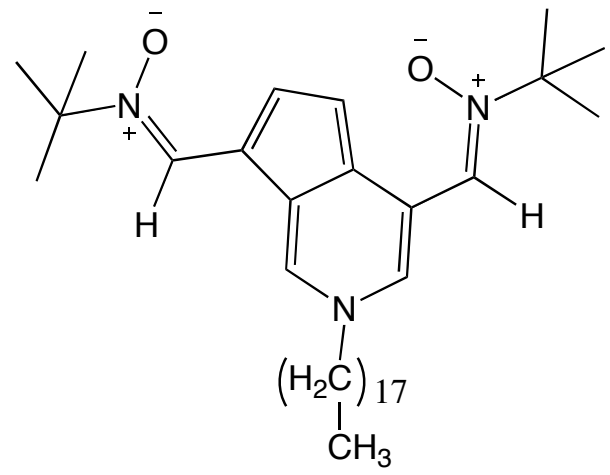

$(88)$ 2-octadecyl-cyclopenta[c]pyridine-4,7dicarbaldehyde (87) (28 $\mathrm{mg}, 0.06 \mathrm{mmol})$ was mixed with N-tert-butyl hydroxylamine $(37 \mathrm{mg}$, $0.3 \mathrm{mmol})$ and magnesium sulfate $(36 \mathrm{mg}, 0.3$ $\mathrm{mmol})$ in $2 \mathrm{ml}$ of pyridine. The reaction was heated at $80^{\circ} \mathrm{C}$ for $48 \mathrm{~h}$. When silica gel thin layer chromatography showed no starting material, the

product was purified by silica gel column chromatography using $\mathrm{CHCl}_{3} / \mathrm{MeOH}(20: 1)$ as eluent. $15 \mathrm{mg}(40 \%)$ of product (88) was collected. $\mathrm{R}_{\mathrm{f}}=0.32$ (chloroform $/$ methanol 20:1).

${ }^{1}$ H NMR (400 MHz, $\left.\mathrm{CDCl}_{3}\right): \delta 9.77(\mathrm{~s}, 1 \mathrm{H}), 9.55(\mathrm{~s}, 1 \mathrm{H}), 8.09$ (s, 1H), 7.79 (d, $J=3.2$ $\mathrm{Hz}, 1 \mathrm{H}), 7.72(\mathrm{~s}, 1 \mathrm{H}), 6.64(\mathrm{~d}, J=3.6 \mathrm{~Hz}, 1 \mathrm{H}), 4.16$ (t, $J=7.8 \mathrm{~Hz}, 2 \mathrm{H}), 1.96$ (quintet, $J=7.3 \mathrm{~Hz}, 2 \mathrm{H}), 1.67$ (s, 9H), 1.64 (s, 9H), 1.25 (m, $30 \mathrm{H}), 0.89-0.85$ (m, 3H).

${ }^{13}$ C NMR (400 MHz, $\left.\mathrm{CDCl}_{3}\right): \delta 137.74,136.28,132.80,128.26,126.07,124.49,124.41$, $116.63,111.62,102.50,71.49,67.56,60.05,32.26,32.05,30.03,29.99,29.92,29.85$, 29.79, 29.69, 29.53, 28.96, 28.68, 26.87, 23.02, 14.44. LRMS: (LC/MS-APCI, MeOH) $m / e 568.2\left(\mathrm{MH}^{+}\right)$. 


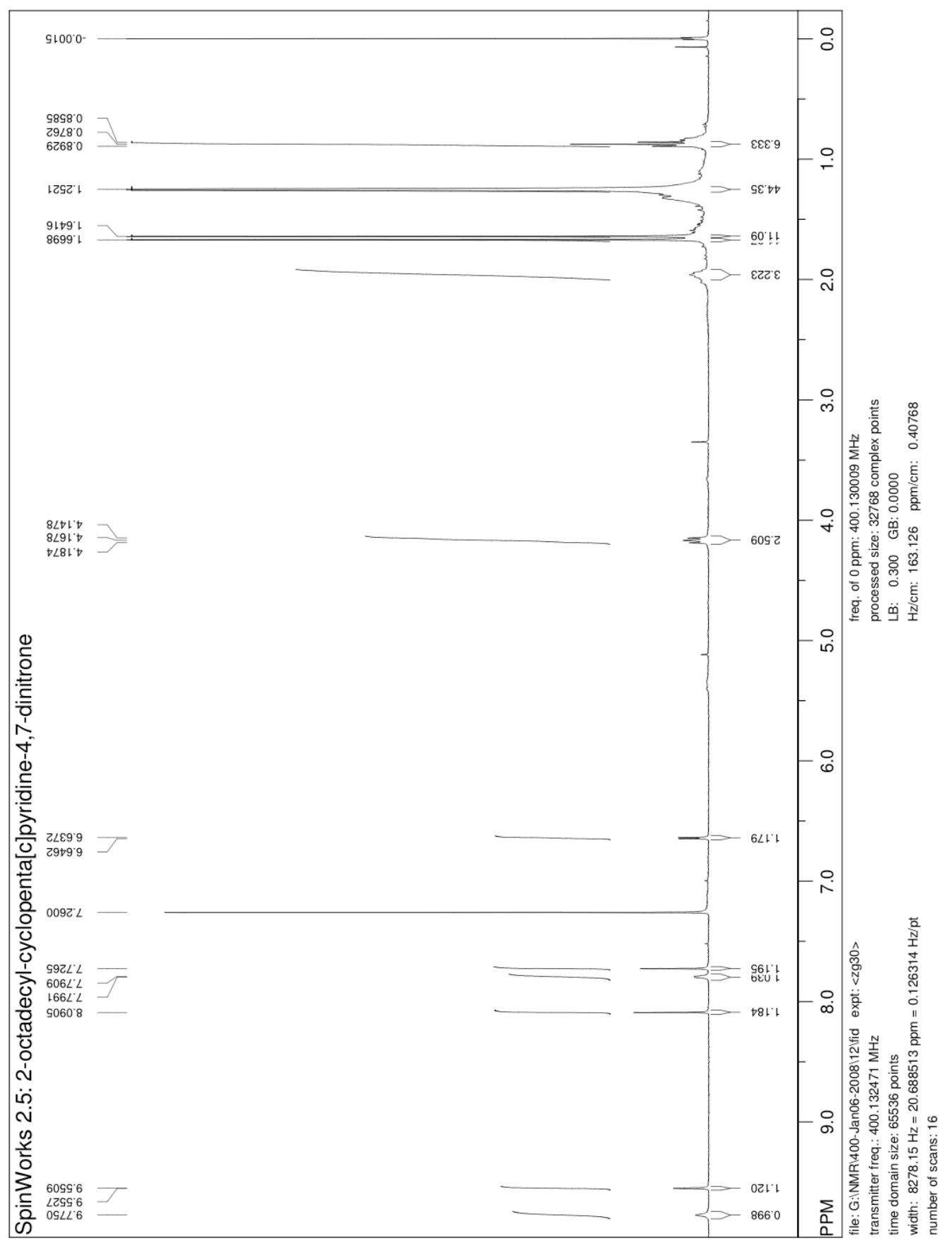




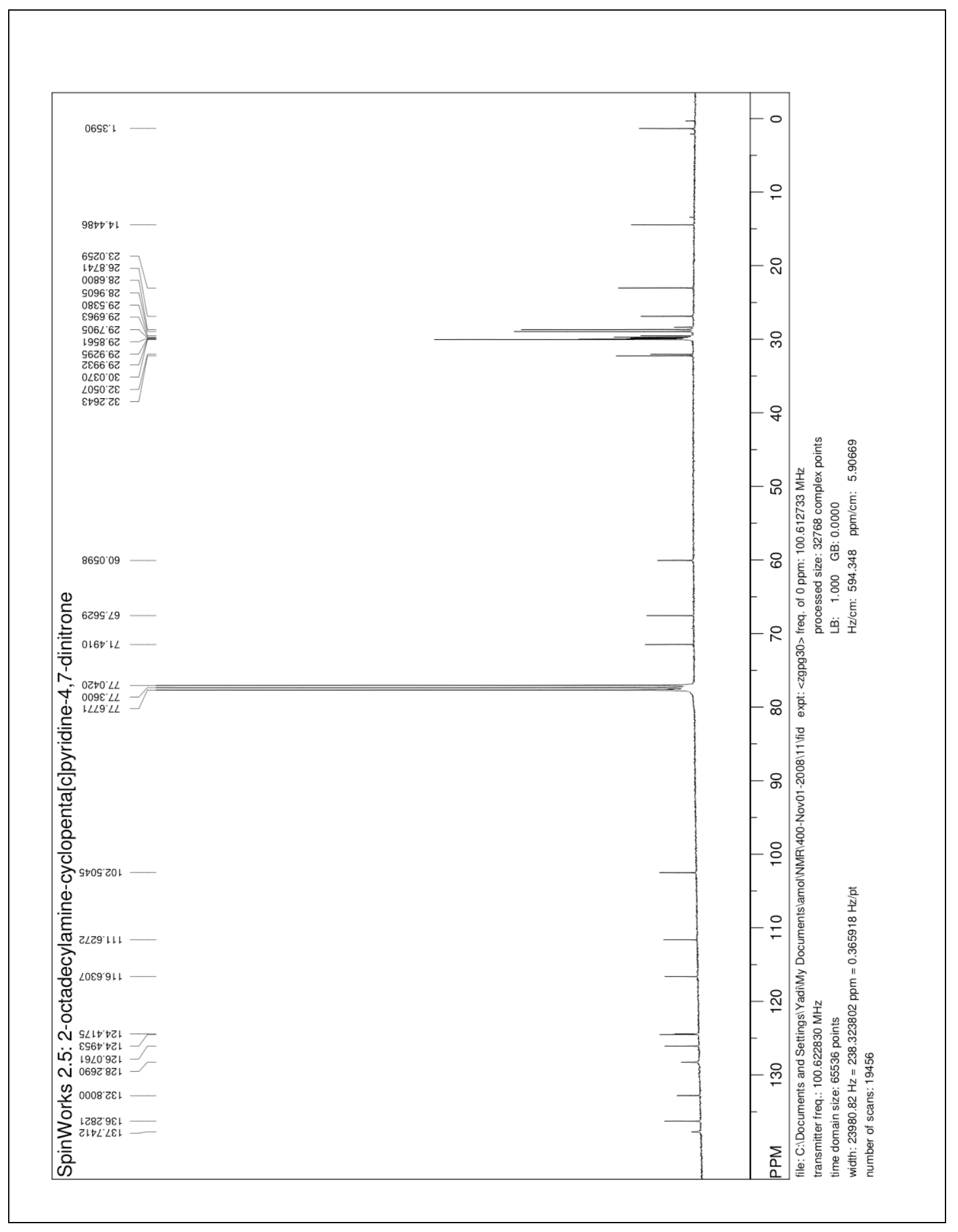




\section{[5.2.3] Synthesis of 2-(6-hexanol)-cyclopenta[c]pyridine-4,7-dicarbaldehyde (90):}

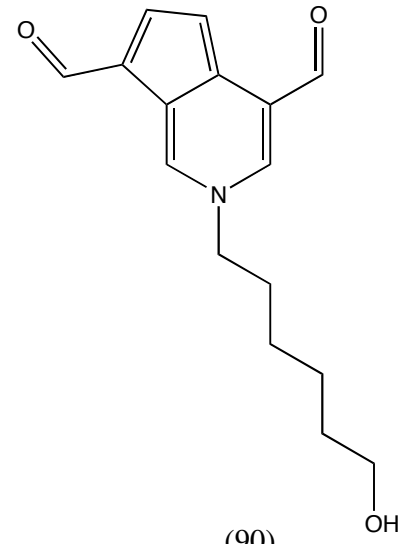

(90)

Baldrinal (60) (150 mg, $0.68 \mathrm{mmol})$ was mixed with 6-amino-1hexanol (152 mg, $1.29 \mathrm{mmol})$ in $4 \mathrm{ml}$ of chloroform. After stirring for $15 \mathrm{~min}$ at room temperature, the solution turned into thick red liquid. When silica gel thin layer chromatography showed no baldrinal, the product was purified by silica gel column chromatography using chloroform/methanol (100:1) as eluent. $17 \mathrm{mg}(9 \%)$ of orange product $(90)$ was collected. $R_{f}=0.11$ (chloroform/methanol 99:1).

${ }^{1}$ H NMR (400 MHz, $\left.\mathrm{CDCl}_{3}\right): \delta 10.22(\mathrm{~s}, 1 \mathrm{H}), 9.88(\mathrm{~s}, 1 \mathrm{H}), 9.01(\mathrm{~s}, 1 \mathrm{H}), 7.96(\mathrm{~d}, J=3.6$ $\mathrm{Hz}, 1 \mathrm{H}), 7.84$ (d, J=1.4 Hz, 1H), 7.22 (d, $J=3.6 \mathrm{~Hz}, 1 \mathrm{H}), 4.29$ (t, $J=7.2 \mathrm{~Hz}, 2 \mathrm{H}), 3.63$ (m, 2H), 1.99 (quintet, $J=7.3 \mathrm{~Hz}, 2 \mathrm{H}), 1.86(\mathrm{~s}, 1 \mathrm{H}), 1.59-1.53(\mathrm{~m}, 2 \mathrm{H}), 1.46-1.43(\mathrm{~m}, 2 \mathrm{H})$, 1.42-1.36 (m, 2H). LRMS: (LC/MS-APCI, MeOH) m/e 274.1 $\left(\mathrm{MH}^{+}\right)$. 


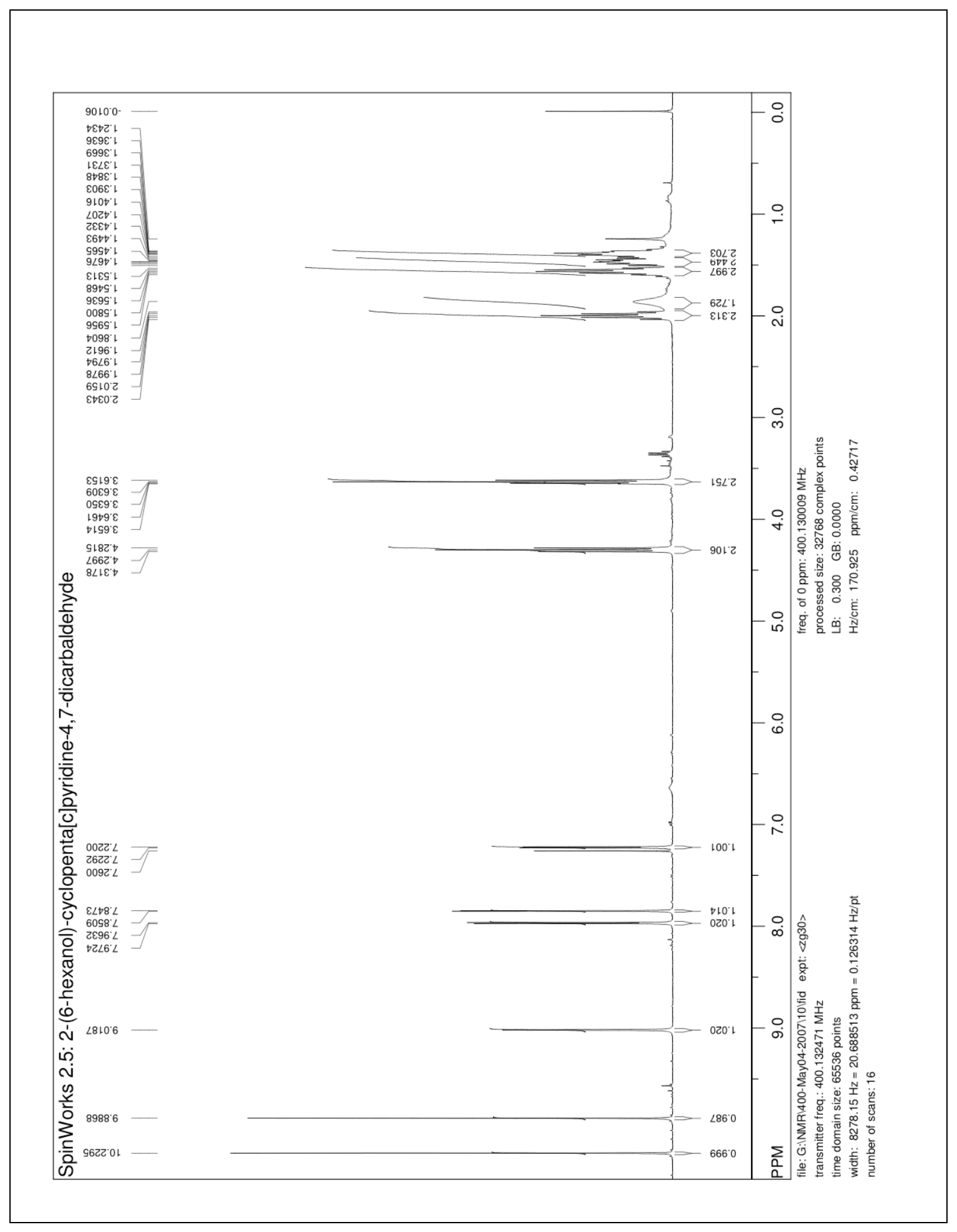




\section{[5.2.4] Synthesis of 2-(6-hexanol)-cyclopenta[c]pyridine-4,7-dinitrone (91):}

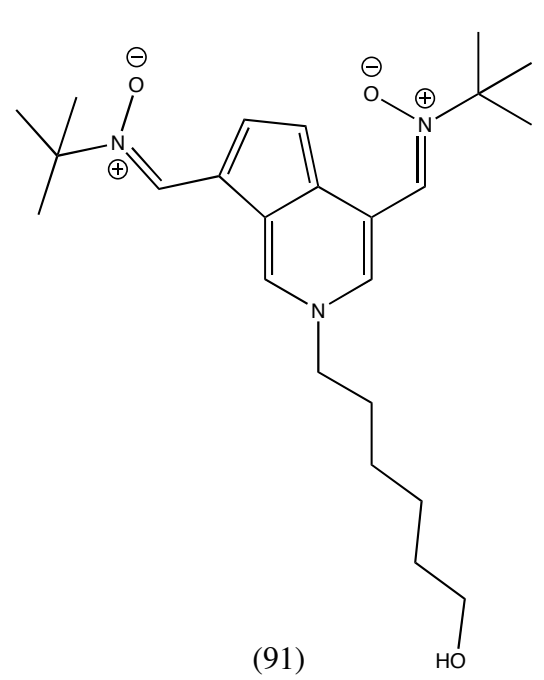

2-(6-hexanol)-cyclopenta[c]pyridine-4,7dicarbaldehyde (90) (17 mg, $0.06 \mathrm{mmol})$ was mixed with N-tert-butyl hydroxylamine (30.6 mg, $0.24 \mathrm{mmol})$ and magnesium sulfate $(29.4 \mathrm{mg}, 0.24 \mathrm{mmol})$ in $2 \mathrm{ml}$ of pyridine. Reaction flask was flushed with argon. Heated at $50{ }^{\circ} \mathrm{C}$ for $48 \mathrm{~h}$. Product was purified via silica gel column chromatography with chloroform/methanol $(50: 1)$ as eluent. $15 \mathrm{mg}(58 \%)$ of product collected. $\mathrm{R}_{\mathrm{f}}=$

0.21 (chloroform/methanol 20:1).

${ }^{1} \mathbf{H}$ NMR (400 MHz, $\left.\mathrm{CDCl}_{3}\right): \delta 9.94(\mathrm{~s}, 1 \mathrm{H}), 9.55(\mathrm{~d}, J=1.2 \mathrm{~Hz}, 1 \mathrm{H}), 8.09(\mathrm{~s}, 1 \mathrm{H}), 7.71$ (s, 1H), $7.65(\mathrm{~d}, J=3.5,1 \mathrm{H}), 6.64(\mathrm{~d}, J=3.6 \mathrm{~Hz}, 1 \mathrm{H}), 4.24(\mathrm{t}, J=6.9 \mathrm{~Hz}, 2 \mathrm{H}), 3.60$ (t, $J=5.5 \mathrm{~Hz}, 2 \mathrm{H}), 1.99$ (quintet, $J=6.9 \mathrm{~Hz}, 2 \mathrm{H}), 1.66(\mathrm{~s}, 9 \mathrm{H}), 1.63(\mathrm{~s}, 9 \mathrm{H}), 1.57-1.52(\mathrm{~m}$, 4H), 1.37-1.30 (m, 2H). ${ }^{13} \mathbf{C}$ NMR (400 MHz, $\left.\mathrm{CDCl}_{3}\right): \delta 136.59,136.51,132.92,129.19$, $125.78,124.28,123.76,116.42,111.13,102.34,71.22,67.19,61.50,58.44,32.22,30.92$ 28.56, 28.32, 24.86, 24.22. LRMS: (LC/MS-APCI, MeOH) m/e $416.5\left(\mathrm{MH}^{+}\right)$. 


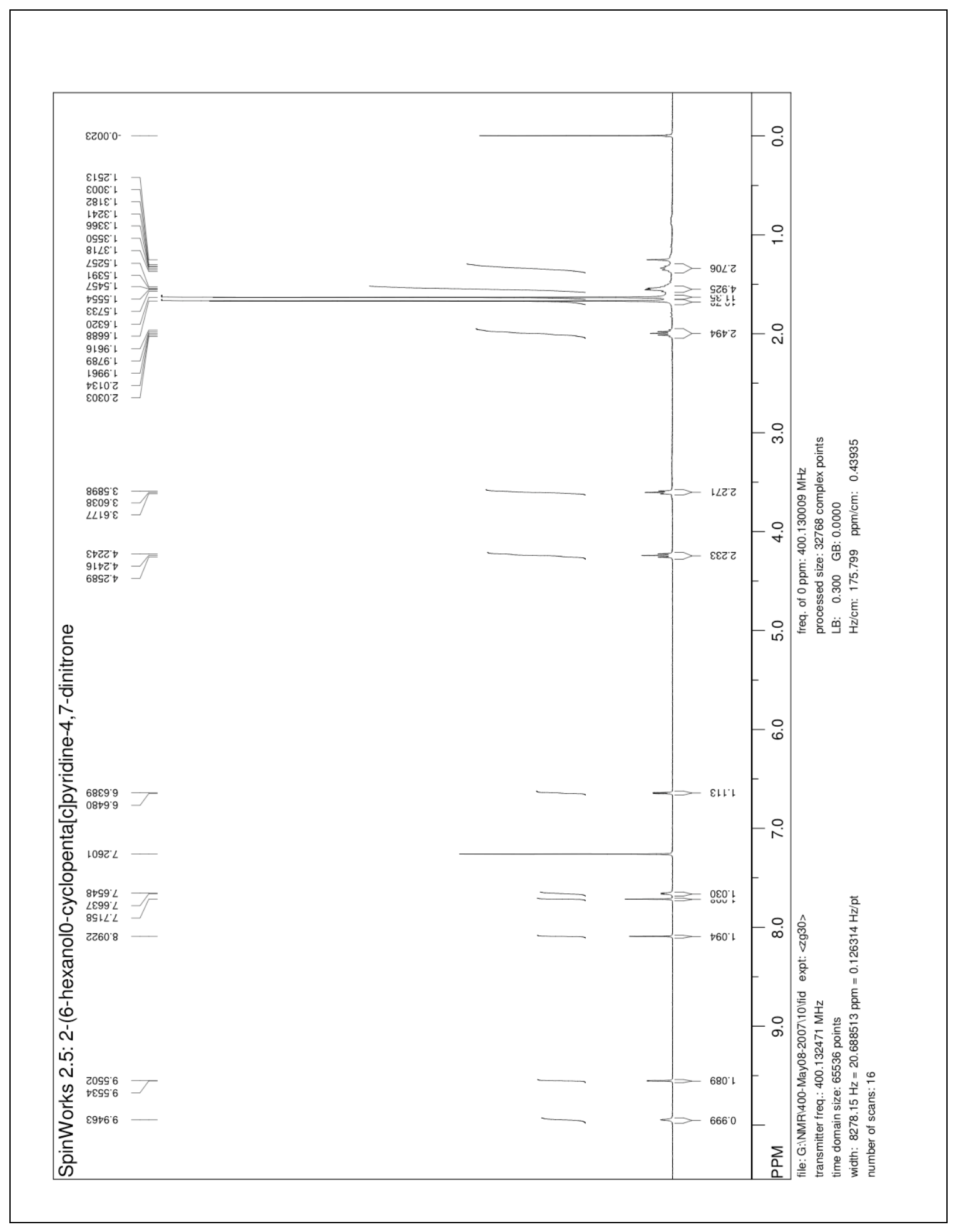




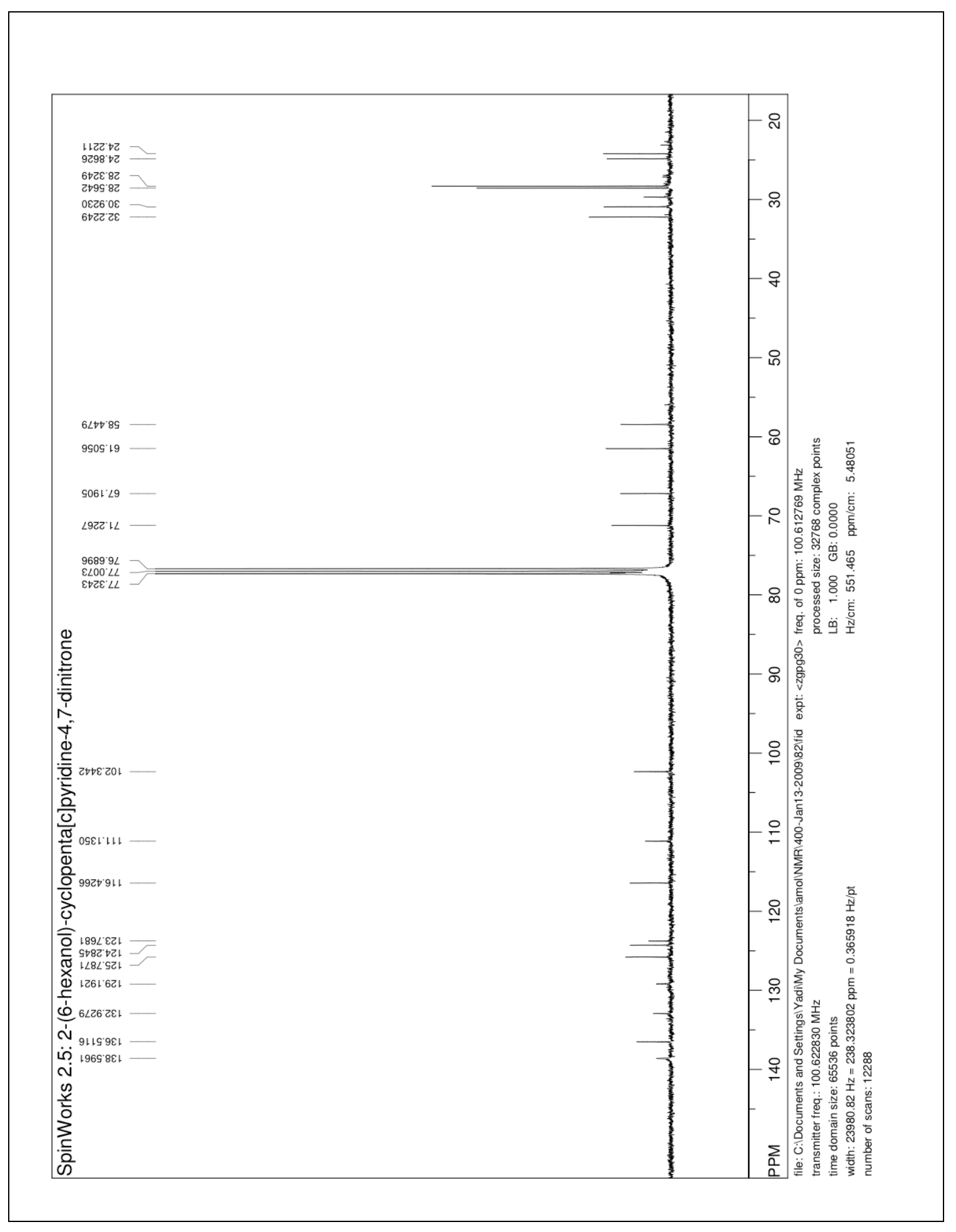




\section{[5.2.5] Synthesis of Spermine analogue of pseudoazulenyl dinitrone (86):}

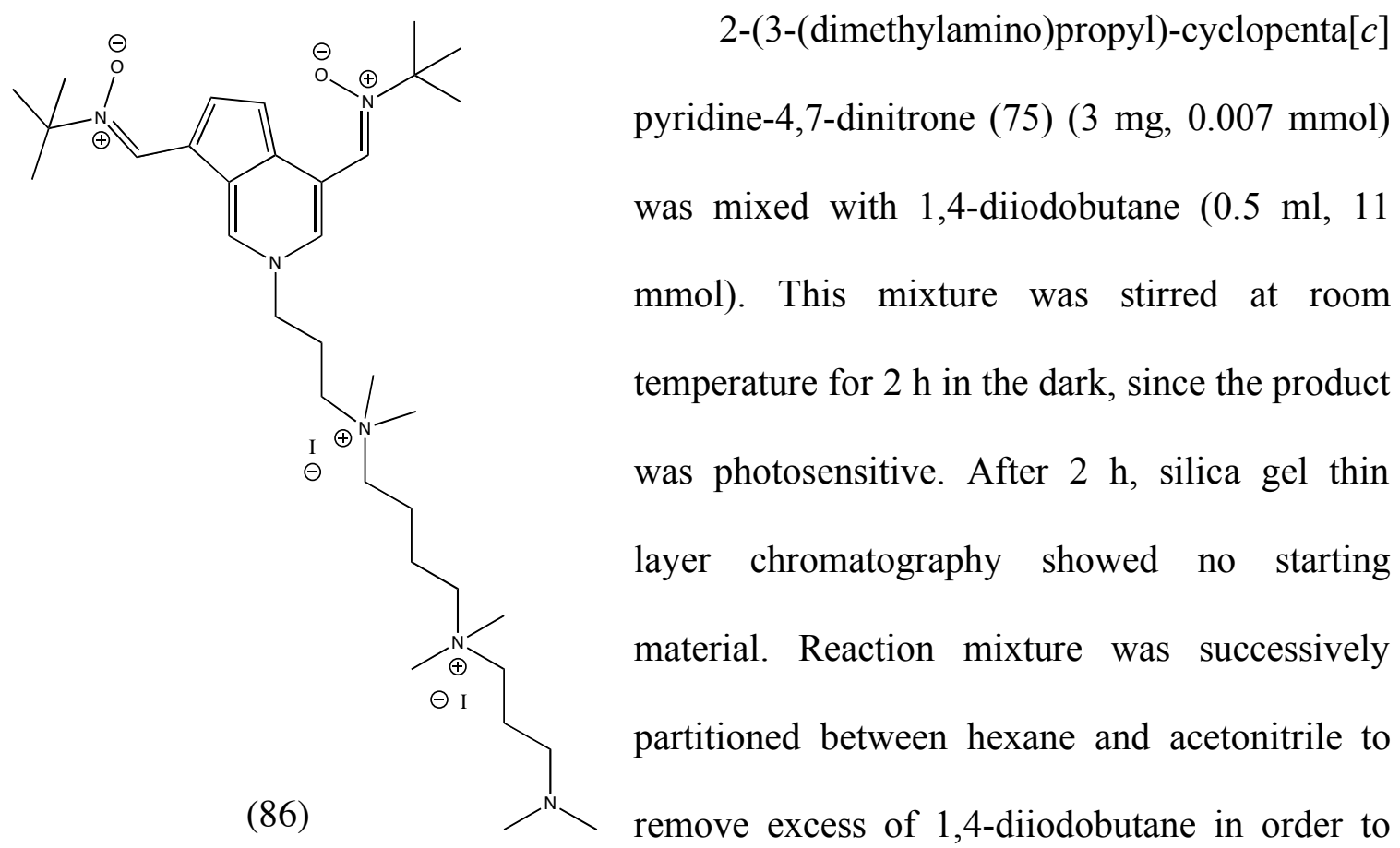

get (84). This product, without further purification, was reacted with $N, N, N^{\prime} N^{\prime}-$ tetramethyl propanediamine (85) (1 $\mathrm{ml}$, excess) in acetonitrile for $1 \mathrm{~h}$ at room temperature in the dark. Acetonitrile and $N, N, N^{\prime} N^{\prime}$-tetramethyl propanediamine were removed under vacuum to get spermine analogue (86).

${ }^{1}$ H NMR (400 MHz, MeOD): $\delta 10.04$ (s, 1H), 9.90 (s, 1H), 8.63 (s, 1H), 8.35 (s, 1H), $8.16(\mathrm{~d}, J=4.7 \mathrm{~Hz}, 1 \mathrm{H}), 7.40(\mathrm{~d}, J=4.6 \mathrm{~Hz}, 1 \mathrm{H}), 4.74(\mathrm{t}, J=7.4 \mathrm{~Hz}, 2 \mathrm{H}), 4.30(\mathrm{~m}, 2 \mathrm{H})$, 3.66-3.62 (m, 2H), 3.58-3.56 (m, 2H), 3.50-3.48 (m, 2H), 3.46-3.35 (m, 2H), $3.22(\mathrm{~s}$, $6 \mathrm{H}), 3.16(\mathrm{~s}, 12 \mathrm{H}), 2.72(\mathrm{~m}, 2 \mathrm{H}), 2.54(\mathrm{t}, J=7.4 \mathrm{~Hz}, 2 \mathrm{H}), 1.99-1.95(\mathrm{~m}, 4 \mathrm{H}), 1.73(\mathrm{~s}, 9 \mathrm{H})$, 1.69 (s, 9H). LRMS: (LC/MS-APCI, MeOH) m/e $293.2\left(\mathrm{M}^{2+}\right)$. 


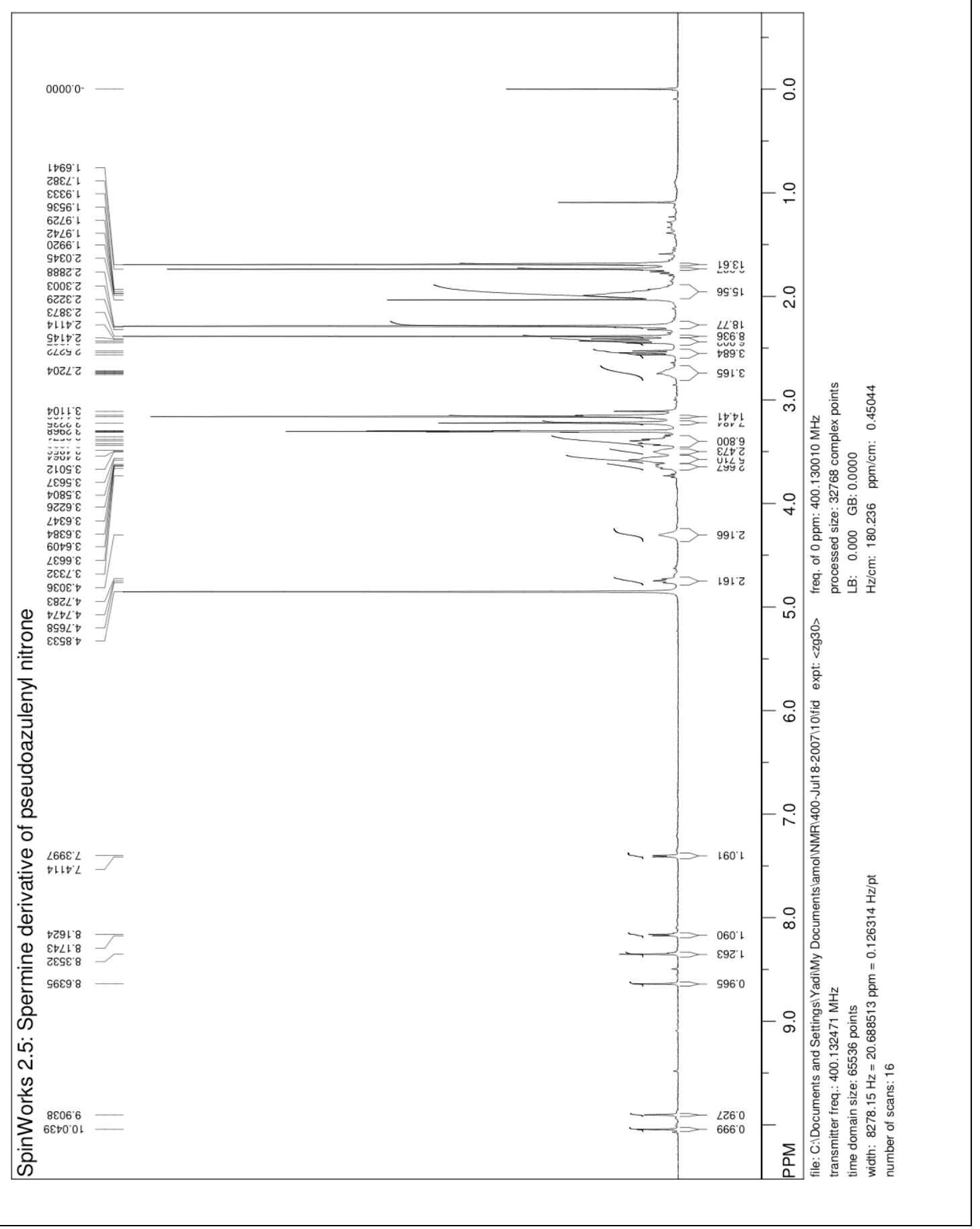




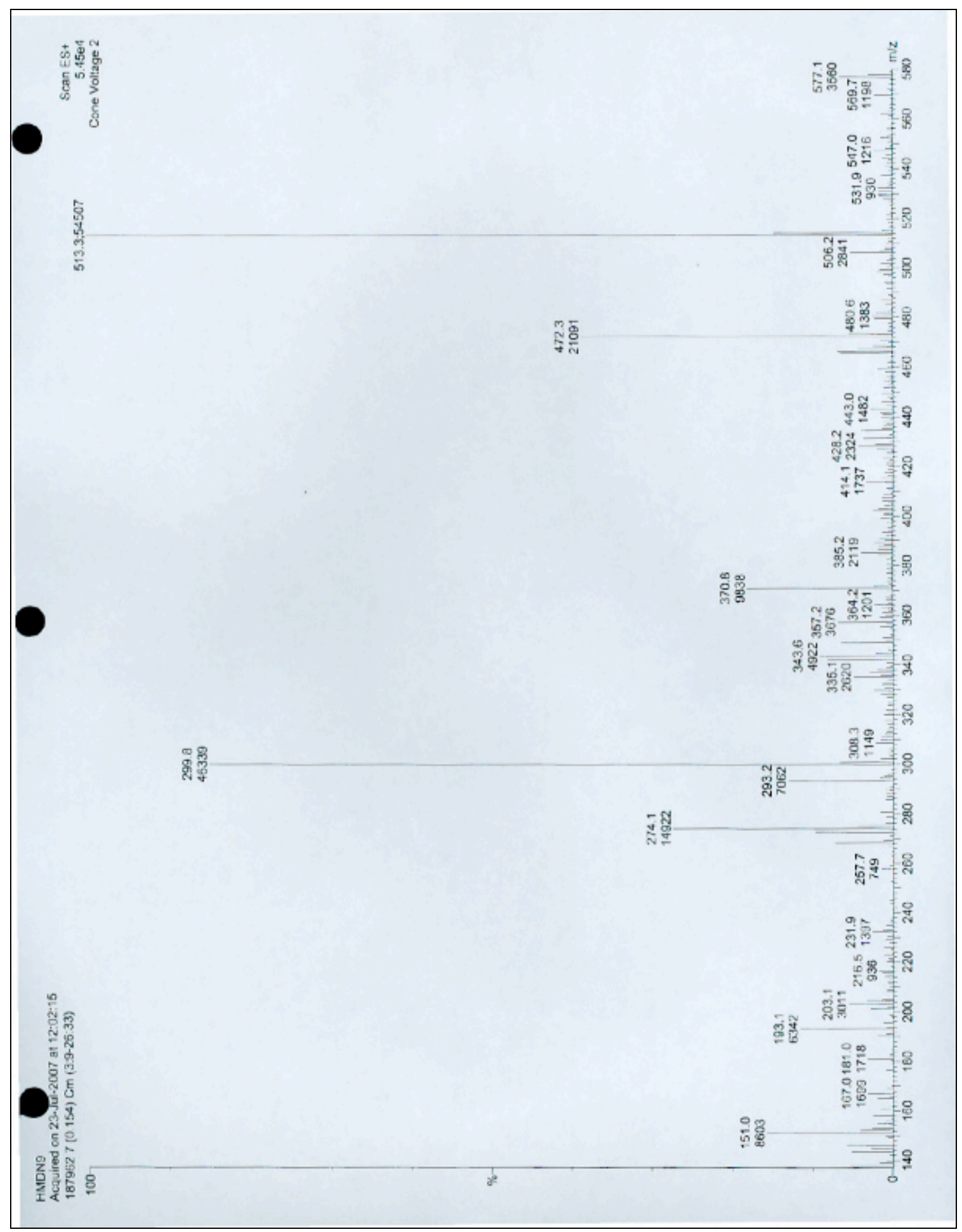




\section{[5.2.6] Cyclic voltammetry}

Cyclic voltammetry experiments were performed at Dr. Angel Keiffer's lab at University of Miami, Miami, Florida. Both the compounds, 2-butyl-5-ethylthiocyclopenta[c]pyridine-4,7-dinitrone (94) and STAZN (32) were tested under the same conditions. Cyclic voltammetry were performed on a solution of compounds (94) and (32) in $\mathrm{CH}_{2} \mathrm{Cl}_{2}$ at a concentration of $100 \mathrm{mM}$ with scan rate of $100 \mathrm{mV} \mathrm{s}^{-1}$. The working electrode used in this experiment was a glassy carbon electrode and the electrolyte was tetrabutylammonium hexaflurophosphate $\left(\mathrm{TBAPF}_{6}\right)$ at a concentration of $100 \mathrm{mM}$. 


\section{LIST OF REFERENCES}

(1) Commoner, B.; Townsend, J.; Pake, G. E. Free Radicals in Biological Materials. Nature 1954, 174, 689-691.

(2) Harman, D. Aging: A Theory Based on Free Radical and Radiation Chemistry. $J$. Gerontol. 1956, 11, 298-300.

(3) McCord, J. M.; Fridovich, I. Superoxide Dismutase. an Enzymic Function for Erythrocuprein (Hemocuprein). J. Biol. Chem. 1969, 244, 6049-55.

(4) Lebovitz, R. M.; Zhang, H.; Vogel, H.; Cartwright, J. J.; Dionne, L.; Lu, N.; Huang, S.; Matzuk, M. M. Neurodegeneration, Myocardial Injury, and Perinatal Death in Mitochondrial Superoxide Dismutase-Deficient Mice. Proc. Natl. Acad. Sci. U.S.A. 1996, 93, 9782-7.

(5) Melov, S.; Coskun, P.; Patel, M.; Tuinstra, R.; Cottrell, B.; Jun, A. S.; Zastawny, T. H.; Dizdaroglu, M.; Goodman, S. I.; Huang, T. T.; Miziorko, H.; Epstein, C. J.; Wallace, D. C. Mitochondrial Disease in Superoxide Dismutase 2 Mutant Mice. Proc. Natl. Acad. Sci. U.S.A. 1999, 96, 846-51.

(6) Halliwell, B. Reactive Oxygen Species in Living Systems: Source, Biochemistry, and Role in Human Disease. Am. J. Med. 1991, 91, S14-S22.

(7) Haber, F.; Weiss, J. The Catalytic Decomposition of Hydrogen Peroxide by Iron Salts. Proc. R. Soc. London, Ser. A (1934-1990) 1934, 147, 332-351.

(8) Mittal, C. K.; Murad, F. Activation of Guanylate Cyclase by Superoxide Dismutase and Hydroxyl Radical: A Physiological Regulator of Guanosine 3',5'Monophosphate Formation. Proc. Natl. Acad. Sci. U.S.A. 1977, 74, 4360-4.

(9) Babior, B. M. Oxygen-Dependent Microbial Killing by Phagocytes. Part 1. N. Engl. J. Med. 1978, 298, 659-668.

(10) Babior, B. M.; Kipnes, R. S.; Curnutte, J. T. Biological Defense Mechanisms. Production by Leukocytes of Superoxide, a Potential Bactericidal Agent. J. Clin. Invest. 1973, 52, 741-744.

(11) Webster, N. R.; Nunn, J. F. Molecular Structure of Free Radicals and their Importance in Biological Reactions. Br. J. Anaesth. 1988, 60, 98-108.

(12) Buttke, T. M.; Sandstrom, P. A. Oxidative Stress as a Mediator of Apoptosis. Immunol. Today 1994, 15, 7-10. 
(13) Cathcart, M. K.; McNally, A. K.; Morel, D. W.; Chisolm GM, 3. Superoxide Anion Participation in Human Monocyte-Mediated Oxidation of Low-Density Lipoprotein and Conversion of Low-Density Lipoprotein to a Cytotoxin. J. Immunol 1989, 142, 1963-9.

(14) Kunsch, C.; Medford, R. M. Oxidative Stress as a Regulator of Gene Expression in the Vasculature. Circ. Res. 1999, 85, 753-66.

(15) Schulze, P. C.; Lee, R. T. Oxidative Stress and Atherosclerosis. Curr. Atheroscler. Rep. 2005, 7, 242-8.

(16) Araujo, V.; Arnal, C.; Boronat, M.; Ruiz, E.; Dominguez, C. Oxidant-Antioxidant Imbalance in Blood of Children with Juvenile Rheumatoid Arthritis. Biofactors $1998,8,155-9$.

(17) Araujo, V.; Arnal, C.; Boronat, M.; Ruiz, E.; Dominguez, C. Oxidant-Antioxidant Imbalance in Blood of Children with Juvenile Rheumatoid Arthritis. Biofactors $1998,8,155-9$.

(18) Ha, H. C.; Thiagalingam, A.; Nelkin, B. D.; Casero RA, J. Reactive Oxygen Species are Critical for the Growth and Differentiation of Medullary Thyroid Carcinoma Cells. Clin. Cancer. Res. 2000, 6, 3783-7.

(19) Hussain, S. P.; Aguilar, F.; Amstad, P.; Cerutti, P. Oxy-Radical Induced Mutagenesis of Hotspot Codons 248 and 249 of the Human p53 Gene. Oncogene 1994, 9, 2277-81.

(20) Nakamura, Y.; Colburn, N. H.; Gindhart, T. D. Role of Reactive Oxygen in Tumor Promotion: Implication of Superoxide Anion in Promotion of Neoplastic Transformation in JB-6 Cells by TPA. Carcinogenesis 1985, 6, 229-35.

(21) Nakamura, Y.; Gindhart, T. D.; Winterstein, D.; Tomita, I.; Seed, J. L.; Colburn, N. H. Early Superoxide Dismutase-Sensitive Event Promotes Neoplastic Transformation in Mouse Epidermal JB6 Cells. Carcinogenesis 1988, 9, 203-7.

(22) Mrowicka, M. Free-Radical Reactions in Diabetes Mellitus. Pol. Merkur Lekarski 2005, 19, 571-6.

(23) Wolff, S. P. Diabetes Mellitus and Free Radicals. Free Radicals, Transition Metals and Oxidative Stress in the Aetiology of Diabetes Mellitus and Complications. $\mathrm{Br}$. Med. Bull. 1993, 49, 642-52.

(24) Finkel, T.; Holbrook, N. J. Oxidants, Oxidative Stress and the Biology of Ageing. Nature 2000, 408, 239-247. 
(25) Getoff, N. Anti-Aging and Aging Factors in Life. The Role of Free Radicals. Radiat. Phys. Chem. 2007, 76, 1577-1586.

(26) Beckman, K. B.; Ames, B. N. The Free Radical Theory of Aging Matures. Physiol. Rev 1998, 78, 547-81.

(27) Rosen, D. R.; Siddique, T.; Patterson, D.; Figlewicz, D. A.; Sapp, P.; Hentati, A.; Donaldson, D.; Goto, J.; O'Regan, J. P.; Deng, H. X.; et, a. Mutations in Cu/Zn Superoxide Dismutase Gene are Associated with Familial Amyotrophic Lateral Sclerosis. Nature 1993, 362, 59-62.

(28) Multhaup, G.; Ruppert, T.; Schlicksupp, A.; Hesse, L.; Beher, D.; Masters, C. L.; Beyreuther, K. Reactive Oxygen Species and Alzheimer's Disease. Biochem. Pharmacol. 1997, 54, 533-9.

(29) Pratico, D.; MY Lee, V.; Trojanowski, J. Q.; Rokach, J.; Fitzgerald, G. A. Increased F2-Isoprostanes in Alzheimer's Disease: Evidence for Enhanced Lipid Peroxidation in Vivo. FASEB J. 1998, 12, 1777-83.

(30) Sayre, L. M.; Zelasko, D. A.; Harris, P. L.; Perry, G.; Salomon, R. G.; Smith, M. A. 4-Hydroxynonenal-Derived Advanced Lipid Peroxidation End Products are Increased in Alzheimer's Disease. J. Neurochem. 1997, 68, 2092-7.

(31) Busciglio, J.; Yankner, B. A. Apoptosis and Increased Generation of Reactive Oxygen Species in Down's Syndrome Neurons in Vitro. Nature 1995, 378, 776-9.

(32) de Haan, J. B.; Cristiano, F.; Iannello, R.; Bladier, C.; Kelner, M. J.; Kola, I. Elevation in the Ratio of $\mathrm{Cu} / \mathrm{Zn}$-Superoxide Dismutase to Glutathione Peroxidase Activity Induces Features of Cellular Senescence and this Effect is Mediated by Hydrogen Peroxide. Hum. Mol. Genet. 1996, 5, 283-92.

(33) Milhavet, O.; McMahon, H. E.; Rachidi, W.; Nishida, N.; Katamine, S.; Mange, A.; Arlotto, M.; Casanova, D.; Riondel, J.; Favier, A.; Lehmann, S. Prion Infection Impairs the Cellular Response to Oxidative Stress. Proc. Natl. Acad. Sci. U.S.A. 2000, 97, 13937-42.

(34) Buettner, G. R. The Pecking Order of Free Radicals and Antioxidants: Lipid Peroxidation, $\alpha$-Tocopherol, and Ascorbate. Arch. Biochem. Biophys. 1993, 300, 535-543.

(35) Beckman, J. S.; Koppenol, W. H. Nitric Oxide, Superoxide, and Peroxynitrite: The Good, the Bad, and Ugly. Am. J. Physiol. 1996, 271, C1424-37.

(36) Huie, R. E.; Padmaja, S. The Reaction of no with Superoxide. Free Radic. Res. Commun. 1993, 18, 195-9. 
(37) Halliwell, B.; Zhao, K.; Whiteman, M. Nitric Oxide and Peroxynitrite. the Ugly, the Uglier and the Not so Good: A Personal View of Recent Controversies. Free Radic. Res. 1999, 31, 651-69.

(38) Halliwell, B. Role of Free Radicals in the Neurodegenerative Diseases: Therapeutic Implications for Antioxidant Treatment. Drugs Aging 2001, 18, 685-716.

(39) Aisen, P.; Listowsky, I. Iron Transport and Storage Proteins. Annu. Rev. Biochem. 1980, 49, 357-93.

(40) Flamm, E. S.; Demopoulos, H. B.; Seligman, M. L.; Poser, R. G.; Ransohoff, J. Free Radicals in Cerebral Ischemia. Stroke 1978, 9, 445-7.

(41) Demopoulos, H. B. The Basis of Free Radical Pathology. Fed. Proc. 1973, 32, 185961 .

(42) Watson, B. D.; Busto, R.; Goldberg, W. J.; Santiso, M.; Yoshida, S.; Ginsberg, M. D. Lipid Peroxidation in Vivo Induced by Reversible Global Ischemia in Rat Brain. J. Neurochem. 1984, 42, 268-274.

(43) Nelson, C. W.; Wei, E. P.; Povlishock, J. T.; Kontos, H. A.; Moskowitz, M. A. Oxygen Radicals in Cerebral Ischemia. Am. J. Physiol. 1992, 263, H1356-62.

(44) Lancelot, E.; Callebert, J.; Revaud, M.; Boulu, R. G.; Plotkine, M. Detection of Hydroxyl Radicals in Rat Striatum during Transient Focal Cerebral Ischemia: Possible Implication in Tissue Damage. Neurosci. Lett. 1995, 197, 85-88.

(45) Stocks, J.; Gutteridge, J. M. C.; Sharp, R. J.; Dormandy, T. L. Inhibition of Lipid Autoxidation by Human Serum and its Relation to Serum Proteins and Alpha Tocopherol. Clin. Sci. Mol. Med. 1974, 47, 223-233.

(46) Makar, T. K.; Nedergaard, M.; Preuss, A.; Gelbard, A. S.; Perumal, A. S.; Cooper, A. J. L. Vitamin E, Ascorbate, Glutathione, Glutathione Disulfide, and Enzymes of Glutathione Metabolism in Cultures of Chick Astrocytes and Neurons: Evidence that Astrocytes Play an Important Role in Antioxidative Processes in the Brain. $J$. Neurochem. 1994, 62, 45-53.

(47) Kondo, T.; Reaume, A. G.; Huang, T. T.; Carlson, E.; Murakami, K.; Chen, S. F.; Hoffman, E. K.; Scott, R. W.; Epstein, C. J.; Chan, P. H. Reduction of CuZnSuperoxide Dismutase Activity Exacerbates Neuronal Cell Injury and Edema Formation After Transient Focal Cerebral Ischemia. J. Neurosci. 1997, 17, 4180-9.

(48) Kinouchi, H.; Epstein, C. J.; Mizui, T.; Carlson, E.; Chen, S. F.; Chan, P. H. Attenuation of Focal Cerebral Ischemic Injury in Transgenic Mice Overexpressing CuZn Superoxide Dismutase. Proc. Natl. Acad. Sci. U.S.A 1991, 88, 11158-62. 
(49) Sheng, H.; Bart, R. D.; Oury, T. D.; Pearlstein, R. D.; Crapo, J. D.; Warner, D. S. Mice Overexpressing Extracellular Superoxide Dismutase have Increased Resistance to Focal Cerebral Ischemia. Neuroscience 1999, 88, 185-191.

(50) Green, A. R.; Ashwood, T.; Odergren, T.; Jackson, D. M. Nitrones as Neuroprotective Agents in Cerebral Ischemia, with Particular Reference to NXY059. Pharmacol. Ther. 2003, 100, 195-214.

(51) Halliwell, B. Reactive Oxygen Species and the Central Nervous System. $J$. Neurochem. 1992, 59, 1609-1623.

(52) Joseph, J. A.; Roth, G. S. Cholinergic Systems in Aging: The Role of Oxidative Stress. Clin. Neuropharmacol. 1992, 15 Suppl 1 Pt A, 508A-509A.

(53) Weinstock, M. The Pharmacotherapy of Alzheimer's Disease Based on the Cholinergic Hypothesis: An Update. Neurodegeneration 1995, 4, 349-356.

(54) Selkoe, D. J. Physiological Production of the Beta-Amyloid Protein and the Mechanism of Alzheimer's Disease. Trends Neurosci. 1993, 16, 403-409.

(55) Goodman, Y.; Mattson, M. P. Secreted Forms of $\beta$-Amyloid Precursor Protein Protect Hippocampal Neurons Against Amyloid $\beta$-Peptide-Induced Oxidative Injury. Exp. Neurol. 1994, 128, 1-12.

(56) Yankner, B. A.; Dawes, L. R.; Fisher, S.; Villa-Komaroff, L.; Oster-Granite, M. L.; Neve, R. L. Neurotoxicity of a Fragment of the Amyloid Precursor Associated with Alzheimer's Disease. Science 1989, 245, 417-420.

(57) Hensley, K.; Carney, J. M.; Mattson, M. P.; Aksenova, M.; Harris, M.; Wu, J. F.; Floyd, R. A.; Butterfield, D. A. A Model for Beta-Amyloid Aggregation and Neurotoxicity Based on Free Radical Generation by the Peptide: Relevance to Alzheimer Disease. Proc. Natl. Acad. Sci. U.S.A. 1994, 91, 3270-3274.

(58) Mark, R. J.; Hensley, K.; Butterfield, D. A.; Mattson, M. P. Amyloid Beta-Peptide Impairs Ion-Motive ATPase Activities: Evidence for a Role in Loss of Neuronal Ca2+ Homeostasis and Cell Death. J. Neurosci. 1995, 15, 6239-6249.

(59) Bains, J. S.; Shaw, C. A. Neurodegenerative Disorders in Humans: The Role of Glutathione in Oxidative Stress-Mediated Neuronal Death. Brain Res. Rev. 1997, 25, 335-58.

(60) Roher, A. E.; Ball, M. J.; Bhave, S. V.; Wakade, A. R. B-Amyloid from Alzheimer Disease Brains Inhibits Sprouting and Survival of Sympathetic Neurons. Biochem. Biophys. Res. Commun. 1991, 174, 572-579. 
(61) Lorenzo, A.; Yankner, B. A. Beta-Amyloid Neurotoxicity Requires Fibril Formation and is Inhibited by Congo Red. Proc. Natl. Acad. Sci. U.S.A. 1994, 91, 12243-12247.

(62) Butterfield, D. A.; Hensley, K.; Harris, M.; Mattson, M.; Carney, J. Beta-Amyloid Peptide Free Radical Fragments Initiate Synaptosomal Lipoperoxidation in a Sequence-Specific Fashion: Implications to Alzheimer's Disease. Biochem. Biophys. Res. Commun. 1994, 200, 710-715.

(63) Behl, C.; Davis, J. B.; Lesley, R.; Schubert, D. Hydrogen Peroxide Mediates Amyloid Beta Protein Toxicity. Cell 1994, 77, 817-827.

(64) Dyrks, T.; Dyrks, E.; Hartmann, T.; Masters, C.; Beyreuther, K. Amyloidogenicity of Beta A4 and Beta A4-Bearing Amyloid Protein Precursor Fragments by MetalCatalyzed Oxidation. J. Biol. Chem. 1992, 267, 18210-18217.

(65) Yan, S. D.; Chen, X.; Fu, J.; Chen, M.; Zhu, H.; Roher, A.; Slattery, T.; Zhao, L.; Nagashima, M.; Morser, J.; Migheli, A.; Nawroth, P.; Stern, D.; Schmidt, A. M. RAGE and Amyloid-[Beta] Peptide Neurotoxicity in Alzheimer's Disease. Nature 1996, 382, 685-691.

(66) Colton, C. A.; Gilbert, D. L. Production of Superoxide Anions by a CNS Macrophage, the Microglia. FEBS Letters, 1987, 223, 284-288.

(67) Halks-Miller, M.; Henderson, M.; Eng, L. F. Alpha Tocopherol Decreases Lipid Peroxidation, Neuronal Necrosis, and Reactive Gliosis in Reaggregate Cultures of Fetal Rat Brain. J. Neuropathol. Exp. Neurol. 1986, 45, 471-84.

(68) Smith, C. D.; Carney, J. M.; Starke-Reed, P. E.; Oliver, C. N.; Stadtman, E. R.; Floyd, R. A.; Markesbery, W. R. Excess Brain Protein Oxidation and Enzyme Dysfunction in Normal Aging and in Alzheimer Disease. Proc. Natl. Acad. Sci. U.S.A 1991, 88, 10540-3.

(69) Jankovic, J. In Pathophysiology and clinical assessment of motor symptoms in Parkinson's disease. Koller, W., Ed.; Handbook of Parkinson's disease; Dekker: New York, 1992; pp 129-57.

(70) Adams JD, J.; Chang, M. L.; Klaidman, L. Parkinson's Disease-Redox Mechanisms. Curr. Med. Chem. 2001, 8, 809-14.

(71) Jenner, P. Oxidative Stress in Parkinson's Disease. Ann. Neurol. 2003, 53, S26-S38.

(72) Schapira, A. H.; Cooper, J. M.; Dexter, D.; Clark, J. B.; Jenner, P.; Marsden, C. D. Mitochondrial Complex I Deficiency in Parkinson's Disease. J. Neurochem. 1990, $54,823-7$. 
(73) Mizuno, Y.; Ohta, S.; Tanaka, M.; Takamiya, S.; Suzuki, K.; Sato, T.; Oya, H.; Ozawa, T.; Kagawa, Y. Deficiencies in Complex I Subunits of the Respiratory Chain in Parkinson's Disease. Biochem. Biophys. Res. Commun. 1989, 163, 1450-5.

(74) Tipton, K. F.; Singer, T. P. Advances in our Understanding of the Mechanisms of the Neurotoxicity of MPTP and Related Compounds. J. Neurochem. 1993, 61, 11911206.

(75) Klivenyi, P.; Matthews, R. T.; Wermer, M.; Yang, L.; MacGarvey, U.; Becker, D. A.; Natero, R.; Beal, M. F. Azulenyl Nitrone Spin Traps Protect Against MPTP Neurotoxicity. Exp. Neurol. 1998, 152, 163-166.

(76) Klivenyi, P.; St. Clair, D.; Wermer, M.; Yen, H.; Oberley, T.; Yang, L.; Beal, M. F. Manganese Superoxide Dismutase Overexpression Attenuates MPTP Toxicity. Neurobiol. Dis. 1998, 5, 253-258.

(77) Adams, R. N.; Murrill, E.; McCreery, R.; Blank, L.; Karolczak, M. 6Hydroxydopamine, a New Oxidation Mechanism. Eur. J. Pharmacol. 1972, 17, 287292.

(78) Spina, M. B.; Cohen, G. Exposure of Striatal [Corrected] Synaptosomes to L-Dopa Increases Levels of Oxidized Glutathione. J. Pharmacol. Exp. Ther. 1988, 247, 5027.

(79) Dexter, D. T.; Wells, F. R.; Lees, A. J.; Agid, F.; Agid, Y.; Jenner, P.; Marsden, C. D. Increased Nigral Iron Content and Alterations in Other Metal Ions Occurring in Brain in Parkinson's Disease. J. Neurochem. 1989, 52, 1830-6.

(80) Sofic, E.; Riederer, P.; Heinsen, H.; Beckmann, H.; Reynolds, G. P.; Hebenstreit, G.; Youdim, M. B. Increased Iron (III) and Total Iron Content in Post Mortem Substantia Nigra of Parkinsonian Brain. J. Neural. Transm. 1988, 74, 199-205.

(81) Hirsch, E. C.; Brandel, J. P.; Galle, P.; Javoy-Agid, F.; Agid, Y. Iron and Aluminum Increase in the Substantia Nigra of Patients with Parkinson's Disease: An X-Ray Microanalysis. J. Neurochem. 1991, 56, 446-51.

(82) Zaleska, M. M.; Floyd, R. A. Regional Lipid Peroxidation in Rat Brain in Vitro: Possible Role of Endogenous Iron. Neurochem. Res. 1985, 10, 397-410.

(83) Double, K. L.; Gerlach, M.; Youdim, M. B.; Riederer, P. Impaired Iron Homeostasis in Parkinson's Disease. J. Neural Transm. Suppl. 2000, 60, 37-58.

(84) Youdim, M. B.; Ben-Shachar, D.; Riederer, P. Is Parkinson's Disease a Progressive Siderosis of Substantia Nigra Resulting in Iron and Melanin Induced Neurodegeneration? Acta Neurol. Scand. Suppl. 1989, 126, 47-54. 
(85) Smith, T. S.; Parker WD, J.; Bennett JP, J. L-Dopa Increases Nigral Production of Hydroxyl Radicals in Vivo: Potential L-Dopa Toxicity? Neuroreport 1994, 5, 100911.

(86) Miller, J. W.; Selhub, J.; Joseph, J. A. Oxidative Damage Caused by Free Radicals Produced during Catecholamine Autoxidation: Protective Effects of O-Methylation and Melatonin. Free Radical Biol. Med. 1996, 21, 241-249.

(87) Jellinger, K.; Linert, L.; Kienzl, E.; Herlinger, E.; Youdim, M. B. Chemical Evidence for 6-Hydroxydopamine to be an Endogenous Toxic Factor in the Pathogenesis of Parkinson's Disease. J. Neural Transm. Suppl. 1995, 46, 297-314.

(88) Bharath, S.; Hsu, M.; Kaur, D.; Rajagopalan, S.; Andersen, J. K. Glutathione, Iron and Parkinson's Disease. Biochem. Pharmacol. 2002, 64, 1037-1048.

(89) Perry, T. L.; Yong, V. W. Idiopathic Parkinson's Disease, Progressive Supranuclear Palsy and Glutathione Metabolism in the Substantia Nigra of Patients. Neurosci. Lett. 1986, 67, 269-74.

(90) Jenner, P. Altered Mitochondrial Function, Iron Metabolism and Glutathione Levels in Parkinson's Disease. Acta Neurol. Scand. Suppl. 1993, 146, 6-13.

(91) Beckman, J. S.; Beckman, T. W.; Chen, J.; Marshall, P. A.; Freeman, B. A. Apparent Hydroxyl Radical Production by Peroxynitrite: Implications for Endothelial Injury from Nitric Oxide and Superoxide. Proc. Natl. Acad. Sci. U.S.A. $1990,87,1620-4$.

(92) Bolanos, J. P.; Almeida, A.; Stewart, V.; Peuchen, S.; Land, J. M.; Clark, J. B.; Heales, S. J. Nitric Oxide-Mediated Mitochondrial Damage in the Brain: Mechanisms and Implications for Neurodegenerative Diseases. J. Neurochem. 1997, $68,2227-40$.

(93) Barker, J. E.; Heales, S. J.; Cassidy, A.; Bolanos, J. P.; Land, J. M.; Clark, J. B. Depletion of Brain Glutathione Results in a Decrease of Glutathione Reductase Activity; an Enzyme Susceptible to Oxidative Damage. Brain Res. 1996, 716, 11822 .

(94) Bindoli, A.; Rigobello, M. P.; Deeble, D. J. Biochemical and Toxicological Properties of the Oxidation Products of Catecholamines. Free Radic. Biol. Med. 1992, 13, 391-405.

(95) Dunnett, S. B.; Bjorklund, A. Prospects for New Restorative and Neuroprotective Treatments in Parkinson's Disease. Nature 1999, 399, A32-9. 
(96) de Belleroche, J.; Orrell, R. W.; Virgo, L. Amyotrophic Lateral Sclerosis: Recent Advances in Understanding Disease Mechanisms. J. Neuropathol. Exp. Neurol. 1996, 55, 747-57.

(97) Williams, D. B.; Windebank, A. J. Motor Neuron Disease (Amyotrophic Lateral Sclerosis). Mayo Clin. Proc. 1991, 66, 54-82.

(98) Rosen, D. R., et al Mutations in $\mathrm{Cu} / \mathrm{Zn}$ Superoxide Dismutase Gene are Associated with Familial Amyotrophic Lateral Sclerosis. Nature 1993, 362, 59-62.

(99) Morrison, B. M.; Morrison, J. H. Amyotrophic Lateral Sclerosis Associated with Mutations in Superoxide Dismutase: A Putative Mechanism of Degeneration. Brain Res. Rev. 1999, 29, 121-135.

(100) Lee, M.; Hyun, D.; Halliwell, B.; Jenner, P. Effect of Overexpression of Wild-Type and Mutant $\mathrm{Cu} / \mathrm{Zn}$-Superoxide Dismutases on Oxidative Stress and Cell Death Induced by Hydrogen Peroxide, 4-Hydroxynonenal Or Serum Deprivation: Potentiation of Injury by ALS-Related Mutant Superoxide Dismutases and Protection by Bcl-2. J. Neurochem. 2001, 78, 209-220.

(101) Gabbianelli, R.; Ferri, A.; Rotilio, G.; Carri, M. T. Aberrant Copper Chemistry as a Major Mediator of Oxidative Stress in a Human Cellular Model of Amyotrophic Lateral Sclerosis. J. Neurochem. 1999, 73, 1175-1180.

(102) Estevez, A. G.; Crow, J. P. Induction of Nitric Oxide-Dependent Apoptosis in Motor Neurons by Zinc-Deficient Superoxide. Science 1999, 286, 2498.

(103) Carri, M. T.; Battistoni, A.; Polizio, F.; Desideri, A.; Rotilio, G. Impaired Copper Binding by the H46R Mutant of Human $\mathrm{Cu}, \mathrm{Zn}$ Superoxide Dismutase, Involved in Amyotrophic Lateral Sclerosis. FEBS Lett. 1994, 356, 314-6.

(104) Migliaccio, E.; Giorgio, M.; Mele, S.; Pelicci, G.; Reboldi, P.; Pandolfi, P. P.; Lanfrancone, L.; Pelicci, P. G. The p66shc Adaptor Protein Controls Oxidative Stress Response and Life Span in Mammals. Nature 1999, 402, 309-313.

(105) Nemoto, S.; Finkel, T. Redox Regulation of Forkhead Proteins through a p66shcDependent Signaling Pathway. Science 2002, 295, 2450-2.

(106) Trinei, M.; Giorgio, M.; Cicalese, A.; Barozzi, S.; Ventura, A.; Migliaccio, E.; Milia, E.; Padura, I. M.; Raker, V. A.; Maccarana, M.; Petronilli, V.; Minucci, S.; Bernardi, P.; Lanfrancone, L.; Pelicci, P. G. A p53-p66Shc Signalling Pathway Controls Intracellular Redox Status, Levels of Oxidation-Damaged DNA and Oxidative Stress-Induced Apoptosis. Oncogene 2002, 21, 3872-3878. 
(107) Hazelton, G. A.; Lang, C. A. Glutathione Contents of Tissues in the Aging Mouse. Biochem. J. 1980, 188, 25-30.

(108) Julius, M.; Lang, C. A.; Gleiberman, L.; Harburg, E.; Difranceisco, W.; Schork, A. Glutathione and Morbidity in a Community-Based Sample of Elderly. J. Clin. Epidemiol. 1994, 47, 1021-1026.

(109) Lang, C. A.; Naryshkin, S.; Schneider, D. L.; Mills, B. J.; Lindeman, R. D. Low Blood Glutathione Levels in Healthy Aging Adults. J. Lab. Clin. Med. 1992, 120, 720-5.

(110) Mithöfer, K.; Sandy, M. S.; Smith, M. T.; Di Monte, D. Mitochondrial Poisons Cause Depletion of Reduced Glutathione in Isolated Hepatocytes. Arch. Biochem. Biophys. 1992, 295, 132-136.

(111) Heales, R.; Davies, S. E. C.; Bates, T. E.; Clark, J. B. Deoletion of Brain Glutathione is Accompanied by Impaired Micochondrial Function and Decreased NAcetyl Aspartate Concentration. Neurochem. Res. 1995, 20, 31-38.

(112) Janzen, E. G.; Blackburn, B. J. Detection and Identification of Short-Lived Free Radicals by Electron Spin Resonance Trapping Techniques (Spin Trapping). Photolysis of Organolead, -Tin, and -Mercury Compounds. J. Amer. Chem. Soc. 1969, 91, 4481-4490.

(113) Janzen, E. G. Spin Trapping. Accounts Chem. Res. 1971, 4, 31-40.

(114) El Hassan, Robert Lauricella, Beatirce Tuccio Preparation of N-Aryl-Ketonitrone Spin Traps. Cent. Eur. J. Chem. 2006, 4, 338.

(115) Pfeiffer, P.; Braude, S.; Fritsch, R.; Halberstadt, W.; Kirchhoff, G.; Kleber, J.; Wittkop, P. Photochemical Syntheses of Indole Derivatives. Justus Liebigs Ann. Chem. 1916, 411, 72-158.

(116) Smith, L. I. Aliphatic Diazo Compounds, Nitrones, and Structurally Analogous Compounds. Systems Capable of Undergoing 1,3-Additions. Chem. Rev. 1938, 23, 193-285.

(117) Hamer, J.; Macaluso, A. Nitrones. Chem. Rev. 1964, 64, 473-495.

(118) Huisgen, R. Kinetics and Mechanism of 1,3-Dipolar Cycloadditions. Angew. Chem. 1963, 75, 742-754.

(119) Thomas, C. E.; Ku, G.; Kalyanaraman, B. Nitrone Spin Trap Lipophilicity as a Determinant for Inhibition of Low Density Lipoprotein Oxidation and Activation of Interleukin-1 Beta Release from Human Monocytes. J. Lipid Res. 1994, 35, 610-619. 
(120) Maples, K.,R.; Ma, F.; Zhang, Y. Comparison of the Radical Trapping Ability of PBN, S-PBN and NXY-059. Free Radic. Res. 2001, 34, 417-426.

(121) Diener, H.; Lees, K. R.; Lyden, P.; Grotta, J.; Davalos, A.; Davis, S. M.; Shuaib, A.; Ashwood, T.; Wasiewski, W.; Alderfer, V.; Hardemark, H.; Rodichok, L. NXY059 for the Treatment of Acute Stroke. Stroke 2008, 39, 1751-1758.

(122) Savitz, S. I.; Fisher, M. Future of Neuroprotection for Acute Stroke: In the Aftermath of the SAINT Trials. Ann. Neurol. 2007, 61, 396-402.

(123) Kim, S.; de A. Vilela, G. V. M.; Bouajila, J.; Dias, A. G.; Cyrino, F. Z. G. A.; Bouskela, E.; Costa, P. R. R.; Nepveu, F. A-Phenyl-N-Tert-Butyl Nitrone (PBN) Derivatives: Synthesis and Protective Action Against Microvascular Damages Induced by ischemia/reperfusion. Bioorg. Med. Chem. 2007, 15, 3572-3578.

(124) Janzen, E. G.; Wang, Y. Y.; Shetty, R. V. Spin Trapping with .Alpha.-Pyridyl 1Oxide N-Tert-Butyl Nitrones in Aqueous Solutions. A Unique Electron Spin Resonance Spectrum for the Hydroxyl Radical Adduct. J. Am. Chem. Soc. 1978, 100, 2923-2925.

(125) Sanderson, D. G.; Chedekel, M. R. Spin Trapping of the Superoxide Radical by 4(N-Methylpyridinium) t-Butyl Nitrone. Photochem. Photobiol. 1980, 32, 573-576.

(126) Haire, D. L.; Hilborn, J. W.; Janzen, E. G. A More Efficient Synthesis of DMPOType (Nitrone) Spin Traps. J. Org. Chem. 1986, 51, 4298-4300.

(127) Frejaville, C.; Karoui, H.; Tuccio, B.; Moigne, F. L.; Culcasi, M.; Pietri, S.; Lauricella, R.; Tordo, P. 5-(Diethoxyphosphoryl)-5-Methyl-1-Pyrroline N-Oxide: A New Efficient Phosphorylated Nitrone for the in Vitro and in Vivo Spin Trapping of Oxygen-Centered Radicals. J. Med. Chem. 1995, 38, 258-265.

(128) Zhang, H.; Joseph, J.; Vasquez-Vivar, J.; Karoui, H.; Nsanzumuhire, C.; Martásek, P.; Tordo, P.; Kalyanaraman, B. Detection of Superoxide Anion using an Isotopically Labeled Nitrone Spin Trap: Potential Biological Applications. FEBS Letters 2000, 473, 58-62.

(129) Kim, S.; de A. Vilela, G. V. M.; Bouajila, J.; Dias, A. G.; Cyrino, F. Z. G. A.; Bouskela, E.; Costa, P. R. R.; Nepveu, F. A-Phenyl-N-Tert-Butyl Nitrone (PBN) Derivatives: Synthesis and Protective Action Against Microvascular Damages Induced by ischemia/reperfusion. Bioorg. Med. Chem. 2007, 15, 3572-3578.

(130) Wheeler, O. H.; Gore, P. H. Absorption Spectra of Azo and Related Compounds. II. Substituted Phenylnitrones. J. Am. Chem. Soc. 1956, 78, 3363-3366. 
(131) Thesing, J.; Mayer, H. Cyclic Nitrones. II. Polymers of 2,3,4,5-Tetrahydropyridine N-Oxide and Related Compounds. Justus Liebigs Ann. Chem. 1957, 609, 46-57.

(132) Thesing, J. Chemistry of Indole. II. A New Synthesis of Beta Indolecarboxaldehyde from Gramine. Chem. Ber. 1954, 87, 507-512.

(133) Johnson, D. H.; Rogers, M. A. T.; Trappe, G. Aliphatic Hydroxylamines. II. Autoxidation. J. Chem. Soc. 1956, 1093-1103.

(134) Thesing, J.; Muller, A.; Michel, G. Hydrazine and Hydroxylamine Derivatives. III. A New Method for the Conversion of Mannich Bases to Aldehydes. Chem. Ber. $1955,88,1027-1037$.

(135) Bernotas, R. C.; Adams, G.; Carr, A. A. Synthesis of Benzazepine-Based Nitrones as Radical Traps. Tetrahedron 1996, 52, 6519-6526.

(136) Bernotas, R. C.; Thomas, C. E.; Carr, A. A.; Nieduzak, T. R.; Adams, G.; Ohlweiler, D. F.; Hay, D. A. Synthesis and Radical Scavenging Activity of 3,3Dialkyl-3,4-Dihydro-Isoquinoline 2-Oxides. Bioorg. Med. Chem. Lett. 1996, 6, 1105-1110.

(137) Watson, T. J. N. Alternative Synthesis of Septic Shock Candidate 3,4-Dihydro-3,3Dimethylisoquinoline N-Oxide (MDL 101002) Utilizing an Improved PictetSpengler Reaction. J. Org. Chem. 1998, 63, 406-407.

(138) Bonnett, R.; Brown, R. F. C.; Clark, V. M.; Sutherland, I. O.; Todd, A. Experiments Towards the Synthesis of Corrins. II. Preparation and Reactions of 1Pyrroline 1-Oxides. J. Chem. Soc. 1959, 2094-2102.

(139) Tufariello, J. J. Alkaloids from Nitrones. Acc. Chem. Res. 1979, 12, 396-403.

(140) Huisgen, R. 1,3-Dipolar Cycloadditions. 76. Concerted Nature of 1,3-Dipolar Cycloadditions and the Question of Diradical Intermediates. J. Org. Chem. 1976, 41, 403-419.

(141) Huisgen, R.; Seidl, H. 1.3-Additionen Der Nitrone an Carbonester Der Acetylenreihe. Tetrahedron Lett. 1963, 4, 2019-2022.

(142) Chang, Z. Y.; Coates, R. M. Diastereoselectivity of Organometallic Additions to Nitrones Bearing Stereogenic N-Substituents. J. Org. Chem. 1990, 55, 3464-3474.

(143) Rosen, G. M.; Britigan, B. E.; Halpern, H. J.; Pou, S. In The Chemistry of Spin Traps and Spin Trapped Adducts; Free Radicals: Biology and Detection by Spin Trapping; 1999; pp 354. 
(144) Nakagawa, H.; Ohyama, R.; Kimata, A.; Suzuki, T.; Miyata, N. Hydroxyl Radical Scavenging by Edaravone Derivatives: Efficient Scavenging by 3-Methyl-1(Pyridin-2-Y1)-5-Pyrazolone with an Intramolecular Base. Bioorg. Med. Chem. Lett. 2006, 16, 5939-5942.

(145) Tsujita, K.; Shimomura, H.; Kaikita, K.; Kawano, H.; Hokamaki, J.; Nagayoshi, Y.; Yamashita, T.; Fukuda, M.; Nakamura, Y.; Sakamoto, T.; Yoshimura, M.; Ogawa, H. Long-Term Efficacy of Edaravone in Patients with Acute Myocardial Infarction. Circ. J. 2006, 70, 832-837.

(146) Mochalin, V. B.; Porshnev, Y. N. Advances in the Chemistry of Azulene. Russ. Chem. Rev. 1977, 46, 530-547.

(147) Kourounakis, A. P.; Rekka, E. A.; Kourounakis, P. N. Effect of Guaiazulene on some Cytochrome P450 Activities. Implication in the Metabolic Activation and Hepatotoxicity of Paracetamol. Arch. Pharm. (Weinheim) 1997, 330, 7-11.

(148) Becker, D. A. Highly Sensitive Colorimetric Detection and Facile Isolation of Diamagnetic Free Radical Adducts of Novel Chromotropic Nitrone Spin Trapping Agents Readily Derived from Guaiazulene. J. Am. Chem. Soc. 1996, 118, 905-906.

(149) Althaus, J. S.; Fleck, T. J.; Becker, D. A.; Hall, E. D.; Vonvoigtlander, P. F. Azulenyl Nitrones: Colorimetric Detection of Oxyradical End Products and Neuroprotection in the Gerbil Transient Forebrain Ischemia/Reperfusion Model. Free Radical Biol. Med. 1998, 24, 738-744.

(150) Becker, D. A.; Natero, R.; Echegoyen, L.; Lawson, R. C. Redox Behaviour of Azulenyl Nitrones: Fully Reversible One Electron Oxidation by Cyclic Voltammetry at Potentials in the Range of Biological Antioxidants. Perkin Trans. 2 1998, 1998, 1289.

(151) Buettner, G. R. The Pecking Order of Free Radicals and Antioxidants: Lipid Peroxidation, $\alpha$-Tocopherol, and Ascorbate. Arch. Biochem. Biophys. 1993, 300, 535-543.

(152) McIntire, G. L.; Blount, H. N.; Stronks, H. J.; Shetty, R. V.; Janzen, E. G. Spin Trapping in Electrochemistry. 2. Aqueous and Nonaqueous Electrochemical Characterizations of Spin Traps. J. Phys. Chem. 1980, 84, 916-921.

(153) Klivenyi, P.; Matthews, R. T.; Wermer, M.; Yang, L.; MacGarvey, U.; Becker, D. A.; Natero, R.; Beal, M. F. Azulenyl Nitrone Spin Traps Protect Against MPTP Neurotoxicity. Exp. Neurol. 1998, 152, 163-166. 
(154) Castagné, V.; Lefèvre, K.; Natero, R.; Becker, D. A.; Clarke, P. G. H. An Optimal Redox Status for the Survival of Axotomized Ganglion Cells in the Developing Retina. Neuroscience 1999, 93, 313-320.

(155) Hünig, S.; Scheutzow, D.; Friedrich, H. J. A Stable Radical-Cation of a Hydrocarbon. Angew. Chem. Int. Ed. 1964, 3, 701.

(156) Belayev, L.; Becker, D. A.; Alonso, O. F.; Liu, Y.; Busto, R.; Ley, J. J.; Ginsberg, M. D. Stilbazulenyl Nitrone, a Novel Azulenyl Nitrone Antioxidant: Improved Neurological Deficit and Reduced Contusion Size After Traumatic Brain Injury in Rats. J. Neurosurg. 2002, 96, 1077-1083.

(157) Becker, D. A.; Ley, J. J.; Echegoyen, L.; Alvarado, R. Stilbazulenyl Nitrone (STAZN): A Nitronyl-Substituted Hydrocarbon with the Potency of Classical Phenolic Chain-Breaking Antioxidants. J. Am. Chem. Soc. 2002, 124, 4678-4684.

(158) Ginsberg, M. D.; Becker, D. A.; Busto, R.; Belayev, A.; Zhang, Y.; Khoutorova, L.; Ley, J. J.; Zhao, W.; Belayev, L. Stilbazulenyl Nitrone, a Novel Antioxidant, is Highly Neuroprotective in Focal Ischemia. Ann. Neurol. 2003, 54, 330-342.

(159) Kuroda, S.; Tsuchidate, R.; Smith, M.; Maples, K. R.; Siesjo, B. K. Neuroprotective Effects of a Novel Nitrone, NXY-059, After Transient Focal Cerebral Ischemia in the Rat. J. Cereb. Blood Flow Metab. 1999, 19, 778-787.

(160) Zhao, Z.; Cheng, M.; Maples, K. R.; Ma, J. Y.; Buchan, A. M. NXY-059, a Novel Free Radical Trapping Compound, Reduces Cortical Infarction After Permanent Focal Cerebral Ischemia in the Rat. Brain Res. 2001, 909, 46-50.

(161) Sydserff, S. G.; Borelli, A. R.; Green, A. R.; Cross, A. J. Effect of NXY-059 on Infarct Volume After Transient Or Permanent Middle Cerebral Artery Occlusion in the Rat; Studies on Dose, Plasma Concentration and Therapeutic Time Window. Br. J. Pharmacol. 2002, 135, 103-112.

(162) Yang, L.; Calingasan, N. Y.; Chen, J.; Ley, J. J.; Becker, D. A.; Beal, M. F. A Novel Azulenyl Nitrone Antioxidant Protects Against MPTP and 3-Nitropropionic Acid Neurotoxicities. Exp. Neurol. 2005, 191, 86-93.

(163) Ley, J. J.; Vigdorchik, A.; Belayev, L.; Zhao, W.; Busto, R.; Khoutorova, L.; Becker, D. A.; Ginsberg, M. D. Stilbazulenyl Nitrone, a Second-Generation Azulenyl Nitrone Antioxidant, Confers Enduring Neuroprotection in Experimental Focal Cerebral Ischemia in the Rat: Neurobehavior, Histopathology, and Pharmacokinetics. J. Pharmacol. Exp. Ther. 2005, 313, 1090-1100. 
(164) Ley, J. J.; Prado, R.; Wei, J. Q.; Bishopric, N. H.; Becker, D. A.; Ginsberg, M. D. Neuroprotective Antioxidant STAZN Protects Against Myocardial ischemia/reperfusion Injury. Biochem. Pharmacol. 2008, 75, 448-456.

(165) Boyd, G. V. Pseudoazulenes. I. Derivatives of Cyclopenta[b]Pyran. J. Chem. Soc. 1958, 1978-1982.

(166) de Meijere, A.; Schirmer, H.; Stein, F.; Funke, F.; Duetsch, M.; Wu, Y.; Noltemeyer, M.; Belgardt, T.; Knieriem, B. An Efficient Three-Step Synthesis of Cyclopenta[b]Pyrans Via 2-Donor-Substituted Fischer Ethenylcarbenechromium Complexes. Chem. Eur. J. 2005, 11, 4132-4148.

(167) Boyd, G. V. Pseudoazulenes Containing Two Fused Five-Membered Rings. Tetrahedron Lett. 1965, 1421-1426.

(168) Ohashi, H.; Tsurushima, T.; Ueno, T.; Fukami, H. Cerbinal, a Pseudoazulene Iridoid, as a Potent Antifungal Compound Isolated from Gardenia Jasminoides Ellis. Agric. Biol. Chem. 1986, 50, 2655-2657.

(169) Porshnev, Y. N.; Erikhov, V. I.; Cherkashin, M. I. Thermal Reaction of Azulenes with Benzothiazolyl Disulfide. Khim. Geterotsikl. Soedin. 1977, 1278-1279.

(170) Palei, R. V.; Plemenkov, V. V.; Lodochnikova, O. A.; Kataeva, O. N.; Litvinov, I. A. Synthesis of Sulfides of the Azulene Series by Reaction of Chamazulene with Sulfenyl Chlorides. Russ. J. Org. Chem. 2000, 36, 1717-1721.

(171) Doyle, A. M.; Reilly, J.; Murphy, N.; Kavanagh, P. V.; O'Brien, J. E.; Walsh, M. S.; Walsh, J. J. Nature's Sedative: Isolation and Structural Elucidation of Valtrate from Centranthus Ruber. J. Chem. Educ. 2004, 81, 1486-1487.

(172) Thies, P. W. Die Konstitution Der Valepotriate , : Mitteilung Über Die Wirkstoffe Des Baldrians. Tetrahedron 1968, 24, 313-347.

(173) Seitz, G.; Moddelmog, G.; Hoelzl, J. Cyclopenta[c]Pyridines from Baldrinal and Homobaldrinal by Reaction with Primary Amines. Arch. Pharm. (Weinheim, Ger.) 1985, 318, 946-950.

(174) Prell, G. D.; Green, J. P. Histamine as a Neuroregulator. Annu. Rev. Neurosci. 1986, 9, 209-254.

(175) Pegg, A. E. Recent Advances in the Biochemistry of Polyamines in Eukaryotes. Biochem. J. 1986, 234, 249-262. 
(176) Agostinelli, E.; Tempera, G.; Molinari, A.; Salvi, M.; Battaglia, V.; Toninello, A.; Arancia, G. The Physiological Role of Biogenic Amines Redox Reactions in Mitochondria. New Perspectives in Cancer Therapy. Amino Acids 2007, 33, 175-187.

(177) Keniry, M. A.; Owen, E. A. An Investigation of the Dynamics of Spermine Bound to Duplex and Quadruplex DNA by 13C NMR Spectroscopy. Eur. Biophys. J. 2007, $36,637-646$.

(178) Muscari, C.; Guarnieri, C.; Stefanelli, C.; Giaccari, A.; Caldarera, C. M. Protective Effect of Spermine on DNA Exposed to Oxidative Stress. Mol. Cell. Biochem. 1995, 144, 125-129.

(179) Ha, H. C.; Sirisoma, N. S.; Kuppusamy, P.; Zweier, J. L.; Wosters, P. M.; Casero, R. A.,Jr The Natural Polyamine Spermine Functions Directly as a Free Radical Scavenger. Proc. Natl. Acad. Sci. U.S.A. 1998, 95, 11140-11145.

(180) Fairlamb, A. H.; Blackburn, P.; Ulrich, P.; Chait, B. T.; Cerami, A. Trypanothione: A Novel Bis(Glutathionyl)Spermidine Cofactor for Glutathione Reductase in Trypanosomatids. Science 1985, 227, 1485-1487.

(181) Fairlamb, A. H.; Cerami, A. Metabolism and Functions of Trypanothione in the Kinetoplastida. Annu. Rev. Microbiol. 1992, 46, 695-729.

(182) Mouteiz, M.; Meziane-Cherif, D.; Aumercier, M.; Sergheraert, C.; Tartar, A. Compared Reactivities of Trypanothione and Glutathione in Conjugation Reactions. Chem. Pharm. Bull. 1994, 42, 2641-2644.

(183) Liu, R.; Althaus, J. S.; Ellerbrock, B. R.; Becker, D. A.; Gurney, M. E. Enhanced oxygen radical production in a transgenic mouse model of familial amyotrophic lateral sclerosis. Ann. Neurol. 1998, 44, 763-770.

(184) Szewczyk, A.; Wojtczak, L. Mitochondria as a Pharmacological Target. Pharmacol. Rev. 2002, 54, 101-127.

(185) Dindo, D.; Dahm, F.; Szulc, Z.; Beilawska, A.; Obeid, L.; Hannun, Y. Y.; Graf, R.; Calvein, P. Cationic long-chain ceramide LCL-30 induces cell death by mitochondrial targeting in SW403 cells. Mol. Cancer Ther. 2006, 5, 1520-1529.

(186) Morin, D.; Hauet, T.; Spedding, M.; Tillement, J. Mitochondria as target for antiischemic drugs. Adv. Drug Deliv. Rev. 2001, 49, 151-174. 
VITA

\section{AMOLKUMAR KOLHE}

January 21, 1976

April 2001

2001- 2002

2002- 2003

2003-2008

2003-2009
Born, Yavatamal, Maharashtra, India

Bachelors of Pharmacy

University Department of Phamaceutical Sciences, Nagpur

Medical sales representative

Elder Pharmaceuticals Ltd.

Chandrapur, Maharashtra, India

Business Officer

Astrum Healthcare Pvt. Ltd.

Nagpur, Maharashtra, India

Teaching Assistant

Florida International University

Miami, Florida, United States of America

Doctoral candidate in chemistry

Florida International University

Miami, Flordia, United States of America

\section{PATENT:}

Pseudoazulenyl Nitrones, PCT/US2007/014921, June 27, 2007 